Portland State University

PDXScholar

$1-1-2011$

\title{
Spatial and Temporal Variability of Glacier Melt in the McMurdo Dry Valleys, Antarctica
}

Matthew James Hoffman

Portland State University

Follow this and additional works at: https://pdxscholar.library.pdx.edu/open_access_etds Let us know how access to this document benefits you.

\section{Recommended Citation}

Hoffman, Matthew James, "Spatial and Temporal Variability of Glacier Melt in the McMurdo Dry Valleys, Antarctica" (2011). Dissertations and Theses. Paper 744.

https://doi.org/10.15760/etd.744

This Dissertation is brought to you for free and open access. It has been accepted for inclusion in Dissertations and Theses by an authorized administrator of PDXScholar. Please contact us if we can make this document more accessible: pdxscholar@pdx.edu. 
Spatial and Temporal Variability of Glacier Melt in the McMurdo Dry Valleys, Antarctica

$$
\text { by }
$$

\title{
Matthew James Hoffman
}

A dissertation submitted in partial fulfillment of the requirements for the degree of

\section{Doctor of Philosophy \\ in}

Environmental Sciences and Resources: Geology

\author{
Dissertation Committee: \\ Andrew G. Fountain, Chair \\ Scott Burns \\ Christina Hulbe \\ Martin Lafrenz \\ Glen Liston \\ Alan Yeakley
}

Portland State University

(C) 2011 


\section{Abstract}

In the McMurdo Dry Valleys, Victoria Land, East Antarctica, melting of glacial ice is the primary source of water to streams, lakes, and associated ecosystems. To better understand meltwater production, three hypotheses are tested: 1) that small changes in the surface energy balance on these glaciers will result in large changes in melt, 2) that subsurface melt does not contribute significantly to runoff, and 3) that melt from $25-\mathrm{m}$ high terminal cliffs is the dominant source of baseflow during cold periods. These hypotheses were investigated using a surface energy balance model applied to the glaciers of Taylor Valley using 14 years of meteorological data and calibrated to ablation measurements. Inclusion of transmission of solar radiation into the ice through a source term in a one-dimensional heat transfer equation was necessary to accurately model summer ablation and ice temperatures.

Results showed good correspondence between calculated and measured ablation and ice temperatures over the 14 years using both daily and hourly time steps, but an hourly time step allowed resolution of short duration melt events and melt within the upper $15 \mathrm{~cm}$ of the ice. Resolution of short duration melt events was not important for properly resolving seasonal ablation totals. Across the smooth surfaces of the glaciers, ablation was dominated by sublimation and melting was rare. Above freezing air temperatures did not necessarily result in melt, and low wind speed was important for melt initiation. According to the model, subsurface melt between 5 and $15 \mathrm{~cm}$ depth was 
extensive and lasted for up to six weeks in some summers. The model was better able to predict ablation if some subsurface melt was assumed to drain, lowering ice density, consistent with observations of a low density weathering crust that forms over the course of the summer on Dry Valley glaciers. In extreme summers, drainage of subsurface melt may have contributed up to half of the observed surface lowering through reduction of ice density and possibly through collapse of highly weathered ice.

When applied spatially, the model successfully predicted proglacial streamflow at seasonal and daily time scales. This was despite omitting a routing scheme, and instead assuming that all melt generated exits the glacier on the same day, suggesting refreezing is not substantial. Including subsurface melt as runoff improved predictions of runoff volume and timing, particularly for the recession of large flood peaks. Because overland flow was rarely observed over much of these glaciers, these model results suggest that runoff may be predominantly transported beneath the surface in a partially melted permeable layer of weathered ice. According to the model, topographic basins, particularly the low albedo basin floors, played a prominent role in runoff production. Smooth glacier surfaces exhibited low melt rates, but were important during high melt conditions due to their large surface area. Estimated runoff contributions from cliffs and cryoconite holes was somewhat smaller than suggested in previous studies. Spatial and temporal variability in albedo due to snow and debris played a dominant role in flow variations between streams and seasons. In general, the model supported the existing assumption that snowmelt is insignificant, but in extreme melt years snowmelt in the accumulation area may contribute significantly to runoff in some locations. 


\section{Acknowledgments}

This dissertation would not have been possible without the input and guidance of many people. First and foremost, I thank my advisor, Andrew Fountain, for his support, patience, and tireless good humor. He has shown me how to synthesize disparate data and analyses, helped me clarify my thoughts on numerous areas of study, and inspired me to become a better scientist. I also offer my gratitude to Christina Hulbe for her devoted instruction and the perspective she has given me on modeling, and to Glen Liston for his keen insight. I would also like to thank the rest of my committee, Scott Burns, Martin Lafrenz, and Alan Yeakley, for their time and assistance.

My experiences with coworkers in the field and in the office will be fondly remembered always, and, in particular, I am truly grateful to Hassan Basagic and Thomas Nylen for the myriad skills they have taught me and the countless enjoyable hours spent with each of them. Additionally, they both have provided endless explanation and interpretation of the data collected in Taylor Valley over the last decade. I thank Erin Pettit, Liz Bagshaw, Josh Carmichael, and Rae Spain and countless others for their noteworthy support in the field, and I acknowledge the contributions Keith Jackson, Shaun Marcott, Pete Sniffen, and Kristina Thorneycroft made to my time at Portland State. I also must thank Jon Ebnet for the pioneering work he did applying this model to Taylor Valley. I am indebted to Tom Neumann for his tremendous support and understanding during the last two years. 
I am deeply thankful for the continued support that I have received from my family, and in particular, my parents who have always provided endless encouragement. Chapters 3 and 5 were largely completed thanks to the hospitality of Craig and Judy Barry. My daughter Penelope came along midway through this dissertation and altered the equation, and I am grateful to her for the patience she has shown me beyond her years.

Finally, I must acknowledge the amazing support of my wife, Amanda. It was her enthusiastic encouragement that convinced me to tackle a project with polar field work in the first place, her experience that helped me navigate the ups and downs of a doctoral program, her companionship and humor on adventures around the globe and at home that has given me peace, and her accommodation of my demanding schedule during the last two years that has ultimately allowed me to complete my work. 


\section{Table of Contents}

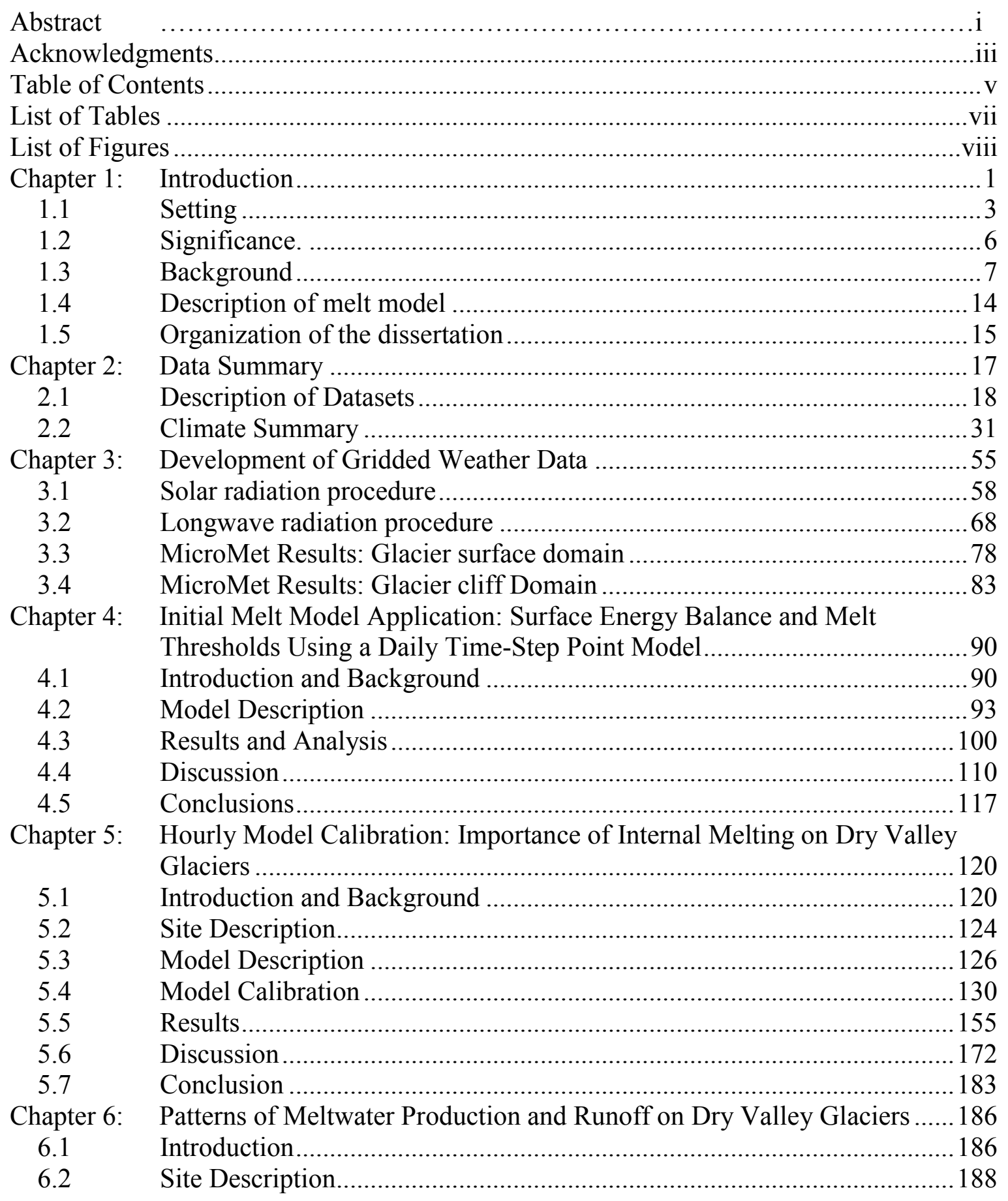


6.3 Spatial Melt Model Description.......................................................... 191

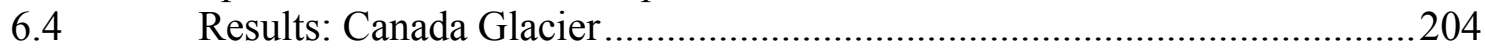

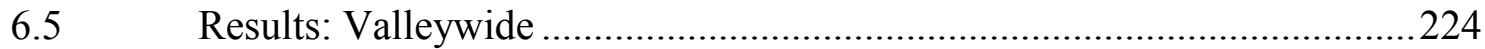

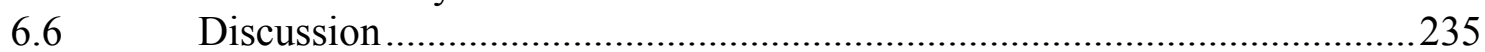

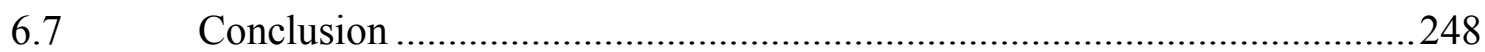

Chapter 7: Conclusions and Future Work ..............................................................2 250

7.1 Collection and Analysis of Climate and Glacier Data .............................250

Energy Balance and Melt Generation ....................................................253

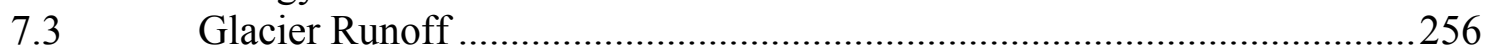

Implications for Melting Glaciers ..................................................258

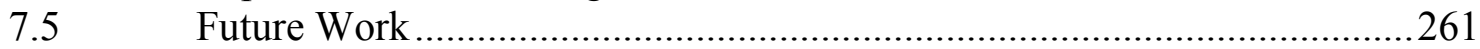

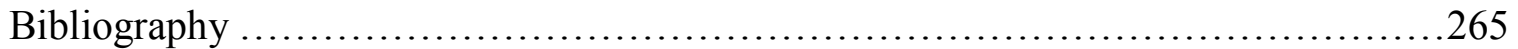

Appendix A: LTER Meteorological Data Summary …............................................ 276

Appendix B: Details of Effective Ice Grain Radius Calibration....................................278

Appendix C: Remote Sensing of Snowcover on Dry Valley Glacier Ablation Zones .....286

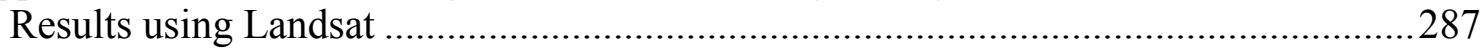

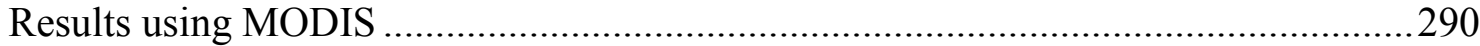

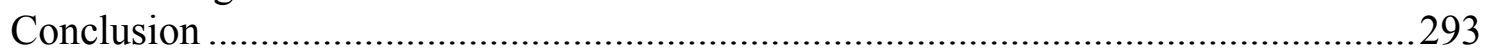

Appendix D: Cliff Model Applied to Taylor Glacier .................................................295 


\section{List of Tables}

Table 2.1: List of long-term MCM LTER meteorological stations in Taylor Valley......... 19

Table 2.2: Summary of typical measurements and instrumentation at LTER

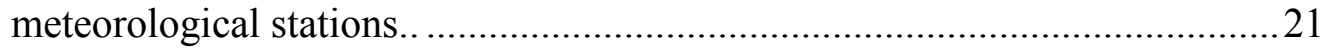

Table 3.1: Monthly temperature and vapor pressure lapse rates between CAA and

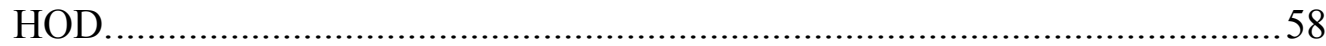

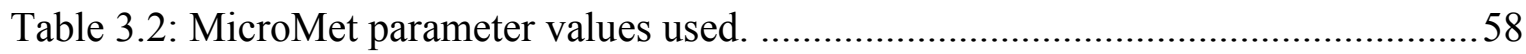

Table 3.3: Comparison of average air temperature, relative humidity, and wind speed for cliff-side meteorological observations and MicroMet output.................. 84

Table 4.1: Summary of surface and subsurface melt for all melt seasons....................... 107

Table 4.2: Average energy balance components for the complete year, summer (December-January), days with surface melt, and days with positive subsurface melt flux.

Table 5.1: Summary of study sites......................................................................... 125

Table 5.2: Summary of model parameters used for calibration.................................... 132

Table 5.3: Optimal values of surface roughness in $\mathrm{mm}$ for various time periods. ......... 140

Table 5.4: Classification of summer seasons at each site. ........................................ 145

Table 5.5: Summary of final model configurations. .................................................... 155

Table 5.6: Summary of SRSF values used by selected glacier energy balance studies.... 182

Table 6.1: Parameter values used for each model configuration. ................................... 192

Table 6.2: Summary of meteorological adjustments and parameters for each

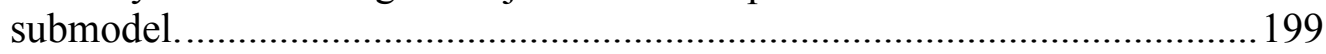

Table 6.3: Summers used for valleywide model........................................................224

Table 6.4: Streams investigated with the valleywide model.......................................224 


\section{List of Figures}

Figure 1.1: Photograph of Canada Glacier and Lake Fryxell showing schematic of Dry Valley hydrology and the ecosystems it supports.....................................2

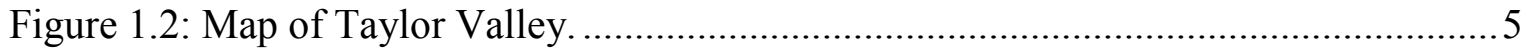

Figure 2.1: Photographs of a) meteorological station, b) mass balance stake, and c) streamgage. 17

Figure 2.2: Map of Taylor Valley showing locations of MCM LTER measurement sites.

Figure 2.3: Difference in measured air temperature between passively ventilated probe (T107) and actively aspirated probe (T aspirated) at CAA during summer 2007-2008.

Figure 2.4: Ice ablation at Taylor Glacier meteorological station (stake 83). ..................26

Figure 2.5: Ice ablation at Canada Glacier meteorological station (stake 50)..................26

Figure 2.6: Ice ablation at Howard Glacier meteorological station (stake 31)................ 27

Figure 2.7: Ice ablation at Commonwealth Glacier meteorological station (stake 11).. ....27

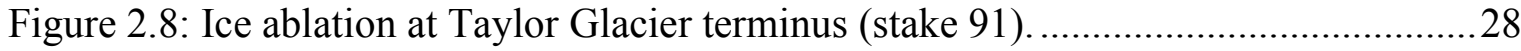

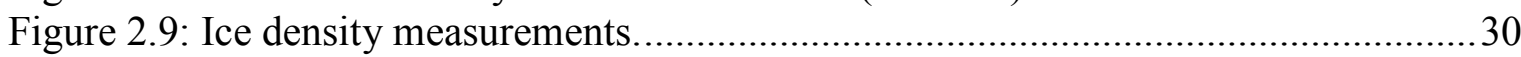

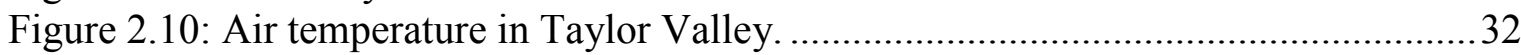

Figure 2.11: Mean monthly air temperature in Taylor Valley..........................................33

Figure 2.12: Mean monthly wind speed in Taylor Valley...........................................35

Figure 2.13: Wind direction histogram for stations in Bonney Basin ..............................36

Figure 2.14: Wind direction histogram for stations in Hoare Basin................................ 37

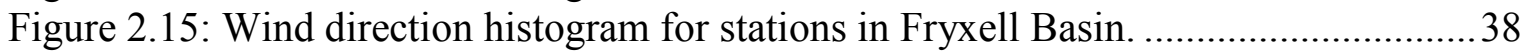

Figure 2.16: Monthly frequency of drainage wind conditions in Taylor Valley...............41

Figure 2.17: Duration of drainage 'events' at each station...........................................43

Figure 2.18: Warming associated with drainage events. Each histogram indicates the frequency of temperature difference between the mean temperature during the 24 hours following the start of a drainage event and the 24 hours preceding the start of the event.

Figure 2.19: Lapse rates in Taylor Valley. Top: Mean monthly lapse rates between selected stations. Middle: Monthly inversion frequency for same station pairs. Bottom: Mean monthly vapor pressure lapse coefficient for same station pairs.

Figure 2.20: Mean monthly air temperature profiles for stations in the Hoare Basin for 2002-2003.

Figure 2.21: Mean bare ice albedo and polynomial fit for Taylor Glacier. ........................50

Figure 2.22: Fraction of summer (November-January) with snowcover at each site. .......53 
Figure 2.23: Relationship between snow depth and albedo at Taylor Glacier meteorological station (top). Bare ice albedo is calculated using polynomial fit shown in Figure 2.21. Bottom: Histogram of albedo for conditions classified as snow-on and snow-off from sonic ranger measurements.

Figure 2.24: Relationship between snow depth and albedo at Howard Glacier meteorological station (top). Bare ice albedo is calculated using polynomial fit shown in Figure 2.21. Bottom: Histogram of albedo for conditions classified as snow-on and snow-off from sonic ranger measurements.

Figure 2.25: Relationship between snow depth and albedo at Commonwealth Glacier meteorological station (top). Bare ice albedo is calculated using polynomial fit shown in Figure 2.21. Bottom: Histogram of albedo for conditions classified as snow-on and snow-off from sonic ranger measurements.

Figure 3.1: Map of model domain grid.

Figure 3.2: Modeled relationship between clearness index $(\mathrm{k})$ and diffuse fraction $\left(\mathrm{K}_{\mathrm{D}}\right)$ for various solar elevations. Modified from Skartveit and Olseth (1987).

Figure 3.3: Comparison of MicroMet and station observations for Commonwealth Glacier meteorological station ( $3^{\circ}$ slope, SE aspect) for part of December 1994.

Figure 3.4: Comparison of MicroMet and station observations for HOD ( $9^{\circ}$ slope, northerly aspect) for part of December 1994.

Figure 3.5: Number of station used for gridding for each time step during the first half of December 1994 (maximum of 7 for this time period)

Figure 3.6: Maps of direct (left), diffuse (center), and global (right) solar radiation for 15:00, December 1, 1994. The upper row is uncorrected for topographic effects, and the bottom row is corrected..

Figure 3.7: Direct (left), diffuse (center), and global (right) solar radiation for 02:00, December 1, 1994.

Figure 3.8: Direct (left), diffuse (center), and global (right) solar radiation for 02:00, December 2, 1994.

Figure 3.9: Evaluation of the 15 parameterizations for clear-sky emissivity in Pirazzini et al. (2001). The Konzelmann et al. (Konzelmann et al. 1994) parameterization is on the right panel in cyan. Each plot shows measured versus estimated values of $\mathrm{Q}_{\mathrm{li}}$ for five different parameterizations.

Figure 3.10: Evaluation of clear-sky emissivity using the Konzelmann et al. (1994) formulation.

Figure 3.11: Results of $\mathrm{Q}_{\text {li }}$ parameterization used for all-sky conditions.

Figure 3.12: Difference between soil surface temperature and air temperature as a function of incoming shortwave radiation at BOY during summer 20072008 . 
Figure 3.13: Mean annual air temperature across glaciers in Taylor Valley as output by MicroMet. Streams, lakes, and measurement sites are shown for reference.. 78

Figure 3.14: MicroMet temperature minus station temperature for model year 20022003.

Figure 3.15: Comparison of MicroMet meteorological output to observations on lower Canada Glacier for December 1998. From top to bottom, the plots show air temperature, relative humidity, and wind speed.

Figure 3.16: Comparison of MicroMet radiation output to observations on lower Canada Glacier for December 1998. The top plot shows incoming shortwave radiation and the bottom shows incoming longwave radiation. Gray lines are MicroMet output (hourly), and black lines are observations made by a temporary meteorological station at stake 55 on lower Canada Glacier (15-minute averages), $2.0 \mathrm{~km}$ to the southeast of CAA, $125 \mathrm{~m}$ a.s.1.

Figure 3.17: Comparison of MicroMet output to observations on Canada Glacier eastside cliff for January 1997. From top to bottom, the plots show air temperature, relative humidity, wind speed, incoming shortwave radiation, and incoming longwave radiation.

Figure 3.18: Comparison of MicroMet output to observations on Canada Glacier westside cliff for January 1997.

Figure 3.19: Comparison of MicroMet longwave radiation output to observations on Canada Glacier east-side cliff for January 1999.

Figure 4.1: Location of Taylor Glacier (T), Lake Bonney (B), Lake Hoare (H), and Canada Glacier (C) meteorological stations within Taylor Valley.

Figure 4.2: Surface of Taylor Glacier showing typical roughness and a melt/freeze patch of smooth ice.

Figure 4.3: Measured (points) and modeled (line) subsurface solar radiation penetration for ice properties used in the model.

Figure 4.4: Measured ablation (black line) and modeled ablation (gray line) and melt (dotted gray line) for each season.

Figure 4.5: Measured ablation (black line) and modeled ablation (gray line) and melt (dotted gray line) for each month that the ultrasonic distance sensor was operational.

Figure 4.6: Measured (black line) and modeled (gray line) ice temperature and measured air temperature (dotted line) during model year 1995 for a) the shallow thermistor (depth ablated from $12 \mathrm{~cm}$ to surface during this time period); and b) the deep thermistor (depth ablated from 92 to $78 \mathrm{~cm}$ ). 103

Figure 4.7: Average daily energy balance components for the 11 model years (July 1995-June 2006).

Figure 4.8: Ice temperature and meltwater fraction ( $2 \%$ water fraction contours in gray) for 2001-2002.

Figure 4.9: Total water column depth for summers with a maximum total water column depth greater than $0.1 \mathrm{~cm}$. 
Figure 5.1: Schematic of how drainage of subsurface melt can reduce ice density and increase the thickness of ice subsequently ablated at the surface. The left panel shows the case of all subsurface melt refreezing in place, and the right panel shows the case of some subsurface melt draining.

Figure 5.2: Optimal effective ice grain radii for the Refreezing Model at TAR (blue), CAA (red), HOD (green), and $\mathrm{COH}$ (gray).

Figure 5.3: Subsurface melt and ice temperatures at TAR in summer 2005-2006. Upper panel: Depth and duration of modeled subsurface melt. Bottom panel: Measured (gray) and modeled (colors) ice temperatures.

Figure 5.4: Modeled ice temperatures and subsurface melt for 2001-2002 at TAR. The upper row shows the Refreeze Model, while the lower row shows the Drain Model.

Figure 5.5: Calculations of net solar flux in the upper $75 \mathrm{~cm}$ for snow and ice. Measurements are from lower Canada Glacier, November 22, 2006.

Figure 5.6: Optimal SRSF for each summer.

Figure 5.7: Variations in mean absolute error (MAE) in summer ablation at TAR. The upper half shows the Refreezing Model and the lower half shows the Drainage Model.

Figure 5.8: Variations in mean absolute error (MAE) in summer ablation at TAR2. The upper half shows the Refreezing Model and the lower half shows the Drainage Model.

Figure 5.9: Variations in mean absolute error (MAE) in summer ablation at CAA. The upper half shows the Refreezing Model and the lower half shows the Drainage Model.

Figure 5.10: Model ablation results at a) TAR, b) TAR2, and c) CAA

Figure 5.11: Surface energy balance terms at a) TAR, b) TAR2, and c) CAA for different model configurations.

Figure 5.12: Fraction of total ablation from melt or subsurface melt at a) TAR, b) TAR2, and c) CAA. Each line is a histogram of relative likelihood over the range of parameters considered.

Figure 5.13: Ice temperatures at TAR, fall 2004, $\sim 30 \mathrm{~cm}$ depth. Black line is ice temperature measured by a thermistor. Ice temperatures were modeled ignoring thermal and optical effects of snow (gray line), and using the range of plausible values for snow thermal conductivity and snow effective grain radius (red and blue lines). Snow depth as measured by sonic ranger is shown with light gray shading.

Figure 5.14: Ice temperatures at HOD, summer 2004-2005, 32 cm depth. Black line is ice temperature measured by a thermistor. Ice temperatures were modeled ignoring thermal and optical effects of snow (gray line), and using the range of plausible values for snow thermal conductivity and snow effective grain radius (red and blue lines). Snow depth as measured by sonic ranger is shown with light gray shading. 
Figure 5.15: Ice temperatures at HOD, summer 2005-2006, 27 cm depth. Black line is ice temperature measured by a thermistor. Ice temperatures were modeled ignoring thermal and optical effects of snow (gray line), and using the range of plausible values for snow thermal conductivity and snow effective grain radius (red and blue lines). Snow depth as measured by sonic ranger is shown with light gray shading....

Figure 5.16: Ice temperatures at $\mathrm{COH}$, summer 2004-2005, 40 cm depth. Black line is ice temperature measured by a thermistor. Ice temperatures were modeled ignoring thermal and optical effects of snow (gray line), and using the range of plausible values for snow thermal conductivity and snow effective grain radius (red and blue lines). Snow depth as measured by sonic ranger is shown with light gray shading....

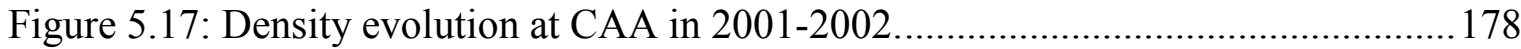

Figure 5.18: Density evolution at CAA in 2007-2008................................................ 178

Figure 6.1: Shaded relief map of stream catchments modeled (colored areas) in Taylor Valley....

Figure 6.2: Shaded relief map of Canada Glacier showing actual (dotted black lines) and modeled (solid black lines) catchment boundaries. Basin floors are shown in red and basin walls in dark blue. Mass balance stakes installed in cliff facse are shown surrounded by a white circle.

Figure 6.3: Photograph of the uniformly sloping surface and cliff topographic morphologies on Howard Glacier.

Figure 6.4: Photo of basin on Taylor Glacier showing the floor, wall, and ridge topographic morphologies.

Figure 6.5: Measured albedo of Canada Glacier westside cliff as a function of incoming solar radiation for the period December 10, 1995 to January 22, 1996.

Figure 6.6: Ablation with elevation for Canada Glacier using the High Sublimation model configuration

Figure 6.7: Ablation with elevation for Canada Glacier using the High Internal Melt model configuration.

Figure 6.8: Ablation with elevation for Canada Glacier using the High Surface Melt model configuration.

Figure 6.9: Cliff submodel results for summer along Canada Glacier westside cliff.......212

Figure 6.10: Cliff submodel results for winter along Canada Glacier westside cliff. ......212

Figure 6.11: Average summer meltwater production $(\mathrm{cm})$ for Canada Glacier with the

a) High Internal Melt and b) High Surface Melt model configurations. 214

Figure 6.12: Measured (squares) and modeled (circles) summer runoff volume using the High Internal Melt model configuration for a) Andersen Creek, b) Canada Stream, and c) Green Creek.

Figure 6.13: Measured (squares) and modeled (circles) summer runoff volume using the High Surface Melt model configuration for a) Andersen Creek, b) Canada Stream, and c) Green Creek. 
Figure 6.14: Correlation coefficient between measured and modeled daily runoff volume using the High Internal Melt model configuration for a) Andersen Creek, b) Canada Stream, and c) Green Creek.

Figure 6.15: Correlation coefficient between measured and modeled daily runoff volume using the High Surface Melt model configuration for a) Andersen Creek, b) Canada Stream, and c) Green Creek.

Figure 6.16: Measured and modeled daily streamflow at Andersen Creek for selected summers.

Figure 6.17: Measured and modeled daily streamflow at Canada Stream for selected summers.

Figure 6.18: Measured and modeled daily streamflow at Green Creek for selected summers.

Figure 6.19: Ablation with elevation for Taylor Glacier using the High Internal Melt model configuration for selected summers.

Figure 6.20: Ablation with elevation for Commonwealth Glacier (black dots) and Howard Glacier (white dots) using the High Internal Melt model configuration for selected summers.

Figure 6.21: Map of average summer sublimation (cm weq) on uniformly sloping surfaces.

Figure 6.22: Maps of summer melt production (cm weq) for a) a low streamflow summer (1997), b) a medium streamflow summer (2004), and c) a high streamflow summer (2001).

Figure 6.23: Measured and modeled daily streamflow at Santa Fe Stream for selected summers.

Figure 6.24: Measured and modeled daily streamflow at Lawson Creek for selected summers.

Figure 6.25: Measured and modeled daily streamflow at House Stream for selected summers.

Figure 6.26: Measured and modeled daily streamflow at Delta Stream for selected summers.

Figure 6.27: Measured and modeled daily streamflow at Lost Seal Stream for selected summers.

Figure 6.28: Measured and modeled daily streamflow at Delta Stream for selected summers using albedo reduced by 0.05 to match the bare ice albedo measured on Howard Glacier.

Figure 6.29: Contribution of different glacier surfaces to modeled summer runoff for a) Andersen Creek and b) Green Creek catchment using the High Surface Melt model.

Figure 6.30: Summer melt from different glacier surfaces scaled by surface area for a) Andersen Creek and b) Green Creek.

Figure 6.31: Contribution of different glacier surfaces to modeled daily runoff for a) Andersen Creek and b) Green Creek catchment using the High Surface Melt model. 


\section{Chapter 1: Introduction}

The McMurdo Dry Valleys (MDV) are the largest ice-free area, $4800 \mathrm{~km}^{2}$, in Antarctica (Drewry et al. 1982). The valley floors are a patchwork of active glacier ice, perennially ice-covered lakes, and large expanses of bedrock and sandy, gravelly soils

(Figure 1.1). Ephemeral streams convey water from the glaciers to the lakes for up to 10 weeks each summer (McKnight et al. 1999). The source of meltwater is the low elevation exposed ice in the glacier ablation zones; the snow-covered accumulation zones rarely melt, and when they do the water refreezes in the colder snow layers at depth (Fountain et al. 1999b). Precipitation is small ( $<10 \mathrm{~cm}$ water equivalent) in the valley bottoms (Keys 1980, Fountain et al. 2010) and snow is not of direct hydrologic significance, because it generally sublimates before melting (Chinn 1981, Gooseff et al. 2006). Consequently, glacial melt is the critically important water source to the streams and lakes in the valleys. Aquatic ecosystems of algae, cyanobacteria, mosses, and diatoms are found in the streams (McKnight et al. 1999), and phytoplankton and benthic algal mats in the lakes (Priscu et al. 1999). Runoff not only supplies water to these ecosystems but also conveys important nutrients (Foreman et al. 2004). Therefore, the MDV landscape and ecosystems are sensitive to climate because small changes lead to large variations in liquid water availability (Dana and Wharton 1998, Fountain et al. 1998). To understand past environmental conditions, their legacies on current hydrochemical processes, and to anticipate future changes resulting from changing and 
varying climate requires an understanding of glacial meltwater production. The purpose of my work is to develop a modeling tool that can reliably be used to predict meltwater production. A functional understanding of glacier meltwater production in the Dry Valleys will require testing the following three hypotheses:

Hypothesis 1: During summer, the glacier surfaces in Taylor Valley are near the threshold of melting and small changes in the energy balance caused by meteorological conditions or ice properties result in large changes in melt flux.

Hypothesis 2: Both surface and subsurface melting occurs on these glaciers but subsurface melting does not contribute significantly to proglacial streamflow.

Hypothesis 3: Melt from the $25 \mathrm{~m}$ high terminal cliffs that are found on these glaciers is the major source of runoff during the beginning and end of the melt season and during cold periods within the melt season.

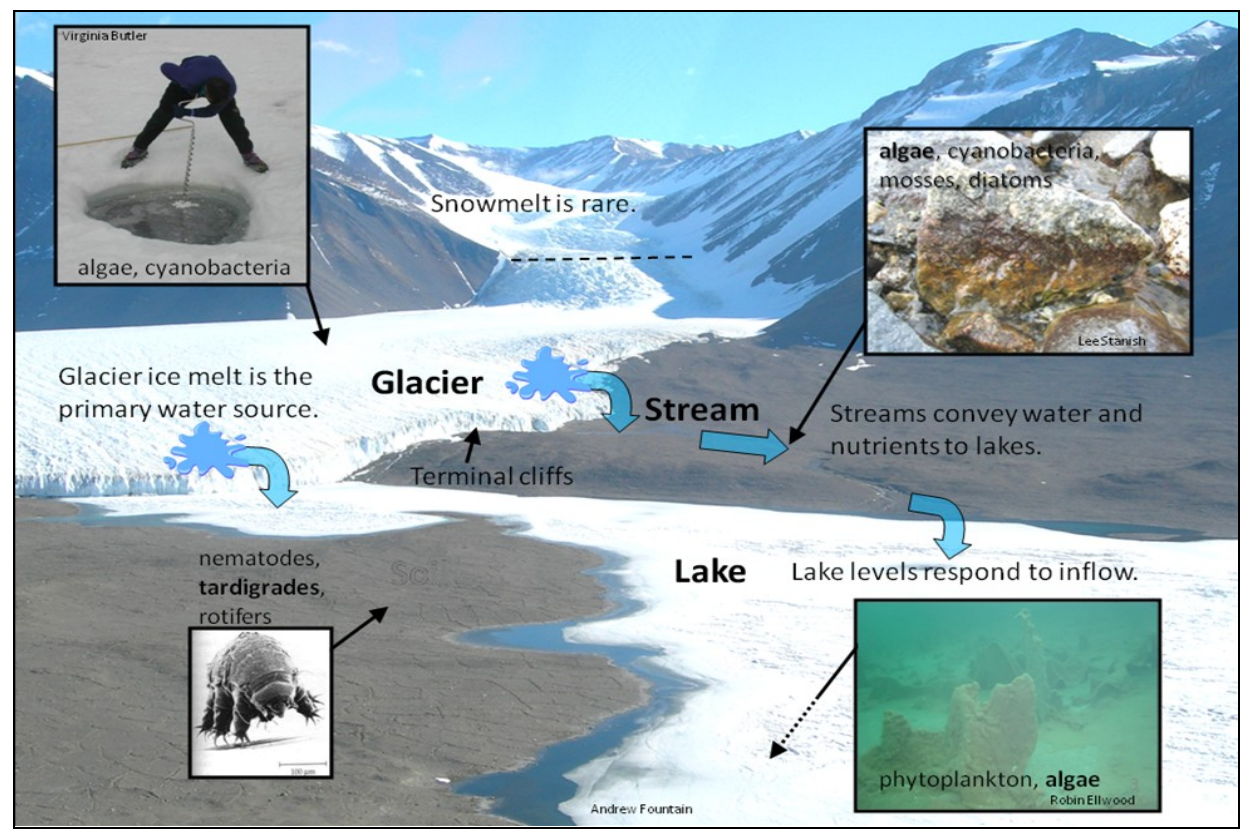

Figure 1.1: Photograph of Canada Glacier and Lake Fryxell showing schematic of Dry Valley hydrology and the ecosystems it supports. 


\subsection{Setting: Climate and glaciers of the Dry Valleys}

Mean annual air temperatures in the Dry Valleys range from $-14^{\circ} \mathrm{C}$ to $-30^{\circ} \mathrm{C}$

(Doran et al. 2002a), but mean summer air temperatures are near $0^{\circ} \mathrm{C}$ in the valley bottoms (Nylen et al. 2004), allowing for a 10-week melt season (McKnight et al. 1999). Drainage winds flowing from the polar plateau are a common feature of the Dry Valleys climate (Nylen et al. 2004, Speirs et al. 2010). Though less common and generally weaker during summer, drainage wind events bring high wind speed, higher air temperature, and lower relative humidity (Nylen et al. 2004). Precipitation falls as snow, is less than $50 \mathrm{~mm}$ water equivalent per year, and shows little seasonality (Keys 1980, Fountain et al. 2010). Taylor Valley is the lowest elevation and warmest of the three main McMurdo Dry Valleys (Doran et al. 2002a). The Nussbaum Riegel forms a topographic obstacle in Taylor Valley, with up-valley locations experiencing windier, warmer, and sunnier conditions than down-valley locations (Fountain et al. 1999b).

Small alpine glaciers flow into the valley bottoms from the mountain ranges that divide the valleys (Fountain et al. 1998). Lobes of the East Antarctic Ice Sheet terminate at the upper ends of Taylor and Wright valleys; piedmont glaciers occupy the mouths of Wright and Victoria valleys, while the mouth of Taylor Valley is ice-free (Fountain et al. 1998). The alpine glaciers currently occupy their most advanced position in the last 12,000 years (Denton et al. 1989). There have been no large changes in their positions during the twentieth century (Chinn 1998, Fountain et al. 2004a), and the glaciers appear to be in equilibrium with current climate (Fountain et al. 2006). Annual net mass loss in the ablation zones is on the order of $10^{-1} \mathrm{~m}$, with $70-90 \%$ in the form of sublimation, 15 - 
$30 \%$ in the form of melt, and 1-3\% in the form of calving from terminal cliffs (Fountain et al. 1998). Runoff occurs in the generally snow-free ablation zones only, as little melt occurs in the snow of the accumulation zones and any that does refreezes at depth (Fountain et al. 1998). The equilibrium line altitudes of the glaciers rise rapidly moving upvalley by $30 \mathrm{~m} \mathrm{~km}^{-1}$, reflecting the climatic gradient in Taylor Valley (Fountain et al. 1999a). This steep gradient is almost an order of magnitude larger than variations in equilibrium line altitude of temperate glaciers and is primarily caused by gradients in precipitation and wind speed within the valley (Fountain et al. 1999a).

The alpine glaciers of the Dry Valleys are polar glaciers whose interior and basal temperatures are well below the melting point and are frozen to their beds (Fountain et al. 1998). The cold ice prevents the development of englacial or subglacial passages for conveying meltwater - runoff is restricted to the glacier surfaces (Fountain et al. 1998). Most of the glaciers in the Dry Valleys terminate in near-vertical terminal cliffs $\sim 20 \mathrm{~m}$ high which can generate $15-20 \%$ of the total runoff from the glaciers, despite representing only $2 \%$ of the surface area of the ablation zone (Lewis et al. 1999). The topography of the glacier ablation zones vary from very smooth, roughness $<10^{-2} \mathrm{~m}$, to surface channels and basins $10^{1} \mathrm{~m}$ deep. Ablation in these channels and basins may be up to 4.5 times greater than the local horizontal ice surfaces due to enhanced melt (Johnston et al. 2005). Despite occupying relatively small areas, these cliffs, channels, and basins may represent a significant fraction of total glacier runoff and dominate runoff during times of low streamflow (Lewis et al. 1999, Johnston et al. 2005). However, their 
effect on glacier runoff has only been explored at two locations within Taylor Valley during two summer seasons (Lewis et al. 1999, Johnston et al. 2005).

Taylor Valley is the most studied of the valleys in the McMurdo Dry Valleys Long Term Ecological Research (MCM LTER) Program, an interdisciplinary and multidisciplinary study of the aquatic and terrestrial ecosystems in this region of Antarctica. Long-term datasets collected by MCM LTER within Taylor Valley include meteorological observations at eight stations, glacier mass balance on four glaciers, and streamflow measurements on 15 streams since the program's inception in 1993 (Figure $1.2)$.

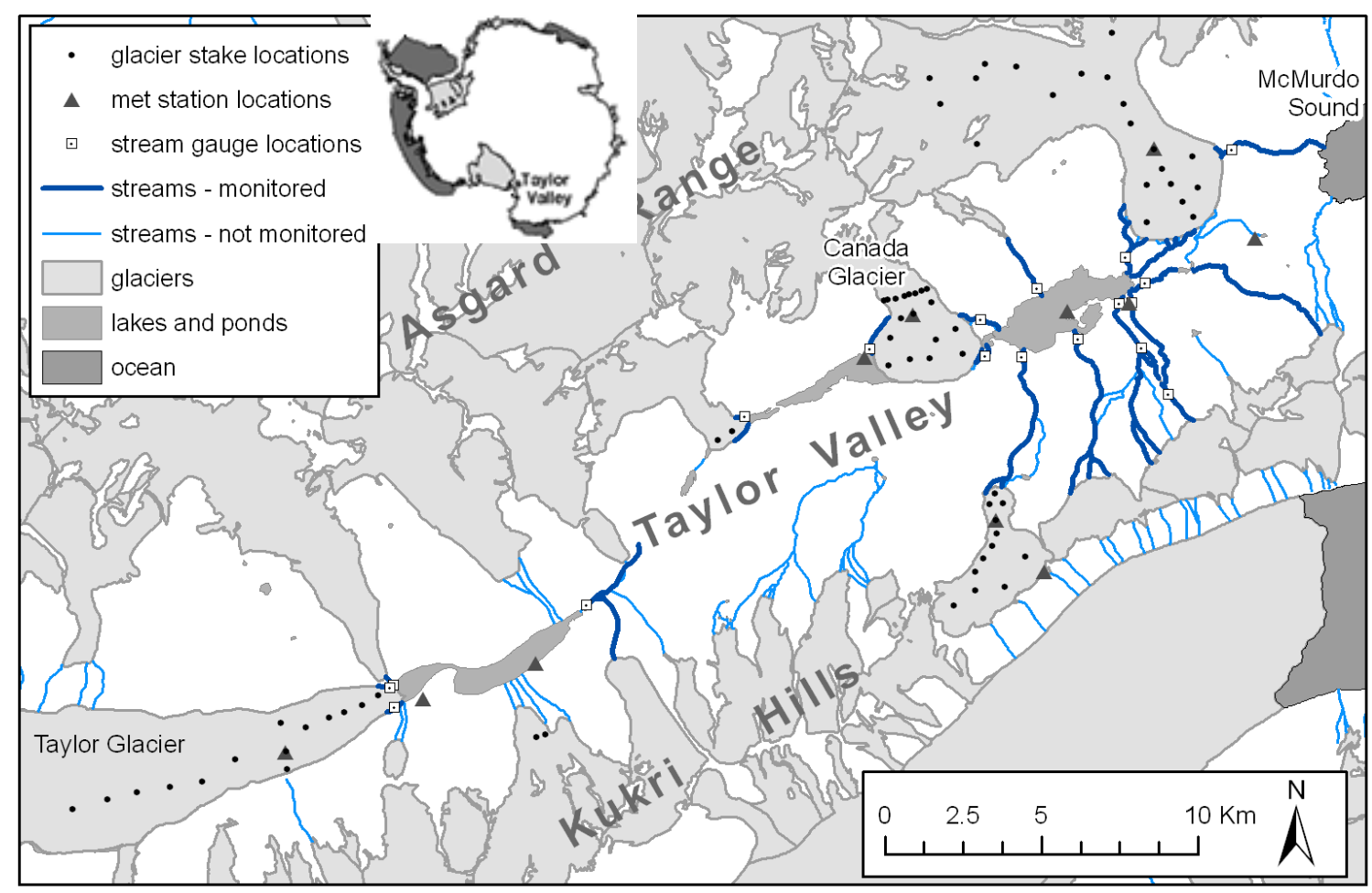

Figure 1.2: Map of Taylor Valley. 


\subsection{Significance: Dry Valleys ecosystems are highly sensitive to climate change.}

The McMurdo Dry Valleys are the coldest and driest deserts in the world (McKnight et al. 1999), and biological communities must be adapted to extreme desiccation, freeze-thaw cycles, high winds, and seasonal light-dark cycles (Fountain et al. 1999b). The primary limit to life in Antarctica is the availability of liquid water (Kennedy 1993), and small changes in climate can lead to extreme changes in water production (Fountain et al. 1999b). Streamflow can vary by more than fivefold during a single day due to variations in sun angle (Conovitz et al. 1998) and can vary seasonally by the same factor due to interannual variations in weather (House et al. 1995). Water is also important for transporting nutrients present in marine and lacustrine sediments to the stream and lake ecosystems (Fountain et al. 1999b).

Though the McMurdo Dry Valleys have experienced warming since they were first explored in the early twentieth century (Chinn 1998), they have cooled $1.2^{\circ} \mathrm{C}$ per decade during summer between 1986 and 2000 (Doran et al. 2002b). This cooling has resulted in decreasing streamflow, lowering lake levels, and increased lake ice thickness (Doran et al. 2002b). These changes in turn have affected the Dry Valley ecosystems, with decreases in primary productivity in the lakes and nematode density in the soils during this period (Doran et al. 2002b).

Despite the fact that the global average temperature has increased by nearly $1{ }^{\circ} \mathrm{C}$ over the twentieth century (IPCC 2007), temperatures for East Antarctica have remained stable or cooled over the last 50 years (Thompson and Solomon 2002, Steig et al. 2009). This cooling is thought to be related to the presence of a high Southern Annular Mode 
caused by the depletion of stratospheric ozone over the continent (Thompson and Solomon 2002). However, temperatures over the continental interior are expected to gradually increase as the ozone hole reduces (Walsh 2009). By the end of the $21^{\text {st }}$ century, Antarctica as a whole is predicted to warm by $1.4^{\circ} \mathrm{C}$ to $5.0^{\circ} \mathrm{C}$ (roughly uniformly across the continent), with an increase in the frequency of very warm summers (IPCC 2007). Precipitation is predicted to increase on the order of 5-20\% for the Dry Valleys region, but there is considerable scatter between individual models (IPCC 2007). There are no published predictions for cloudiness or wind. Furthermore, global models fail to resolve the complex topographic effects that control weather in the Dry Valleys (Monaghan et al. 2005), so it is unclear how applicable the General Circulation Model predictions used by the IPCC are for the Dry Valleys. Because of the sensitivity of melt to small changes in atmospheric forcing, the uncertainty in the predictions of future climate change for the Dry Valleys may represent a wide range of potential hydrologic, and, in turn, ecosystem response. In sum, there currently is no model able to predict the range of changes in melt production at a valley-wide scale due to climate change.

\subsection{Background}

\subsubsection{Prediction of melt is complex at temperatures near freezing.}

The exposed ice of the ablation zones of Dry Valley glaciers generally lose mass through melting in rates similar amounts to sublimation (Fountain et al. 1999b). This is in contrast to high elevation exposed ice on the Antarctic Ice Sheets which experiences no melt (Bintanja 1999) and to exposed ice of temperate glaciers where melt dominates 
over sublimation (Paterson 1994, p.54). Though both processes remove heat through phase change of water, sublimation requires eight times more energy to ablate the same ice mass as melting, so small changes in the distribution of energy between these two ablative processes can result in large changes in total ablation. Sublimation occurs through the turbulent exchange of latent heat from the ice surface to the air above. It removes heat from the ice surface, and its magnitude is determined by the profiles of wind speed and vapor pressure in the air above the ice surface. Melt, on the other hand, only occurs when there is residual energy available at the ice surface after all of the other sources and sinks of energy (including sublimation) have been accounted for and the ice surface has reached $0^{\circ} \mathrm{C}$. Thus, atmospheric conditions that result in high sublimation (high wind speed, low relative humidity) can suppress melt even if the ice temperature is at $0^{\circ} \mathrm{C}$ and the air temperature is above freezing (Hoffman et al. 2008). In these situations, energy losses due to sublimation must be compensated by increases in energy sources (e.g. solar radiation or sensible heat) before melt can occur. Unless air temperature is well above freezing, the partitioning of ablation between sublimation and melt remains equivocal. On Taylor Glacier, about half of days with melt have occurred when the air temperature was below freezing, and only about one quarter of all days with air temperature above $0^{\circ} \mathrm{C}$ experience melt (Hoffman et al. 2008).

Furthermore, the effect of increasing temperature and increasing precipitation resulting in increased melt, as seen on temperate glaciers, does not necessarily hold across the Dry Valleys. In the western portion of Taylor Valley where higher temperatures are accompanied by less humidity and greater wind speed, the gain of 
sensible heat to the glacier is offset by the increased loss due to latent heat (sublimation) (Fountain et al. 1999b). Because precipitation falls as snow, increased precipitation raises the albedo and reduces the amount of solar radiation absorbed by the glacier (Fountain et al. 1999b). For these reasons, temperature alone cannot explain spatial and temporal variations in melt (Ebnet et al. 2005).

Further complicating the prediction of melt is the ability of radiatively heated ice to melt below the surface through a solid-state greenhouse effect (Brandt and Warren 1993). Solar radiation absorbed beneath the surface raises the ice temperature, and if this additional energy is not conducted away rapidly enough, subsurface melting may occur even when the ice surface remains below freezing due to low air temperature or longwave radiative cooling. In clear ice, this effect can raise ice temperature up to $14^{\circ} \mathrm{C}$ (Brandt and Warren 1993), and when air temperature is near $0^{\circ} \mathrm{C}$, substantial melt pools can develop beneath the surface (Liston et al. 1999). On Dry Valley glaciers subsurface melt occurs in cryoconite holes that form around sediment trapped on the glacier surface (Fountain et al. 2004b). Subsurface melt in cryoconite holes may generate more than $10 \%$ of the observed runoff in some Dry Valley glaciers, however the subsurface liquid water transport mechanism is not well understood (Fountain et al. 2004b). It may be along intergranular veins that form from partial melt at grain boundaries (Fountain et al. 1998) or through connecting passageways that form along cracks in the ice and other linear features (Fountain et al. 2004b). This near-surface flow system represents a transitional stage between the completely frozen near-surface of a polar glacier and the 
water-saturated surface of a temperate glacier, and the flow system on the Dry Valley glaciers reaches these extremes in some seasons (Fountain et al. 2004b).

Because this subsurface system is difficult to observe and direct measurements have been limited, modeling will provide insight into the spatial variability of its evolution and operation. Better defining the magnitude and routing of subsurface melt is important for determining the accuracy of mass balance calculations and melt calculations that assume surface melt only. Mass balance calculations are based on ablation stakes measurements of surface lowering and do not account for mass loss beneath the surface (Fountain et al. 1998). Subsurface melt is not affected by evaporation as surface melt is, but may be more likely to refreeze before leaving the glacier, complicating estimates of glacier runoff (Fountain et al. 1998). Subsurface melt in the Dry Valleys is significant ecologically because cryoconite holes host isolated on-glacier ecosystems (Fountain et al. 2004b), and the volume of liquid water in the holes and its exchange with the atmosphere and between holes affects their chemical and biological compositions (Bagshaw et al. 2007).

\subsubsection{Variations in glacier surface properties can emulate changes in weather}

Ablation and melt vary greatly due to topographic effects that effectively alter local climate by causing increased air temperature, decreased wind speed, and, at times, increased radiation in sheltered depressions (e.g. channels, basins, cliff faces and bases) (Chinn 1987, Lewis et al. 1999, Johnston et al. 2005). During summer, sensible heat is minor because both air temperature and ice temperature commonly hover near $0^{\circ} \mathrm{C}$ 
(Lewis et al. 1998). However, latent heat flux via sublimation is a major loss from the glacier surfaces because of the dry air. In locations protected from the wind, latent heat losses are greatly reduced (Lewis et al. 1998), which leaves more energy available for melt. Additionally, daily peak solar radiation is larger on sloping surfaces than on horizontal surfaces due to low solar elevation angles at high latitude.

In some cases a feedback occurs. On Taylor Glacier channels incised $\sim 20 \mathrm{~m}$ into the glacier surface experience air temperature higher by $1.7^{\circ} \mathrm{C}$, wind speeds reduced by $\sim 50 \%$, and net shortwave radiation increased by up to $37 \%$, relative to the adjacent flat surface. Ablation (and melt) in the channel was about 5 times greater than on adjacent horizontal surfaces allowing the channels to deepen more rapidly than the adjacent surfaces (Johnston et al. 2005). Similarly, winds are reduced along the $\sim 20 \mathrm{~m}$ high cliffs that form the lower glacier margins, and cliff melt can account for $15-20 \%$ of the total glacier runoff despite comprising only $2 \%$ of the surface area of the ablation zone of nearby Canada Glacier (Lewis et al. 1999).

In addition to topographically induced microclimates that alter exchange of energy with the atmosphere, variations in ice properties modify the amount of absorbed solar radiation and its distribution with depth. The absorption of solar radiation is controlled by surface albedo, ice grain size, and ice density (Brandt and Warren 1993). The difference in these ice properties between snow and blue ice can result in differences in subsurface melt rates by an order of magnitude (Liston et al. 1999). The blue ice lids of cryoconite holes cover about $4-6 \%$ of the ice surface on Dry Valley glaciers (Fountain et al. 2004b), but absorbs about $20 \%$ more solar energy than the surrounding white ice 
(Lewis 2001). Additionally, thin patches of sediment on the glacier surfaces may potentially double summer melt at those locations (Lewis 2001). The distribution of sediment on the glaciers is nonuniform, but locations with extensive sediment may play an important role in meltwater production (Johnston 2004). While some studies have considered the effect on melt production due to variations in ice surface properties at particular locations (Lewis et al. 1999, Lewis 2001, Johnston et al. 2005), there has been no systematic study of an entire glacier or valley that accounts for the important effects of microclimate in sheltered depressions, blue ice distribution, and sediment distribution.

\subsubsection{Energy balance modeling offers promise to understanding meltwater production}

Previous efforts to model runoff in the MDV have included both statistical and physically-based approaches. Statistical models have examined the relation between temperature, solar radiation, and runoff (e.g. Bomblies 1998, Dana et al. 2002, Jaros 2003). Ebnet et al. (2005) modeled seasonal runoff for all lake basins in Taylor Valley and did very well in parts of Taylor Valley and less well in windy regions such as Taylor

Glacier. However, the model was not applied to sub-seasonal time-scales, and being statistically-based, it is unknown how it would perform if extrapolated outside of the current climate.

Physically-based energy balance models should be applicable across a wider range of climate forcings. Energy balance models have been employed successfully to investigate spatial variations in the energy balance over the ablation zones of some Taylor Valley glaciers (Lewis et al. 1999, Johnston et al. 2005). These studies have been 
useful for exploring the spatial variations of energy balance, but their limited duration (a few summer weeks) has precluded understanding of the day-to-day variation over the seasonal cycle, including the onset and termination of the melt season. Additionally, these studies have only been applied in two locations in Taylor Valley and do not consider variations between glaciers or the prominent climatic gradients present in Taylor Valley. Lastly, these studies do not adequately address the subsurface heating of the ice which can lead to subsurface melting and water flow (Liston et al. 1999, Fountain et al. 2004b).

The streamflow measurements collected by MCM LTER provide a record of historic liquid water availability to the terrestrial ecosystem, but this record does not indicate where on the glaciers the water is coming from, how much water is present in ungaged streams, or how streamflow would vary with past or future climate variations. Similarly, the glacier mass balance data collected does not directly provide melt quantities from the glacier surfaces because the ablation measured in the mass balance data is the sum of both melt and sublimation. Furthermore, the mass balance measurements do not include all glaciers and may not be representative for some areas that have heterogeneous ablation. For these reasons, modeling glacier melt, run using meteorological measurements, calibrated with glacier mass balance measurements, and tested against streamflow measurements, provides a more promising path to understanding valleywide glacial meltwater production. 


\subsection{Description of melt model}

The melt model used in this dissertation is based on that of Liston et al. (1999)

which includes representations of the physical processes necessary to model both surface and subsurface melt. It computes the surface energy balance by accounting for the fluxes of incoming and outgoing shortwave radiation, incoming and outgoing longwave radiation, the turbulent heat fluxes of sensible and latent heat, and heat conducted into or out of the glacier. Any heat gain after accounting for these fluxes is assumed to be consumed by melt. Incoming and outgoing shortwave radiation and incoming longwave radiation are measured directly, and the other terms are cast as a function of ice surface temperature. These energy terms are solved for the ice surface temperature that balances the gains and losses of energy to the surface, conserving energy. If the resulting temperature is above $0^{\circ} \mathrm{C}$, the ice temperature is reset to $0^{\circ} \mathrm{C}$, and the extra energy is used to melt ice.

The surface energy balance is coupled with a one-dimensional heat transfer equation that is used to calculate the heat flux into or out of the glacier and includes a source term for solar radiation absorbed beneath the surface. The distribution of solar radiation with depth is determined by a spectrally-dependent extinction coefficient which is a function of the solar spectrum, ice surface albedo, ice density, and effective ice grain radius (which differs from the measured ice grain radius) (Brandt and Warren, 1993). The model uses as input the meteorological variables of air temperature, relative humidity, wind speed, incoming solar radiation, surface albedo, incoming and outgoing longwave radiation, and atmospheric pressure. Model outputs include ablation 
components of sublimation and melt, ice surface temperature, and the temperature, melt flux, and water fraction of subsurface ice. I used the effective ice grain radius, the aerodynamic surface roughness length (which affects the magnitude of the turbulent heat fluxes), and a coefficient for partitioning absorbed solar radiation between the surface and the subsurface as parameters to tune the model to best match observations. The model was written in Fortran77, and post-processing and analysis scripts were written primarily in Matlab.

\subsection{Organization of the dissertation}

Using over a decade of meteorological and mass balance observations in Taylor Valley (Doran et al. 2002a, Fountain et al. 2006), I applied the energy balance model (Liston et al. 1999) for the prediction of streamflow in Taylor Valley. My approach synthesized previous glacier melt studies in Taylor Valley, combining the long duration and broad spatial extent of the previous statistical models with the sub-daily temporal resolution, detailed spatial resolution, and process-based foundation of the previous energy balance models. I improved upon previous energy balance models by explicitly modeling subsurface melt.

Chapter 2 describes the extensive array of meteorological, mass balance, and streamflow measurements spanning 14 years that were used to apply the melt model. The chapter also includes a summary of relevant aspects of Taylor Valley climate based on analysis of the meteorological dataset. Chapter 3 describes the generation of the gridded meteorological forcing fields necessary to run the spatially-distributed melt 
model. For this purpose, I use a quasi-physically based meteorological distribution system called MicroMet (Liston and Elder 2006). MicroMet uses spatial interpolations with corrections for known relationships between temperature-elevation, windtopography, humidity-cloudiness, and radiation-cloud-topography, and it includes a preprocessor to fill short gaps in the record at each station with reasonable values. I describe significant modifications that I have made to MicroMet for improved application in Taylor Valley, including new parameterizations for incoming solar and longwave radiation.

Application of the melt model is covered in Chapters 4-6, which are meant to be journal manuscripts and can each largely standalone. Chapter 4 describes the initial application of the point-based model using a daily time-step. The purpose of this initial application of the melt model is to explore the feasibility of using a daily time step and perform a detailed analysis of the surface energy balance at a single point. Chapter 5 introduces a more complex version of the model using an hourly time-step and explores a detailed calibration of model parameters. The calibration illuminates important physical processes including the phenomenon of internal melting of glacier ice, which has applicability beyond polar glaciers. Finally, Chapter 6 applies the melt model in a spatially-distributed fashion to estimate melt quantities for entire stream catchments. The spatial model is used to assess the contribution of subsurface melting to runoff on Dry Valley glaciers.

Chapter 7 presents general conclusions, and suggests future directions for this line of research. 


\section{Chapter 2: Data Summary}

Meteorological data are used to run the energy balance model, measurements of ablation are used to calibrate the model, and streamflow measurements are used to test the model. The McMurdo Dry Valleys Long Term Ecological Research (MCM LTER) project has collected extensive datasets for all three of these types of measurements for about 15 years at different locations within the Dry Valleys (Figure 2.1). All MCM LTER data is publicly available at http://mcmlter.org. The subset of these measurements made within Taylor Valley form the primary datasets of my dissertation and are described in the first section of this chapter. Because these datasets are described in detail elsewhere (Doran et al. 2002a, Nylen et al. 2004, Fountain et al. 2006), here I focus on aspects that are most relevant to application of the model. Additionally, supplemental measurements that I conducted as part of my dissertation work are described in the following section. The second half of this chapter explores analysis of three aspects of the meteorological data record that are important for later chapters.

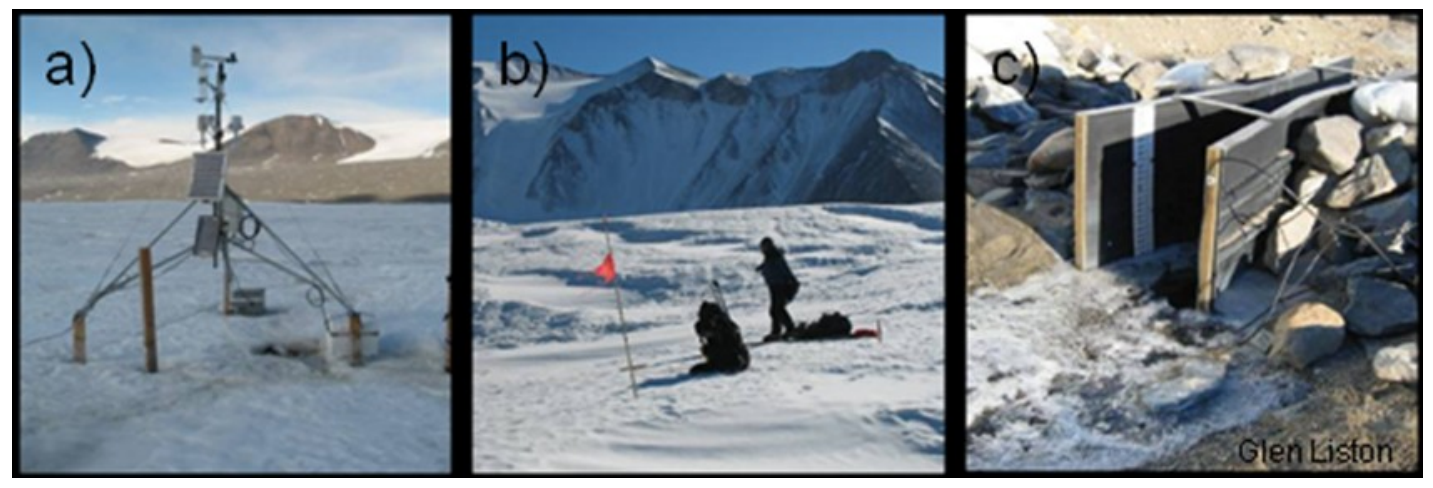

Figure 2.1: Photographs of a) meteorological station, b) mass balance stake, and c) streamgage. 


\subsection{Description of Datasets}

\subsubsection{Meteorological Data}

There are eight long-term meteorological stations in Taylor Valley, with four located on the valley floor and four located on glacier ablation zones (Table 2.1, Figure 2.2) (Doran et al. 1995, Doran et al. 2002a). Additionally a ninth station operated for about three years on the ridgetop above Howard Glacier. Valley floor stations exist in the three primary basins within the valley (Bonney, Hoare, and Fryxell) and all are below $100 \mathrm{~m}$ a.s.1. With the exception of Explorer's Cove, all valley floor stations are located along the shore of, or on islands within, the valley's ice-covered lakes. The glacier stations are located on the four glaciers that have extensive mass balance stake networks and range in elevation from 264 to $475 \mathrm{~m}$ a.s.1. With exception of Explorer's Cove, the eight long-term stations were all in standardized operation starting in summer 1995/1996. Measurements from the few available years prior to that season used different sampling intervals, and in some cases different instrumentation of processing. For simplicity I restrict my analysis to the time period from summer 1995/1996 through summer 2008/2009, 14 summers and 13 winters. 
Table 2.1: List of long-term MCM LTER meteorological stations in Taylor Valley

\begin{tabular}{lllllr}
\hline ID & Name & Location & Setting & Start season & Elevation $(\mathbf{m})$ \\
\hline 1 & TAR & Taylor Glacier & Glacier & $1994 / 1995$ & 334.1 \\
2 & BOY & Lake Bonney & Valley floor & $1993 / 1994$ & 64.4 \\
3 & HOE & Lake Hoare & Valley floor & $1993 / 1994$ & 77.1 \\
4 & CAA & Canada Glacier & Glacier & $1994 / 1995$ & 264.4 \\
5 & HOD & Howard Glacier & Glacier & $1993 / 1994$ & 472.5 \\
6 & FRL & Lake Fryxell & Valley floor & $1993 / 1994$ & 19.0 \\
7 & COH & Commonwealth & Glacier & $1993 / 1994$ & 290.2 \\
& & Glacier & & & 25.7 \\
8 & EXE & Explorer's Cove & Valley floor & $1997 / 1998$ & 905.0 \\
\hline & UHD & Upper Howard & Ridgetop & $2001 / 2002$ & (ends 2003/2004) \\
\hline
\end{tabular}

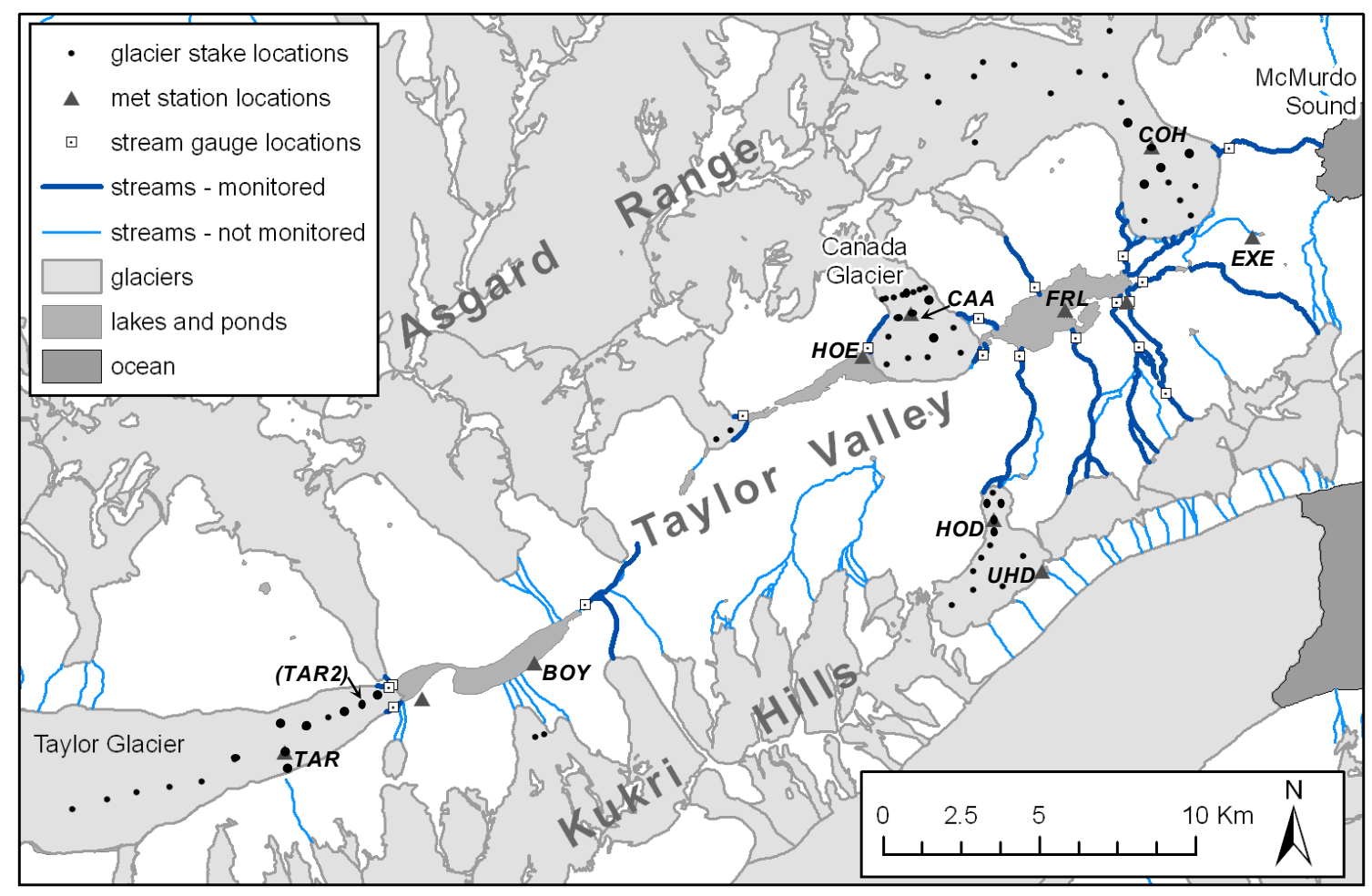

Figure 2.2: Map of Taylor Valley showing locations of MCM LTER measurement sites. Meteorological stations used in my analysis are labeled with their abbreviation (Table 2.1). Glacier stakes used in the mass balance summaries shown in Figures 2.4 - 2.8 are indicated with larger dots, including the non-meteorological stations site TAR2.

All meteorological stations collect measurements of air temperature, relative humidity, wind speed (all at $3 \mathrm{~m}$, except $2 \mathrm{~m}$ at CAA), and incoming and outgoing 
shortwave (solar) radiation (Table 2.2) (Doran et al. 2002a). Additionally, some stations have at times made measurements of incoming longwave (thermal) radiation, ice temperature at depths between 0 and $100 \mathrm{~cm}$, ice surface elevation change, and ice surface temperature. Most of the sensors collect data every $30 \mathrm{~s}$ (every $4 \mathrm{~s}$ for wind speed) and 15-minute averages are stored on a solid-state data logger.

At the glacier stations, ablation of the glacier surface causes the instrument height to increase over time and the station is periodically reset. Linearly interpolated measurements of seasonal ablation were used to generate a daily time series of instrument height for each glacier station. For consistency, wind speed measurements were adjusted to a constant $3 \mathrm{~m}$ height. Each wind speed measurement was adjusted to $3 \mathrm{~m}$ assuming a neutral stability logarithmic wind speed profile:

$$
v_{3}=v_{m}\left(\frac{\ln (3.0)}{\ln \left(z_{0}\right)}\right)\left(\frac{\ln \left(z_{m}\right)}{\ln \left(z_{0}\right)}\right)^{-1}
$$

where $\mathrm{v}_{3}$ and $\mathrm{v}_{\mathrm{m}}$ are wind speed at $3 \mathrm{~m}$ and at the measurement height, respectively, $z_{\mathrm{m}}$ is the measurement height in meters, and $z_{0}$ is the surface roughness length, assumed to be $0.00025 \mathrm{~m}$ (the calibrated surface roughness at Taylor Glacier meteorological station for hourly measurements in Chapter 4). After adjustment of wind speed to $3 \mathrm{~m}$, hourly averages of all meteorological variables are made, with the value for each hour equaling the average of the previous 60 minutes. Hourly averages are calculated using whatever 15-minute averages are available for each hour, even when some 15-minute averages are missing. Additionally daily averages are calculated from the hourly averages. 
Table 2.2: Summary of typical measurements and instrumentation at LTER meteorological stations. Detailed information is in Appendix A.

\begin{tabular}{|c|c|c|c|c|}
\hline Measurement & Location & Instrument & Accuracy & Time Period \\
\hline Air temperature & All & $\begin{array}{l}\text { Campbell Scientific 107/207 } \\
\text { probe }\end{array}$ & $\pm 5^{\circ} \mathrm{C}$ & All \\
\hline \multirow[t]{2}{*}{ Relative humidity } & All & $\begin{array}{l}\text { Campbell Scientific } 207 \\
\text { probe }\end{array}$ & $<5 \%$ & $\begin{array}{l}1995- \\
2000 / 01\end{array}$ \\
\hline & & Vaisala HMP45C RH probe & $\begin{array}{l} \pm 2 \% \text { over } 10-90 \% \mathrm{RH} \\
\pm 3 \% \text { over } 90-100 \% \mathrm{RH}\end{array}$ & 2000/01- \\
\hline Wind speed & All & $\begin{array}{l}\text { R.M. Young model } 05103 \\
\text { wind monitor }\end{array}$ & $2 \%$ & All \\
\hline \multirow[t]{2}{*}{$\begin{array}{l}\text { Shortwave } \\
\text { radiation (up and } \\
\text { down) }\end{array}$} & $\begin{array}{l}\text { TAR, } \\
\text { HOD, } \\
\text { COH }\end{array}$ & $\begin{array}{l}\text { Eppley precision spectral } \\
\text { pyranometer }\end{array}$ & $\begin{array}{l} \pm 3 \% \text { for zenith angles }> \\
70^{\circ} ; \\
\pm 1 \% \text { for zenith angles }< \\
70^{\circ}\end{array}$ & All \\
\hline & All others & $\begin{array}{l}\text { LI-COR model } \\
\text { LI200S/LI200X silicon } \\
\text { pyranometer }\end{array}$ & $\pm 5 \%$ & All \\
\hline \multirow[t]{2}{*}{$\begin{array}{l}\text { Longwave } \\
\text { radiation (down) }\end{array}$} & & $\begin{array}{l}\text { Eppley precision infrared } \\
\text { radiometer (pyrgeometer) }\end{array}$ & $<5 \%$ & $\begin{array}{l}\text { Dec. } 1995- \\
\text { Nov. } 1997\end{array}$ \\
\hline & BOY & & & $\begin{array}{l}\text { Dec. } 1999- \\
\text { Jan. } 2006\end{array}$ \\
\hline \multirow[t]{2}{*}{$\begin{array}{l}\text { Atmospheric } \\
\text { pressure }\end{array}$} & $\mathrm{HOE}$ & $\begin{array}{l}\text { Vaisala model PTA427 } \\
\text { Barometric pressure sensor }\end{array}$ & $\pm 0.5 \mathrm{mb}$ & $\begin{array}{l}\text { 1995- May } \\
1999 ; \\
\text { Feb. } 2002- \\
2006\end{array}$ \\
\hline & CAA & $\begin{array}{l}\text { Vaisala model PTA427 } \\
\text { Barometric pressure sensor }\end{array}$ & $\pm 0.5 \mathrm{mb}$ & $\begin{array}{l}\text { June } 1999- \\
\text { Jan. } 2002\end{array}$ \\
\hline $\begin{array}{l}\text { Ice surface } \\
\text { elevation change }\end{array}$ & $\begin{array}{l}\text { TAR, } \\
\text { HOD, } \\
\text { COH }\end{array}$ & $\begin{array}{l}\text { Campbell Scientific Inc. } \\
\text { SR50 Ultrasonic Distance } \\
\text { Sensor }\end{array}$ & $1 \mathrm{~cm}$ & $2004-$ \\
\hline $\begin{array}{l}\text { Ice temperature } \\
(0-100 \mathrm{~cm} \text {, } \\
\text { variable depth })\end{array}$ & $\begin{array}{l}\text { All glacier } \\
\text { stations }\end{array}$ & $\begin{array}{l}\text { Fenwall Thermisters (192- } \\
\text { 102DEW-A01) and } \\
\text { Caddock Tetrinox }{ }^{\circledR} \\
\text { (TF050N) hi precision } \\
\text { resistor (10Kohm) }\end{array}$ & $\begin{array}{l} \pm 5 \mathrm{ppm} / \text { celcius and } \\
0.01 \% \text { Resistor }\end{array}$ & Variable \\
\hline $\begin{array}{l}\text { Ice surface } \\
\text { thermal infrared }\end{array}$ & TAR & $\begin{array}{l}\text { Apogee Infrared Radiometer } \\
\text { Precision Temperature } \\
\text { Sensor (IRR-P) }\end{array}$ & $\pm 0.5^{\circ} \mathrm{C}$ & $2007 / 08-$ \\
\hline
\end{tabular}

At Canada Glacier, incoming and outgoing solar radiation is measured with LI-

COR LI-200 pyranometers, rather than the more accurate Eppley PSP pyranometers used

at the other three glacier sites. The LI-COR pyranometers have an uneven spectral

response and are calibrated to make accurate measurements under direct sunlight (King 
and Myers 1997). Because the spectral response of the LI-COR pyanometers is limited to the visible wavelengths where snow and ice have the highest spectral albedo, the instruments overestimate the albedo of snow and ice (Henneman and Stefan 1998). The LI-COR error is likely a function of solar zenith angle, cloudiness, and individual sensor response (King and Myers 1997). By comparing measurements with more accurate pyranometers, previous studies have estimated the LI-COR albedo overestimation to be 0.04 to 0.09 for snow and ice in Greenland (Stroeve et al. 2005), 0.06 for snow and lake ice in Minnesota (Henneman and Stefan 1998), and $\sim 0.03$ for snow and lake ice in Iowa (Klein 2003). I made a comparison between albedo as measured by LI-COR pyranometers and Eppley PSP pyranometers the terminus of Canada Glacier on 29 November 2006. The LI-COR measured albedo 0.04 higher than the Eppley over ice and 0.07 over snow, which is about $8 \%$ of the average measured value for each surface type. Based on these measurements and previous studies, I reduced the entire record of measured albedo at Canada Glacier by $8 \%$.

An additional concern is elevated air temperature measurements when using passively ventilated radiation shields for temperature probes when wind speed is low and solar radiation is high. Passively ventilated shields rely on wind to keep the air within the radiation shield mixed with the ambient air. If this does not occur, the air inside the shield can heat up if solar radiation heats the shield itself or is absorbed within the shield, resulting in air temperature measurements that are up to $6^{\circ} \mathrm{C}$ too high (Arck and Scherer 2001). This situation is of particular concern for glacier meteorological stations, because reflected solar radiation from a high albedo snow or ice surface can nearly double the 
solar radiation that reaches the radiation shield (Arck and Scherer 2001). This effect can be greatly reduced with an actively aspirated thermistor housing, but such shields require a power supply to run a fan or pump, and the mechanical parts are a reliability concern in polar conditions.

To investigate this problem, I constructed a low power actively-aspirated radiation shield using a computer power supply fan and PVC pipe (T. Pfeffer, pers. comm.). The aspirated temperature probe was run alongside the passively ventilated probe at CAA during the summer of 2007-2008. For the majority of 15-minute time periods, the two sensors measured temperatures within $1{ }^{\circ} \mathrm{C}$ (Figure 2.3). At wind speeds below $2 \mathrm{~m} \mathrm{~s}^{-1}$, the passively ventilated sensor measures temperatures up to $3.8^{\circ} \mathrm{C}$ higher than the aspirated sensor, but the majority of time periods are still within $1^{\circ} \mathrm{C}$. The 'excess temperature' effect that I measure it smaller than has been previously reported. It may be that this effect is less of a problem over ice surfaces with relatively low albedo ( 0.6) compared to a snow surface with a high albedo (0.9).

Periods of time with high solar radiation tend to have higher excess temperature than periods with low solar radiation, but the difference is relatively small, even at low wind speed. One question is why there are so many periods of time at low wind speed where the aspirated sensor measured higher temperatures than the passively ventilated sensor. If the aspirated unit is not aspirating long enough and the aspirated shield heats up more than the ventilated shield, then negative excess temperature is possible at low wind speeds. This issue requires further investigation, but considering the relatively few periods of time with excess temperatures over $1{ }^{\circ} \mathrm{C}$, I choose to ignore the effect of solar 
heating of temperature sensors in the LTER temperature dataset. Should additional investigations determine this is a problem, corrections (e.g. Arck and Scherer 2001, Smeets 2006) can be assessed for the dataset.

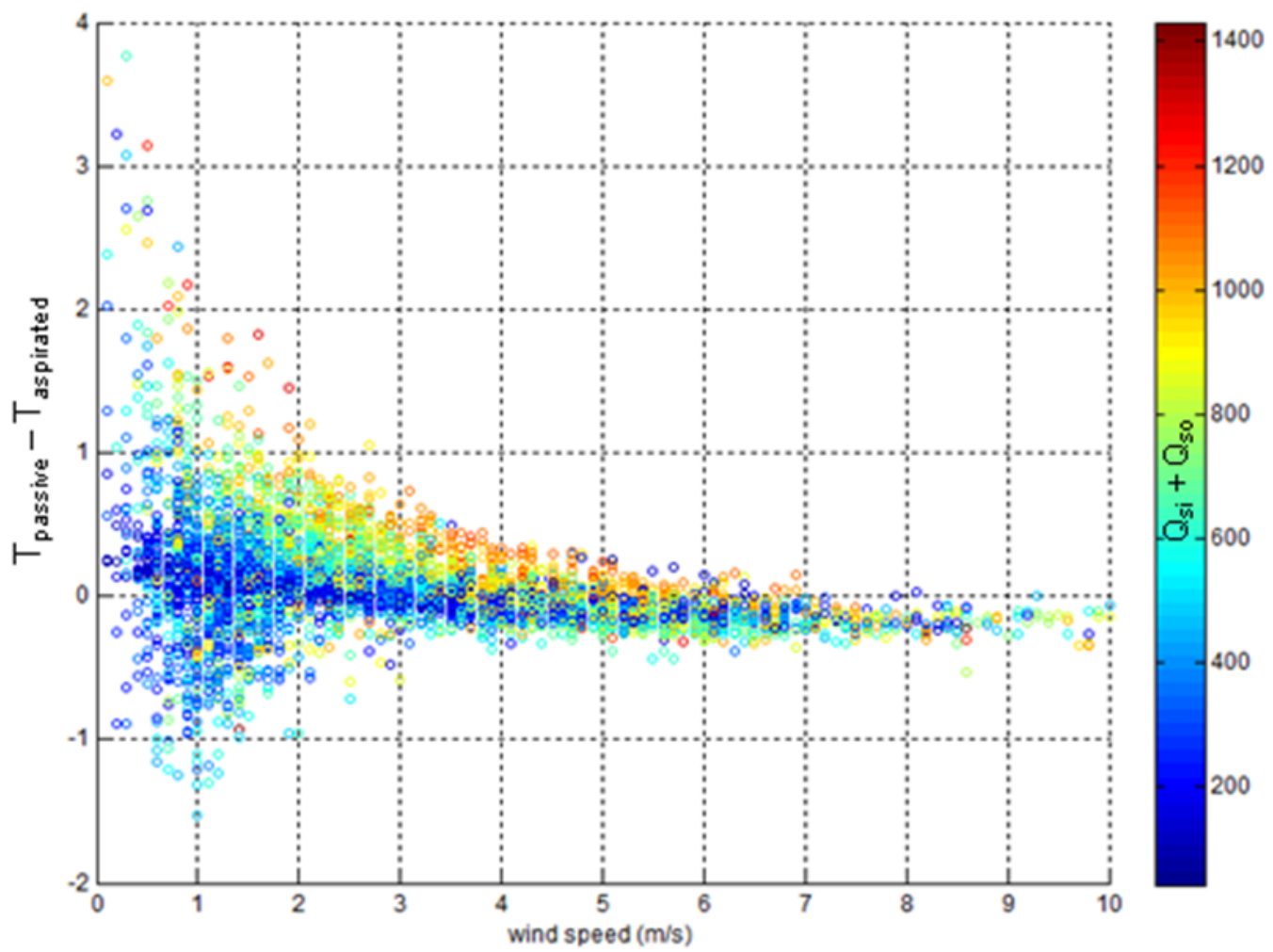

Figure 2.3: Difference in measured air temperature between passively ventilated probe (T107) and actively aspirated probe (T aspirated) at CAA during summer 2007-2008. Each point is a 15-minute temperature average, and point color represents the sum of incoming and outgoing solar radiation during that period.

\subsubsection{Mass Balance Data}

Summer (early November to late January) and winter (remainder of the year) mass balance measurements using bamboo poles have been made over the ablation zones of Commonwealth, Howard, Canada, and Taylor glaciers from 1994 to the present (Figure 2.2) (Fountain et al. 2006). At each stake, four measurements are made around a wooden board $10 \mathrm{~cm}$ in radius in order to average local surface roughness. 
Though the accuracy of measurements of the height of stakes drilled in the ice is $\pm 0.7 \mathrm{~cm}$ weq at the $95 \%$ confidence level (Fountain et al. 2006), ablation is subject to local variations and individual stake measurements may not be representative (Braithwaite et al. 1998). To reduce this uncertainty for detailed analysis, I use the mean of ablation measured at nearby stakes (Figure 2.2) to represent the ablation at each of the four glacier meteorological station sites and a fifth site near the terminus of Taylor Glacier. For the few instances where stakes recorded accumulation of superimposed ice, ablation was set to zero. Additionally, a few outliers were removed when observations indicated that the ablation measurement was influenced by a process other than 'normal ablation', such as a stake being located in a meltwater channel. From 2003 or 2004 to present, sonic rangers provide an additional measurement of surface lowering locally at Taylor, Howard, and Commonwealth glacier meteorological stations. Figures 2.4 - 2.8 show summer and winter ablation for each of the study sites for 1995-2008. Ice density has been adjusted from $900 \mathrm{~kg} \mathrm{~m}^{-3}$ to $870 \mathrm{~kg} \mathrm{~m}^{-3}$ based on measurements described below. 

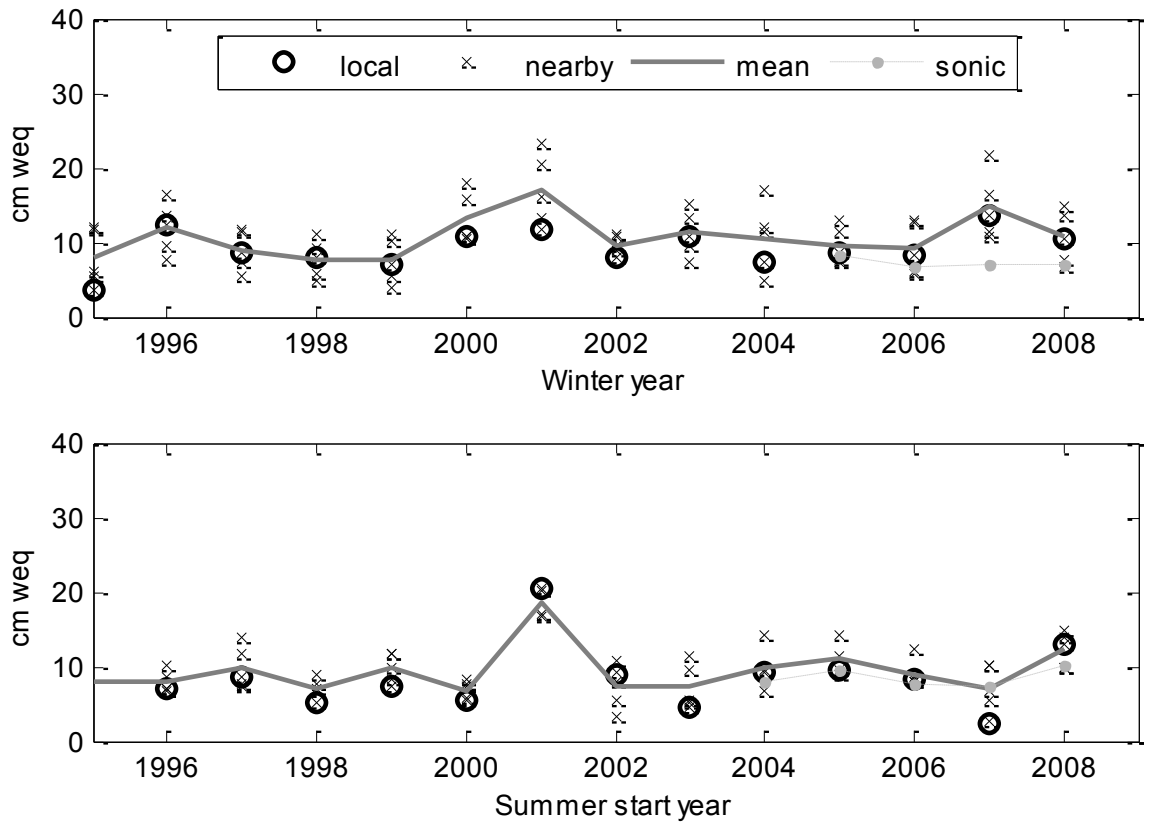

Figure 2.4: Ice ablation at Taylor Glacier meteorological station (stake 83). Circles mark the stake local to the meteorological station, and X's mark stake measurements in the vicinity (stakes 81, 82, 84, and 85). The gray lines are the average of all stakes.
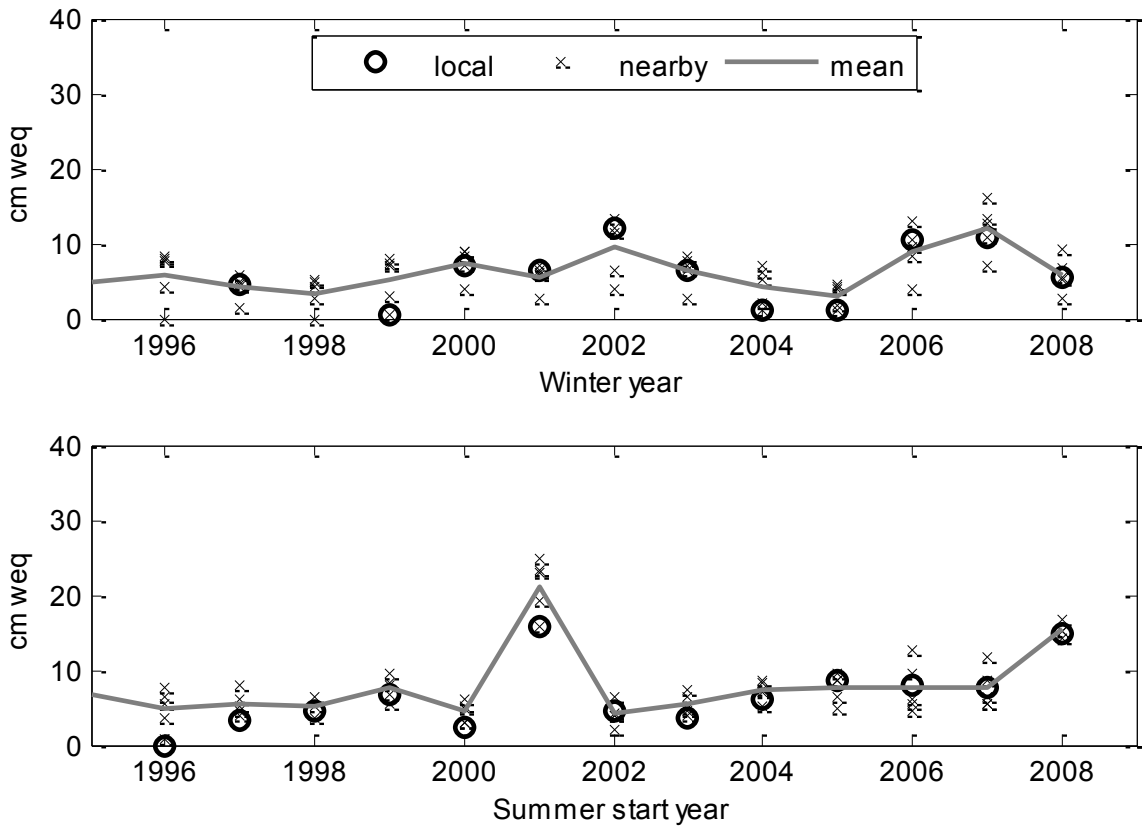

Figure 2.5: Ice ablation at Canada Glacier meteorological station (stake 50). Neighboring stakes used are 44, 49, 51, and 53. 

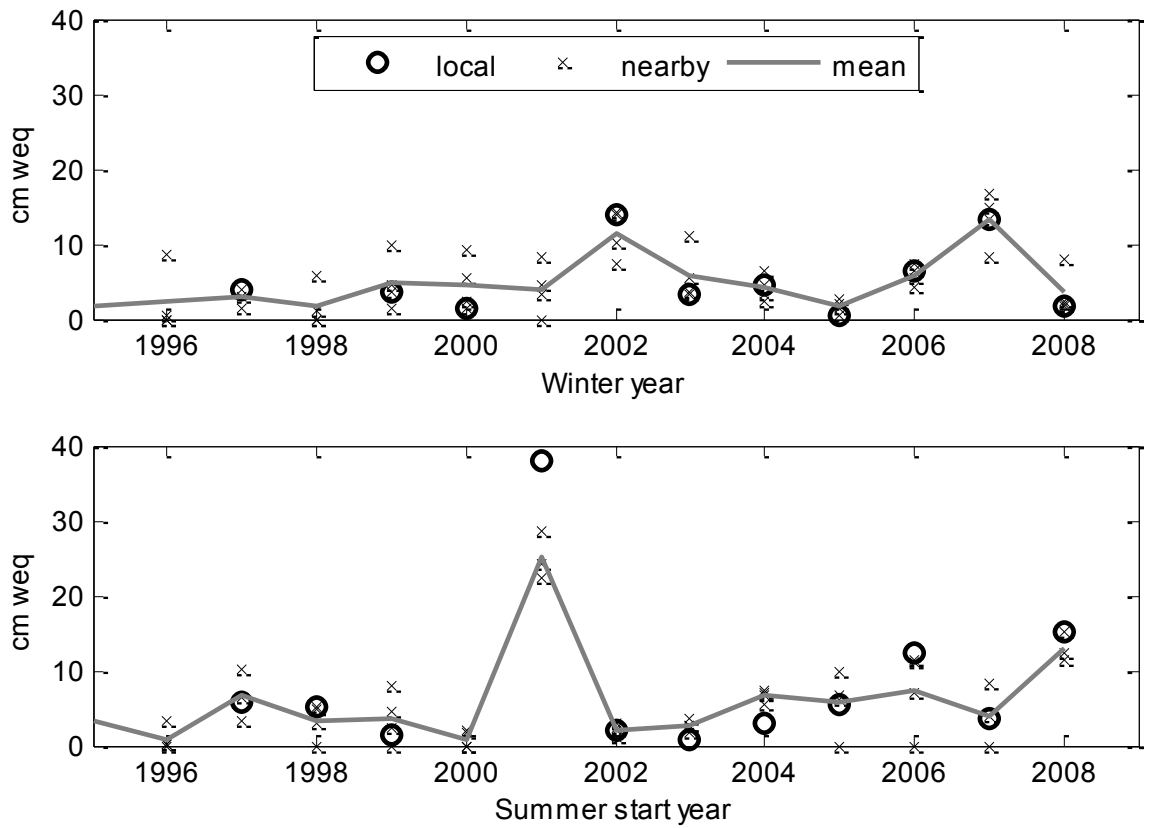

Figure 2.6: Ice ablation at Howard Glacier meteorological station (stake 31). Neighboring stakes used are 30,32 , and 33 .
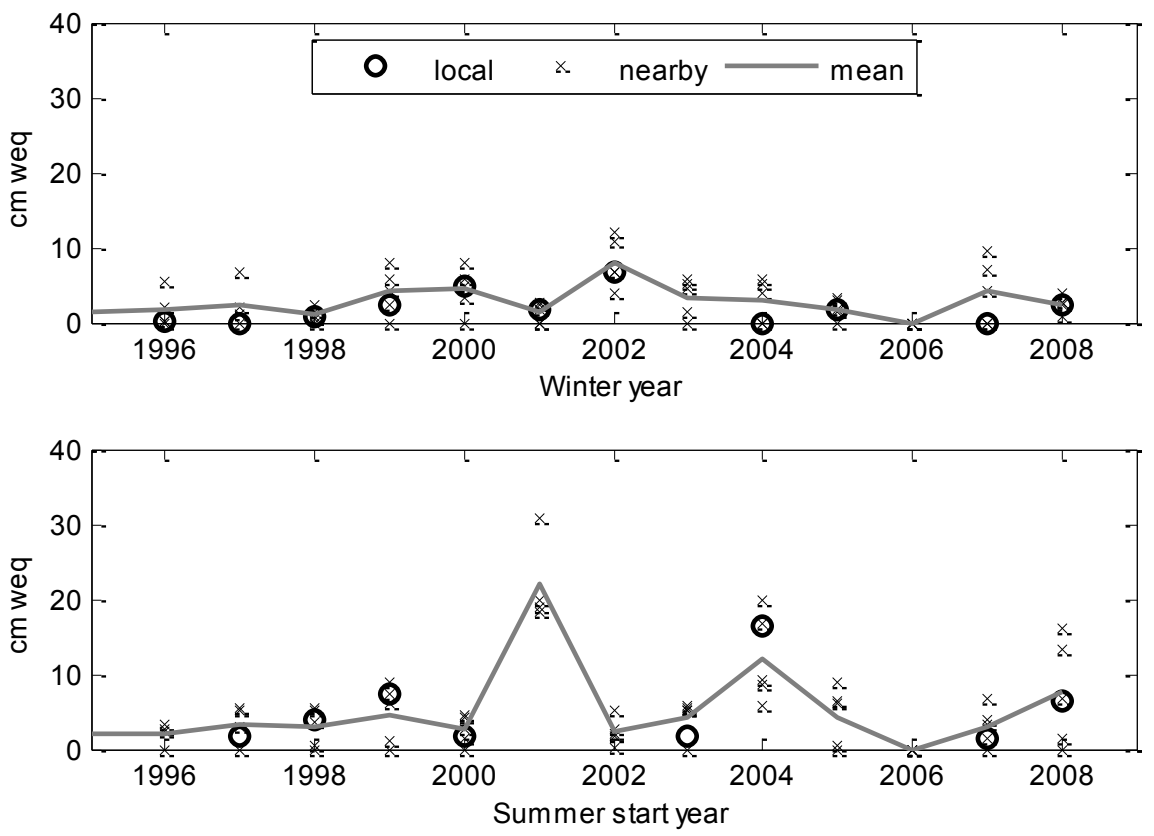

Figure 2.7: Ice ablation at Commonwealth Glacier meteorological station (stake 11). Neighboring stakes used are 5, 6, 10, and 12. 

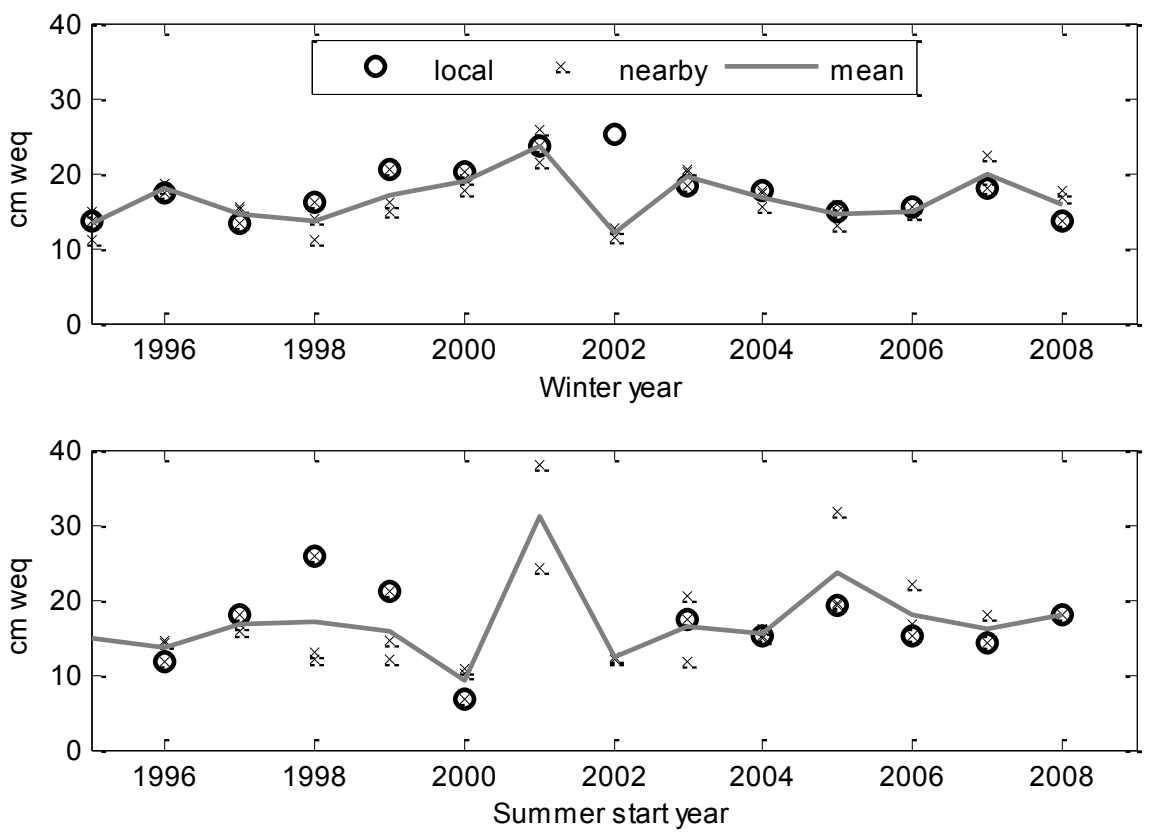

Figure 2.8: Ice ablation at Taylor Glacier terminus (stake 91). Neighboring stakes used are 79 and 92.

The standard deviation among the group of three to five stakes in the vicinity of each glacier meteorological station for each season is $2.1 \mathrm{~cm}$ weq on average, and generally less than $5 \mathrm{~cm}$ weq, although some summers have slightly higher values. Braithwaite et al. (1998) measured ablation at 10 closely placed stakes $\left(<100 \mathrm{~m}^{2}\right)$ in northern Greenland and found a standard deviation of about $0.4 \mathrm{~cm}$ weq for an ablation rate of $4.5 \mathrm{~cm}$ weq per year. The uncertainty I calculate is an order of magnitude higher, but the groups of stakes I am using span up to $2.5 \mathrm{~km}$ and $165 \mathrm{~m}$ in elevation, so some of the differences between stakes may be due to actual differences in climate. An additional difference is that the ablation rates reported by Braithwaite et al. (1998) imply that melt was the dominant ablative process, but sublimation is a large fraction of summer ablation on the Dry Valley glaciers. Because melting can ablate eight times as much ice as 
sublimation for the same amount of energy, melting that only occurs locally will generate highly spatially variable ablation rates.

To investigate variations in ice density near the surface due to internal melting, I collected six shallow $(\sim 50-100 \mathrm{~cm})$ ice cores from Commonwealth, Canada, and Taylor glaciers during summers 2007-2008 and 2008-2009 (Figure 2.9). Each core was cut into segments between 4 and $43 \mathrm{~cm}$ long. The mass of each segment was measured, and the volume was calculated from measurements of length and diameter, to yield density variations with depth similar conceptually to the procedure described for snow by LaChapelle (1959). Ice below $40 \mathrm{~cm}$ depth had a uniform, unaltered appearance, and density was calculated to be $870 \pm 30 \mathrm{~kg} \mathrm{~m}^{-3}$. Multiple cores with similar density and uncertainty calculations suggest the uncertainty is smaller. This density is lower than the $900 \mathrm{~kg} \mathrm{~m}^{-3}$ used by Fountain et al. (2006) and commonly assumed for glacier ice (Paterson 1994, Braithwaite et al. 1998) but comparable to values reported for Antarctic blue ice (Bintanja 1999). The two cores from early summer ("Taylor 1 December 2008" and "Commonwealth 18 November 2008") show no significant change in density with depth, while the other cores show lower values in the upper 10-20 $\mathrm{cm}$ (Figure 2.9). The core obtained from a rapidly melting block of calved ice at the base of Canada glacier ("Canada berry 5 January 2008") had a density as low as $740 \mathrm{~kg} \mathrm{~m}^{-3}$ in the upper $7 \mathrm{~cm}$. This is an upper bound as the shallowest few cm were crumbly and therefore unsampled. Integrating a linear change in density from $740 \mathrm{~kg} \mathrm{~m}^{-3}$ at the surface to $870 \mathrm{~kg} \mathrm{~m}^{-3}$ at 15 $\mathrm{cm}$ yields a subsurface mass loss of about $1 \mathrm{~cm}$ weq for that sample. 


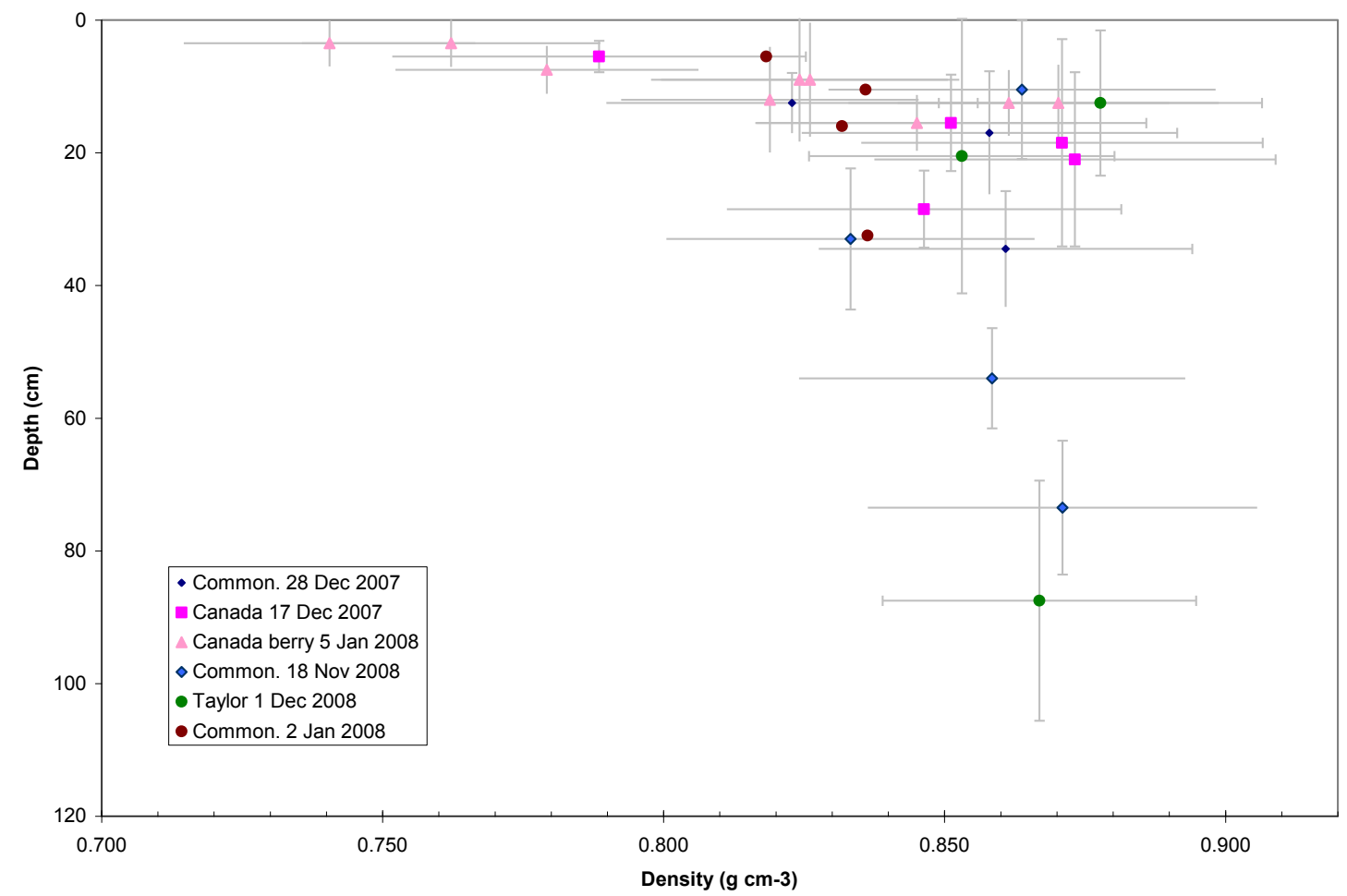

Figure 2.9: Ice density measurements. Vertical bars indicate the range of depths that each core sample represents, with the data point located at the average depth. Horizontal bars indicate uncertainty in density calculation.

\subsubsection{Streamflow Data}

Streamflow is measured at fifteen streams in Taylor Valley (Figure 2.2). Stream stage is measured at 15 -minute intervals using a pressure transducer and converted to discharge using a rating curve (McKnight et al. 1994). The rating curve at each station is determined through some combination of cross-sectional velocity measurements using a pygmy or AA flowmeter or a weir or flume installed in the stream. Often different techniques are used for low and high flow. Rating curves are generally recalculated each summer because stream geometry is very unstable in unconsolidated alluvium without vegetation. Though rating curves are calculated from discharge measurements under low 
and high flow conditions, accurate streamflow measurements are difficult to obtain due to highly variable flow rates, unstable channels, and icing of the water surface at low flow, especially when a weir is used. Each individual measurement includes a data quality flag (good=most data accurate within 10\%, fair=most data accurate within $25 \%$, poor $=$ significant amounts of data may be $>25 \%$ off) determined by the hydrologists collecting the measurements based on the condition of the gage over the course of each season (Ebnet et al. 2005). Canada Stream has the longest and most complete discharge record, while discharge data from Lyons and Santa Fe streams draining Taylor Glacier are particularly poor due to unstable channels and high sediment loads on these streams (Ebnet 2005).

\subsection{Climate Summary}

Using meteorological measurements from 1995 to 2009 reveals a similar climate

to that described in detail by Doran et al. (2002a) for the period up to 2000, but I am able to extend the analysis from the four valley floor stations in Taylor Valley to include the four glacier stations as well. As explained by Doran et al. (2002a), mean annual air temperature is largely controlled by the exposure to drainage winds which bring adiabatically warmed air downvalley and are frequent during all season except summer. Mean annual air temperature of the glacier stations is higher than that of the valley stations (Figure 2.10) despite being at higher elevations, because the higher elevation glaciers are more likely to be above the temperature inversions that often form in valley bottoms during winter and block warm drainage winds from reaching the ground locally 
(Doran et al. 2002a, Nylen et al. 2004). In contrast, temperatures are higher at the valley stations than the glacier stations during summer (DJ) when drainage winds are rare (Figure 2.10). Summer temperatures are strongly controlled by distance from the coast, because the dominant offshore winds progressively warm upvalley as they pass due to radiative warming of the dark valley floor (Doran et al. 2002a). Mean annual air temperatures range from $-17.0^{\circ} \mathrm{C}$ at Taylor Glacier to $-20.5^{\circ} \mathrm{C}$ at Lake Fryxell. Mean summer temperatures range from $-1.2^{\circ} \mathrm{C}$ at Lake Bonney to $-5.0^{\circ} \mathrm{C}$ at Howard Glacier (Figure 2.10) and mean monthly winter temperatures are between $-23^{\circ} \mathrm{C}$ and $-34^{\circ} \mathrm{C}$ (Figure 2.11).

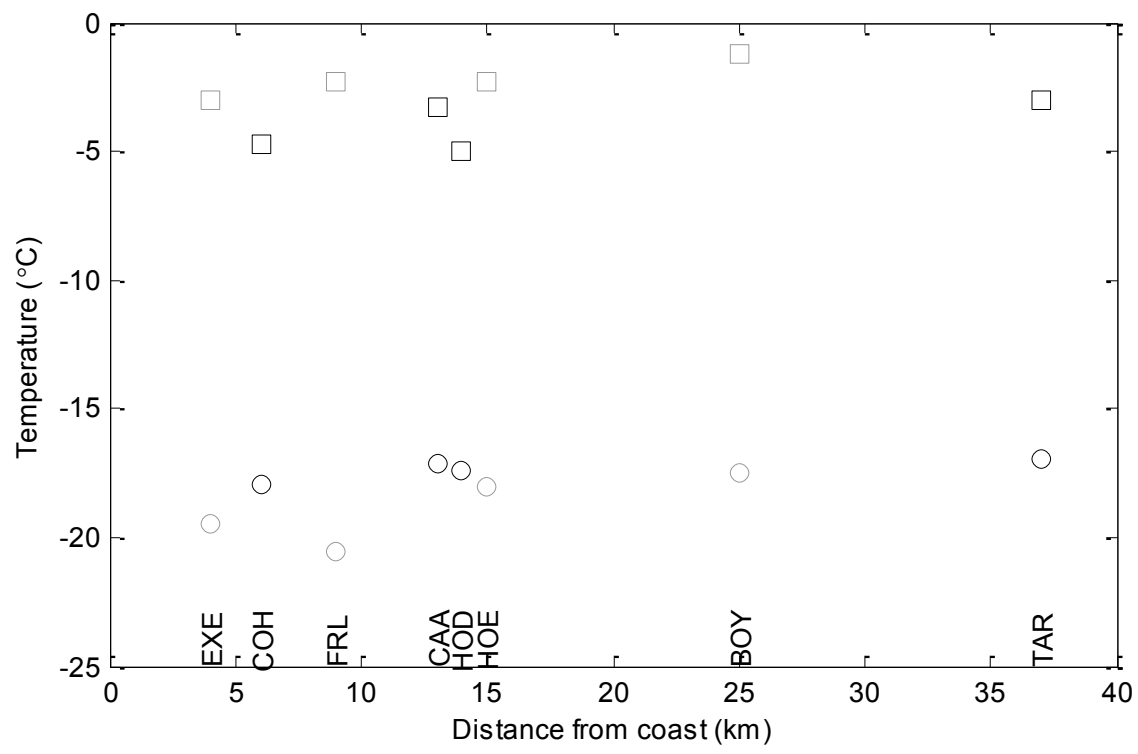

Figure 2.10: Air temperature in Taylor Valley. Circles are mean annual air temperature, and squares are mean summer (DJ) air temperature. Glacier stations are shown in black, and valley stations are shown in gray.

Similarly, mean annual relative humidity tends to decrease with distance from the coast, but additionally glacier stations have lower relative humidity due to their greater exposure to drying drainage winds. In summer when drainage winds are less frequent, 
the spatial patterns of relative humidity breaks down. Both mean annual and mean summer relative humidity varies from $55 \%$ to $75 \%$ across the valley.
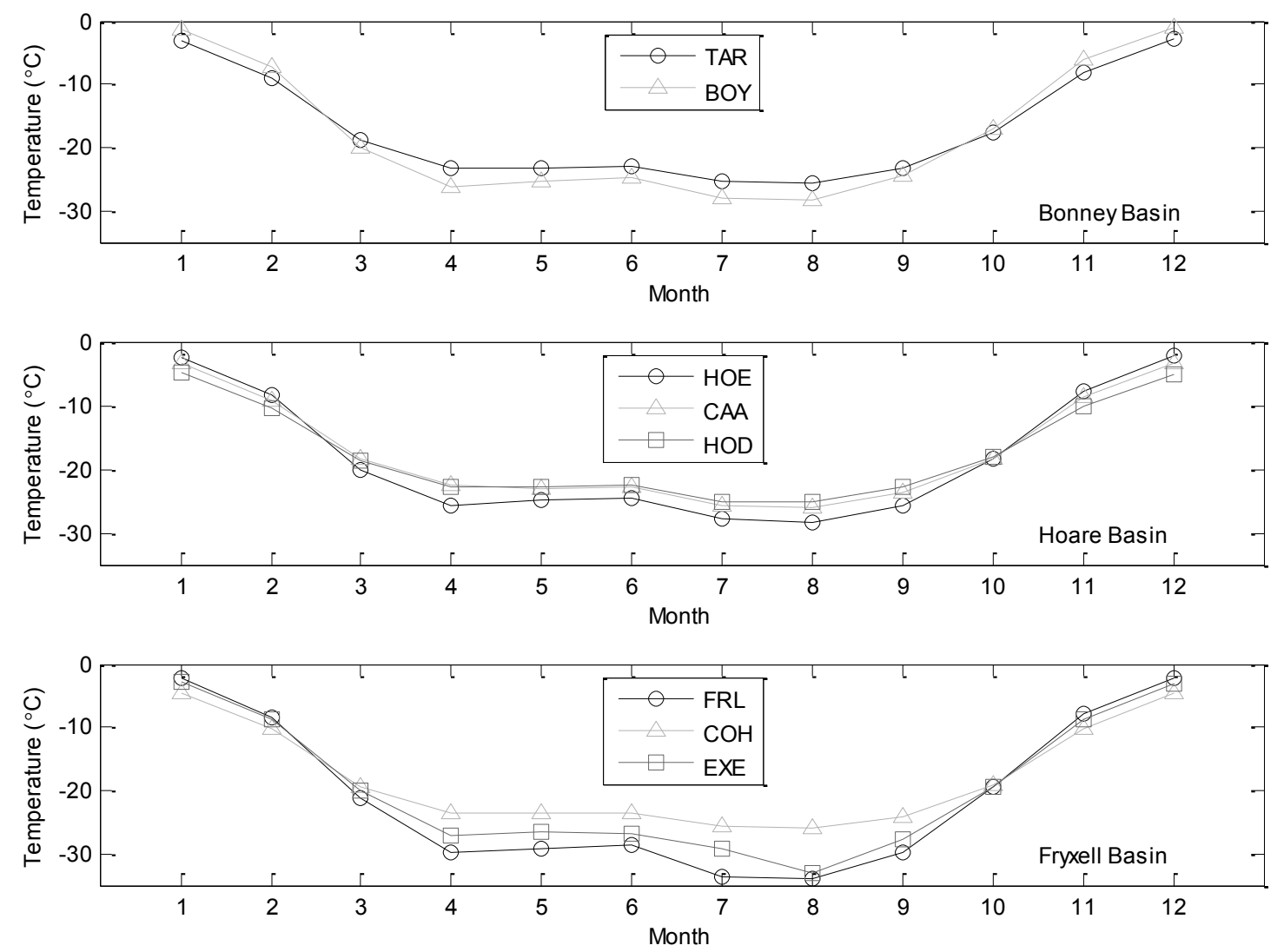

Figure 2.11: Mean monthly air temperature in Taylor Valley.

Mean annual wind speed increases upvalley with increasing proximity to the polar plateau, from which drainage winds originate (Doran et al. 2002a). Additionally, I see that glacier stations have higher wind speeds than valley stations in winter but similar or slightly lower values in summer (Figure 2.12). The difference in winter is largely due to the prevalence inversions in valley bottoms restricting the access of drainage winds, which has less of an effect at higher elevation glacier stations. While high speed, warm, downvalley drainage winds are dominant in winter, low to moderate speed upvalley sea 
breezes are dominant in summer (Doran et al. 2002a, Nylen et al. 2004) (Figures 2.132.15). The impact of drainage winds on winter wind speed is stronger at the upvalley stations, while the impact of ocean breezes on summer wind speed is stronger at the downvalley stations (Figure 2.12). There are transition periods in spring and fall with lower wind speeds when neither wind type is at full strength, although the magnitude and duration differs between stations (Figure 2.12). The timing of the greatest frequency of drainage winds results in April being colder than May and June at most stations (Figures $2.1-2.12$ ). Solar radiation is largely absent by April, resulting in rapid cooling, but the air temperature warms once frequent drainage winds bring adiabatically warmed air into the valley. 

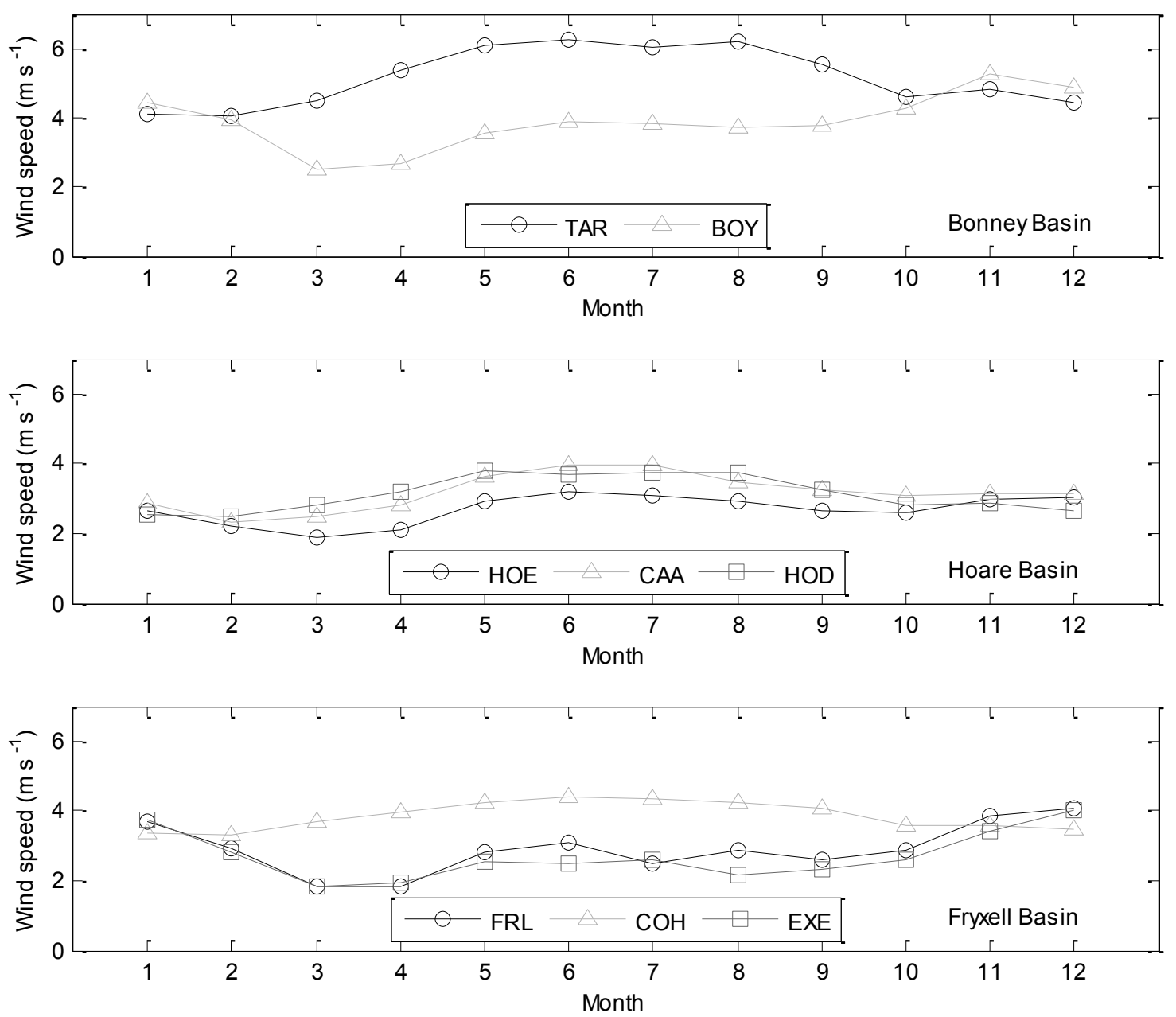

Figure 2.12: Mean monthly wind speed in Taylor Valley.

The strongest winds blow downvalley in all seasons at all stations, despite the low frequency of downvalley winds in summer (Doran et al. 2002a, Nylen et al. 2004). This relationship extends to the glacier stations (Figures 2.13-2.15). The Bonney Basin stations are the only ones that show a sizable frequency of downvalley winds during summer (Figure 2.13). The glacier stations $\mathrm{COH}$ and HOD (and to a lesser extent CAA) experience a dominant downslope glacier drainage wind in winter and often during summer (Figures 2.14 - 2.15). At these stations, downvalley winds are rare, suggesting that the glacier wind may counteract the dominant drainage flow at these locations. 

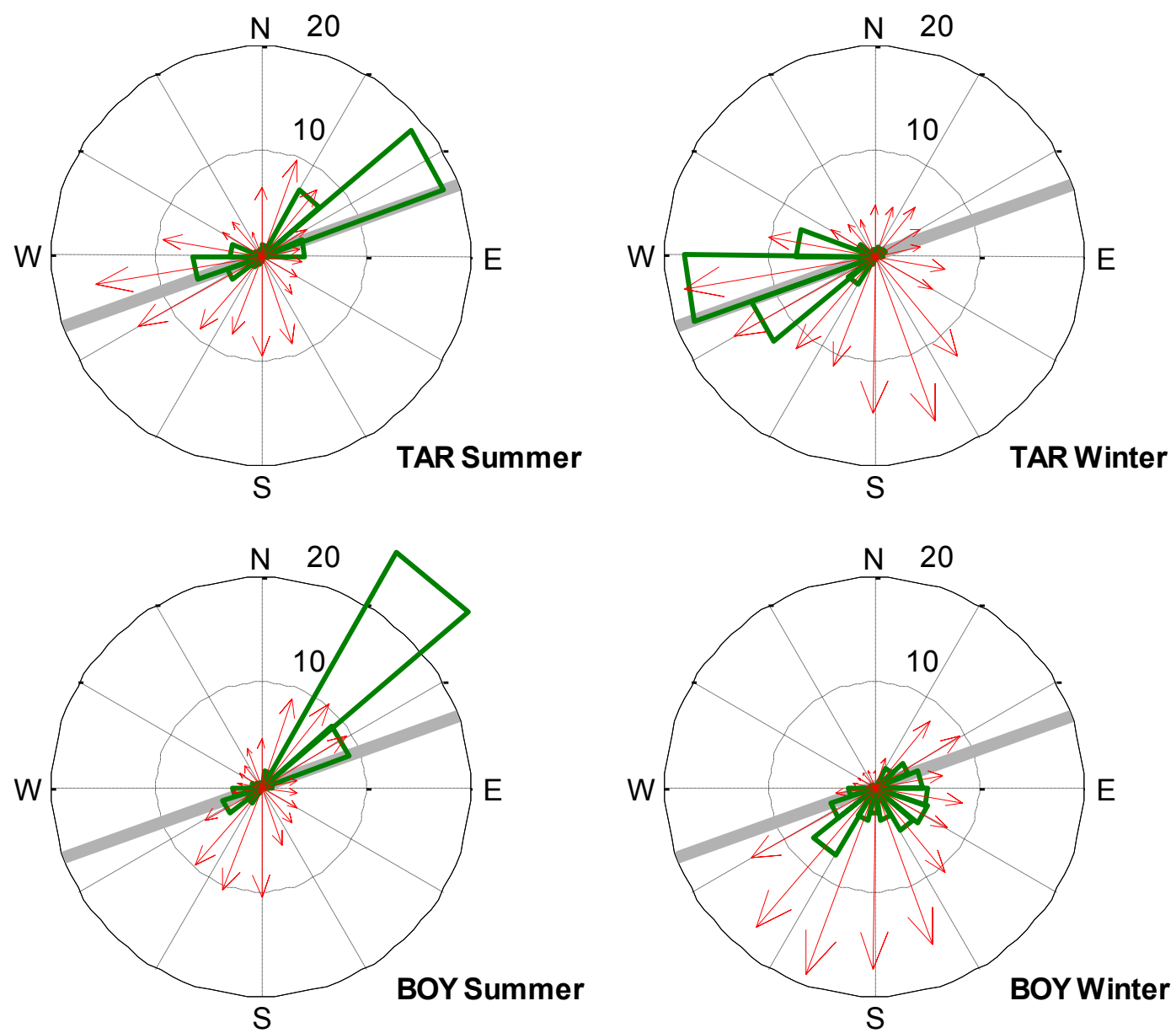

Figure 2.13: Wind direction histogram for stations in Bonney Basin. Green lines indicate\% frequency of wind direction for each $20^{\circ}$ angle bin. Outer ring is $20 \%$ and inner ring is $10 \%$. Red lines indicate mean wind speed for each bin in $\mathrm{m} \mathrm{s}^{-1}$. Wind speed is scaled $\times 2$ so outer ring is $10 \mathrm{~m} \mathrm{~s}^{-1}$ and inner ring is $5 \mathrm{~m} \mathrm{~s}^{-1}$. The gray line marks the approximate valley axis. Summer is December and January, and winter is May through August. 

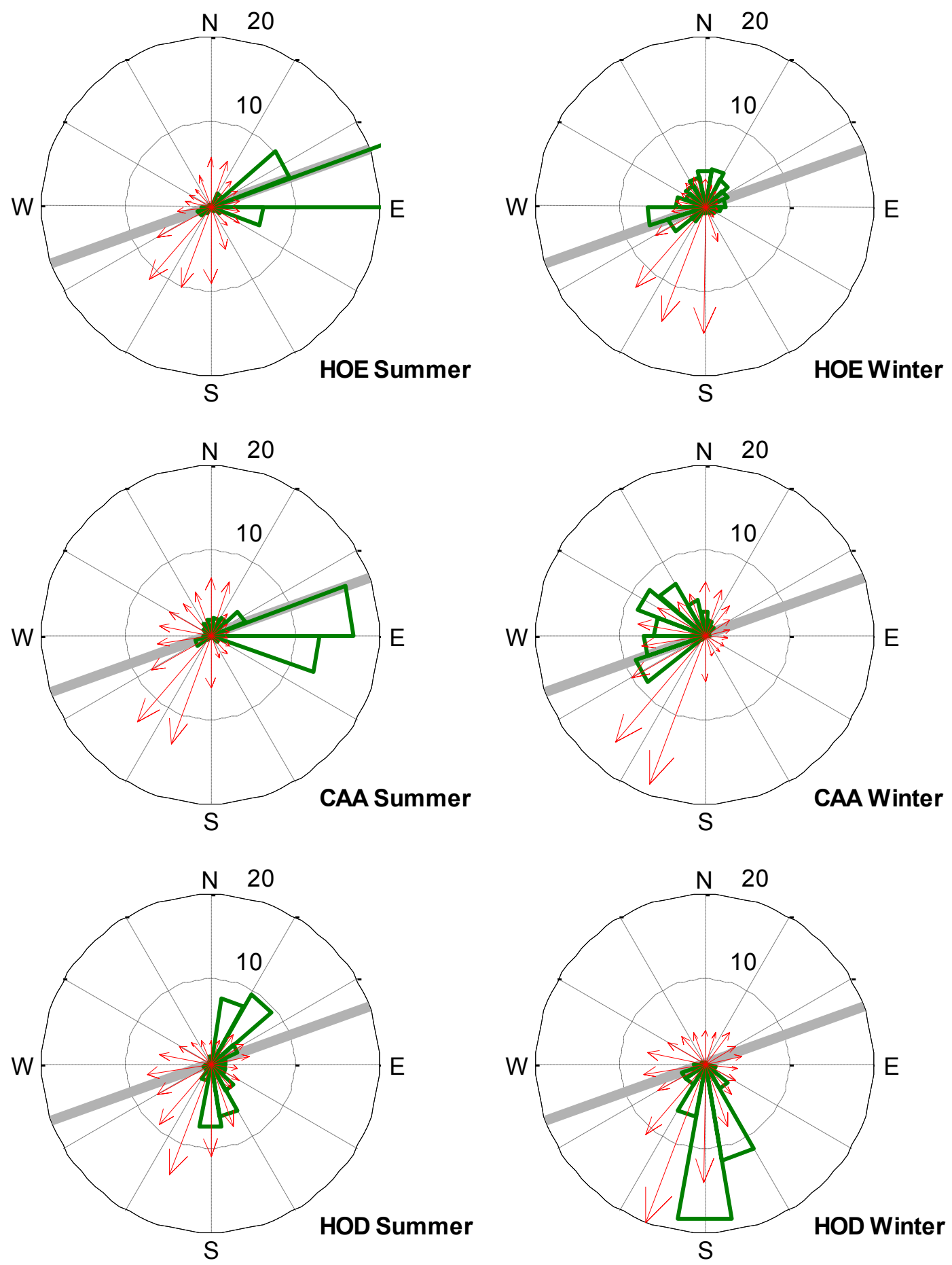

Figure 2.14: Wind direction histogram for stations in Hoare Basin. See Figure 2.13 for explanation. 

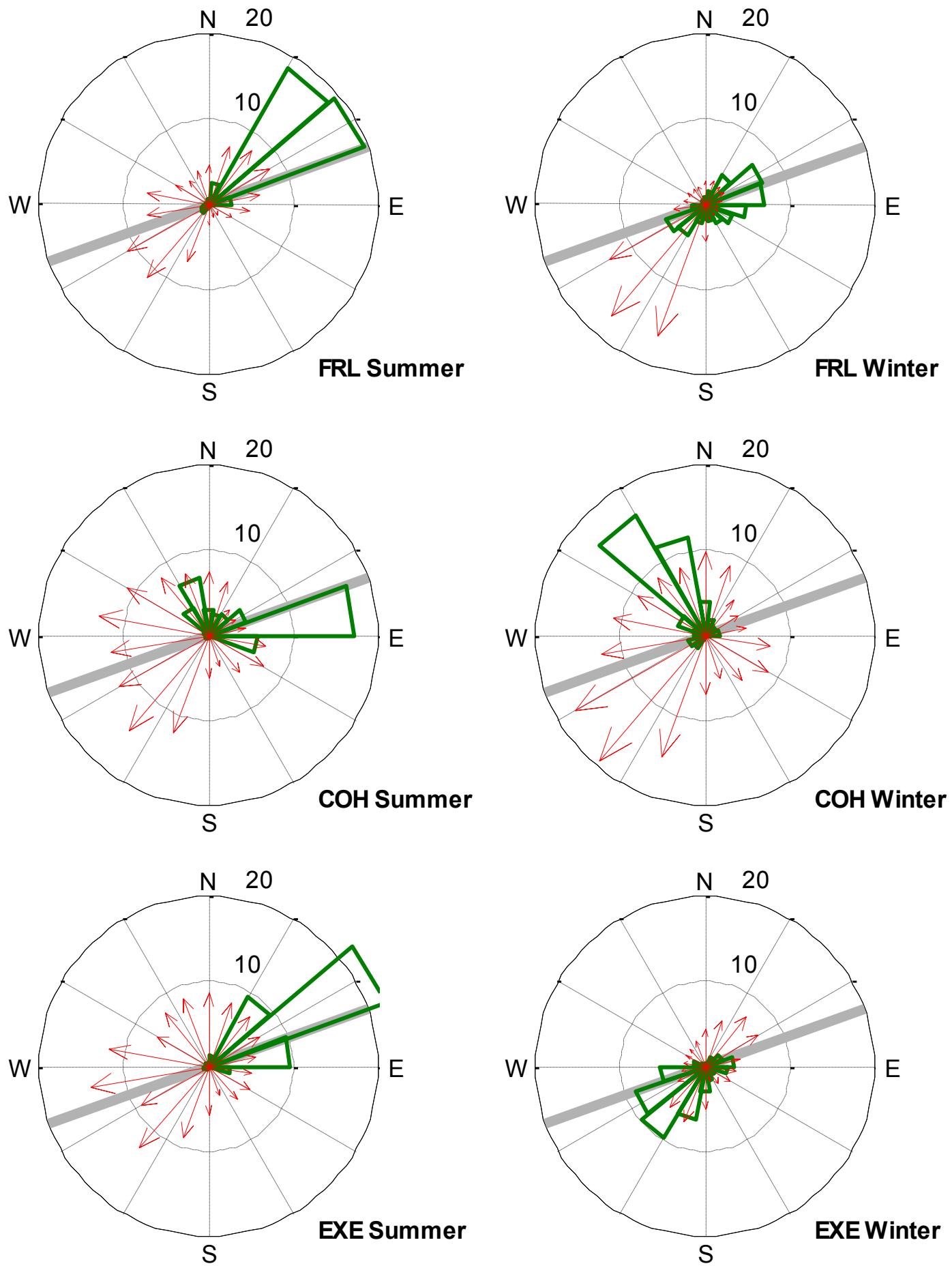

Figure 2.15: Wind direction histogram for stations in Fryxell Basin. See Figure 2.13 for explanation. 
During summer the sun dips below the horizon only briefly each night, if at all, but because the maximum solar elevation angle is $35^{\circ}$, the high relief topography of the valley generates considerable spatial variability in solar radiation (Dana and Wharton 1998). The diurnal variations in solar radiation (which peaks at $\sim 14: 00$ local time) drive modest diurnal variations in temperature, relative humidity, and wind speed. Most stations have a mean diurnal temperature range of 2 to $3{ }^{\circ} \mathrm{C}$, although at Howard and Taylor glaciers it is somewhat larger at $3.6{ }^{\circ} \mathrm{C}$. Daily maximum temperature occurs between 14:00 and 17:00 and daily minimum temperature between 03:00 and 06:00 at all stations. Maximum and minimum daily wind speed has approximately the same timing, while the timing is reversed for relative humidity.

\subsubsection{Drainage Wind Events}

Drainage winds, gravity-driven winds that typically reach high speeds and exhibit low humidities, are a characteristic feature of the McMurdo Dry Valleys, reaching recorded speeds up to $37 \mathrm{~m} \mathrm{~s}^{-1}$ (Nylen et al. 2004, Speirs et al. 2010). Formerly thought of as katabatic winds draining from the polar plateau (e.g. Doran et al. 2002a, Nylen et al. 2004), it has recently been clearly established that they are 'drainage' or foehn winds, as found in many midlatitude mountainous regions (Speirs et al. 2010). These winds typically originate from synoptic pressure gradients forcing airflow interactions with the Transantarctic Mountains and resulting in adiabatic warming of air as it descends through the valleys (Speirs et al. 2010).

The strongest and most frequent drainage winds in McMurdo Dry Valleys occur at Taylor Glacier, with a winter frequency greater than $50 \%$ and $15 \%$ during summer 
(Nylen et al. 2004). I extend the drainage analysis that Nylen et al. (2004) performed for a single year to the 1995-2009 period and find similar monthly frequency (Figure 2.16). Building on the thresholds defined by Nylen et al. (2004), I define a drainage wind 'condition' as any hour when wind speed is greater than $5 \mathrm{~m} \mathrm{~s}^{-1}$ and wind direction is between $180^{\circ}$ and $315^{\circ}$. [Note that I use hourly averages and Nylen et al. (2004) used 15-minute averages.] Additionally, I define a drainage wind 'event' as a period of time meeting the drainage wind condition for eight or more consecutive hours. This definition of an event may eliminate (or break into multiple events) any events during which wind speed or direction temporarily fail to meet the thresholds, but this definition allows us to objectively define events and automate their detection over 14 years of observations. 

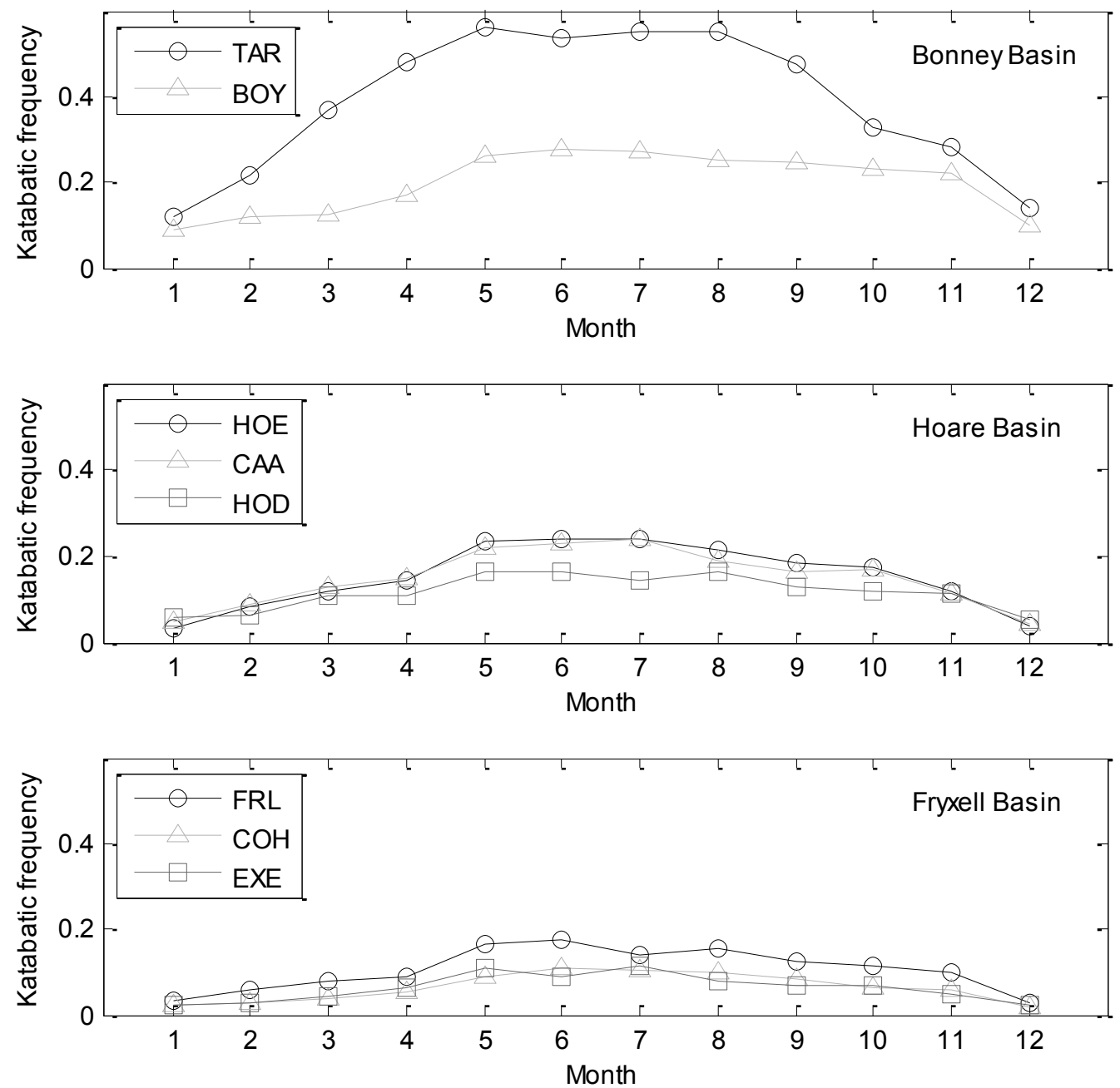

Figure 2.16: Monthly frequency of drainage wind conditions in Taylor Valley. Drainage wind conditions are defined as wind speed greater than $5 \mathrm{~m} \mathrm{~s}^{-1}$ and a wind direction between $180^{\circ}$ and $315^{\circ}$ (Nylen et al. 2004).

Uninterrupted drainage wind events last up to six days in the Bonney Basin, but typically last less than one day (Figure 2.17). In addition to having the most frequent drainage wind conditions, TAR also has the longest lasting drainage wind events. There is only a slight drop in the duration of drainage events between BOY and FRL, but the glacier stations at $\mathrm{HOD}$ and $\mathrm{COH}$ and the station at the valley mouth (EXE) typically have shorter events. The warming during drainage wind events varies from $-5^{\circ} \mathrm{C}$ to 
$+30^{\circ} \mathrm{C}$ but is most commonly between $0^{\circ} \mathrm{C}$ and $10^{\circ} \mathrm{C}$ (Figure 2.18 ). The valley stations generally experience more warming during drainage wind events than the glacier stations. This is likely due to the persistent inversions that form in the valleys in winter due to longwave radiative cooling of the valley floor during the polar night. Should the drainage wind be able to erode the cold cell along the valley floors, the inversion conditions there provide a lower pre-event temperature. Though the temperature increase during drainage wind events is often substantial, air temperature returns to pre-event values within 6-12 hours of the termination of most events (considering summer and winter together), indicating that this warming is temporary while the event occurs. 

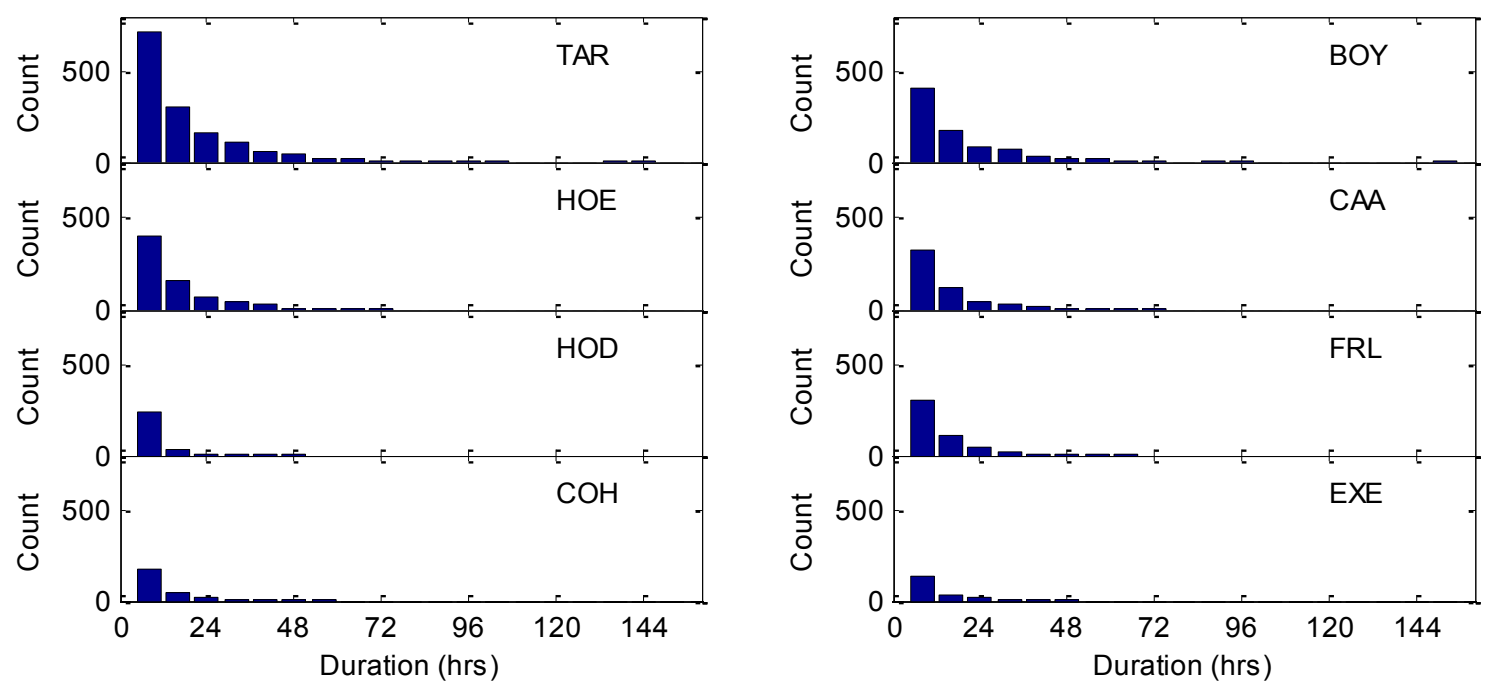

Figure 2.17: Duration of drainage 'events' at each station. Events are defined as 8 continuous hours or longer of the drainage condition of wind speed greater than $5 \mathrm{~m} \mathrm{~s}^{-1}$ and a wind direction between $180^{\circ}$ and $315^{\circ}$ (Nylen et al. 2004).
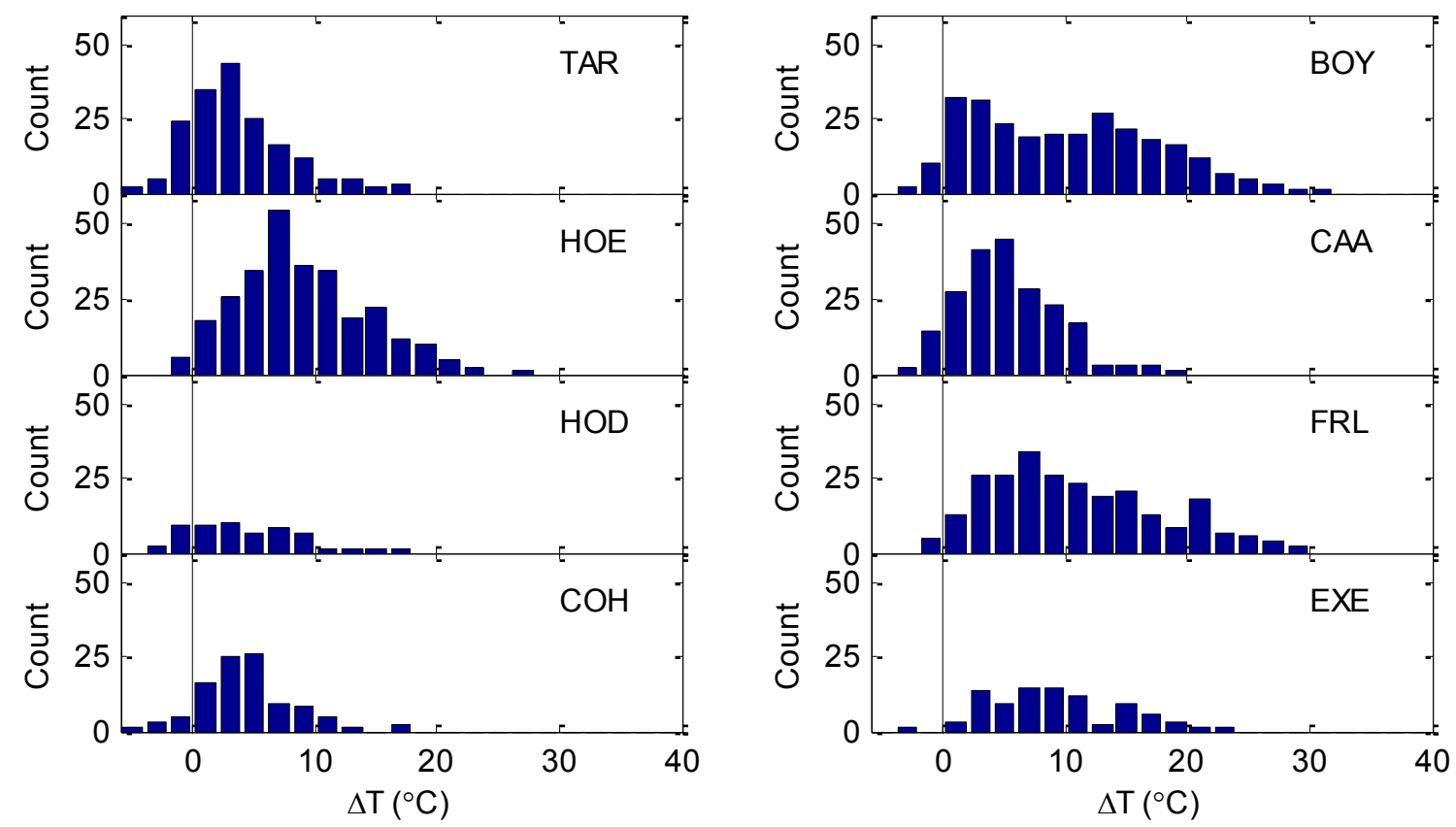

Figure 2.18: Warming associated with drainage events. Each histogram indicates the frequency of temperature difference between the mean temperature during the 24 hours following the start of a drainage event and the 24 hours preceding the start of the event. Events for which another event occurred within the preceding 24 hours are not included. Note that most events last less than 24 hours. 


\subsubsection{Lapse Rates}

To investigate the importance of temperature inversions in valley basins and the intermittent drainage winds, I calculated the lapse rates for selected pairs of adjacent stations, including the short term Upper Howard Glacier ridgetop station, where lapse rate, $\gamma$, is defined for temperature, $\mathrm{T}$, and elevation, $\mathrm{z}$, as:

$$
\gamma=-\frac{d T}{d z}
$$

All stations pairs show positive lapse rates during summer that are reasonably close to the environmental lapse rate of $6.5^{\circ} \mathrm{C} \mathrm{km}^{-1}$ (Figure 2.19). This is in contrast to observations by Johnston (2004) on Taylor Glacier of a lapse rate averaging $8.0^{\circ} \mathrm{C} \mathrm{km}^{-1}$, closer to the dry adiabatic lapse rate of $9.8^{\circ} \mathrm{C} \mathrm{km}^{-1}$.

Lapse rates decrease substantially in winter reaching values below $-10{ }^{\circ} \mathrm{C} \mathrm{km}^{-1}$ between some stations. The lapse rate between the two nearby glacier stations CAA and HOD remains higher than rates between valley stations and glacier stations. Similarly, there is generally a lower inversion frequency in winter between CAA and HOD than other station pairs (Figure 2.19). Strong inversions are common in the winter and the glaciers are usually warmer than the valley floor. Hourly lapse rates vary dramatically in time and space, which is in part due to uncertainty in temperature measurements, but also to complex wind patterns. In winter hourly lapse rates range from near $-100{ }^{\circ} \mathrm{C} \mathrm{km}^{-1}$ to near $+15^{\circ} \mathrm{C} \mathrm{km}^{-1}$. Summer variation is much less but still significant. The initiation of inversions in March and continued strengthening through August can be seen clearly in mean monthly air temperature profiles in the Hoare Basin (Figure 2.20). 

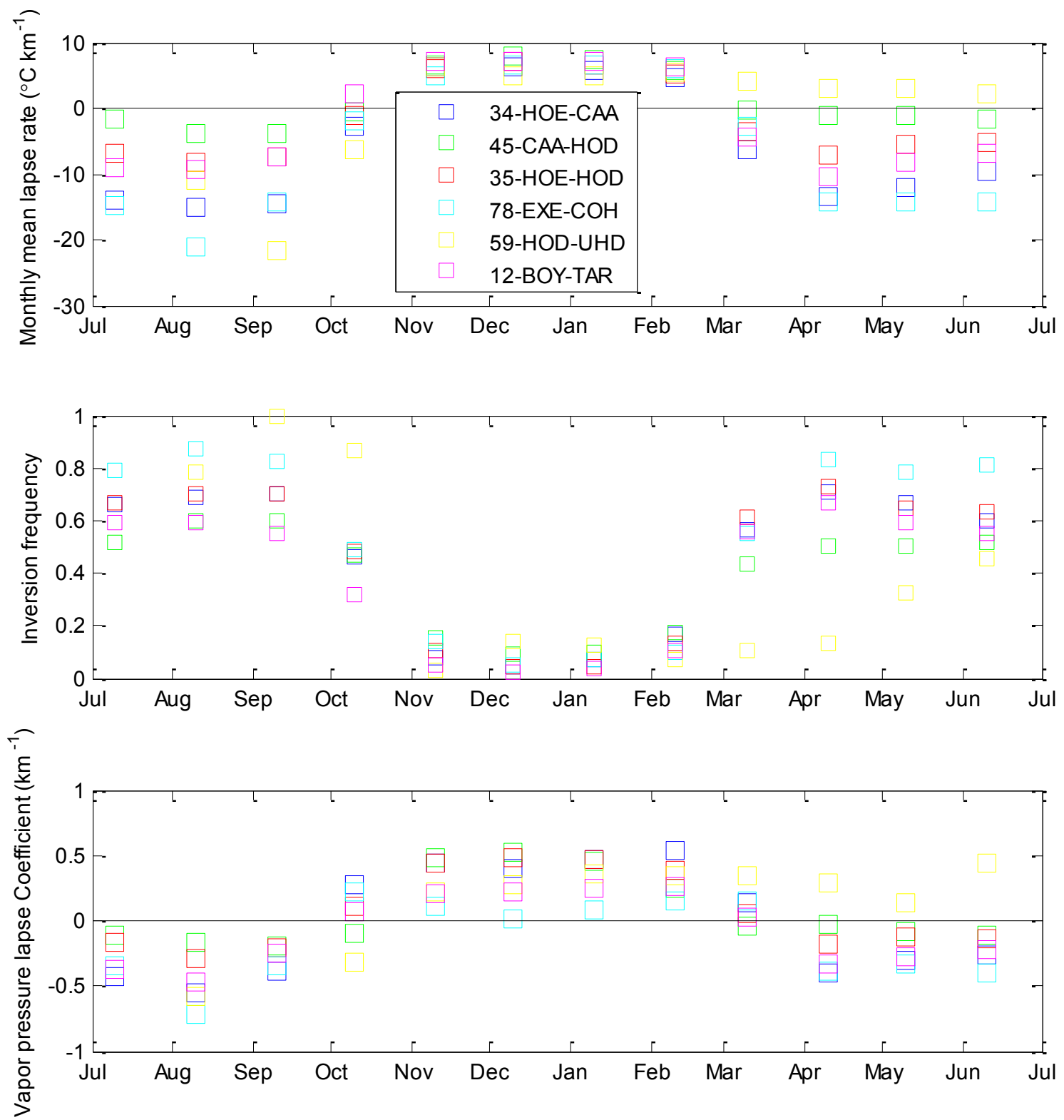

Figure 2.19: Lapse rates in Taylor Valley. Top: Mean monthly lapse rates between selected stations. Middle: Monthly inversion frequency for same station pairs. Bottom: Mean monthly vapor pressure lapse coefficient for same station pairs. 


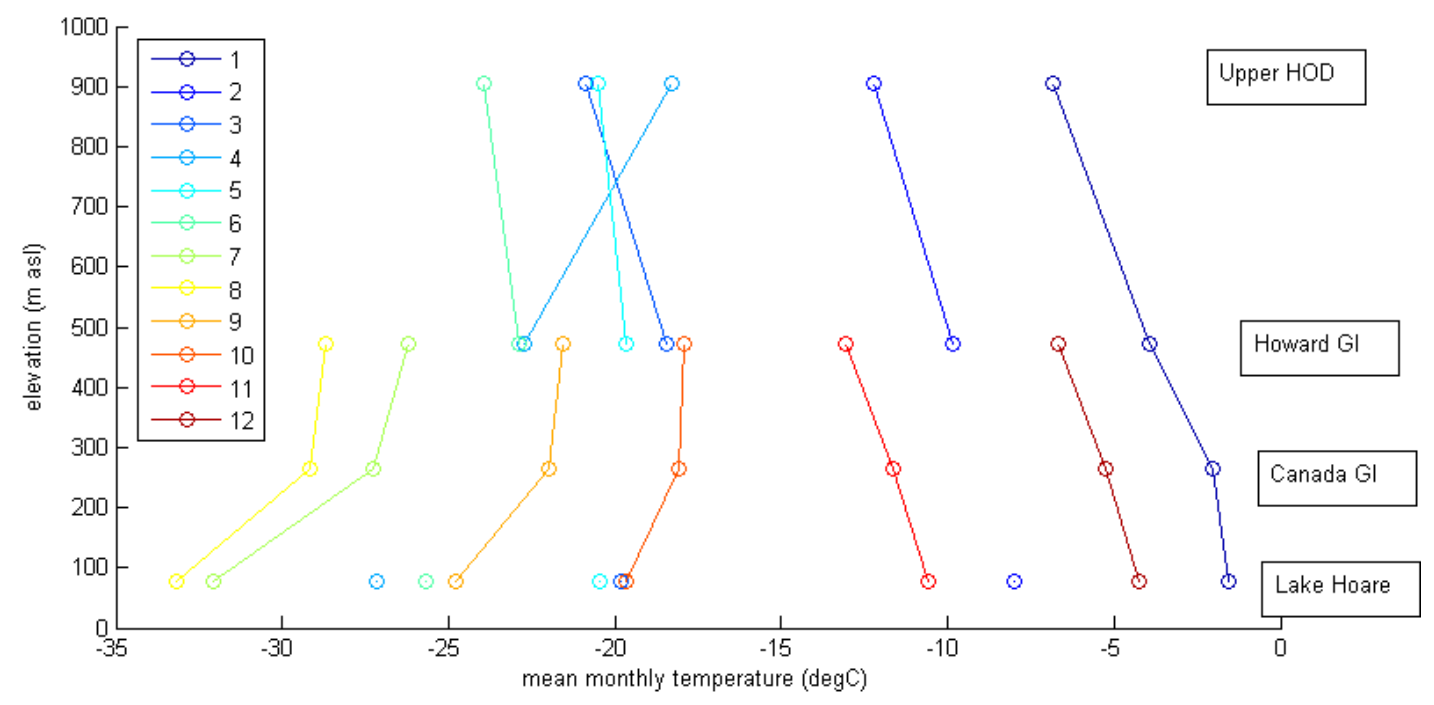

Figure 2.20: Mean monthly air temperature profiles for stations in the Hoare Basin for 2002-

2003. There are data gaps in the record at UHD and CAA, and the April value for UHD is based on a small number of hours within the month.

Vapor pressure lapse coefficient, $\lambda$, is a measure of the rate at which vapor pressure decreases with elevation. It is calculated from the vapor pressures, $\mathrm{e}_{1}$ and $\mathrm{e}_{2}$, at two elevations, $\mathrm{z}_{1}$ and $\mathrm{z}_{2}$ as Kunkel (1989):

$$
\lambda=-\frac{\ln \left(\frac{e_{2}}{e_{1}}\right)}{z_{2}-z_{z}}
$$

Similar to temperature lapse rate, the vapor pressure lapse coefficient for all stations has similar values to mid-latitude locations during summer (Figure 2.19). However, for much of winter, the vapor pressure lapse coefficient is negative, indicating that vapor pressure profiles are inverted and vapor pressure actually increases with elevation, presumably a consequence of higher temperatures aloft. 


\subsubsection{Snowcover}

To assess the frequency of snowcover at the four glacier meteorological stations, I use both albedo (at all sites) and measurements of surface height changes (at Taylor, Howard, and Commonwealth glaciers). Snow has a higher albedo than ice, but thin snowcover may be difficult to classify conclusively using albedo and albedo is also affected by solar zenith angle, cloudiness, and the presence of debris or impurities (Gardner and Sharp 2010). Measurements of surface height change clearly identify snow accumulation, but snowcover less than a few $\mathrm{cm}$ thick is difficult to detect.

In practice, the record of surface height change is a more reliable indicator of snowcover than albedo and provides additional information in the snow depth. However these measurements are only available at three of the four glacier meteorological stations, and only since January 2003 (Commonwealth) or 2004 (Taylor and Howard). In contrast, albedo has been measured at all four glacier sites for the entirety of the measurement record. In this section, I use the few years of surface height change data to help define an albedo threshold for detecting the presence of snow from the albedo record. Though the surface height change record extends year-round, albedo can only be measured from September to April when the sun is above the horizon, and includes significant uncertainty and bias in spring and fall when solar zenith angles are low. However, the purpose of determining the presence of snow on the glaciers is to allow me to prescribe a temporary snow layer in the melt model which eliminates ablation of the ice. As the melt season is primarily restricted to November through January, I restrict 
this analysis to that time period, for which the uncertainty and variation in albedo is greatly reduced.

The albedo of snow $(\alpha=0.84)$ is greater than ice $(\alpha=0.40)$ (Paterson 1994, p.54), although both materials can have a wide range of values that overlap (Grenfell and Maykut 1977, Gardner and Sharp 2010). Albedo of snow and ice increases with solar zenith angle; due to forward scattering on these surfaces, low angle incident light has a higher chance of reflecting off of the surface (Warren 1982, Gardner and Sharp 2010). For this reason, albedo for snow and ice in spring and fall is significantly higher than at midsummer, particularly at high latitudes, which makes a constant albedo threshold illsuited to discriminate between the two. To isolate the effect of solar zenith angle, I create a bare ice albedo time-series by manually removing periods of snowcover at Taylor Glacier meteorological station for all fourteen summers (1995-1996 to 2008-2009), using daily averaged albedo. Taylor Glacier was used because snowfalls are relatively infrequent and when they do occur they are typically obvious in the record. The resulting yearly bare ice albedo time series were averaged by day of the year since July 1 (Figure 2.21). A fourth-order polynomial was chosen to fit the averaged time series because there is a moderate increase in ice albedo during midsummer in many years, making the seasonal albedo time-series asymmetrical (Figure 2.21). I assume the bare ice curve for Taylor Glacier applies to the glaciers in general and to the three other meteorological station sites, though some variations in bare ice albedo between sites may exist. For example, bare ice albedo on Howard Glacier tends to be higher than the other three sites 
in early and late season, presumably because its north facing aspect amplifies the nonlinear increase in albedo at low solar elevation angles.

There reason for the asymmetry in seasonal albedo is unclear, but it is more likely related to changes in ice properties than to changes in incoming solar radiation; variations in solar zenith angle are symmetric about the solstice, and we do not observe significant changes in cloudiness over the season that would substantially affect the solar spectrum. The rise in albedo in December may be caused by summer melting changing the optical properties of the ice. The most likely explanation is the melting and subsequent drainage of ice beneath the surface creating air voids. Air bubbles increase the albedo of ice (Mullen and Warren 1988, Gardner and Sharp 2010), and draining of brine from sea ice has been observed to increase ice extinction coefficients (Buckley and Trodahl 1987), which would raise the albedo. Conversely, the presence of undrained meltwater should instead lower albedo, as liquid water tends to infill voids between grains, effectively increasing grain size (Colbeck 1979, Gardner and Sharp 2010). Similarly, though I observe changes in ice surface roughness from a smooth, scalloped surface to a rougher, crumbly surface over the course of many summers, a rougher ice surface will exhibit lower albedo by locally increasing the angle of incidence of radiation (Warren et al. 1998, Gardner and Sharp 2010). 


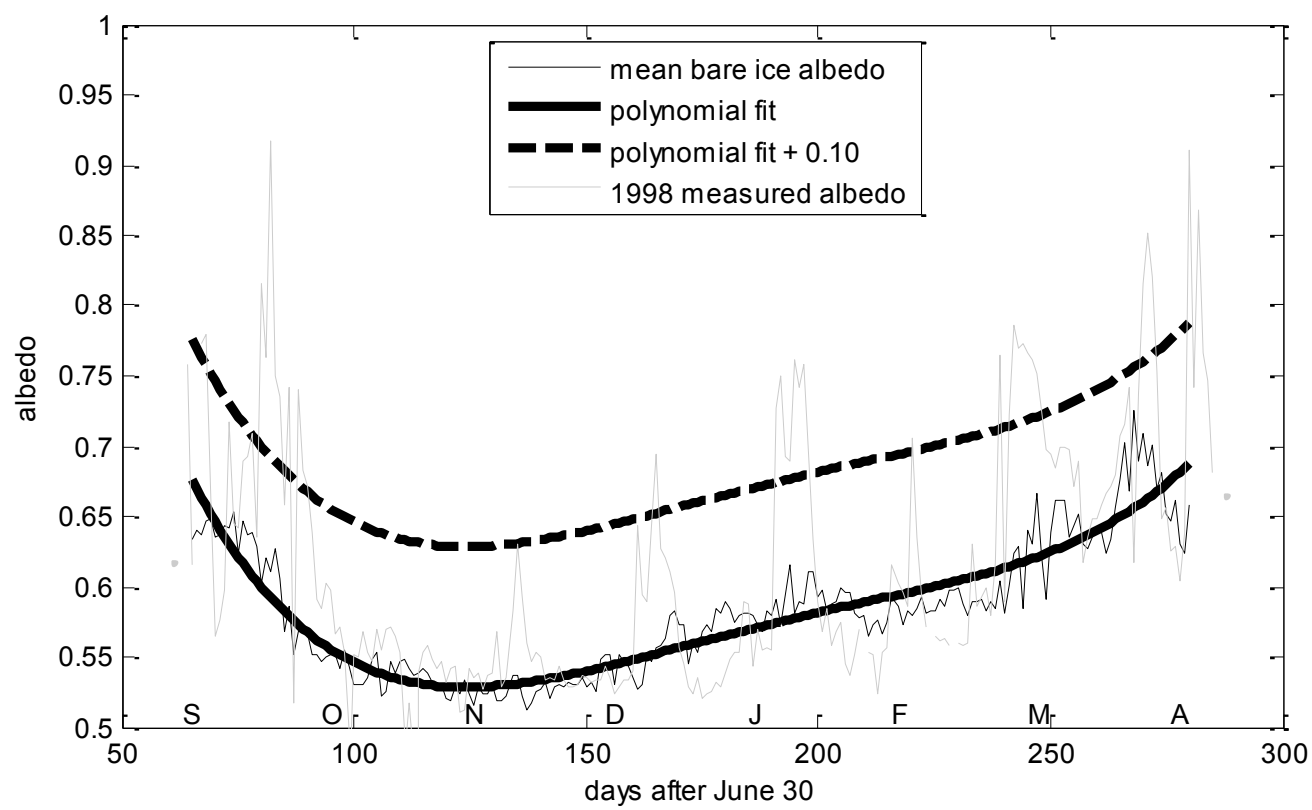

Figure 2.21: Mean bare ice albedo and polynomial fit for Taylor Glacier. Measured albedo from 1998 is also shown as an example. The first day of each month is indicated for reference.

Using the parameterized bare ice albedo curve, I calculate an albedo deviation for each day, which is the amount the measured albedo is above the bare ice value for that day (Figures 2.23-2.25). To help determine an appropriate threshold to use to differentiate ice and snow, I compare these albedo deviation values to the presence of snow as detected by the record of surface height change. The sonic ranger measures changes in distance from a fixed point on the meteorological station; increases in distance represent ablation and decreases in distance represent accumulation of snow. The sonic ranger has an accuracy of $\sim 1 \mathrm{~cm}$ (Table 2.2 ) so snowfalls $\leq 1 \mathrm{~cm}$ are difficult to detect. I use daily averages of surface height to calculate snow presence in order to reduce the uncertainty of the measurements. I found a threshold of a $1 \mathrm{~cm}$ decrease in the distance to the surface within a period of two days to match my visual interpretation of snow 
accumulation events. I use this threshold to automate the detection of snow accumulation events within the record. After snow presence is detected, snow depth is calculated as the difference between the sonic ranger measurements and the last known distance to the ice surface. When the distance to the surface returns to within $0.5 \mathrm{~cm}$ of the last known ice surface, snow depth is set to 0 .

In comparing the albedo and sonic ranger methods of snow detection, I expect some discrepancy because thin snowcover may be ambiguous for both methods and the albedo is influenced by many other factors that complicate a simple interpretation. Also, there is high spatial variability in snow presence and depth due to wind redistribution of snow (Fountain et al. 2010), and I expect differences to occur over the $\sim 1 \mathrm{~m}$ between the fields of view of the pyranometers measuring albedo and the sonic ranger at each meteorological station. Figures 2.23-2.25 show the relationship between the sonic ranger snow record and albedo. At each site there are instances of snow being measured by the sonic ranger while albedo close to the bare ice value is measured. Conversely, there are instances of albedo above bare ice values while no snow is measured by the sonic ranger, which could be due to snow depths $<1 \mathrm{~cm}$. Differentiation between snow and ice is difficult at Taylor Glacier where few days with snow are detected and the measured snow depths are typically $<5 \mathrm{~cm}$. Despite these difficulties, there is separation between the histograms of albedo for days with no detectable snow and those with detectable snow. Based on this analysis, I choose a threshold of 0.10 above bare ice albedo to differentiate between ice and snow. I expected that thinner snowcover might 
have a lower albedo as the optical properties of ice would contribute to the albedo, but I do not see a well-defined relationship between snow depth and albedo.

The sonic ranger and albedo records of snowcover are generally in agreement, but substantial differences exist in some years, e.g. summer 2004 at Howard Glacier, highlighting the uncertainty in snow detection (Figure 2.22). On average at the meteorological station sites, Taylor Glacier has snowcover for $12 \%$ of summer, Canada for $24 \%$, Howard for $69 \%$, and Commonwealth for $70 \%$. The only summer with low snowcover at all sites is the 2001-2002 summer, which was a record year with high temperatures and strong drainage winds (Doran et al. 2008). The Commonwealth and Howard glacier meteorological station sites remain snow covered for nearly the entirety of summer in some years, which is not unexpected given their locations near the equilibrium line of their respective glaciers, and their proximity to the coast, which receives substantially more snow than further inland (Fountain et al. 2010). 


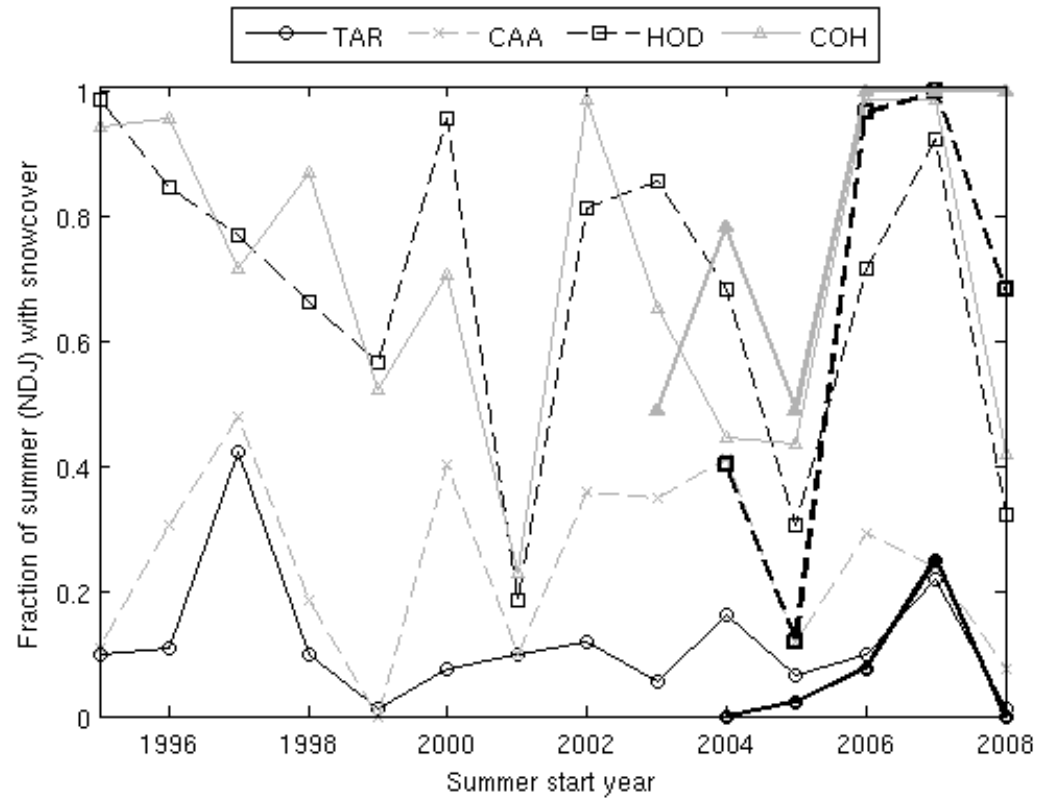

Figure 2.22: Fraction of summer (November-January) with snowcover at each site. Thin lines are based on albedo, and thick lines are based on sonic ranger data.
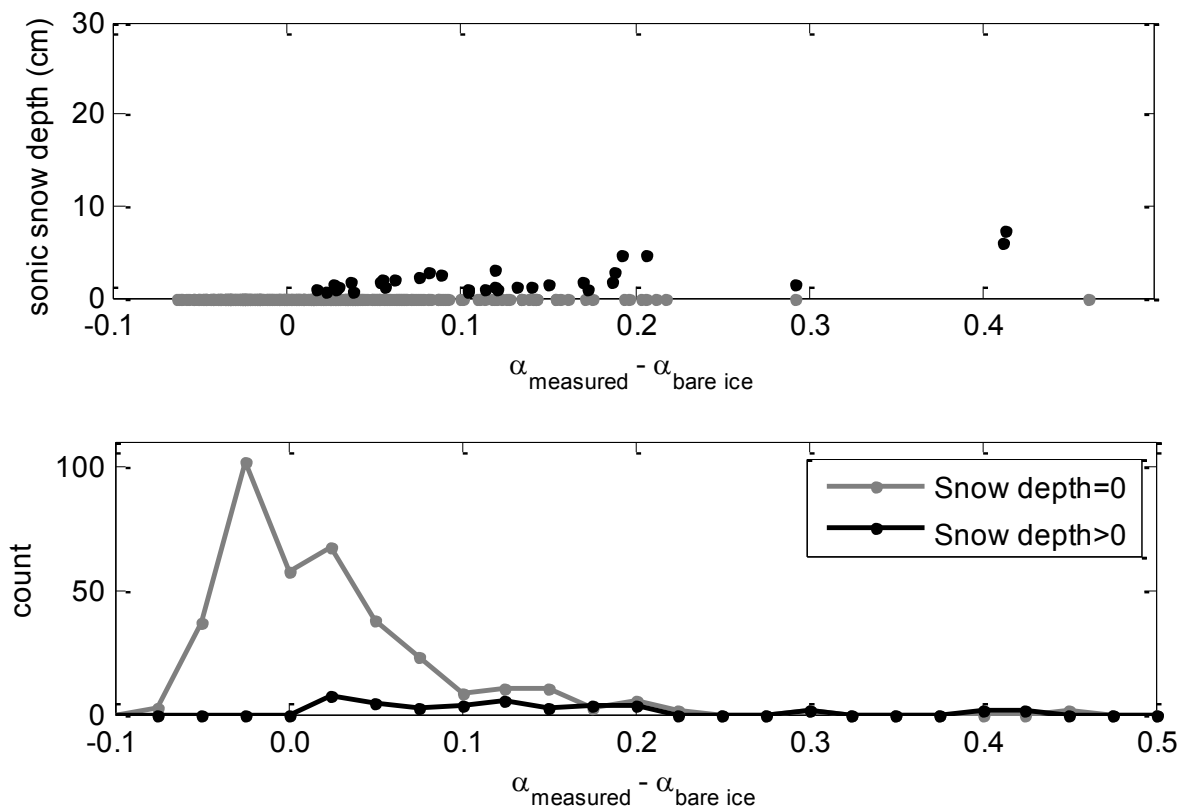

Figure 2.23: Relationship between snow depth and albedo at Taylor Glacier meteorological station (top). Bare ice albedo is calculated using polynomial fit shown in Figure 2.21. Bottom: Histogram of albedo for conditions classified as snow-on and snow-off from sonic ranger measurements. 

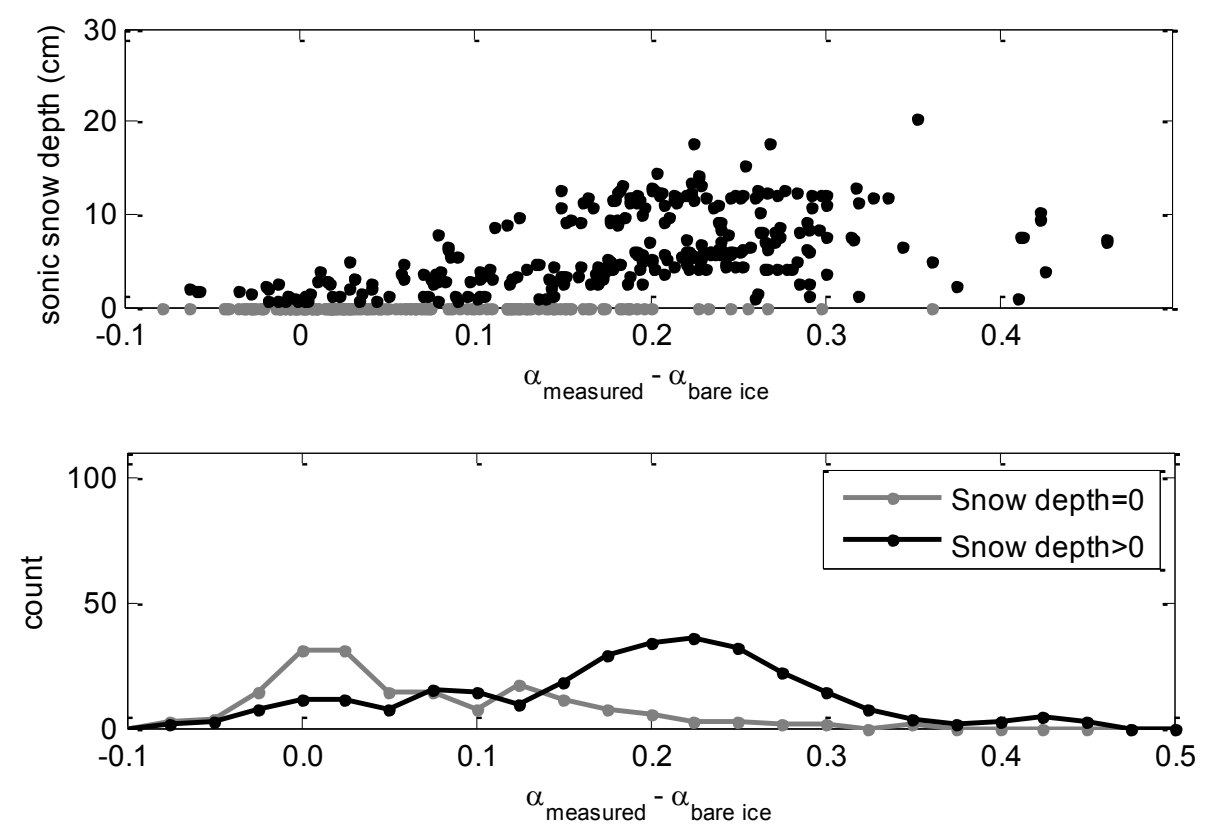

Figure 2.24: Relationship between snow depth and albedo at Howard Glacier meteorological station (top). Bare ice albedo is calculated using polynomial fit shown in Figure 2.21. Bottom: Histogram of albedo for conditions classified as snow-on and snow-off from sonic ranger measurements.
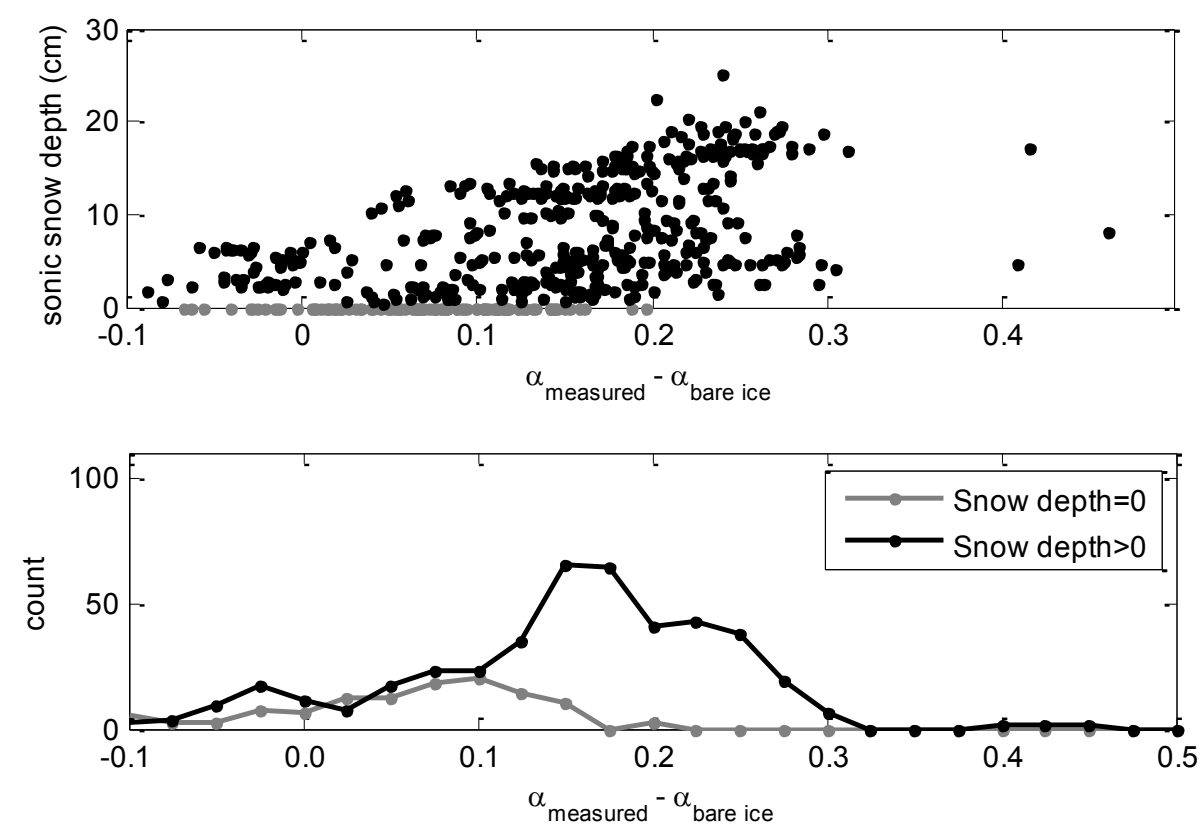

Figure 2.25: Relationship between snow depth and albedo at Commonwealth Glacier meteorological station (top). Bare ice albedo is calculated using polynomial fit shown in Figure 2.21. Bottom: Histogram of albedo for conditions classified as snow-on and snow-off from sonic ranger measurements. 


\section{Chapter 3: Development of Gridded Weather Data}

Distributed weather data are required for the spatial melt model. MicroMet (Liston and Elder 2006) was used to generate gridded weather data from the point observations at meteorological stations in Taylor Valley. The model is a quasi-physically based meteorological model of intermediate complexity that is suitable for generating gridded atmospheric forcings at high-resolution ( 30-1000 m grid increments) (Liston and Elder 2006). It combines spatial interpolation with known physical relationships between weather and topography for the variables of air temperature, relative humidity, wind speed and direction, incoming solar radiation, incoming longwave radiation, surface pressure, and precipitation. MicroMet includes a preprocessor for filling short gaps in the measurement time series at each station, and makes use of an autoregressive integrated moving average (ARIMA) calculation for filling gaps in diurnally varying variables. MicroMet requires a digital elevation model and the time-series of individual weather variables at various sites in or near the modeling domain. For spatial interpolation from irregularly spaced stations to a gridded dataset, MicroMet uses a Barnes objective analysis scheme (Barnes 1964, Koch et al. 1983). In this method, the contribution of each station to the interpolated value in a given grid cell decreases with distance. Two passes of the interpolation scheme are applied - the first generates the gridded data field, and the second pass is applied to the residuals to restore small wavelength components to the smoothed data field. 
For topography, I resampled a $40 \mathrm{~m}$ digital elevation model from SPOT-5

(SPIRIT Program (C) CNES 2008 and Spot Image 2008 all rights reserved) to a $250 \mathrm{~m}$ grid size. This application of MicroMet uses a total of 25 million individual observations (6 variables at 8 stations measured every 15 minutes over 15 years) to generate approximately 1.2 billion gridded data points ( 7 variables at 1300 glacier grid cells every 60 minutes over 15 years). MicroMet is run for two separate domains: the near horizontal glacier surfaces and the vertical terminal cliffs of the glaciers (Figure 3.1). The application is the same, but the cliff geometry is different. For the glacier surface domain, slope and aspect are determined from the digital elevation model. Mean aspect of the glacier outline and a constant slope of $89^{\circ}$ are used for each cliff domain grid cell.

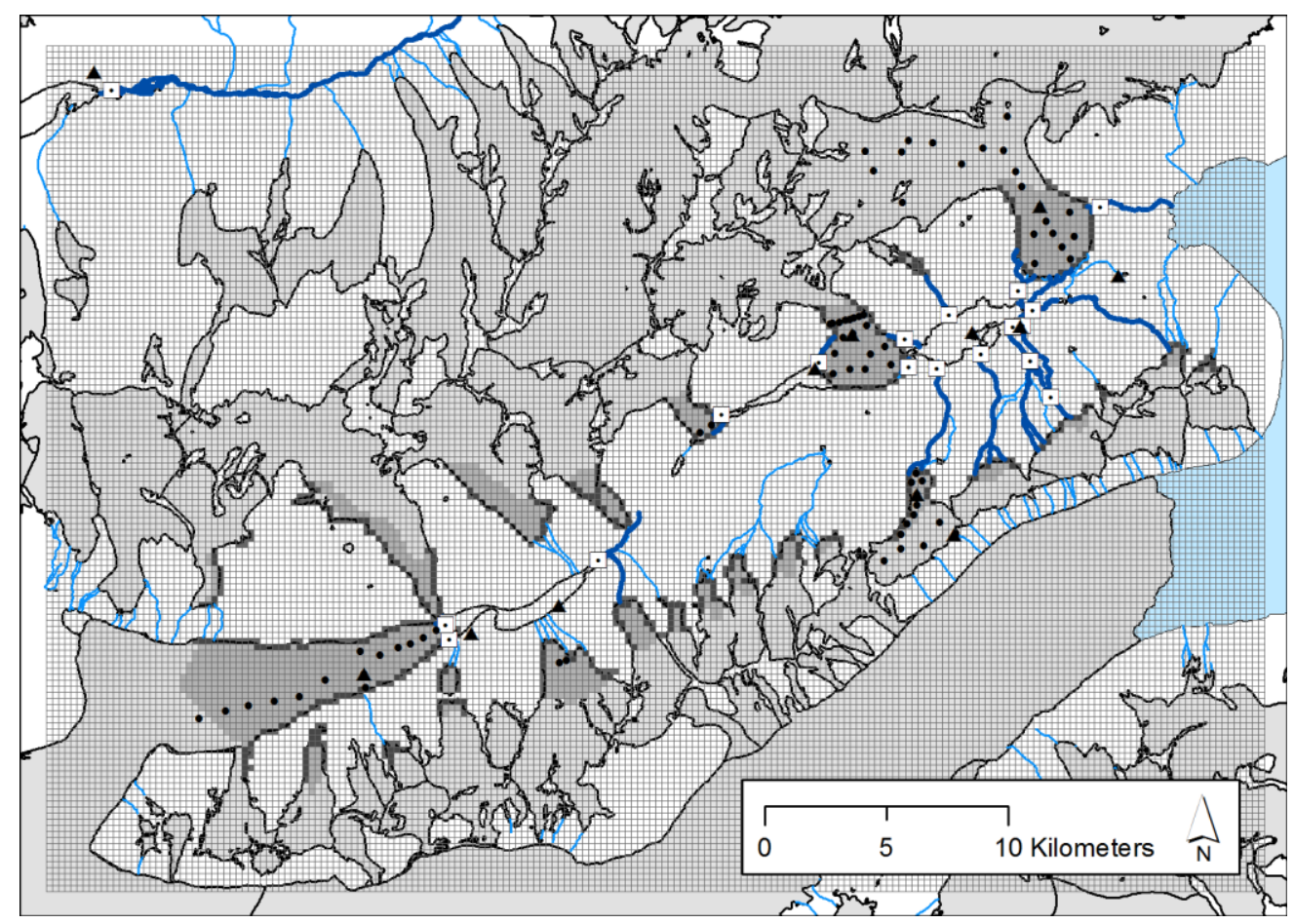

Figure 3.1: Map of model domain grid. Glacier ablation zones modeled are shown in medium gray, and glacier areas not modeled are shown in light gray. The terminal cliff domain is shown in dark gray. Streams, lakes, and measurement sites are shown for reference (see Figure 2.2 for details). 
I use standard MicroMet procedures to distribute air temperature, relative humidity, wind speed and direction, and surface pressure, but I developed new subroutines within MicroMet for incoming shortwave and longwave radiation that are better suited to our application. Because of the complexities of snowfall within the Dry Valleys (Fountain et al. 2010), I do not use MicroMet to distribute snow. MicroMet distributes temperature by first adjusting all observed station air temperatures to a reference elevation (sea level) using a prescribed lapse rate. Next the reference-level station temperatures are interpolated across the model grid using the Barnes objective analysis methodology. Finally the gridded reference-level temperatures are adjusted back to elevations of the topographic dataset. The procedure for relative humidity is similar, but uses dew point temperatures and dew point temperature lapse rate, where conversions between relative humidity and dew point temperature use the air temperature and saturation vapor pressure. Monthly lapse rates are used for temperature and vapor pressure lapse coefficient (Table 3.1), which are calculated from the mean monthly lapse rates between stations Canada and Howard glacier meteorological stations and then applied uniformly across the entire model domain. These stations were chosen for lapse rate calculations because they are on-glacier stations that span a large range in elevation $(208 \mathrm{~m})$ and are close to one another $(7.1 \mathrm{~km})$. Wind speed and direction are distributed within MicroMet by gridding the zonal and meridional wind speed components separately using the Barnes objective analysis scheme and then converting back to wind speed magnitude and direction. MicroMet modifies the resulting grids of wind speed and 
direction using a simple topographic model that considers slope and curvature.

Parameter values used within MicroMet are indicated in Table 3.2.

Table 3.1: Monthly temperature and vapor pressure lapse rates between CAA and HOD.

\begin{tabular}{|c|c|c|}
\hline Month & $\begin{array}{l}\text { Temperature lapse } \\
\text { rate }\left({ }^{\circ} \mathrm{C} \mathrm{km}^{-1}\right)\end{array}$ & $\begin{array}{l}\text { Vapor pressure } \\
\text { coefficient }\left(\mathbf{k m}^{-1}\right)\end{array}$ \\
\hline January & 6.5 & 0.47 \\
\hline February & 5.1 & 0.39 \\
\hline March & -3.5 & 0.05 \\
\hline April & -7.2 & -0.18 \\
\hline May & -5.5 & -0.12 \\
\hline June & -5.3 & -0.14 \\
\hline July & -6.9 & -0.16 \\
\hline August & -8.2 & -0.29 \\
\hline September & -7.5 & -0.21 \\
\hline October & -1.1 & 0.11 \\
\hline November & 6.0 & 0.44 \\
\hline December & 7.1 & 0.48 \\
\hline
\end{tabular}

Table 3.2: MicroMet parameter values used. See Liston and Elder (2006) and Koch et al. (1983) for detailed explanation of parameters.

\begin{tabular}{|c|c|c|}
\hline Parameter & Value & Description \\
\hline \multicolumn{3}{|l|}{ General } \\
\hline $\mathrm{dx}, \mathrm{dy}$ & $250 \mathrm{~m}$ & horizontal grid size \\
\hline & & time step \\
\hline $\mathrm{dn}$ & $7125 \mathrm{~m}$ & $\begin{array}{l}\text { radius of influence: interpolation only considers observations } \\
\text { within this distance }\end{array}$ \\
\hline gamma & 0.2 & $\begin{array}{l}\text { smoothing parameter in Barnes interpolation scheme: aids } \\
\text { convergence between interpolated grid and point observations }\end{array}$ \\
\hline \multicolumn{3}{|r|}{ 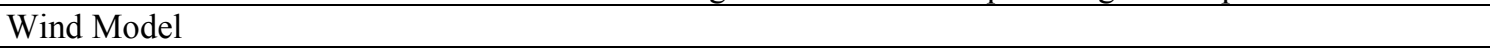 } \\
\hline curvature length scale & $2000 \mathrm{~m}$ & $\begin{array}{l}\text { length scale for curvature calculations in the wind model: } \\
\text { approximately one-half the wavelength of topographic features }\end{array}$ \\
\hline slope weight & 0.58 & weighting for slope correction to wind speed \\
\hline curvature weight & 0.42 & weighting for curvature correction to wind speed \\
\hline minimum wind speed & $0.1 \mathrm{~m} \mathrm{~s}^{-1}$ & calculated wind speeds below this value get set to this \\
\hline
\end{tabular}

\subsection{Solar radiation procedure}

The standard procedure for calculating grids of solar radiation in MicroMet uses

the gridded air temperature and relative humidity to estimate cloudiness, and cloudiness to estimate the net sky transmissivities for direct and diffuse radiation. Theoretical top of atmosphere solar irradiance is modified using these transmissivities, solar zenith angle 
and azimuth, and surface slope angle and azimuth. Optionally, observations of incoming solar radiation can be assimilated by generating a difference field between the observations and the gridded solar radiation using the Barnes analysis scheme and using it to adjust the gridded solar radiation field. This technique should work well in areas with few observations and with little topographic shading. However, the Taylor Valley meteorological network has good coverage of solar radiation measurements that can provide much better information regarding local cloudiness conditions than the parameterization based on air temperature and relative humidity, which presented a systematically low bias to solar radiation estimates in our study area. Additionally, the high mountains surrounding Taylor Valley and the proximity of the glacier ablation zones to the valley walls makes topographic shading a significant concern. For these reasons I developed a new procedure for calculating solar radiation within MicroMet.

The major enhancements of the solar radiation procedure that I created are that it accounts for topographic shading and uses observations of incoming solar radiation within the model domain to estimate cloudiness. The new procedure follows the following major steps: 1) eliminate observations that are shadowed from surrounding topography, 2) generate a grid of global radiation on a horizontal plane from observations, 3) partition global radiation at each grid cell into direct and diffuse components, 4) apply topographic corrections to each component considering slope, aspect, and shadowing from surrounding terrain, 5) sum the direct and diffuse components at each grid cell. I chose to grid the observations of global radiation rather than the individual direct and diffuse components (e.g. Dubayah and Loechel 1997), 
because the parameterization to separate the components is not very accurate and gridding total radiation should ensure smoother radiation fields. No adjustments to solar radiation are made for elevation since the areas to be modeled only span about $400 \mathrm{~m}$ in elevation. If this algorithm were to be applied to a wider range of elevations, an elevation correction may improve the results (Dubayah and Loechel 1997).

The division of the global radiation into direct and diffuse components uses the relationship between the so-called "clearness index", $k$ (ratio of global radiation measured at the surface to the theoretical top-of-atmosphere value), and "diffuse fraction", $K_{D}$ (ratio of diffuse radiation to global radiation) (Liu and Jordan 1960). This relationship has been investigated for a wide range of climates and latitudes, so I choose the parameterization described by Skartveit and Olseth (1987) and Skartveit et al. (1998) because it is based on high latitude observations from Norway and explicitly includes effects of low sun elevation angles (Figure 3.2). The parameterization incorporates the following features. When solar irradiance at the surface is a small fraction of the top of atmosphere value $(\mathrm{k}<0.2)$, global radiation is entirely composed of diffuse radiation $\left(\mathrm{K}_{\mathrm{D}}=1.0\right)$, i.e. heavy cloud cover. As solar irradiance at the surface increases $(0.4<\mathrm{k}<0.8)$ direct radiation becomes the dominant component of global radiation (minimum $\mathrm{K}_{\mathrm{D}}$ ). Clear sky conditions result in a minimum value for the diffuse fraction, but certain conditions can result in a clearness index higher than that found for clear sky conditions. For example, light clouds away from the sun and high surface albedo permit high direct radiation to reach the surface but also result in high diffuse radiation due to multiple reflections 
between the surface and clouds. Many studies ignore the increase in diffuse fraction at high clearness index because it is only important at low sun elevation angles (Figure 3.2).

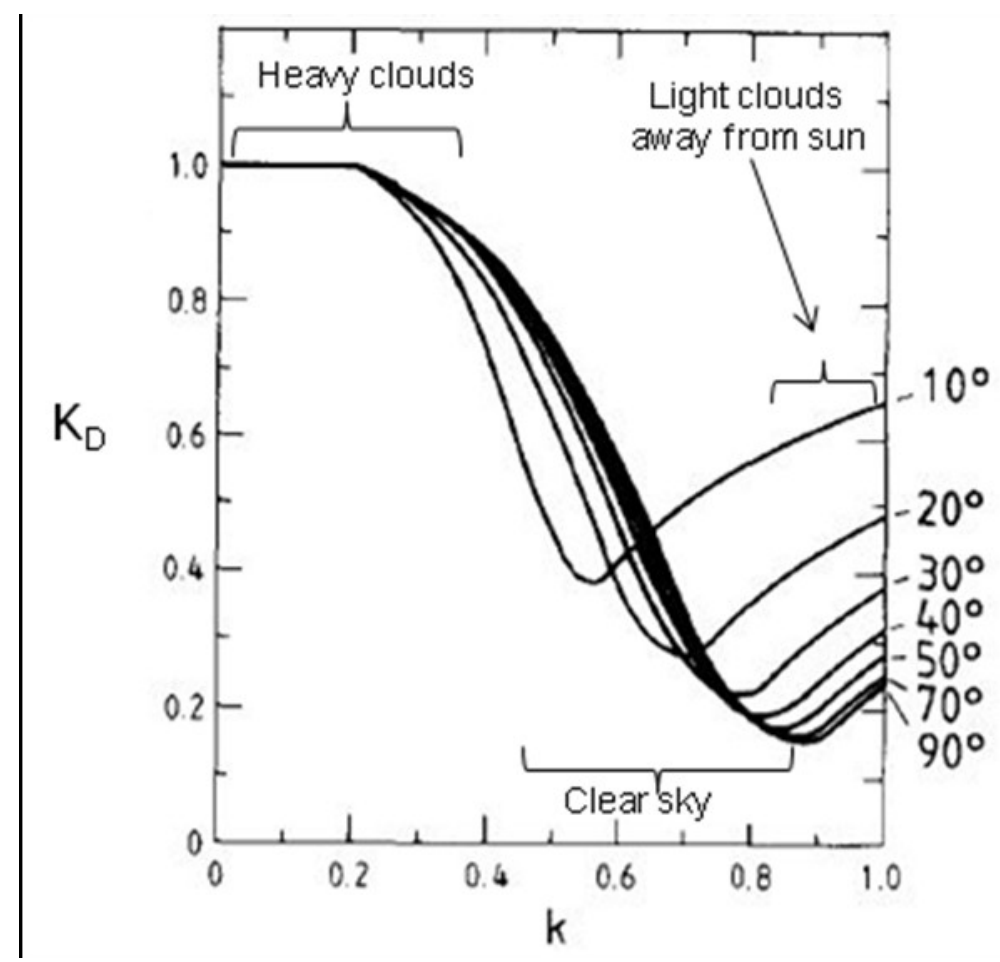

Figure 3.2: Modeled relationship between clearness index $(k)$ and diffuse fraction $\left(K_{D}\right)$ for various solar elevations. Modified from Skartveit and Olseth (1987). Typical conditions are indicated for various regions of the relationship.

To apply the Skartveit and Olseth (1987) approach, the following steps are conducted at each grid cell. The routine first calculates solar elevation angle, azimuth, and top of atmosphere irradiance on a horizontal surface for each hour (Ham 2005). A check is made of solar elevation angle and azimuth against the topographic horizon elevation angle calculated in 32 directions (Dozier and Frew 1990). Measurements are only included in the analysis if the sun was more than $6^{\circ}$ above the horizon, and then the remaining measurements of global radiation are gridded. At each grid cell, the interpolated value of global radiation is used to calculate the clearness index, which is in 
turn used to calculate diffuse fraction (Figure 3.2), allowing generation of grids for direct and diffuse radiation. If no observations are available in a given time step, the original MicroMet procedure is instead followed. In each grid cell the direct component is set to zero if the sun is below the topographic horizon and otherwise corrected for terrain slope and azimuth. The diffuse component is scaled by the skyview factor, the fraction of the sky hemisphere that is unobstructed by the surrounding topography (Dozier and Frew 1990). Finally the terrain-corrected direct and diffuse components are added together to generate a grid of global radiation. The method ignores reflected solar radiation, since it should be small relative to the direct and diffuse components.

To assess the accuracy of the solar radiation scheme, I compare the results to the station observations. The value from the two MicroMet formulations may differ from the station value for two reasons: 1) adjustments for terrain slope and aspect since the pyranometers are horizontal but the glacier surfaces are sloped; 2) deviations caused by the Barnes interpolation smoothing the global radiation field. Results at the gently sloping Commonwealth Glacier site, match both the original solar subroutine and the observations (Figure 3.3). The gridded values are slightly smaller than the horizontal pyranometer measurements at midday when the glacier surface is sloping away from the sun. 


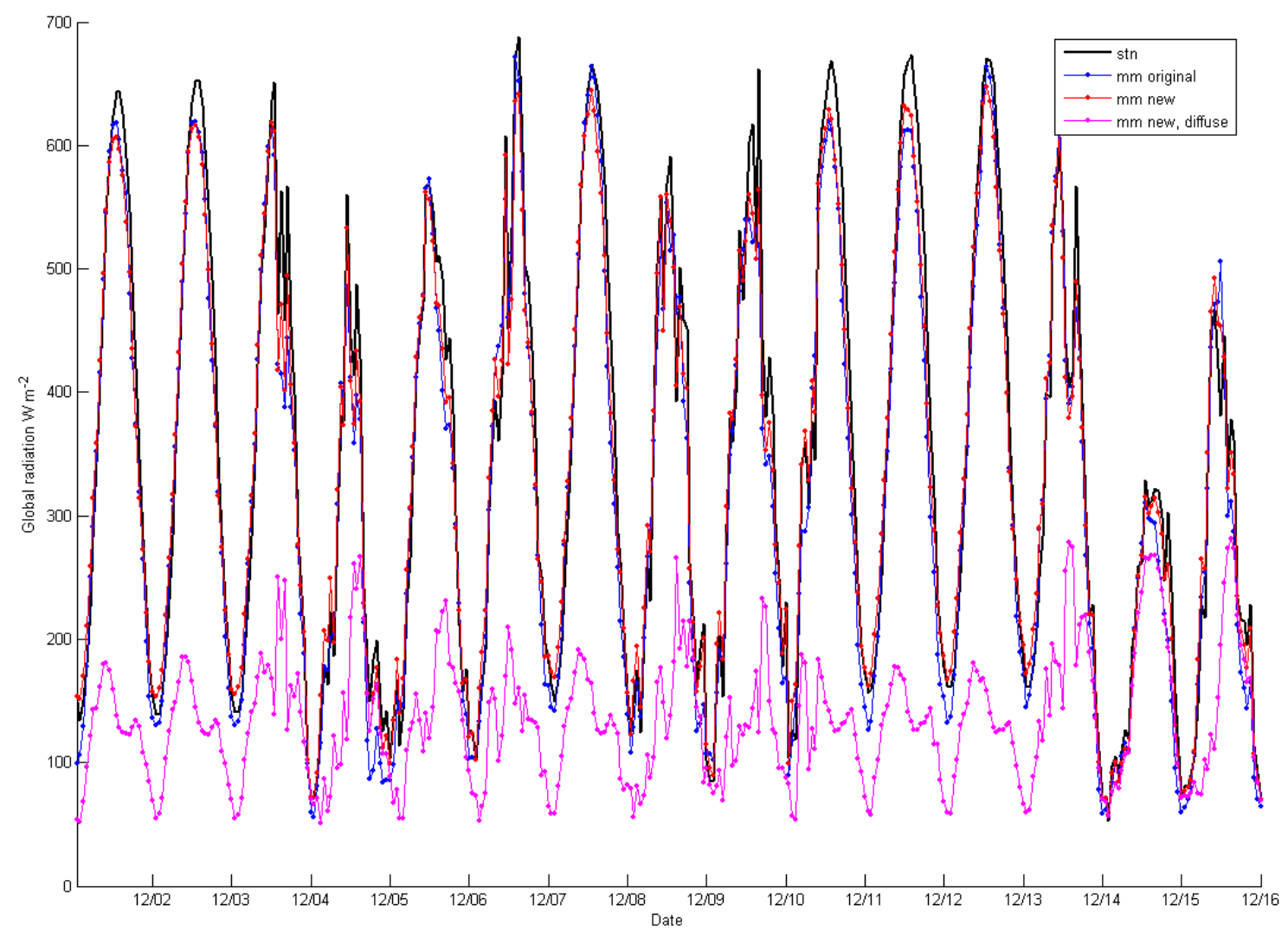

Figure 3.3: Comparison of MicroMet and station observations for Commonwealth Glacier meteorological station ( $3^{\circ}$ slope, SE aspect) for part of December 1994. Black line is pyranometer observations of global radiation on a horizontal plane. Global radiation on the sloping glacier surface as calculated from the original MicroMet formulation is in blue and as calculated from the new MicroMet formulation is in red. The pink line shows the diffuse component as calculated by the new MicroMet formulation.

For Howard Glacier meteorological station, the new solar subroutine has higher values than the horizontal station data during midday, consistent with its relatively steep northerly aspect (Figure 3.4). The old solar subroutine does not capture that behavior because the assimilation was done with the horizontal measurements and the Barnes interpolation scheme smoothes the data. Also, the new solar subroutine does a relatively good job of estimating the diffuse component that makes up $100 \%$ of global radiation 
when this location is shaded each night by the crest of the Kukri Hills to the south. The diffuse component is determined from the clearness index, a good check on that method.

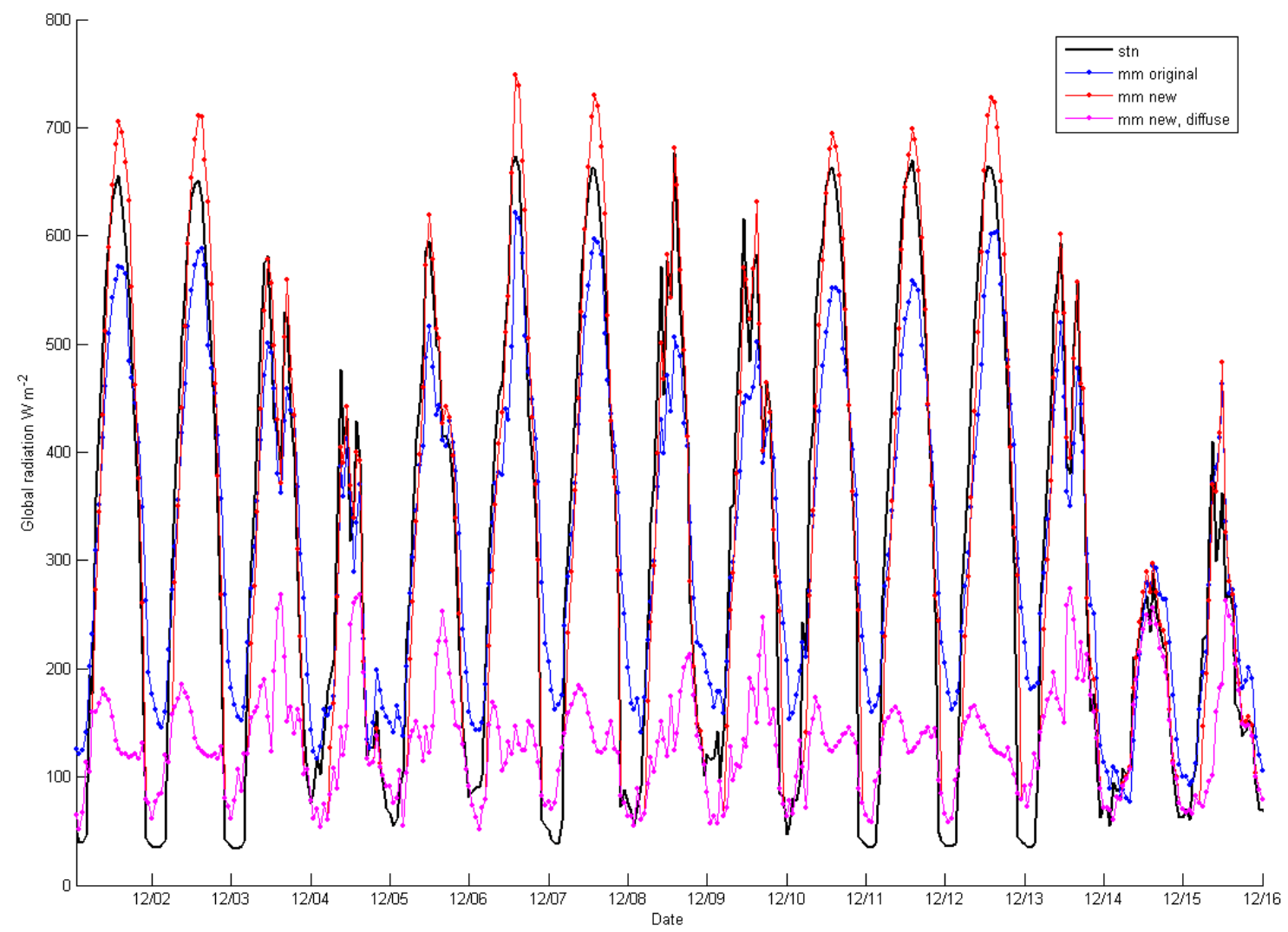

Figure 3.4: Comparison of MicroMet and station observations for HOD $\left(9^{\circ}\right.$ slope, northerly aspect) for part of December 1994. Symbology is same as for Figure 3.3.

One issue is that at low solar elevation angles (spring and fall and during summer 'nights'), many of the meteorological stations are in shadow and are excluded from the interpolation (Figure 3.5). However, these are times when melt is unlikely to occur, so errors have little to no impact on melt. Even if significant errors in global radiation occur at these times, the inclusion of corrections for topographic shading by the new scheme 
should result in improved results over the original formulation due to the prevalence of topographic shading in this high latitude/high relief environment.

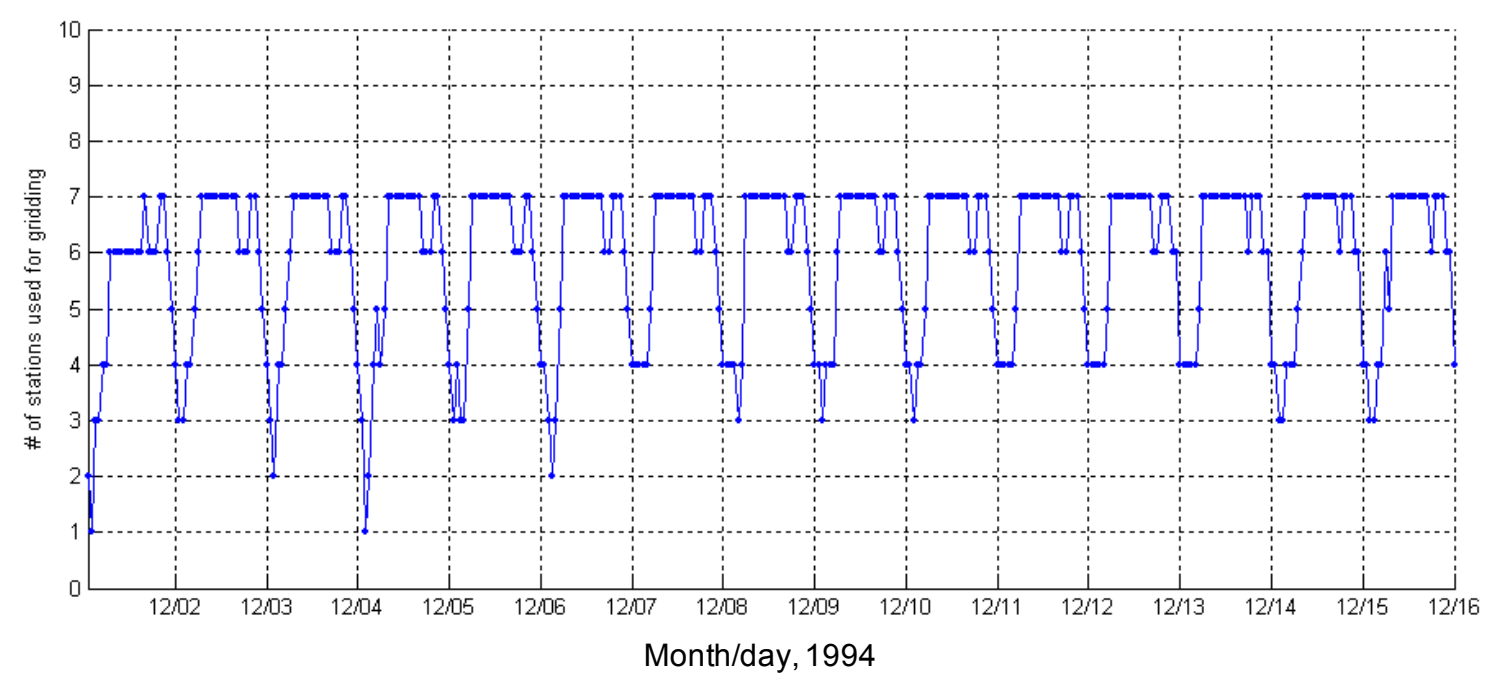

Figure 3.5: Number of station used for gridding for each time step during the first half of December 1994 (maximum of 7 for this time period).

Figure 3.6 shows how the calculations work for a typical daytime situation. Six stations have contributed to the interpolation (circles in upper right plot), while two stations have missing data for this time step (X's). The interpolation of global radiation on a horizontal surface accounts for spatial variations in cloud cover and in this case results in a gridded field with highest values $\left(>700 \mathrm{~W} \mathrm{~m}^{-2}\right)$ in the west and lower values in the center and eastern parts of Taylor Valley (upper right plot). This pattern represents cloudy conditions across much of the valley with clear sky in the west. The grid of global radiation on a horizontal surface (upper right) is divided into direct and diffuse components (upper left and center plots) using the Skartveit and Olseth (1987) approach (Figure 3.2). The direct component at each grid cell is checked for shading from the surrounding topography and then adjusted for the slope and aspect of the terrain (lower 
left plot). The gray areas in the center of this map show areas that are in the shadow of the steep southern face of the Asgard Range at this time of day. The diffuse component at each grid cell is adjusted for the skyview (lower center plot). Finally, the two topographically adjusted components are added together to get the global radiation corrected for topography (lower right plot).

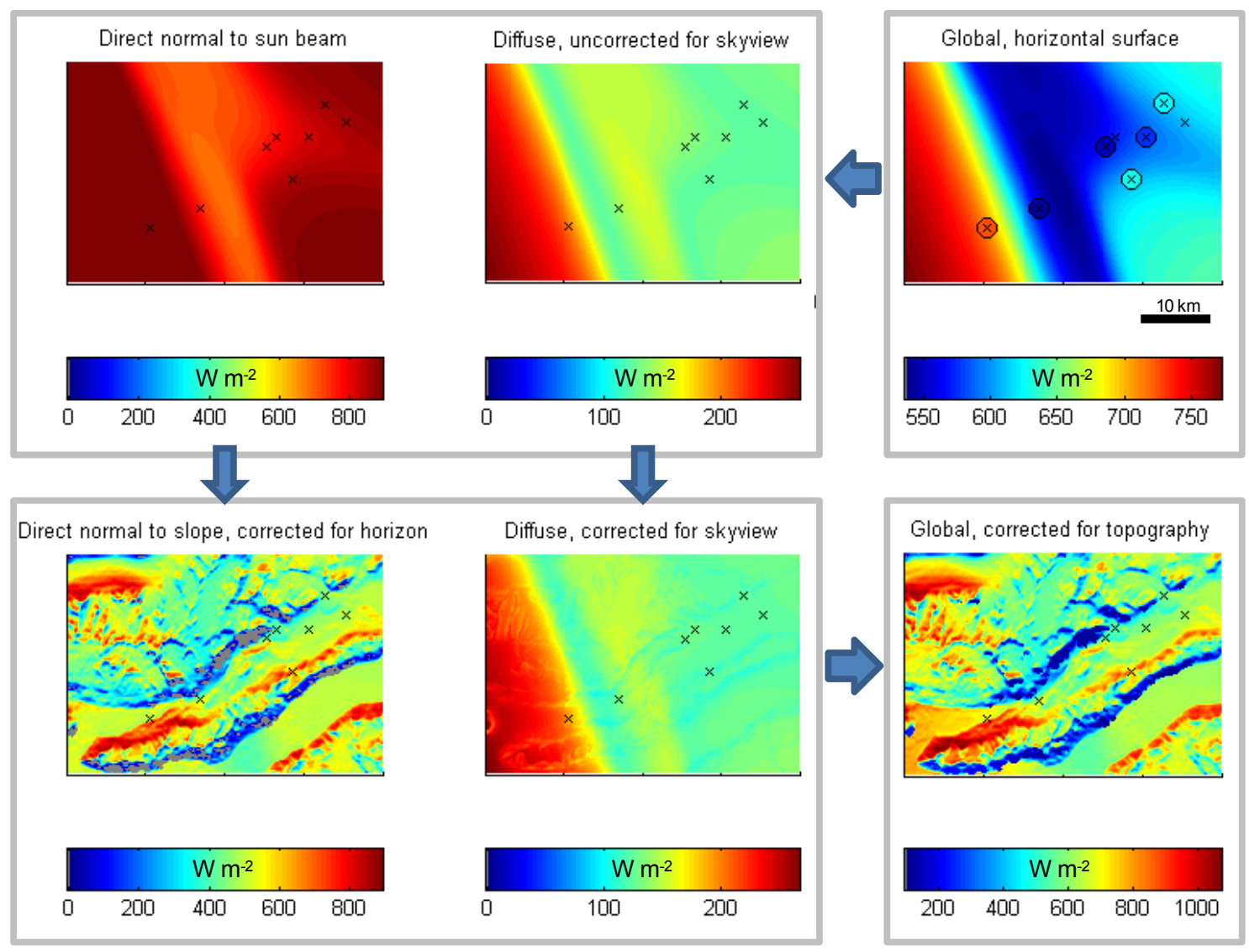

Figure 3.6: Maps of direct (left), diffuse (center), and global (right) solar radiation for 15:00, December 1, 1994. The upper row is uncorrected for topographic effects, and the bottom row is corrected. The upper right map results from the Barnes interpolation scheme. X's indicate meteorological station locations. The global radiation values measured at meteorological stations used in the interpolation for this time step are shown with filled circles. The color scale is the same for the two direct component plots and for the two diffuse component plots, but the global radiation plots have different color scales from each other to show detail. Gray values in the lower left plot indicate areas in shadow with 0 direct solar radiation. Units are $\mathrm{W} \mathrm{m}^{-2}$. 
Figure 3.7 shows the situation where only one station is available to be used in the gridding. Spatial variation in solar radiation (which would primarily due to cloud cover) is lost. However, this type of situation only occurs during summer 'night' or on the shoulders of summer. The original solar subroutine would still include spatial variability (via the spatial variability of relative humidity), but I have chosen to only use to the original subroutine when no solar radiation measurements are available.

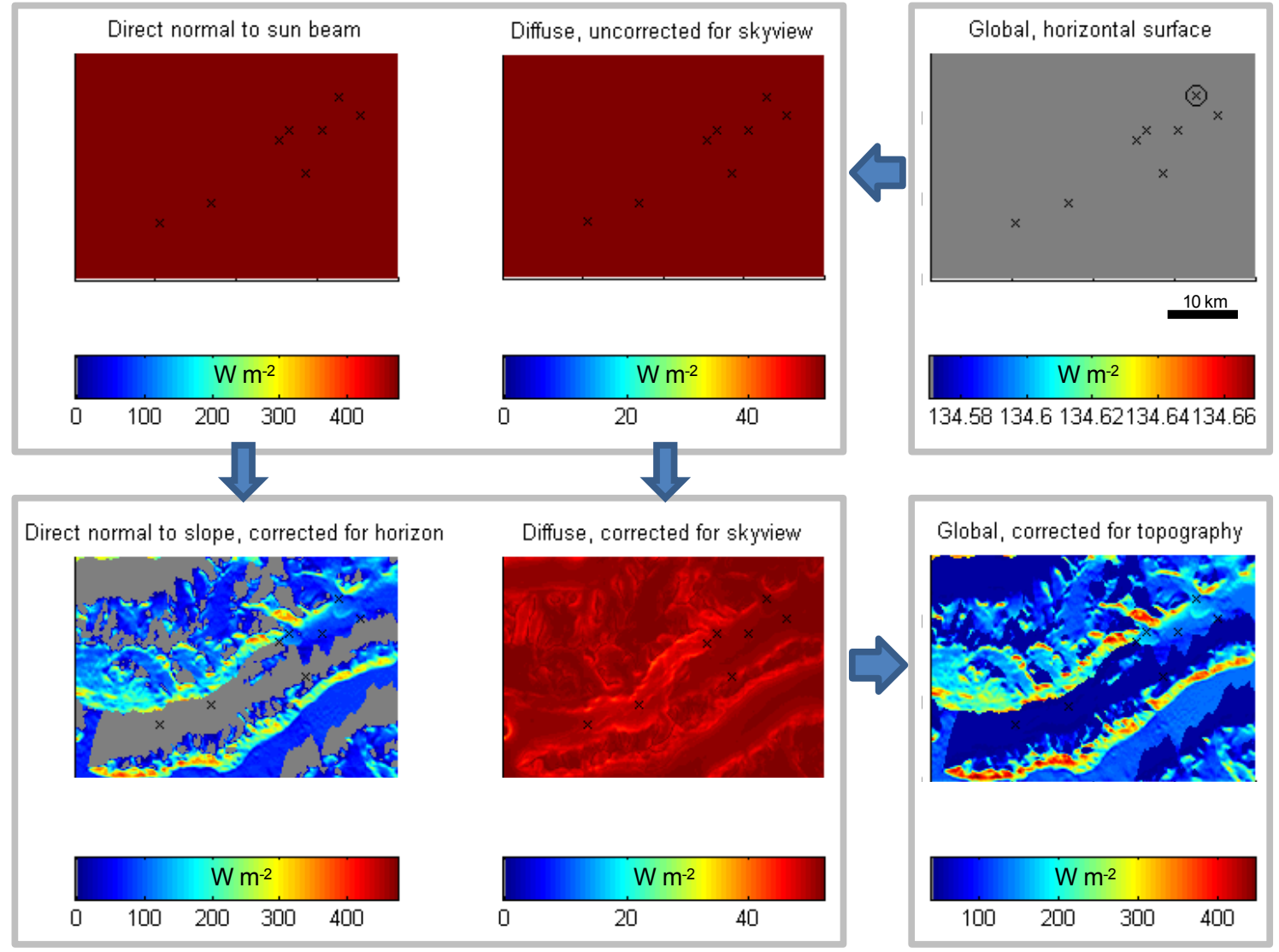

Figure 3.7: Direct (left), diffuse (center), and global (right) solar radiation for 02:00, December 1, 1994. Symbology is the same as for Figure 3.6.

Figure 3.8 shows the situation where gridded values are well beyond the range of measured values due to extrapolation into regions without valid observations. This may 
occur during summer 'night' or on the shoulders of the season when the only stations available for gridding are close together but have dramatically different values. The Barnes interpolation does poorly under these conditions, as might be expected. To ensure reasonable values, I include a check for gridded values of global radiation less than 0 .

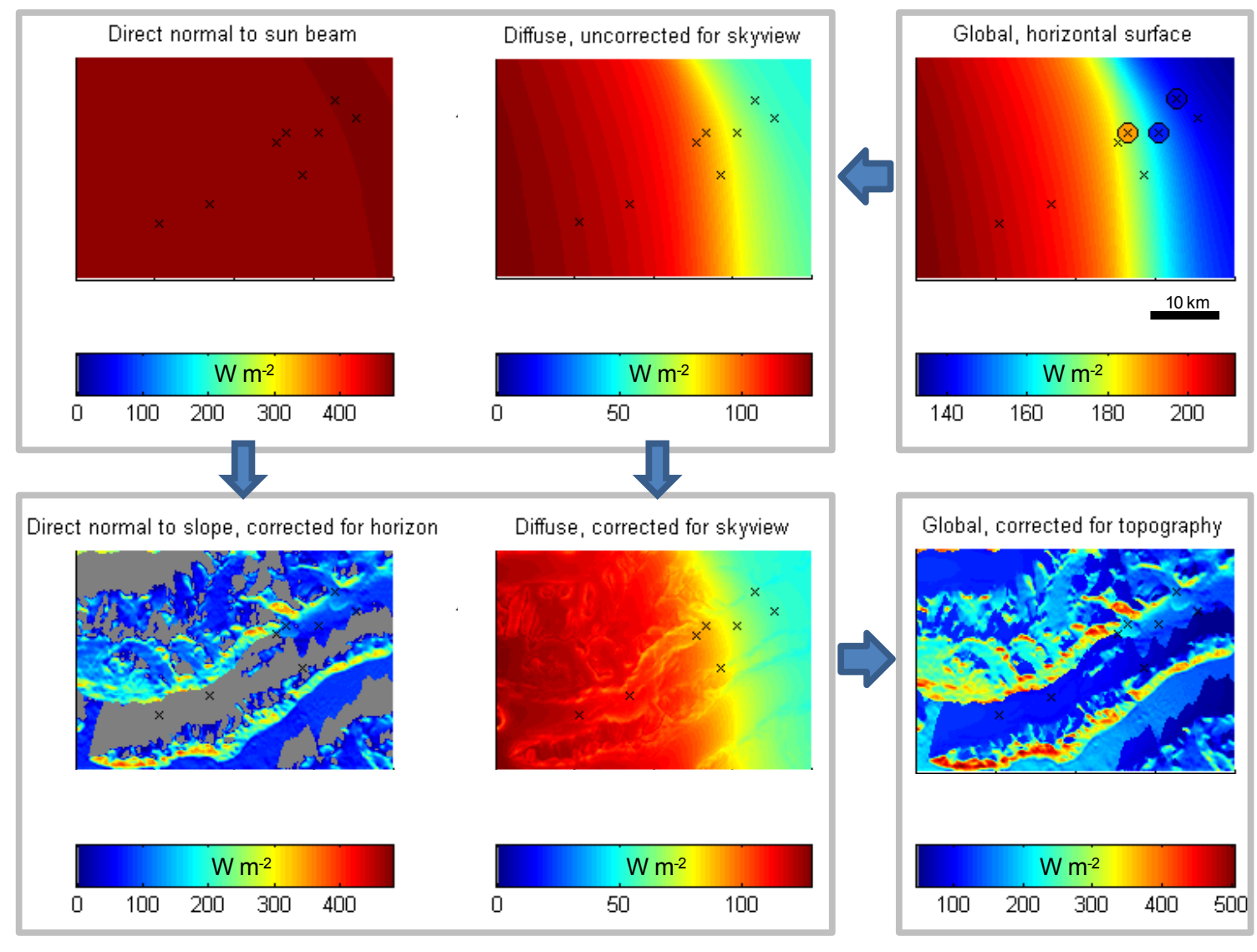

Figure 3.8: Direct (left), diffuse (center), and global (right) solar radiation for 02:00, December 2, 1994. Symbology is the same as for Figure 3.6.

\subsection{Longwave radiation procedure}

Incoming longwave radiation reaching earth's surface, $\mathrm{Q}_{\mathrm{li}}\left(\mathrm{W} \mathrm{m}^{-2}\right)$, is given by

$$
Q_{l i}=\varepsilon \sigma T^{4}
$$


where $\sigma$ is the Stefan-Boltzmann constant, and $\mathrm{T}(\mathrm{K})$ is the air temperature. The atmospheric emissivity, $\varepsilon$, can be parameterized for clear-sky conditions or for so-called all-sky conditions which extends the applicability of Equation 4 to cloudy conditions.

Clear-sky emissivity is typically parameterized as a function of screen level air temperature and/or vapor pressure, and all-sky emissivity adds an adjustment for cloud cover correction. The existing formulation for estimating $\mathrm{Q}_{\mathrm{li}}$ in MicroMet is based on that of Iziomon et al. (2003) and calculates all-sky emissivity as a function of air temperature, vapor pressure, cloud-cover fraction, and a set of elevation dependent parameters that are calibrated to observations in Germany and Colorado (Liston and Elder 2006). Because there are extensive measurements of $\mathrm{Q}_{\mathrm{li}}$ at Commonwealth Glacier, Taylor Glacier, and Lake Bonney meteorological stations and the range in elevations I am concerned with is relatively small ( $\sim 500 \mathrm{~m})$, I explored alternate parameterizations for $\mathrm{Q}_{\mathrm{li}}$ that may perform better in the Dry Valleys. First I consider a number of parameterizations for clear-sky emissivity, and then explore various parameterizations for emissivity under all-sky conditions, most of which are based on a cloud-factor correction that is multiplied by the clear-sky emissivity.

Using observations of air temperature, relative humidity, and $\mathrm{Q}_{\mathrm{li}}$, I evaluated parameterizations for clear-sky atmospheric emissivity from the following reviews: four parameterizations from König-Langlo and Augstein (1994), fifteen parameterizations from Pirazzini et al. (2001), and thirteen parameterizations from Flerchinger et al. (2009). Some overlap exists between the three compilations. The parameterizations vary in 
complexity from a constant clear-sky emissivity to a function of air temperature and/or vapor pressure, with various functional forms and constants.

Rather than report the performance of all parameterizations considered, I show a representative sampling in Figure 3.9. Because cloud observations have not been made in Taylor Valley, it is not possible for me to reliably restrict my analysis to observations during clear-sky conditions. However, clear-sky conditions will correspond to the lowest $\mathrm{Q}_{\mathrm{li}}$ values measured for given air temperature and relative humidity because clouds raise $\mathrm{Q}_{\mathrm{li}}$. There is a dense 'cloud' of points along the upper left of each plotted parameterization (Figure 3.9), and this corresponds to clear-sky conditions. I visually assessed the performance of each parameterization for this clear-sky 'cloud' of points.

Many parameterizations had a large positive bias for Taylor Valley, presumably due to being calibrated for different environments (typically mid-latitudes). Considering all parameterizations, I chose to use the one originally described by Konzelmann et al. (1994) (Figure 3.9, right panel, cyan), because it is one of the ones that gave best agreement to measured $\mathrm{Q}_{\mathrm{li}}$ for clear-sky conditions, it considers both air temperature and vapor pressure, it was created for a polar environment (west Greenland), and it is commonly used in glacier studies (Sedlar and Hock 2009). It is possible that other parameterizations could be calibrated to work as well as that of Konzelmann et al. (1994), but for simplicity I chose the parameterization that would require the least adjustment. 

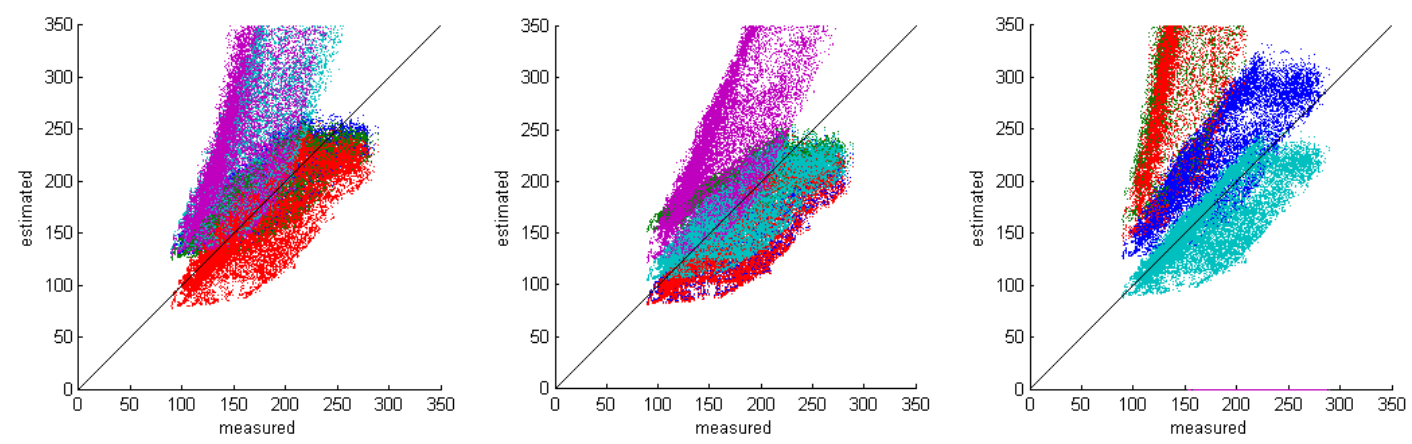

Figure 3.9: Evaluation of the 15 parameterizations for clear-sky emissivity in Pirazzini et al. (2001). The Konzelmann et al. (Konzelmann et al. 1994) parameterization is on the right panel in cyan. Each plot shows measured versus estimated values of $Q_{l i}$ for five different parameterizations. Because it was not possible to restrict the analysis to observations during clear-sky conditions, there is considerable spread for each parameterization. The thicker density cloud of points forming the upper-left boundary of each point cloud represents clear-sky conditions. Each cloud of points contains all hourly average values from 1994-2009 at Taylor Glacier meteorological station.

Next I explored minor adjustments to the coefficient values $\mathrm{a}, \mathrm{b}$, and $\mathrm{m}$ in the Konzelmann et al. (1994) formulation for clear-sky emissivity, $\varepsilon_{\mathrm{cs}}$, calculated as:

$$
\varepsilon_{c s}=a+b\left(\frac{e_{a}}{T_{a}}\right)^{1 / m}
$$

where the optimal values determined by Konzelmann et al. (1994) for west Greenland are $a=0.23, b=0.484$, and $n=8$. Because it is difficult to identify clear-sky conditions without observations of cloud cover, I used all data points and visually identified the cluster of points that represent clear-sky conditions as described above. I considered using the solar radiation clearness index (Figure 3.2) to identify periods of time with clear-sky conditions, as described in the previous section. However, the clearness index primarily provides cloudiness information in the direction of the sun only, and due to the low solar elevation angles at high latitude, cloudiness in that direction may differ substantially from that above. Because my visual inspection approach precluded the ability to perform 
statistical parameter optimization, I systematically varied each of the tree parameters and assessed the best fits visually (Figure 3.10). I chose optimal values for Taylor Valley observations of $\mathrm{a}=0.23, \mathrm{~b}=0.44$, and $\mathrm{n}=8$, the same values found by Sedlar and Hock (2009) at Storglaciären, Sweden. Slightly better agreement at the Taylor Valley sites can be obtained by altering the $a$ and $n$ values from the original formulation. However, I do not do this because the difference is small, and the $a$ coefficient has a theoretical basis. Konzelmann et al. (1994) determined the value of $\mathrm{a}=0.23$ as the clear-sky emittance of a completely dry atmosphere using a numerical radiative band model.
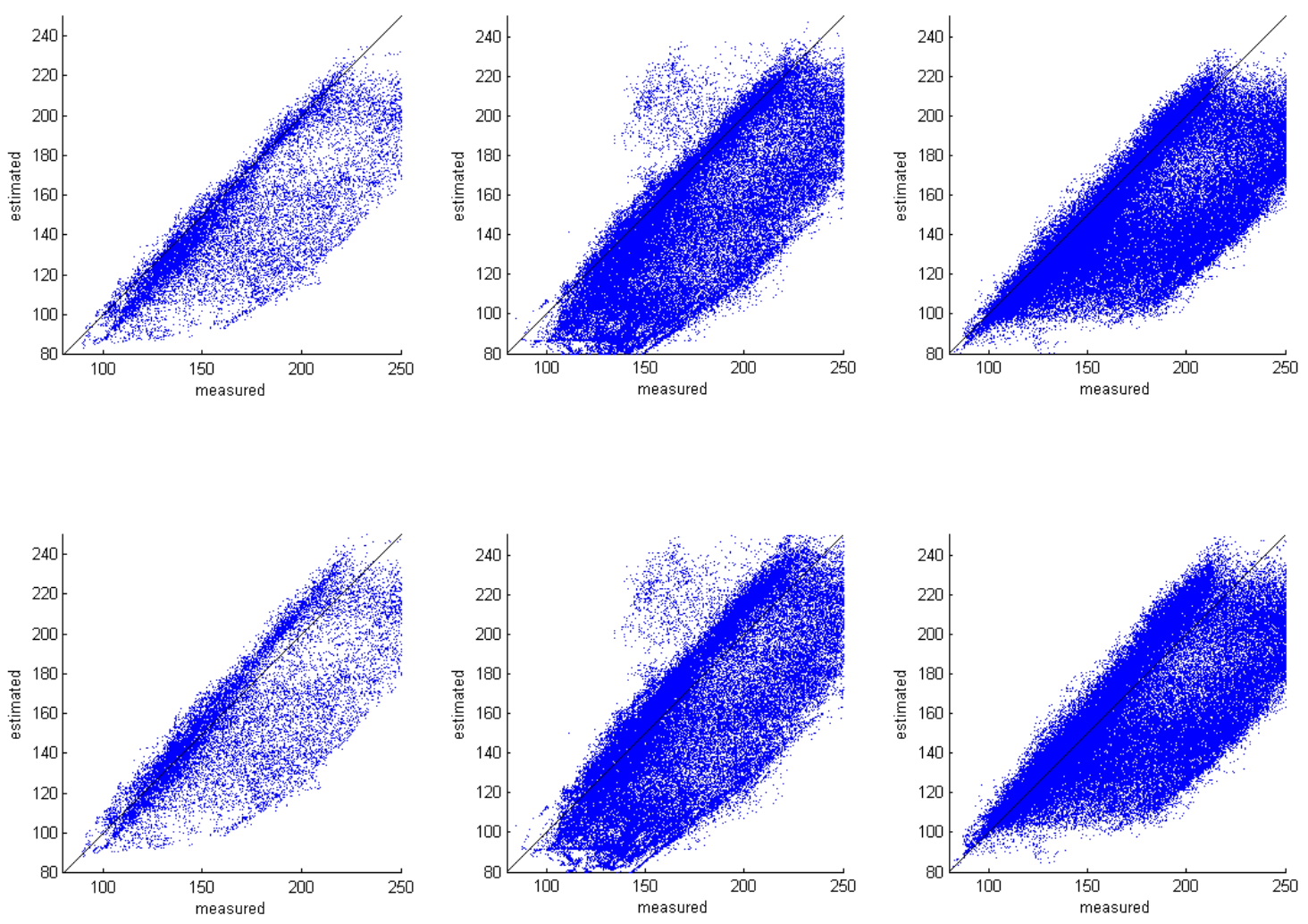

Figure 3.10: Evaluation of clear-sky emissivity using the Konzelmann et al. (Konzelmann et al. 1994) formulation. The top row shows results using the optimal parameter values $(a=0.23$, $b=0.44, n=8)$, and the bottom row shows results using the original parameter values from Konzelmann et al. (Konzelmann et al. 1994) $(a=0.23, b=0.484, n=8)$. In each row, the left panel is for Taylor Glacier, the center panel is for Lake Bonney, and the right panel is for Commonwealth Glacier. 
Having selected and tuned a parameterization for clear-sky emissivity, I next considered various parameterizations for emissivity under all-sky conditions, most of which are a cloud-factor correction that is multiplied by the clear-sky emissivity. This analysis included two components - all-sky emissivity parameterizations and estimates of cloudiness (since cloudiness observations have not been made in Taylor Valley). Cloud corrections are typically a nonlinear function of cloud cover and various coefficients. Based on the review by Flerchinger et al. (2009), I considered all-sky emissivity parameterizations described by Konzelmann et al. (1994), Unsworth and Monteith (1975), Kimball et al. (1982), and Maykut and Church (1973). Most all-sky emissivity parameterizations were developed using direct observations of cloud cover, sometimes adding cloud type. Since those observations are not available in my dataset, I consider three methods for estimating cloudiness: 1) fitting 1 st and $2^{\text {nd }}$-order regressions between solar clearness index and cloudiness, as described in the previous section (which is only possible when the sun is up); 2) estimating cloudiness from relative humidity following the methods of Walcek (1994) (used in MicroMet) or Xu and Randall (1996); and 3) using a constant cloudiness (either 0 or $50 \%$ ). I paired the various all-sky emissivity parameterizations with the various cloudiness estimates, allowing the coefficients of each formula to vary. The choice of cloudiness estimation function and the coefficients chosen had a greater effect than choice of all-sky emissivity parameterization.

The Konzelmann et al. (1994), Kimball et al. (1982), and Maykut and Church (1973) all-sky emissivity parameterizations all could achieve a root mean square deviation of $\sim 16 \mathrm{~W} \mathrm{~m}^{-2}$, but the choice of cloudiness estimation function mattered. The 
Unsworth and Monteith (1975) correction did not perform as well. For consistency with my choice of clear-sky emissivity parameterization, I chose to use the all-sky emissivity parameterization of Konzelmann et al. (1994):

$$
Q_{l i}=\left[\varepsilon_{c s}\left(1-n^{p}\right)+\varepsilon_{o s} n^{p}\right] \sigma T_{a}^{4}
$$

where here $\mathrm{n}$ is cloudiness, $\mathrm{p}=2$, and the emissivity of a completely overcast sky is $\varepsilon_{o s}=0.96$. The optimal values I find for $\mathrm{p}$ and $\varepsilon_{\mathrm{os}}$ are different from those used by Konzelmann et al. (1994), but again are very similar to the values used by Sedlar and Hock (2009).

Of the three methods for estimating cloudiness, the first method of fitting a polynomial relationship between solar clearness index and cloudiness worked better than estimating cloudiness from relative humidity or assuming a constant cloudiness (e.g. Figure 3.11). Because little difference existed between assuming a $1^{\text {st }}$ or $2^{\text {nd }}$-order regression, I chose to use $1^{\text {st }}$ order for simplicity. I adjusted the form of the relationship between solar clearness index and cloudiness and found a best fit matching solar clearness index of 0.2 to a cloudiness fraction of 1.0 and a solar clearness index of 0.9 to a cloudiness fraction of 0.0 , with a linear relationship between those points, and a cloudiness fraction of 0 or 1 beyond those limits of solar clearness index.

Based on these analyses, our parameterization for Qli is uses the clear-sky and allsky emissivity parameterizations of Konzelmann et al. (1994) with coefficients adjusted for our dataset, and a $1^{\text {st }}$-order regression between solar clearness index and cloudiness (Figure 3.11). When solar radiation estimates are not available, a constant cloudiness value of 0.57 is assumed, which is the value that minimizes the mean bias deviation. 
Using constant cloudiness during these times yielded a root mean square deviation lower than using relative humidity to estimate cloudiness.
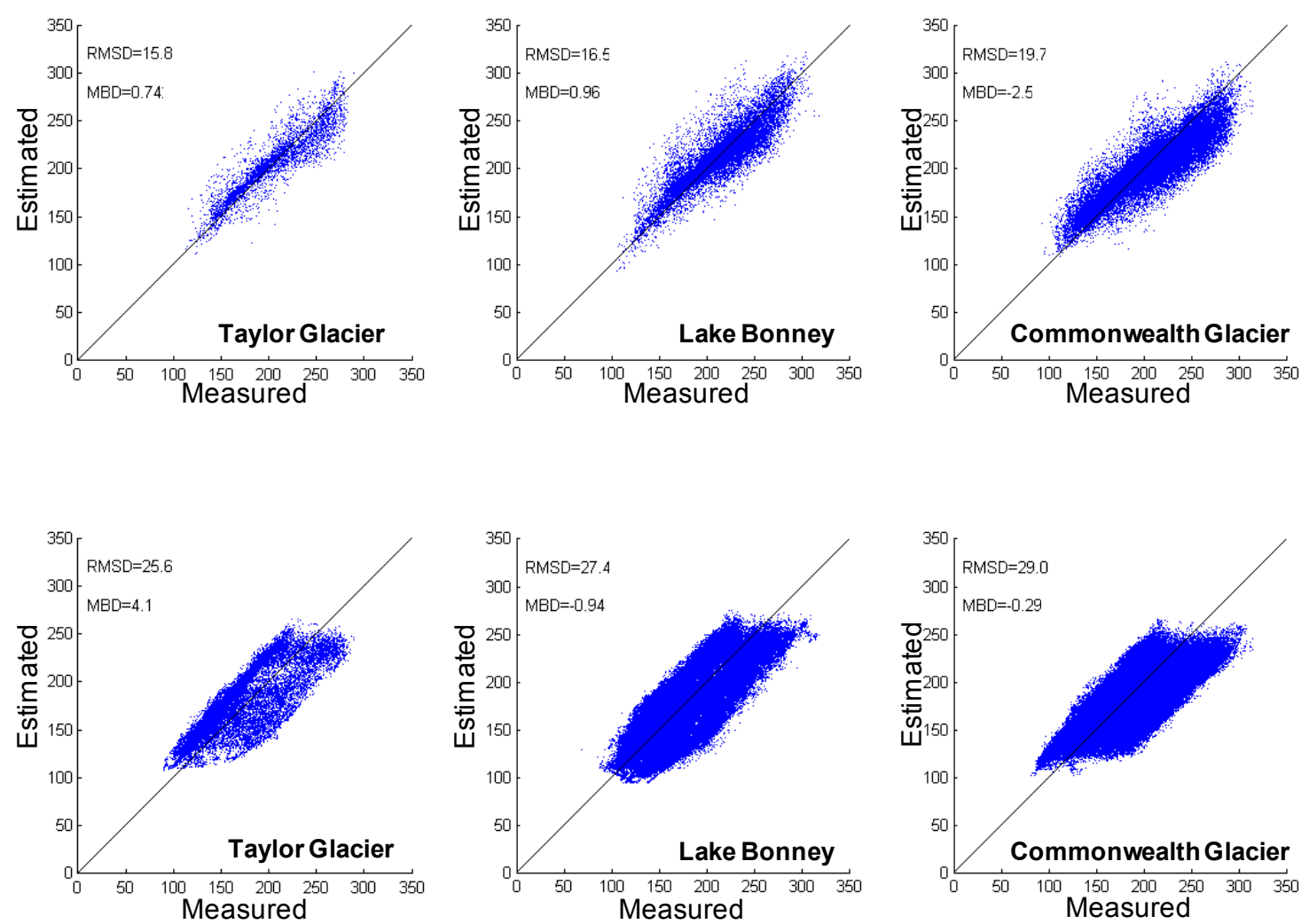

Figure 3.11: Results of $Q_{\text {li }}$ parameterization used for all-sky conditions. The upper row shows measured versus estimated $Q_{l i}$ for sun-up periods when solar radiation is available to estimate cloudiness fraction. The bottom row shows results for all times, assuming a constant cloud fraction of 0.57 during sun-down periods. Values of Root Mean Square Deviation (RMSD) and Mean Bias Deviation (MBD).

This approach is implemented in MicroMet by calculating an all-sky emissivity following Equation 6 for each grid cell, using the gridded values of air temperature, relative humidity, and incoming shortwave radiation. Additionally, all-sky emissivity is calculated at each meteorological station with longwave radiation observations, and the observed all-sky emissivity values are assimilated into the gridded estimates by applying the Barnes interpolation scheme. Lastly, I include a component of $\mathrm{Q}_{\mathrm{li}}$ for longwave 
radiation emitted from surrounding terrain. I use the skyview fraction at each grid cell to determine the fraction of the hemisphere normal to the terrain surface that is obscured by terrain rather than sky. For this fraction, the all-sky emissivity is replaced with a terrain emissivity, $\varepsilon_{\text {ter }}=0.92$ (Lewis et al. 1998). Thus, the final calculation for the gridded incoming longwave radiation is:

$$
Q_{l i}=V_{d}\left(\varepsilon_{a s^{\prime}} \sigma T_{a^{\prime}}^{4}\right)+\left(1-V_{d}\right)\left(\varepsilon_{\text {ter }} \sigma T_{\text {ter }}^{4}\right)
$$

where $V_{d}$ is the skyview factor (between 0 and 1), $T_{\text {ter }}$ is the terrain temperature, and the primed variables indicate gridded estimates.

At each grid cell the temperature of the surrounding terrain is set to the local air temperature, which I assume may be a good first approximation without having to perform a complete energy balance for all soil and rock surfaces in the valley. Though the low albedo soil and rock surfaces can warm substantially in direct sunlight, most of the surrounding terrain 'seen' by the glacier surfaces is at significantly higher elevation, so the lower temperature ambient conditions at higher elevations in summer may cancel out much of the solar-induced warming of the rock surfaces. In any case, most glacier grid cells have a skyview factor of 0.90 to 0.98 , so the contribution from surrounding terrain to longwave radiation is small.

Exceptions to this are the terminal cliffs, which typically have skyview factors about 0.4 . However, the terrain 'seen' by the cliffs is predominantly as a similar elevation to the cliffs themselves (the soil in front of the glacier), meaning that solar radiative heating of the low albedo soils may generate terrain temperatures that are 
substantially higher than the local air temperature. For the cliff domain, the terrain temperature, $\mathrm{T}_{\mathrm{t}}$, is instead estimated as a function of incoming solar radiation:

$$
T_{t}=T_{a}+0.024 Q_{s i}
$$

where $T_{a}$ is the air temperature and $Q_{s i}$ is incoming solar radiation calculated for the local cliff grid cell. This relationship was estimated from soil surface temperature, air temperature, and incoming solar radiation measurements at Lake Bonney from summer 2007-2008 and accounts for the warming of dark soil and rocks relative to the air (Figure 3.12). This is certainly a simplification as it does not account for the slope and aspect of the terrain versus the cliff face (for which $\mathrm{Q}_{\mathrm{si}}$ is calculated) and it makes no distinction of snow-covered versus bare soil (the points below the regression line in Figure 3.12 may represent snowy conditions). However, summer snow in Taylor Valley tends to last for only a few days to a week on the soils (Fountain et al. 2010). Additionally, when snow is present on the soil near the cliffs, the decrease in longwave radiation emitted from the surrounding terrain will be somewhat offset by an increase in reflected shortwave radiation from the surrounding terrain, which is not calculated in the model.

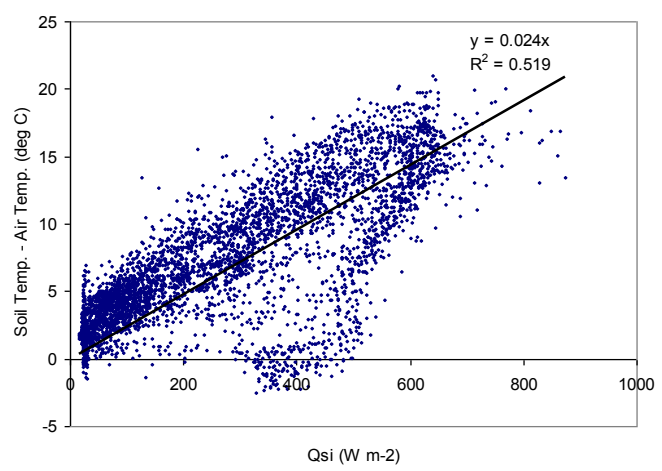

Figure 3.12: Difference between soil surface temperature and air temperature as a function of incoming shortwave radiation at BOY during summer 2007-2008. 


\subsection{MicroMet Results: Glacier surface domain}

MicroMet produced grids of air temperature, relative humidity, wind speed and direction, incoming solar radiation, and incoming longwave radiation for all grid cells in the domain located on glaciers. Output to areas covered by soil, lakes, or ocean was suppressed to reduce the file size of the output. The output grid of mean annual air temperature shows a pattern of increasing temperature with distance from the coast (Figure 3.13). Doran et al. (2002a) describe this pattern for the valley floor meteorological stations during summer, but found it is not significant for mean annual air temperature. However, they considered stations in other valleys which were outliers, and if their analysis were restricted to Taylor Valley a stronger pattern may emerge. We also see a pattern of increasing mean annual air temperature with elevation due to the negative lapse rates applied during most months (Table 3.1). This pattern was not observed by Doran et al. (2002a), but again, if their analysis was restricted to Taylor Valley, it appears that their results would be similar to what I see here.

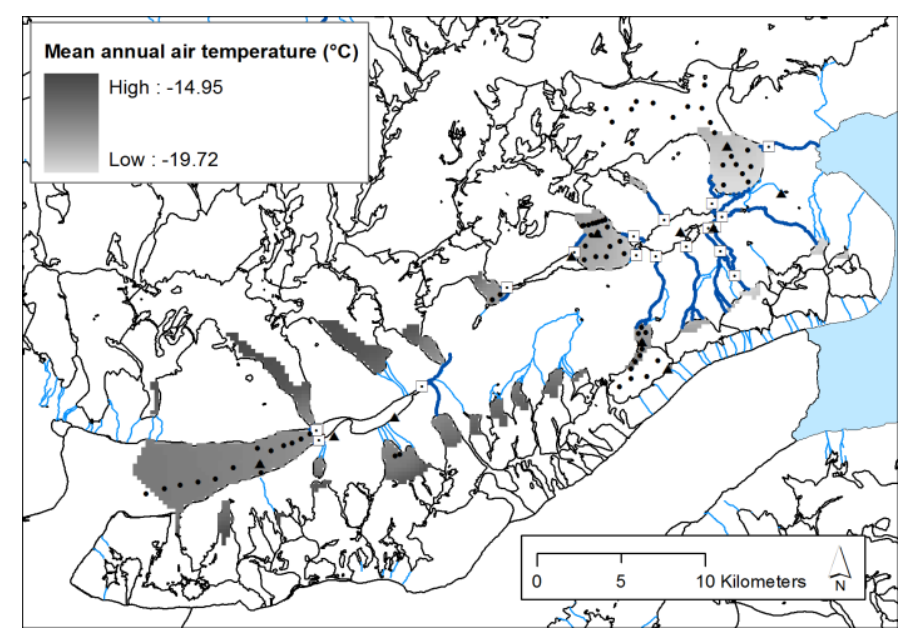

Figure 3.13: Mean annual air temperature across glaciers in Taylor Valley as output by MicroMet. Streams, lakes, and measurement sites are shown for reference (see Figure 2.2 for details). 
A requirement of MicroMet is that it reproduce observations at the point of observation (Liston and Elder 2006). For the Taylor Valley domain, MicroMet appears to reliably reproduce observations during summer, but performs less well during winter (Figure 3.14). In summer, the atmosphere is well mixed because the soil surface is commonly much warmer than the air. In winter, the atmosphere is poorly mixed because of inversions developing due to the soil being cooler than the air. In addition higher errors in winter, some stations have a bias during winter. For example, of the adjacent Canada Glacier, Lake Fryxell, and Commonwealth Glacier stations, estimated air temperature at the two glacier stations tends to be lower than the observations while the output at the valley station (Lake Fryxell) tends to be greater than the observations. Though these differences can be as large as $5^{\circ} \mathrm{C}$ in winter, bias during summer is less than $1{ }^{\circ} \mathrm{C}$ at most stations. As expected, observations are reproduced very well at stations whose neighboring stations are far away (e.g. Taylor Glacier, Lake Bonney), because the interpolated field in those locations is based almost exclusively on the local observation; the interpolated values at stations with close neighbors are strongly affected by the neighboring observation values and are therefore more likely to differ from the local observation.

Results for relative humidity show similar patterns as air temperature, with more reliable results for summer than winter. Interestingly, at most stations results have a slight negative bias for wind speed, suggesting that either wind speed is not conserved or more tuning could be done with the topographic parameters used for wind calculations. Diurnally varying errors are slight at all stations for all variables. 
I also tested using an hourly lapse rate by modifying the MicroMet code, but because the short-term calculations are more affected by observation error, this provided only marginal improvement. Hourly lapse rates also introduced problems with data gaps and made the model unnecessarily more complicated, so I chose to continue with the mean monthly lapse rates. Because MicroMet is being applied to melt modeling, the slightly poorer quality output during winter is not a concern.
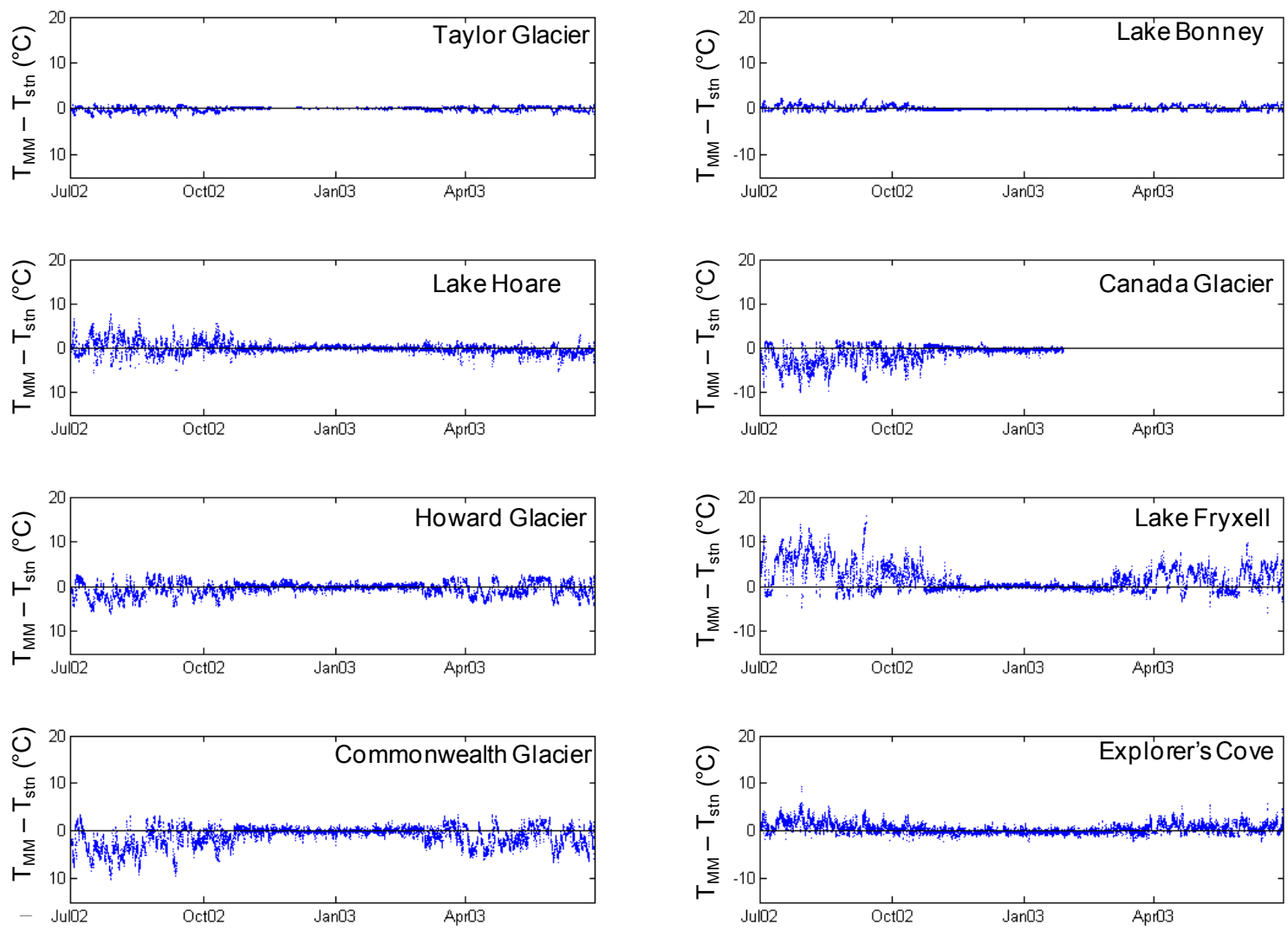

Figure 3.14: MicroMet temperature minus station temperature for model year 2002-2003. Other years show similar patterns.

A more vigorous test of MicroMet is its ability to reproduce observations at locations not used in the analysis (Liston and Elder 2006). I further test my implementation of MicroMet by comparing it to temporary observations made on lower 
Canada Glacier for 7 days in December 1998 (Lewis 2001). This location is about $2 \mathrm{~km}$ away from, and $140 \mathrm{~m}$ lower in elevation than, the nearest meteorological station (Canada Glacier). Although this is a relatively short distance, most glacier surfaces are within this distance of a meteorological station. MicroMet matches air temperature, relative humidity, and wind speed well (Figure 3.15). Wind speed is slightly low, as identified previously in comparing MicroMet output to the input observations.

MicroMet radiation output has a good match in general, but with some notable discrepancies (Figure 3.16). Modeled incoming solar radiation underestimates observed values, particularly under clear-sky conditions, and has a slight lag. Modeled incoming longwave radiation matches the daily averages well, but the diurnal pattern poorly. However, incoming longwave radiation was not measured directly at this site, but is calculated as a residual using observations of net radiation, incoming and outgoing solar radiation, and surface temperature (Lewis 2001):

$$
Q_{l i}=Q_{n e t}-\left(Q_{s i}-Q_{s o}\right)+\varepsilon \sigma T_{s f c}^{4}
$$

where $\mathrm{Q}_{\mathrm{li}}$ is incoming longwave radiation, $\mathrm{Q}_{\text {net }}$ is net radiation, $\mathrm{Q}_{\mathrm{si}}$ is incoming shortwave radiation, $\mathrm{Q}_{\mathrm{so}}$ is outgoing shortwave radiation, all measured in $\mathrm{W} \mathrm{m}^{-2}$. The final term represents outgoing longwave radiation assuming an ice emissivity of 0.98 . Because the ice surface temperature was not measured, I assume it to be between $0^{\circ} \mathrm{C}$ and $-5^{\circ} \mathrm{C}$, the lowest air temperature measured during this time period. Most likely the diurnal variation of the $\mathrm{Q}_{\mathrm{li}}$ observations is an artifact of those calculations. Previous studies in Antarctica have shown that incoming longwave radiation has muted diurnal variations (Wendler et al. 1988, Bintanja and van den Broeke 1995b, van As et al. 2005), and direct 
observations of $\mathrm{Q}_{\mathrm{li}}$ in Taylor Valley indicate typical diurnal amplitude of $<10 \%$. Based on these cursory comparisons, I consider the MicroMet output to be suitable for applying over the glacier ablation zones.
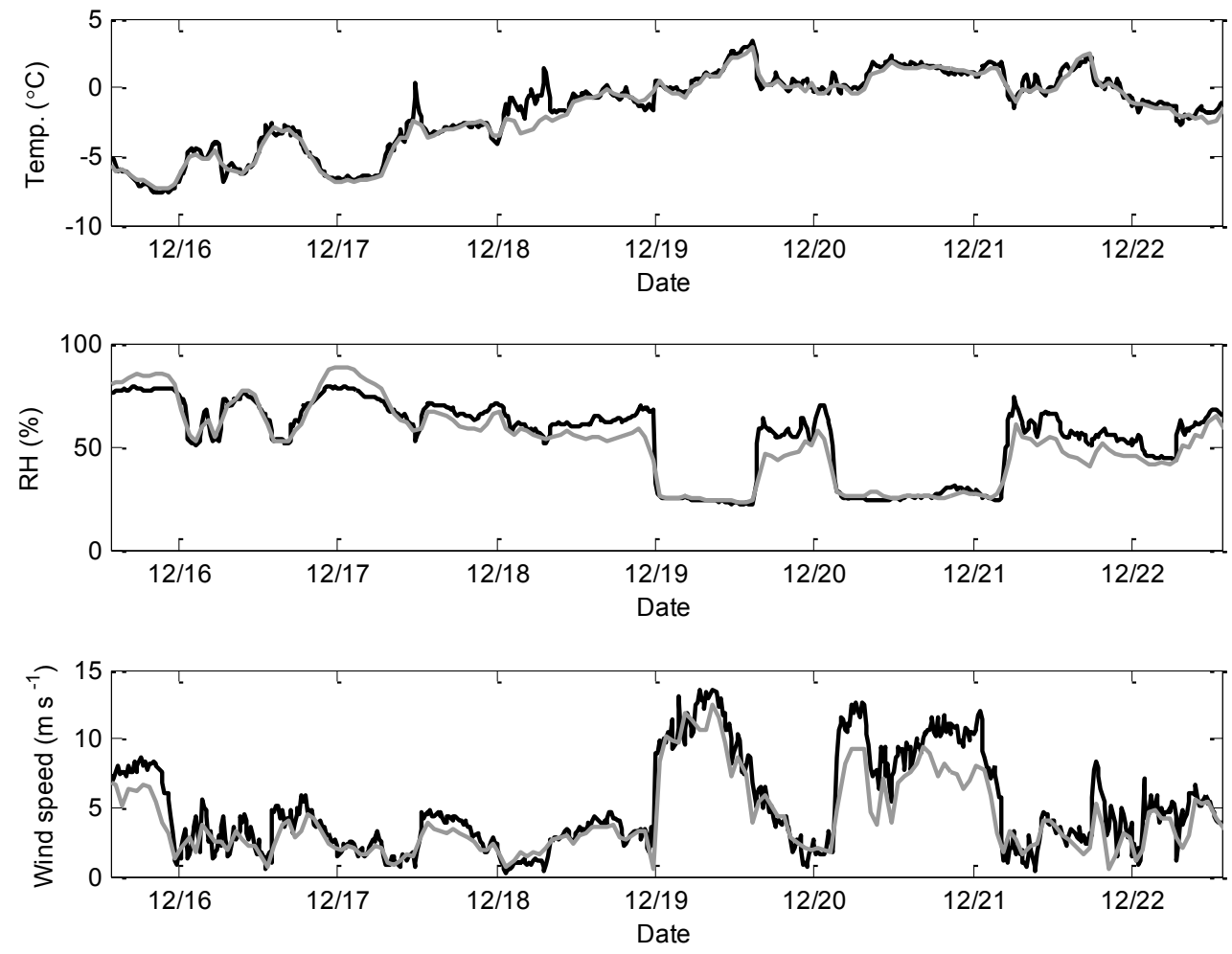

Figure 3.15: Comparison of MicroMet meteorological output to observations on lower Canada Glacier for December 1998. From top to bottom, the plots show air temperature, relative humidity, and wind speed. Gray lines are MicroMet output (hourly), and black lines are observations made by a temporary meteorological station at stake 55 on lower Canada Glacier (15-minute averages), $2.0 \mathrm{~km}$ to the southeast of CAA, $125 \mathrm{~m}$ a.s.l. 

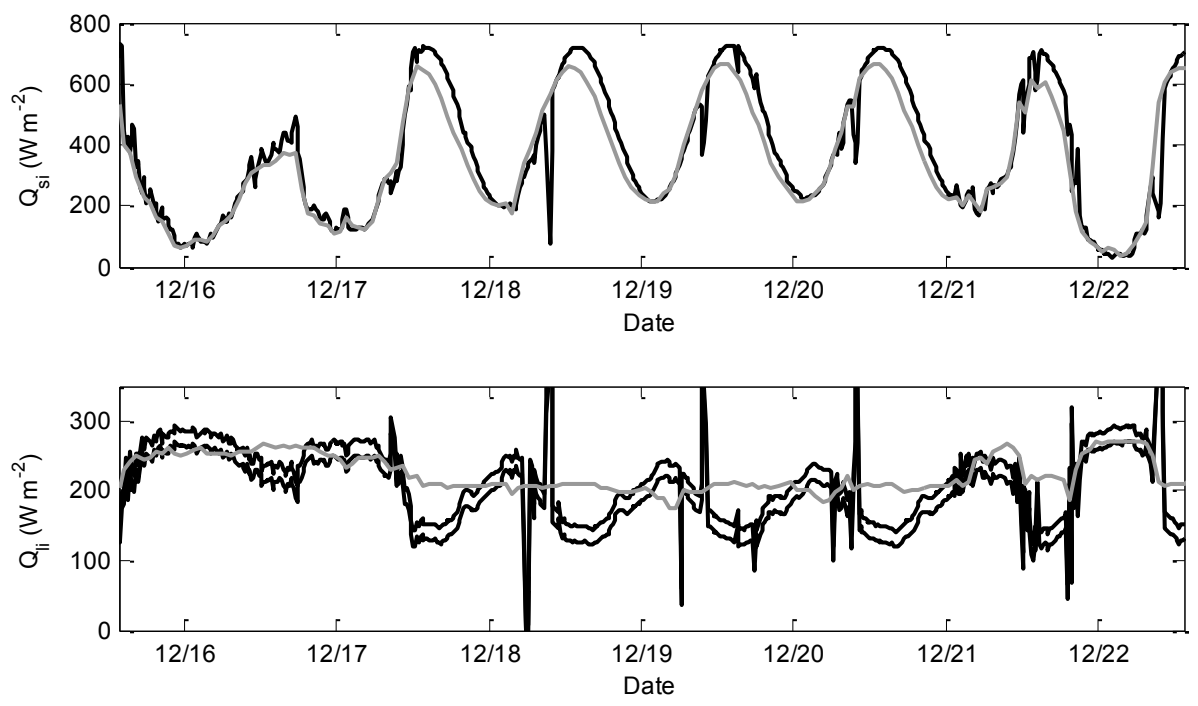

Figure 3.16: Comparison of MicroMet radiation output to observations on lower Canada Glacier for December 1998. The top plot shows incoming shortwave radiation and the bottom shows incoming longwave radiation. Gray lines are MicroMet output (hourly), and black lines are observations made by a temporary meteorological station at stake 55 on lower Canada Glacier (15-minute averages), $2.0 \mathrm{~km}$ to the southeast of CAA, $125 \mathrm{~m}$ a.s.l. The observations of incoming longwave radiation are estimates using Equation 9. The upper black line assumes an ice surface temperature of $0^{\circ} \mathrm{C}$, and the lower black line assumes $-5^{\circ} \mathrm{C}$, the lowest observed air temperature during this time period.

\subsection{MicroMet Results: Glacier cliff Domain}

I assess the MicroMet output for the glacier cliff domain separately from the glacier surface domain. Though there are no long-term meteorological observations along the glacier cliffs, I evaluate short-term observations at three locations: the westside cliff of Canada Glacier, the eastside cliff of Canada Glacier (Lewis et al. 1999), and the northside cliff of Taylor Glacier (E. Pettit, unpublished data) (Table 3.3). The meteorological stations at Canada Glacier were located along the actual cliff faces (Lewis et al. 1999), while the station at Taylor Glacier was located about $10 \mathrm{~m}$ away from the cliff on a moraine, and therefore may not accurately reflect conditions at the cliff itself. In assessing the performance of MicroMet, I determine adjustments to air temperature, 
relative humidity, wind speed, and shortwave and longwave radiation to better reflect the microclimate found along the cliffs.

The MicroMet cliff output reproduces observations of air temperature and relative humidity well (Figures 3.17 - 3.18). Temperature from MicroMet averages within $1^{\circ} \mathrm{C}$ of observations, and relative humidity from MicroMet averages within 5\% of observations. The increase in air temperature near the cliff relative to the horizontal surface above probably varies with the wind speed and incoming radiation at the cliff face, which change in time. However, for simplicity I apply a constant increase in temperature of $0.5^{\circ}$ for cliff microclimate when incoming solar radiation is greater than $50 \mathrm{~W} \mathrm{~m}^{-2}$, so that the correction is only applied in the summer. Because the differences in relative humidity are equivocal, I make no adjustment to relative humidity.

Table 3.3: Comparison of average air temperature, relative humidity, and wind speed for cliffside meteorological observations and MicroMet output. Statistics for Taylor-North are a subset of that dataset for December and January only.

\begin{tabular}{lllll}
\hline \hline & Canada-West & Canada-West & Canada-East & Taylor-North \\
\hline Dates of operation & $12 / 10 / 1995-$ & $1 / 9 / 1997-$ & $1 / 16 / 1997-$ & $11 / 14 / 2004-$ \\
& $1 / 22 / 1996$ & $1 / 26 / 1997$ & $1 / 27 / 1997$ & $11 / 22 / 2006$ \\
Number of days & 43 & 17 & 11 & 738 \\
$\mathrm{~T}_{\mathrm{MM}}-\mathrm{T}_{\text {met }}$ & $-0.4^{\circ} \mathrm{C}$ & $+0.1^{\circ} \mathrm{C}$ & $-0.5^{\circ} \mathrm{C}$ & $-0.8^{\circ} \mathrm{C}$ \\
$\mathrm{RH}_{\mathrm{MM}}-\mathrm{RH}_{\text {met }}$ & $0 \%$ & $-1 \%$ & $-1.5 \%$ & $+5 \%$ \\
$\mathrm{u}_{\mathrm{MM}} / \mathrm{u}_{\text {met }}$ & $\mathrm{n} / \mathrm{a}$ & $146 \%$ & $300 \%$ & $127 \%$ \\
\hline
\end{tabular}

MicroMet output does a poor job of reproducing wind speed along the cliffs, which is unsurprising since the MicroMet topography is too coarse to include the cliffs. Furthermore, the complexity of the wind microclimate along the cliff is likely greater than MicroMet's wind routine can resolve. Thus I rely on comparisons with cliff wind observations to modify MicroMet output for application along the cliffs, and for 
simplicity I consider a constant scalar correction. However, the corrections vary greatly between the three cliff locations used (Table 3.3), for which there are probably a number of reasons. Taylor-North has the smallest correction which may have to do with cliff orientation. At that location the cliffs are oriented near parallel to the primary wind directions coming from downvalley and upvalley. Thus the cliff there acts as less of a windbreak than for the two cliff sites at Canada Glacier which are oriented more perpendicular to the primary wind directions. Similarly, the wind correction probably varies by direction since the cliff geometry relative to the wind direction changes, something I am ignoring for simplicity. The fact that the meteorological station at Taylor-North was about $10 \mathrm{~m}$ away from the cliff face may also influence the smaller wind correction calculated there. The large wind correction needed at Canada-East is puzzling, but may relate to that site being farther from one of the meteorological stations used in the MicroMet analysis. The local cliff observations of mean wind speed along the east and west sides of Canada (for the same time period) are nearly identical, but the MicroMet wind speed for the eastside is almost twice as large as for the westside. It may be that MicroMet predictions for the east side of Canada Glacier are overly affected by the higher wind speeds found at the Lake Fryxell meteorological station during summer (Figures $2.14-2.15$ ). This problem highlights the danger in including valley floor stations in the data interpolation, which may have a different climatology than the glaciers. Based on these three comparisons, I choose to apply the correction at CanadaWest and reduce MicroMet wind speed by $32 \%$ to represent the microclimate along the cliffs. 

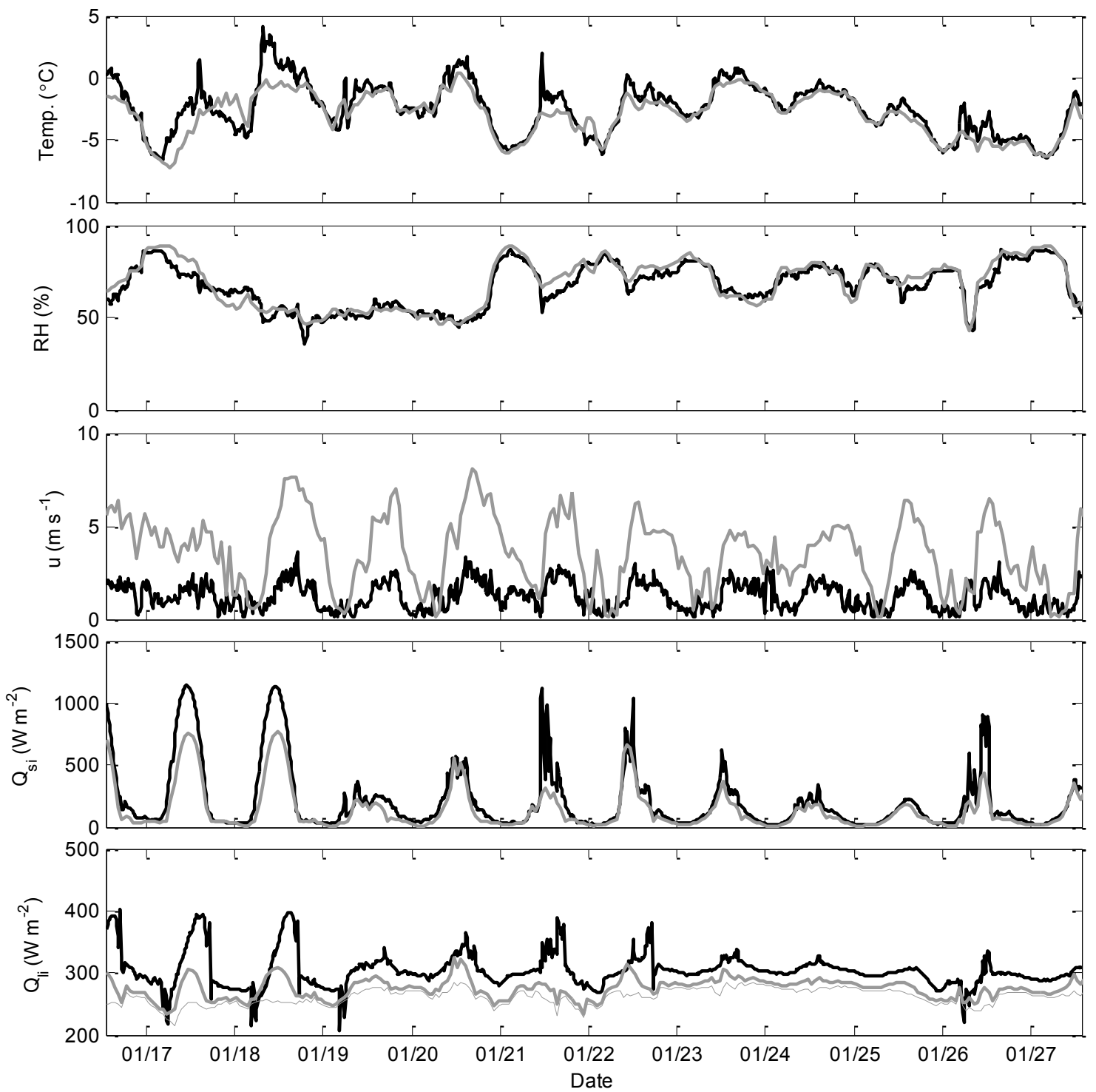

Figure 3.17: Comparison of MicroMet output to observations on Canada Glacier east-side cliff for January 1997. From top to bottom, the plots show air temperature, relative humidity, wind speed, incoming shortwave radiation, and incoming longwave radiation. Both radiation components are measured/calculated for a hemisphere oriented normal to the vertical cliff face. Gray lines are MicroMet output (hourly), and black lines are observations made by a temporary meteorological station on the cliff face (15-minute averages). The observations of incoming longwave radiation are estimates using Equation 9 with measured ice surface temperature. The thick gray line for longwave radiation uses a terrain temperature that is a function of air temperature and incoming shortwave radiation (Equation 8), while the thin gray line assumes the terrain temperature is equal to the air temperature. 


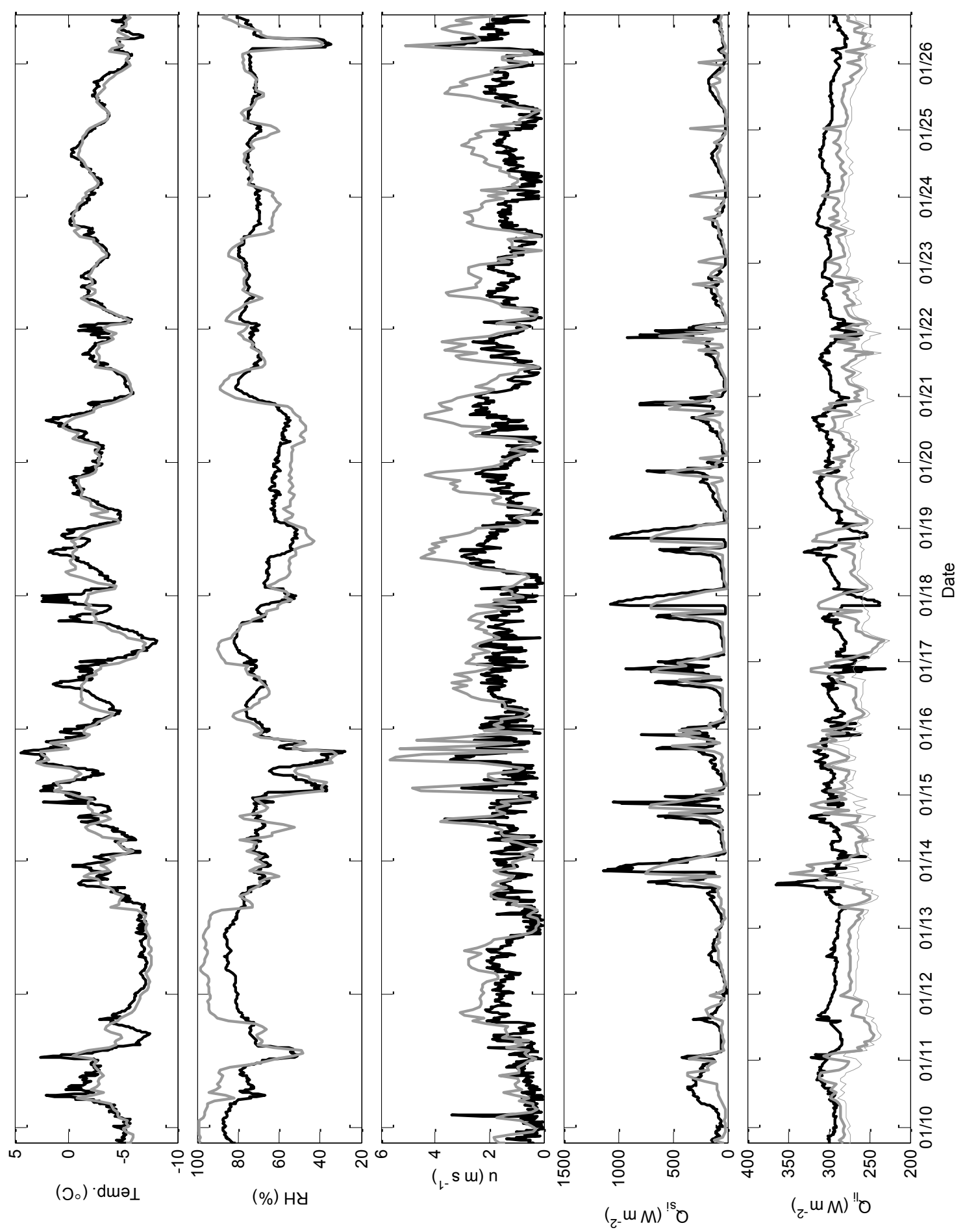

Figure 3.18: Comparison of MicroMet output to observations on Canada Glacier west-side cliff for January 1997. See previous figure for details. 
The MicroMet estimates of incoming solar radiation for the two cliff sites at Canada Glacier are too low under clear-sky conditions. This appears to be the same problem identified for the glacier surfaces, but seems to be more pronounced for the cliffs (Figures 3.17 - 3.18). Additional differences may be due to measurements, since the pyranometers were not re-calibrated for facing horizontally (Lewis et al. 1999), and the orientation of the pyranometers may have differed from the $89^{\circ}$ assumed in my MicroMet application. Alternatively, there may be a physical explanation (e.g. reflected solar radiation that is not accounted for in MicroMet), or a deficiency with the MicroMet solar radiation procedure that I have applied.

The MicroMet estimates of incoming longwave radiation on the two cliff sites at Canada Glacier are too low most of the time (Figures 3.17 - 3.18). Inclusion of terrain temperature that is a function of incoming shortwave radiation (Equation 8) improves the MicroMet estimates somewhat. However, the observations may be inaccurate since they are derived estimates of incoming longwave radiation from measurements of net radiation, following Equation 9. To better assess the quality of the MicroMet output for incoming longwave radiation, I consider a series of short duration direct observations of incoming longwave radiation made for the Canada-Westside site in 1999 (Figure 3.19) (Lewis 2001). These measurements show that incoming longwave radiation increases from the ground level to the top of the cliff, a variation that is excluded by my assumption of a single value for the entire cliff face. However, given this variation, MicroMet does a reasonable job of reproducing incoming longwave radiation when the terrain temperature correction is included. 


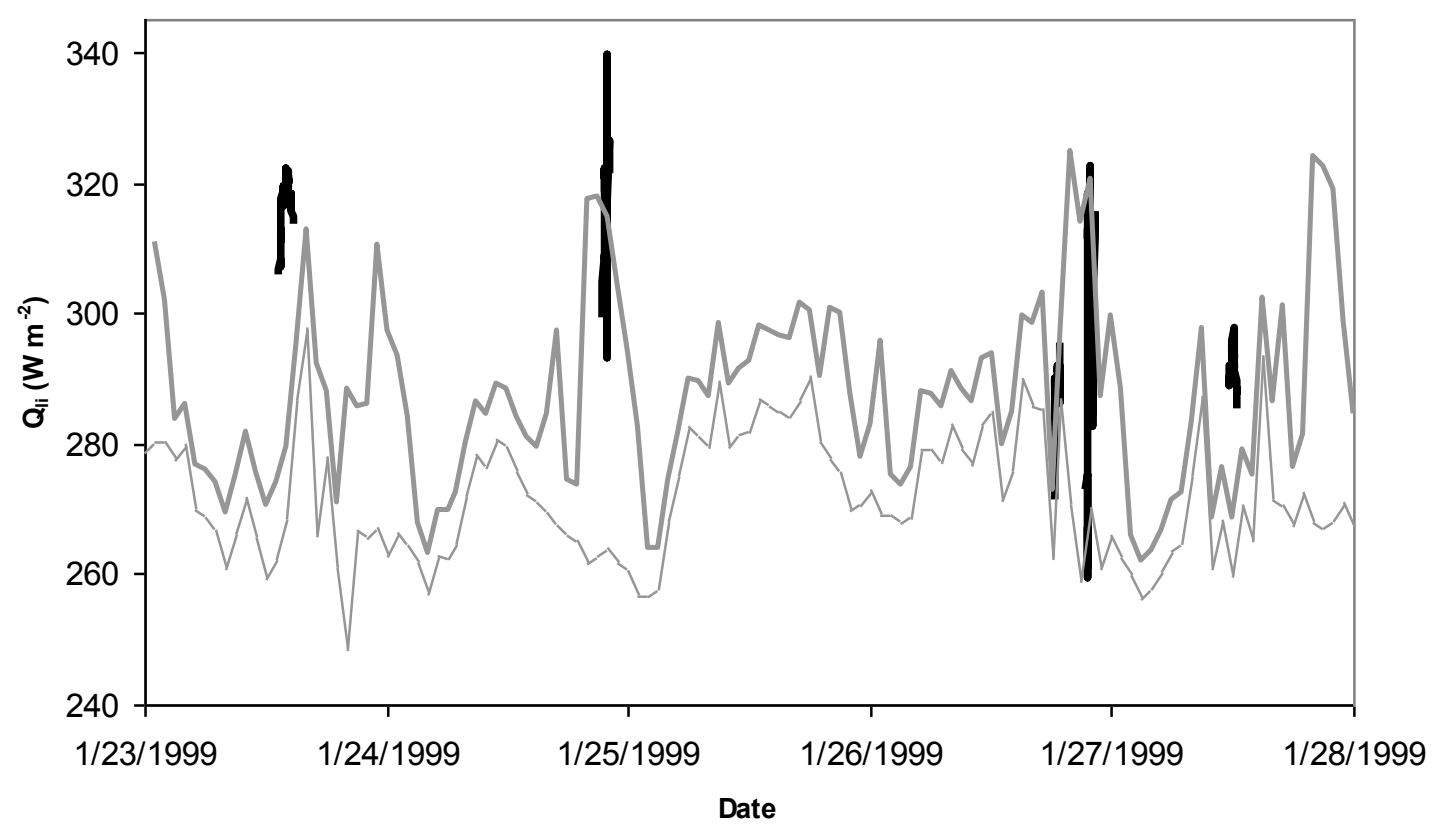

Figure 3.19: Comparison of MicroMet longwave radiation output to observations on Canada Glacier east-side cliff for January 1999. Gray lines are MicroMet output (hourly). The thick gray line uses a terrain temperature that is a function of air temperature and incoming shortwave radiation (Equation 8), while the thin gray line assumes the terrain temperature is equal to the air temperature. The black lines are instantaneous observations of incoming longwave radiation made by hoisting a pyrgeometer perpendicular to the cliff face at five separate times during this time period. For each set of pyrgeometer measurements, the instrument was raised from $2 \mathrm{~m}$ to $12 \mathrm{~m}$ and back down; the low values correspond to measurements at $2 \mathrm{~m}$ above the ground and the high values correspond to measurements at $12 \mathrm{~m}$. 


\section{Chapter 4: Initial Melt Model Application: Surface Energy Balance and Melt Thresholds Using a Daily Time-Step Point Model}

[This chapter was published with slight modifications under the title "Surface energy balance and melt thresholds over 11 years at Taylor Glacier, East Antarctica" in the Journal of Geophysical Research, Earth Surface, vol. 113, F04014 in 2008 with coauthors Andrew G. Fountain and Glen E. Liston. The purpose of this initial application of the melt model is to explore the feasibility of using a daily time step and perform a detailed analysis of the surface energy balance at a single point. Some methods and analysis time periods differ slightly than described previously because this work was completed prior to the in depth meteorological analysis described in Chapters 2 and 3.]

\subsection{Introduction and Background}

Previous glacier energy balance studies in Taylor Valley (Lewis et al. 1998, Lewis et al. 1999, Johnston et al. 2005) have been useful for understanding the causes for enhanced melt along cliffs and in channels and basins on the glacier surfaces, but their limited duration (a few summer weeks) has precluded understanding of the day-to-day variation over the seasonal cycle, including the onset and termination of the melt season. Additionally, these studies do not adequately address the subsurface heating of the ice which can lead to subsurface melting and water flow (Liston et al. 1999, Fountain et al. 2004b). With over a decade of meteorological and mass balance observations in Taylor Valley (Doran et al. 2002a, Fountain et al. 2006), I apply an energy balance model at the 
Taylor Glacier meteorological station. I test its capability to model 11 years of ablation at a daily time step and compare the results to blue ice areas elsewhere in Antarctica (e.g. Bintanja and van den Broeke 1995b, Liston et al. 1999).

The test site that I choose for the initial application of the model is the Taylor Glacier meteorological station $\left(77^{\circ} 42^{\prime} \mathrm{S}, 162^{\circ} 8^{\prime} \mathrm{E}\right)$, chosen because the surface topography is smooth and relatively level, the surface is free of sediment, and snow accumulation is rare. Taylor Glacier is an outlet of the East Antarctic Ice Sheet that terminates into Lake Bonney (57 m a.s.1.) at the west end of Taylor Valley, about $90 \mathrm{~km}$ from its source at Taylor Dome and $25 \mathrm{~km}$ from the coast of McMurdo Sound (Figure 4.1). The equilibrium line is approximately $70 \mathrm{~km}$ up-glacier of the terminus, and only the lower $15 \mathrm{~km}$ occupy Taylor Valley. The surface ice in the ablation zone is generally white, bubbly ice (Figure 4.2).

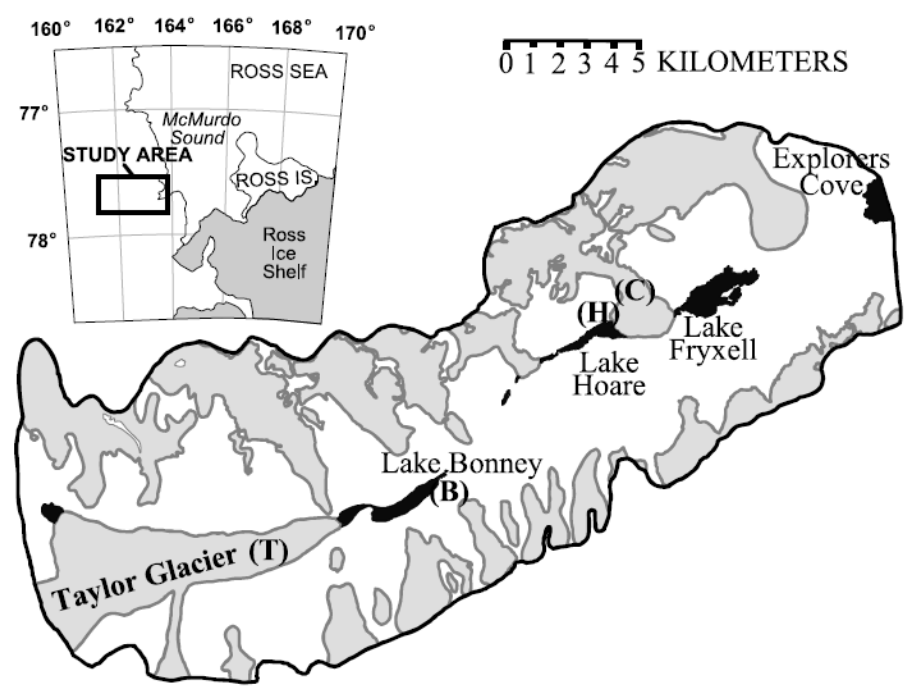

Figure 4.1: Location of Taylor Glacier (T), Lake Bonney (B), Lake Hoare (H), and Canada Glacier (C) meteorological stations within Taylor Valley. Glaciers in gray, lakes in black, and soil in white. 


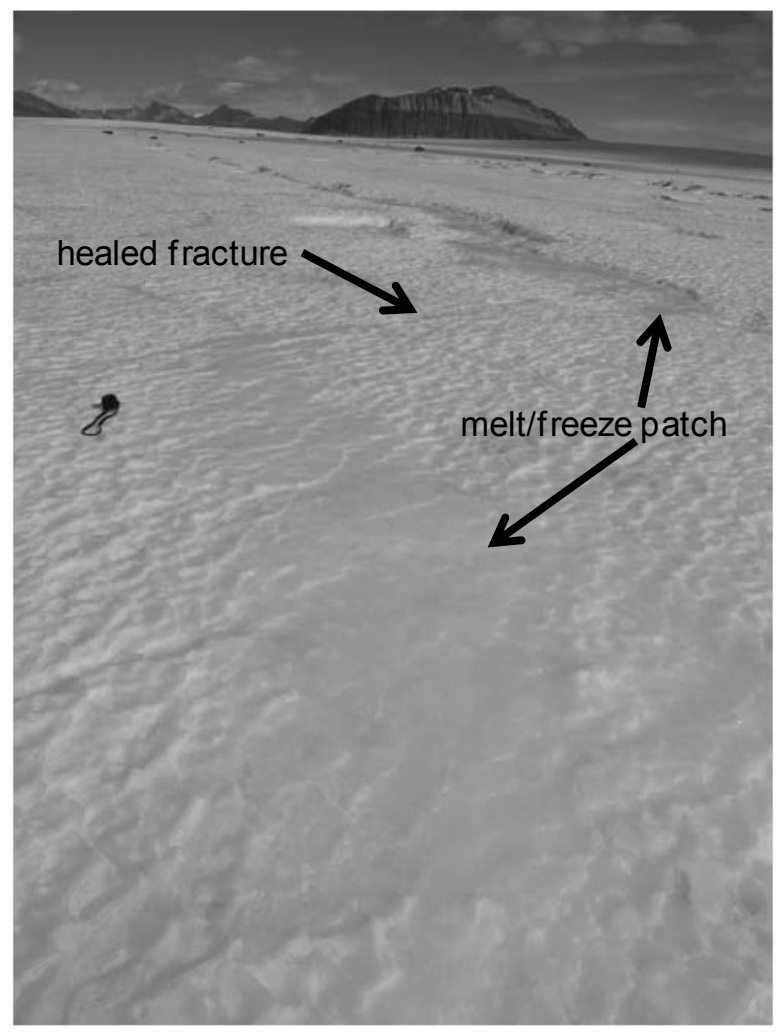

Figure 4.2: Surface of Taylor Glacier showing typical roughness and a melt/freeze patch of smooth ice. Camera case with strap is approximately $50 \mathrm{~cm}$ long.

For the 11-year period, 1995-2006, the mean annual air temperature at Taylor Glacier was $-17.1^{\circ} \mathrm{C}$, with an average summer (December-January) temperature of $3.0^{\circ} \mathrm{C}$. On average, 4.7 days per year had daily air temperatures warmer than $0^{\circ} \mathrm{C}$. Mean annual relative humidity was $60 \%$, with a slight increase in summer (62\%) lasting into April. Solar radiation is absent May-August, averages $290 \mathrm{~W} \mathrm{~m}^{-2}$ during DecemberJanuary, and reaches a daily maximum of $\sim 400 \mathrm{~W} \mathrm{~m}^{-2}$. Wind speed averaged $5.1 \mathrm{~m} \mathrm{~s}^{-1}$ annually and was lower in summer $\left(4.4 \mathrm{~m} \mathrm{~s}^{-1}\right)$. Gravity driven drainage winds that typically reach high speeds and exhibit low humidity are a characteristic feature of the Dry Valleys, reaching recorded speeds up to $37 \mathrm{~m} \mathrm{~s}^{-1}$ (Nylen et al. 2004). The strongest and most frequent drainage winds measured in the Dry Valleys occur at Taylor Glacier, 
with a winter frequency greater than 50\% and 15\% during summer (Nylen et al. 2004).

During winter drainage winds effectively increase average temperature by $3.5^{\circ} \mathrm{C}$, increase average wind speed by $3.2 \mathrm{~m} \mathrm{~s}^{-1}$, and decrease relative humidity by $8.5 \%$ at Taylor Glacier, with smaller effects during summer (Nylen et al. 2004). These winds strongly affect ice ablation by generating large latent heat fluxes (sublimation) and redistributing snow (van den Broeke and Bintanja 1995).

A single stake located $20 \mathrm{~m}$ away from the meteorological station was used to compare against modeled ablation values. For the period since 2004 data from an ultrasonic distance sensor provide daily measurements of surface height. I use the terms summer and winter to refer to the periods defined by the stake measurements, except where I explicitly define the seasons differently to allow direct comparisons to other studies. Snow depth and density were recorded for the single incidence of snow present during stake measurements that occurred during the study period.

\subsection{Model Description}

Using a daily time step, I apply the one-dimensional model of Liston et al. (1999) because it accounts for both the surface energy balance and subsurface solar heating. The surface energy balance takes the form,

$$
\chi(1-\alpha) Q_{s i}+Q_{l i}+Q_{l e}+Q_{h}+Q_{e}+Q_{c}=Q_{m}
$$

where $\chi$ allocates the total solar radiation between the surface energy balance and the solar-radiation source term in the heat-transfer equation (a modification from the original model), $\alpha$ is albedo, $Q_{s i}$ is incoming shortwave solar radiation, $Q_{l i}$ is incoming longwave 
radiation, $Q_{l e}$ is emitted thermal radiation, $Q_{h}$ is sensible heat flux, $Q_{e}$ is latent heat flux, $Q_{c}$ is heat conduction in the ice, and $Q_{m}$ is the energy available for melt, calculated as a residual. All heat flux terms have units of $\mathrm{W} \mathrm{m}^{-2}$, and a positive sign is energy directed toward the surface. $Q_{s i}, \alpha$, and $Q_{l i}$ are measured directly, and the terms that cannot be directly measured $\left(Q_{l e}, Q_{h}, Q_{e}, Q_{c}\right)$ are cast in a form that leaves surface temperature, $T_{0}$, as the only unknown (Liston et al. 1999). The turbulent terms $Q_{h}$ and $Q_{e}$, are estimated using a bulk energy method with a correction for stability based on Monin-Obukhov theory (Brutsaert 1982). The only adjustable variable in the turbulent fluxes is the momentum surface roughness length, $z_{0}$. I set the scalar roughness lengths of temperature and water vapor equal to $z_{0}$, a simplification often made over smooth glacier surfaces in dry and cold climates (e.g. Bintanja and van den Broeke 1995b, Lewis et al. 1999, Bintanja and Reijmer 2001, Mölg and Hardy 2004) that can potentially produce an overestimation of turbulent fluxes when applied to rougher surfaces. I ignored the effect of drifting snow on surface roughness (Schmidt 1982) because snowfall is infrequent. $T_{0}$ is solved iteratively using (Equation 10), and if its value is above $0^{\circ} \mathrm{C}, T_{0}$ is reset to $0^{\circ} \mathrm{C}$, and the temperature difference is used to calculate melt energy and the corresponding volume of meltwater produced.

$Q_{c}$ is calculated by a one-dimensional heat-transfer equation,

$$
\rho_{i} C_{p} \frac{\partial T_{i}}{\partial t}=\frac{\partial}{\partial z}\left[k \frac{\partial T_{i}}{\partial z}\right]-\frac{\partial q}{\partial z}
$$

where $T_{i}(\mathrm{~K})$ is the ice temperature, $z(\mathrm{~m})$ is the vertical coordinate, $t(\mathrm{~s})$ is time, $C_{p}(\mathrm{~J}$ $\left.\mathrm{kg}^{-1} \mathrm{~K}^{-1}\right)$ is the specific heat of the ice, and $q\left(\mathrm{~W} \mathrm{~m}^{-2}\right)$ is the solar radiative flux. In a 
change from the described Liston et al. (1999) model, the thermal conductivity of the ice, $k\left(\mathrm{~W} \mathrm{~m}^{-1} \mathrm{~K}^{-1}\right)$, is given by Paterson (1994), accounting for water fraction, if present:

$$
\begin{gathered}
k=\frac{2 k_{p} \rho}{3 \rho_{p}-\rho} \\
k_{p}=9.828 \exp \left(-5.7 \times 10^{-3} T_{i}\right)
\end{gathered}
$$

where $\rho$ is ice density, and $k_{p}$ and $\rho_{p}$ are the thermal conductivity and density $\left(917 \mathrm{~kg} \mathrm{~m}^{-}\right.$

${ }^{3}$ ) of pure ice. The spectrally dependent solar-radiation source term, $\partial q / \partial z$, is described in detail by Liston et al. (1999). The surface energy balance (Equation 10) represents the upper boundary condition for Equation 11, and the bottom boundary condition is no heat flux at depth $15 \mathrm{~m}$, approximately the depth of attenuation of the seasonal temperature variations and where the ice temperature equals the mean annual temperature (Paterson 1994).

Because snow accumulation on Taylor Glacier is rare and of short duration, I used a simple parameterization for snow events that differs from that described in Chapter 2. When measured albedo is greater than 0.85 , I applied a snow layer to the glacier surface within the model. The snow layer was removed when measured albedo dropped below 0.7 or average daily wind speed exceeded $8.5 \mathrm{~m} \mathrm{~s}^{-1}$. These thresholds were determined from empirical observations using the ultrasonic distance sensor to detect snow accumulation on the glacier surface. When albedo measurements were unavailable (April - August), snow was ignored. I justify this because only three snow accumulation events occurred during the three winters that ultrasonic distance sensor data were available, all lasting less than a week. Because single-storm snow accumulation is typically less than 2 
$\mathrm{cm}$ (Fountain et al. 2010) and drainage wind events occur with greater than $50 \%$ frequency during winter (Nylen et al. 2004), snow is quickly removed during winter. I did not calculate ablation when snow is present in the model. I also did not change the thermal or optical characteristics of the ice when snow is present, because our observations indicate snow cover is thin $(\sim \mathrm{cm})$ and transient.

\subsubsection{Model Implementation and Calibration}

Although $Q_{l i}$, is measured, about one-fifth of the record is missing (1 July 1995 18 December 1995; 18 November 1997 - 14 January 1998; 9 July 1998 - 11 November 1998; 28 October 2000 - 16 November 2000; 4 July 2003 - 4 September 2003; 22 June 2004 - 28 December 2004; 5 January 2006 - 30 June 2006). To complete the record I applied the parameterization for atmospheric emissivity, ${ }^{\varepsilon}$, used by Liston and Elder (2006):

$$
\varepsilon=\kappa\left(1+Z_{s} \sigma_{c}^{2}\right)\left[1-X_{s} \exp \left(-Y_{s} e / T\right)\right]
$$

where $\sigma_{c}$ is the cloud fraction determined as a function of relative humidity, $e(\mathrm{~Pa})$ is atmospheric pressure, $T$ is air temperature $(\mathrm{K})$, and the coefficients $\kappa, X_{s}, Y_{s}$, and $Z_{s}$ are calculated as a function of elevation. I filled an 8-month gap in wind speed (winter 2003) using data from nearby stations adjusted with a polynomial regression between Taylor Glacier and those stations. Two other gaps in the meteorological record, of 8 days (January 2001) and 18 days (November 2002) in duration, were filled with the average value of the record before and after the gap equal to the length of the gap for each meteorological variable. For example, for the missing data spanning eight days, each day 
in the gap was filled using the average of the eight days before the gap and the eight days after. As mentioned, the height of the instruments is nominally $3 \mathrm{~m}$, but changes because of ice ablation. A linear interpolation between ablation stake measurements was used to estimate the change in instrument height with an uncertainty of less than $10 \mathrm{~cm}$. Atmospheric pressure was not measured at Taylor Glacier and I used the nearest measurements, at Canada Glacier and Lake Hoare about $23 \mathrm{~km}$ down valley, corrected for altitude at Taylor Glacier.

The spectrally dependent solar-radiation source term described in detail by Liston et al. (1999), $\partial q / \partial z$, is a function of the solar spectrum (I retained that used by Liston et al., 1999), the surface albedo (I used the measured snow-free average of 0.56 ), ice density (I used the value measured on ice cores from Canada and Commonwealth Glaciers of $\rho_{\text {ice }}$ $=870 \mathrm{~kg} \mathrm{~m}^{-3}$ ), and ice grain radius. The calculations of the downward bulk extinction coefficient do not include the effects of bubbles or impurities, so I chose to estimate an 'effective' ice grain radius by measuring the downward flux of solar radiation within the ice, rather than using a measured grain radius. I drilled three $27 \mathrm{~cm}$ diameter holes horizontally into a $\sim 1 \mathrm{~m}$ vertical cliff on the surface of Canada Glacier at depths of 26 , $59,73 \mathrm{~cm}$ below the upper surface and oriented to the sun so that the hole entrances were shaded by the cliff. Canada Glacier was used for logistical reasons; comparison of thinsections from both glaciers shows that both glaciers have ice with similar bubble content and grain radius (Canada: $\mathrm{r}_{\mathrm{avg}}=2.7 \mathrm{~mm}$, Taylor: $\mathrm{r}_{\mathrm{avg}}=2.8 \mathrm{~mm}$ ). An Eppley broadband pyranometer was placed approximately level $1 \mathrm{~m}$ deep inside each of the holes facing upwards to measure the downward solar radiation flux within the ice, while an additional 
pyranometer measured the downward flux at the surface. A black cloth fitted around the subsurface pyranometer absorbed light reflecting against the cylindrical walls of the hole and blocked any light from the hole entrance. The drilling of the hole and the placement of the pyranometer created disturbances to the ice and affected the upward flux below the pyranometer and, in turn, the backscattering that contributes to the downward flux above the pyranometer. I have neglected this effect for lack of a robust way to account for it. The best agreement with measurements of downward flux occurs with a model grain radius of $0.24 \mathrm{~mm}$ (Figure 3), an order of magnitude smaller than the measured grain radius. Bubbles present have a radius of 0.05 to $0.5 \mathrm{~mm}$. This suggests that scattering due to bubbles may dominate the scattering due to grain boundaries. However, additional measurements and modeling are necessary to conclusively determine such effects.

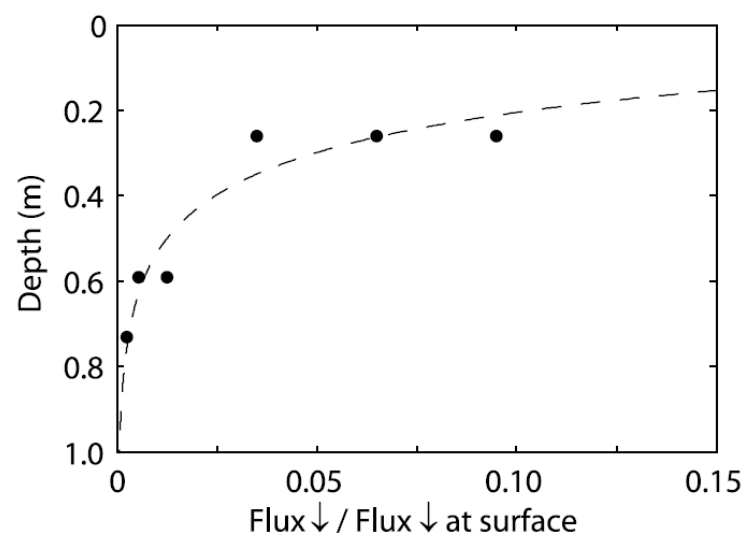

Figure 4.3: Measured (points) and modeled (line) subsurface solar radiation penetration for ice properties used in the model.

The parameter, $\chi$, or solar radiation surface fraction, partitions the net solar radiation between the surface and subsurface is based on the method of Bintanja and van den Broeke (1995b). In so doing I essentially define the thickness of the air-ice interface or 'surface' that interacts with the atmosphere over the duration of the time step, in this 
case, daily. The surface thickness, $d_{x}$, therefore gains energy from solar radiation through absorption at the surface equal to $\chi(1-\alpha) Q_{s i}$. Subsurface heating begins below depth $d_{\chi}$ and totals $(1-\chi)(1-\alpha) Q_{s i}$, thereby conserving absorbed solar energy. To calibrate the model, $\chi$ and $z_{0}$ (roughness) were adjusted together through an iterative process to minimize the root mean square error (RMSE) in ablation for the 22 seasons (11 years) of measurements. I chose to calibrate our model with $z_{0}$ because profile measurements on MDV glaciers do not exist to determine $z_{0}$ directly. I recognize that model error will be included in our calibration parameter values, and they do not represent their true values. Because adjustment of $z_{0}$ affects the calculation of both summer and winter ablation, and adjustment of $\chi$ primarily affects summer, the calibration leads to a unique pair of values. The surface thickness, $d_{\chi}$, is a consequence of the adjusted $\chi$. Based on our field observations, I assume all surface melt is lost to runoff and subsurface melt is retained. The final calibration values were $\chi=0.817, d_{\chi}=13 \mathrm{~cm}$, and $z_{0}=0.25 \mathrm{~mm}$, which produce RMSE of $1.97 \mathrm{~cm}$.

To test my interpretation that $\chi$ is dependent on the chosen time step, I ran the model with an hourly time step for a single year (2005-2006) calibrated to monthly measurements of surface lowering (maintaining $z_{0}=0.25 \mathrm{~mm}$ ), with resulting values of $\chi$ $=0.567$ and $d_{\chi}=4 \mathrm{~cm}$, consistent with our expectation. The root mean square deviation of the residuals of monthly ablation between the daily and hourly models was $0.4 \mathrm{~cm}$, suggesting that adjusting $\chi$ alone accounts for the difference in time step. Because the agreement between the daily and hourly models was so high, I feel justified using a daily time step to model a process that likely occurs over shorter time scales; while melt and 
ablation may perhaps be calculated incorrectly for individual days, seasonal totals seem robust.

\subsection{Results and Analysis}

\subsubsection{Model Performance}

Modeled ablation compares well to seasonal (winter, summer) measurements (Figure 4.4), as expected because the model is calibrated to ablation. The model performs better in winter (RMSE $=1.5 \mathrm{~cm}$ w.e. $)$ than in summer $(\mathrm{RMSE}=2.3 \mathrm{~cm}$ w.e. $)$, probably due to the different heat required to sublimate versus melt ice. Sublimation requires eight times more energy to ablate the same ice mass as melting, and errors in the energy balance near the warmest time of the year may be the reason why there are more summers than winters with sizable residuals. At the monthly intervals, the model also compares well to measurements, but large errors in December and January of the 20052006 summer (Figure 4.5) are presumably due to errors in calculating melt. These errors offset one another, suggesting that the model predicts summer totals better than ablation at shorter time scales. 

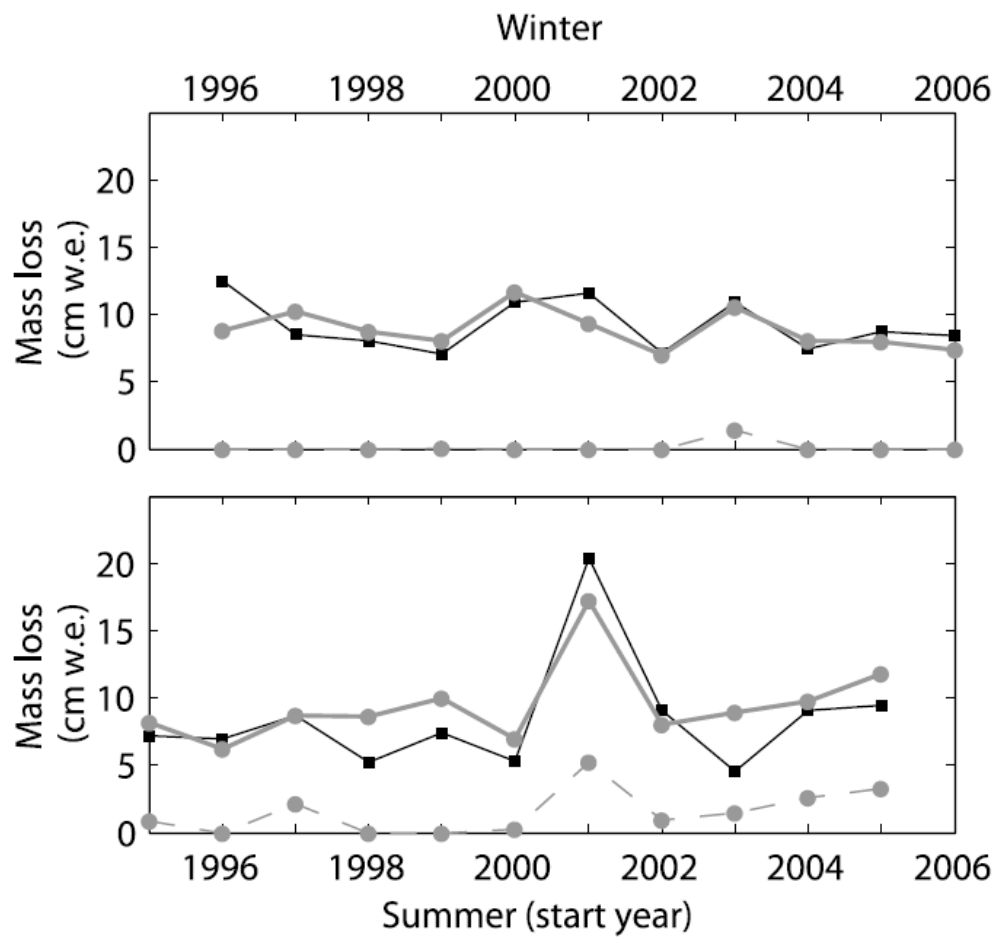

Figure 4.4: Measured ablation (black line) and modeled ablation (gray line) and melt (dotted gray line) for each season.

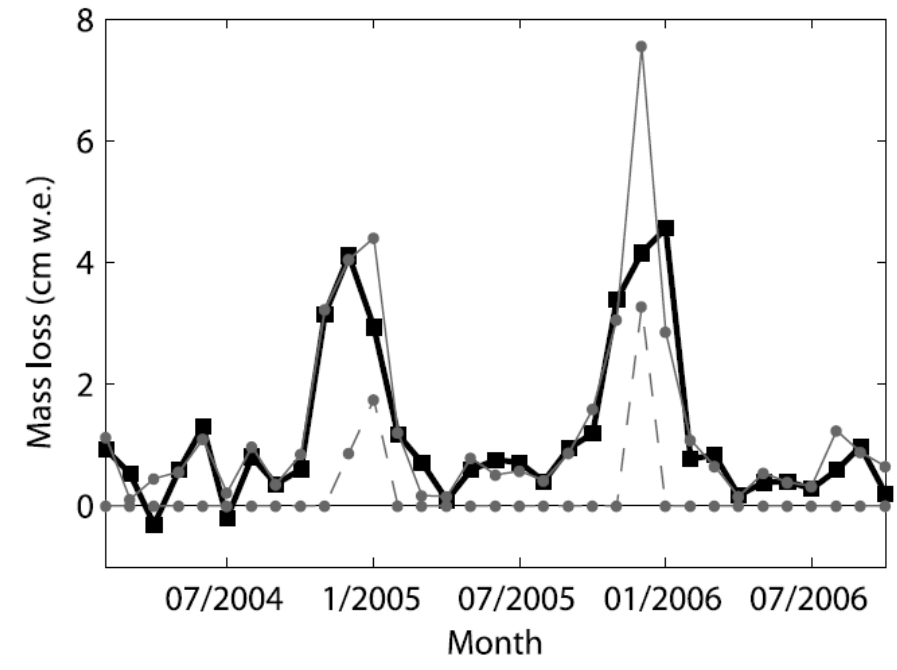

Figure 4.5: Measured ablation (black line) and modeled ablation (gray line) and melt (dotted gray line) for each month that the ultrasonic distance sensor was operational.

Unlike ablation, measured ice temperatures provide an independent test of the model. Comparison of modeled and measured ice temperatures, spanning significant portions of 8 different model years, shows that the model captures ice temperature 
magnitudes and variations across the range of depths sufficiently to provide confidence in model accuracy (Figure 4.6). Quantitative comparisons must be undertaken with care, however, because summer radiative heating of the thermistors exceeds that of the surrounding ice, causing the measured temperature to be warmer than the true ice temperature (e.g. Brandt and Warren 1993, Liston et al. 1999). Second, thermistor depth is only known accurately when installed, and estimated thermistor depth using ablation measurements becomes less accurate with time. Therefore, I expect measured temperatures to be a little warmer than modeled in summer but identical in winter, as is the case, and the fit between the modeled and measured ice temperatures decreases with time since installation, also shown in the data. Moreover, ice temperatures within $1 \mathrm{~m}$ of the surface are strongly affected by radiative heating, and close correspondence with modeled temperatures supports our choice of effective grain radius and solar radiation surface fraction. I acknowledge that accurately calculated ice temperatures may not necessarily be a powerful constraint on the surface energy balance since the conduction term is typically a minor contribution to the surface energy balance. However, I believe that they provide a meaningful check on our calculation of subsurface melting, particularly since I am unable to make direct long-term, quantitative observations of subsurface melting. 


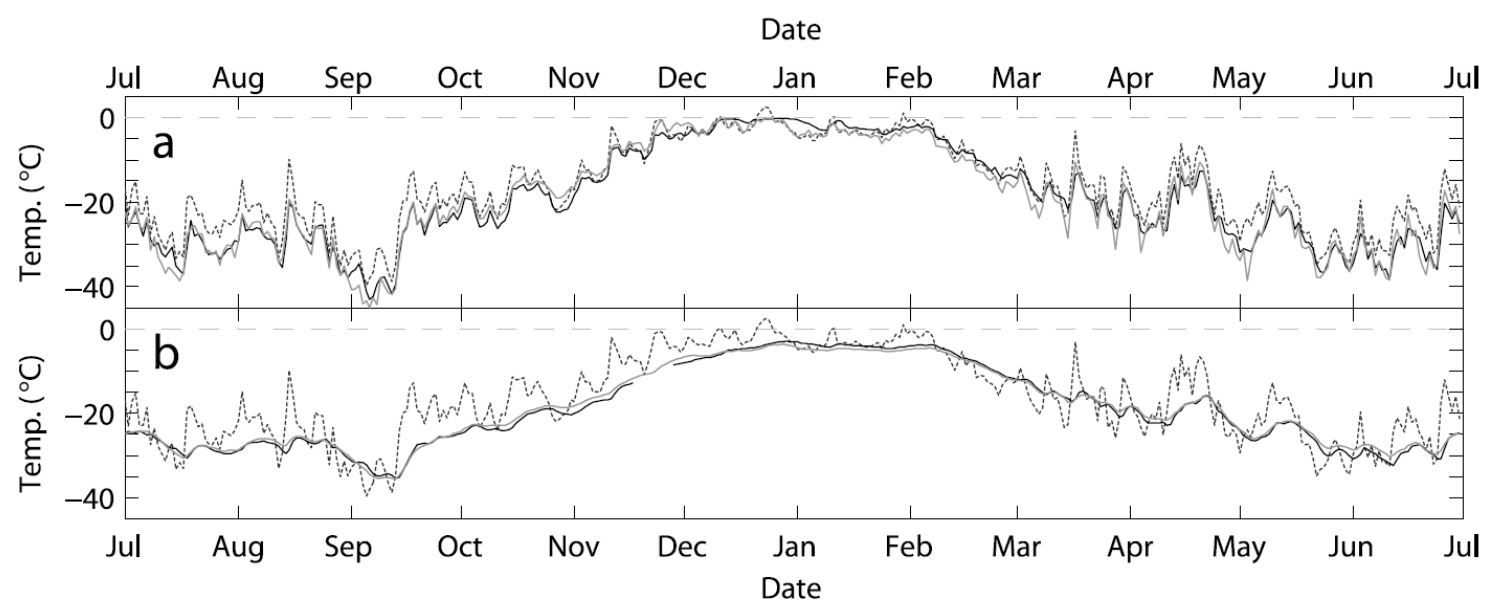

Figure 4.6: Measured (black line) and modeled (gray line) ice temperature and measured air temperature (dotted line) during model year 1995 for a) the shallow thermistor (depth ablated from $12 \mathrm{~cm}$ to surface during this time period); and b) the deep thermistor (depth ablated from 92 to $78 \mathrm{~cm}$ ).

The magnitude of $\chi$ determined through calibration indicates that the majority of the net solar radiation $(82 \%)$ is absorbed at the 'surface'. Despite the large percentage absorbed at the surface, including the solar-radiation transmission into the ice in the model provided a much better fit than using a 'traditional' energy balance approach where $100 \%$ of net solar radiation is included in the surface energy balance. Eliminating the source term leaves $z_{0}$ as the only calibration parameter, and the minimum RMSE in seasonal ablation becomes $4.35 \mathrm{~cm}$, using $z_{0}=0.50 \mathrm{~mm}$. With the 'traditional' approach, the total ablation of all 11 summer seasons is overestimated by more than $50 \%$, regardless of choice of $z_{0}$. These results suggest that accounting for the absorption of a significant portion of the net solar radiation below the ice surface greatly improves the ability to model the energy balance on the snow-free glacier ablation zones of the Dry Valleys. I acknowledge the alternative explanations of a systematic over-heating of the surface by the model during the summer or a bias in our meteorological measurements. 
However, my interpretation is supported by modeled ice temperatures at $\sim 85 \mathrm{~cm}$ being $\sim 3^{\circ} \mathrm{C}$ too low throughout summer but accurate during winter using the 'traditional' approach, while being a good match $\left( \pm 0.5^{\circ} \mathrm{C}\right)$ to measured ice temperatures year-round when I include the solar-radiation source term.

\subsubsection{Energy Balance}

The average daily energy balance over the eleven modeled years (1995-2006) shows that during the austral winter (April-September), net longwave radiation, $Q_{l}$, is the largest energy loss, $\sim-55 \mathrm{~W} \mathrm{~m}^{-2}$, while sensible heat, $Q_{h}$, provides the largest energy gain to the surface, $\sim+60 \mathrm{~W} \mathrm{~m}^{-2}$ (Figure 4.7 ). Latent heat, $Q_{e}$, is comparatively small, $10 \mathrm{~W} \mathrm{~m}^{-2}$, indicating low sublimation rates as confirmed by the ablation measurements. Conduction between the subsurface and the surface, $Q_{c}$, generally provides energy to the surface, $<+15 \mathrm{~W} \mathrm{~m}^{-2}$, but during warm drainage events, it is an energy sink.

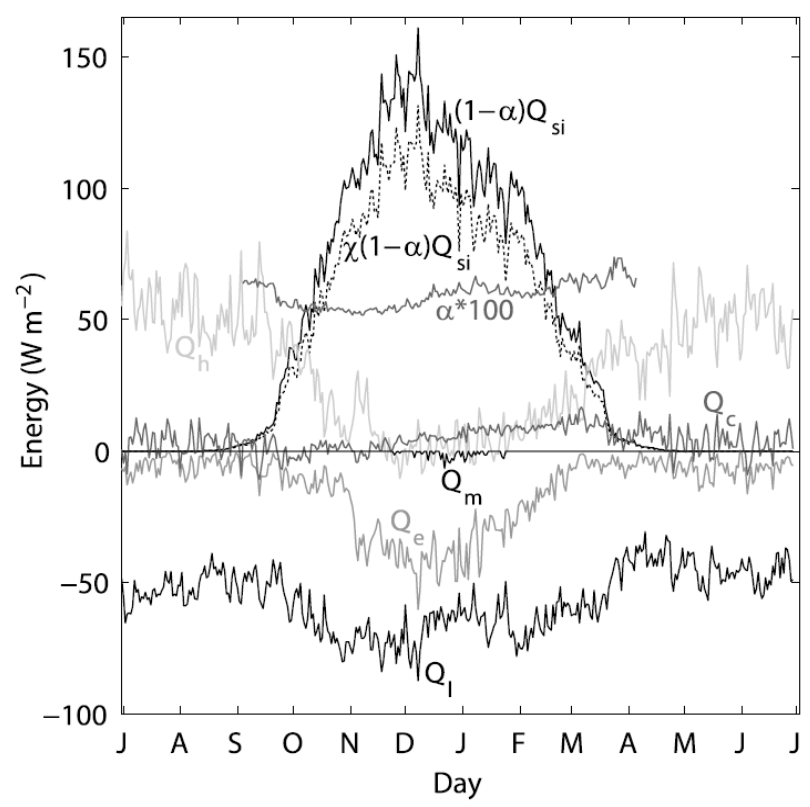

Figure 4.7: Average daily energy balance components for the 11 model years (July 1995-June 2006). 
During austral summer (October-March), net shortwave radiation is the dominant source of energy to the ice, up to $\sim+140 \mathrm{~W} \mathrm{~m}^{-2}$, as expected. Its temporal distribution shows the expected bell shape curve, peaking at solstice, but with a pronounced drop in midsummer due to an increase in ice albedo. Field observations indicate that the albedo increase is due to a noticeable brightening of the ice from blue-grey to white. This increase does not occur in all years. $Q_{l}$ becomes slightly more negative compared to winter, $\sim-70 \mathrm{~W} \mathrm{~m}^{-2}$, and $Q_{h}$ is small, $<\sim+20 \mathrm{~W} \mathrm{~m}^{-2}$, and generally remains positive. $Q_{e}$ approaches $\sim-50 \mathrm{~W} \mathrm{~m}^{-2}$ during midsummer as sublimation rates increase almost an order of magnitude from winter rates, becoming almost as large an energy loss as $Q_{l}$. $Q_{c}$ increases steadily from near zero at the start of summer to a peak of $\sim+15 \mathrm{~W} \mathrm{~m}^{-2}$ in late summer and represents subsurface heating by solar radiation in the top $50 \mathrm{~cm}$ of the ice. Ice temperatures in the upper $50 \mathrm{~cm}$ typically range from -50 to $-20^{\circ} \mathrm{C}$ in winter, with brief warmer periods caused by drainage events. In summer, ice temperatures are less variable, typically between -5 and $0^{\circ} \mathrm{C}$, because air temperature is less variable and heat stored in the ice from solar radiation helps to buffer against surface losses. Melting occurs infrequently and is a minor component of the energy balance, $>\sim-5 \mathrm{~W} \mathrm{~m}^{-2}$.

\subsubsection{Ablation and Surface Melt}

Ablation during the $\sim 10$ month winter varies between 7 and $13 \mathrm{~cm}$ w.e., while ablation during the $\sim 2$ month summer varies between 4 and $10 \mathrm{~cm}$ w.e., with one summer (2001-2002) reaching $21 \mathrm{~cm}$ w.e. On average, the mid-November to late-January summer period accounts for nearly $50 \%$ of annual ablation. For the 2.5 years over which continuous surface elevation change was measured, both the measurements and modeling 
indicate that a distinct summer season lasts from November through January (Figure 5).

The largest average monthly ablation rate occurs in December $\left(1.6 \mathrm{~mm}\right.$ w.e. day $\left.{ }^{-1}\right)$. The winter season from late February through October is characterized by low ablation rates $\left(0.24 \mathrm{~mm}\right.$ w.e. day $\left.^{-1}\right)$ and high month-to-month variability. Winter drainage events play an important role in increasing sublimation; causing $50 \%$ of the sublimation during MayAugust to occur on $10 \%$ of the days.

Of the 11 years modeled, surface melting occurred for a total of 42 days in nine of the eleven years, yielding an average daily rate of $0.4 \mathrm{~cm} \mathrm{w}$.e. and average annual rate of $1.7 \mathrm{~cm}$ w.e. (Table 4.1). The melt events occurred between November 26 and January 24. No temporal pattern exists for the modeled melt events, except that events in early/late summer tended to be smaller. Even during the 'flood year' (2001-2002) (Foreman et al. 2004, Doran et al. 2008) when air temperatures at Taylor Glacier were above freezing for about three weeks, sublimation accounted for the majority of summer ablation on Taylor Glacier.

Modeled melt events occurred on warm $\left(-2.7\right.$ to $\left.+3.4^{\circ} \mathrm{C}\right)$ days with low wind speeds $\left(\right.$ mean $\left.=3.6 \mathrm{~m} \mathrm{~s}^{-1}\right)$ and moderate to high incoming solar radiation $(190$ to $387 \mathrm{~W}$ $\mathrm{m}^{-2}$ ). Twenty melt days (48\%) occurred when daily air temperatures were below freezing. In contrast, no melt occurred on 48 of 67 days (72\%) with air temperatures above freezing. Most warm days are associated with drainage winds resulting in high latent heat fluxes that suppress melt. Because average daily temperature was rarely warmer than $2^{\circ} \mathrm{C}$, low wind speed seems to be critical for surface melt; 32 of $42(76 \%)$ melt days occurred during winds $<4.0 \mathrm{~m} \mathrm{~s}^{-1}$. Six of the melt days (14\%) seem to result 
from 'radiation paradox' conditions (Wendler 1986) when cloud cover results in a gain in longwave radiation that more than compensates for the reduction in shortwave radiation.

On days with melt, the average latent and sensible heat flux have smaller magnitudes than for the summer as a whole, whereas net radiation is much larger (Table 4.2).

Table 4.1: Summary of surface and subsurface melt for all melt seasons.

\begin{tabular}{|c|c|c|c|c|c|c|c|c|c|}
\hline \multirow[t]{2}{*}{ Season } & \multicolumn{2}{|c|}{ Surface Melt } & \multicolumn{3}{|c|}{ Subsurface Melt } & \multicolumn{4}{|c|}{ Dec.-Jan. Avg. Met. Data } \\
\hline & $\begin{array}{l}\text { Depth } \\
\text { (cm } \\
\text { w.e.) }\end{array}$ & $\begin{array}{l}\text { \# of } \\
\text { days }\end{array}$ & $\begin{array}{l}\text { Max. } \\
\text { Water } \\
\text { Column } \\
\text { Depth } \\
\text { (cm) } \\
\end{array}$ & $\begin{array}{l}\text { Depth } x \\
\text { Duration } \\
\text { (cm*days) }\end{array}$ & $\begin{array}{l}\text { \# of } \\
\text { days }\end{array}$ & \begin{tabular}{|l}
$\mathbf{T}$ \\
$\left({ }^{\circ} \mathbf{C}\right)$
\end{tabular} & $\begin{array}{l}\mathbf{Q}_{\mathrm{si}} \\
\left(\mathrm{W} \mathrm{m}^{-2}\right)\end{array}$ & $\begin{array}{l}\text { RH } \\
(\%)\end{array}$ & $\begin{array}{l}\text { Wind } \\
\left(\mathrm{m} \mathrm{s}^{-1}\right)\end{array}$ \\
\hline 1995-1996 & 0.9 & 2 & 0.02 & 0.04 & 2 & -2.5 & 285.9 & 60.5 & 4.3 \\
\hline 1996-1997 & 0.0 & 0 & 0.05 & 0.07 & 3 & -2.6 & 266.6 & 58.6 & 4.1 \\
\hline 1997-1998 & 2.2 & 5 & 0.09 & 0.19 & 4 & -4.3 & 277.4 & 67.7 & 4.1 \\
\hline 1998-1999 & 0.0 & 1 & 0.04 & 0.08 & 2 & -2.7 & 292.5 & 56.0 & 4.7 \\
\hline $1999-2000$ & 0.0 & 0 & 0.01 & 0.02 & 2 & -3.4 & 296.4 & 53.5 & 4.3 \\
\hline $2000-2001$ & 0.2 & 1 & 0.00 & 0.00 & 0 & -4.5 & 307.1 & 63.8 & 4.5 \\
\hline $2001-2002$ & 5.3 & 13 & 1.65 & 34.44 & 39 & -1.6 & 299.2 & 55.4 & 5.2 \\
\hline $2002-2003$ & 2.4 & 5 & 0.35 & 2.97 & 19 & -3.3 & 287.3 & 66.7 & 4.3 \\
\hline 2003-2004 & 1.4 & 3 & 0.58 & 4.10 & 15 & -3.4 & 304.1 & 65.2 & 4.2 \\
\hline 2004-2005 & 2.6 & 7 & 0.15 & 0.89 & 16 & -2.5 & 273.9 & 63.8 & 4.0 \\
\hline $2005-2006$ & 3.3 & 5 & 0.41 & 3.67 & 29 & -2.6 & 294.5 & 62.7 & 4.2 \\
\hline $\mathrm{AVG}$ & 1.7 & 3.8 & 0.30 & 4.22 & 11.9 & -3.0 & 289.5 & 61.3 & 4.4 \\
\hline
\end{tabular}

Table 4.2: Average energy balance components for the complete year, summer (DecemberJanuary), days with surface melt, and days with positive subsurface melt flux. Positive values indicate transport towards the surface. Components in italics are not used in the surface energy balance, but are included for comparison to other studies.

\begin{tabular}{lllll}
\hline \hline & Annual & Summer & $\begin{array}{l}\text { Days with } \\
\text { melt }\end{array}$ & $\begin{array}{l}\text { Days with } \\
\text { positive } \\
\text { subsurf. flux }\end{array}$ \\
\hline Net shortwave $\left(\mathrm{W} \mathrm{m}^{-2}\right)$ & & & & 140.1 \\
Net shortwave-surface $\left(\mathrm{W} \mathrm{m}^{-2}\right)$ & 35.8 & 116.4 & 140.9 & 114.5 \\
Net shortwave-subsurface $\left(\mathrm{W} \mathrm{m}^{-2}\right)$ & 8.0 & 21.3 & 25.8 & 25.6 \\
Incoming longwave $\left(\mathrm{W} \mathrm{m}^{-2}\right)$ & 175.7 & 229.7 & 244.8 & 236.5 \\
Outgoing longwave $\left(\mathrm{W} \mathrm{m}^{-2}\right)$ & -232.3 & -295.4 & -309.3 & -307.9 \\
Net longwave $\left(\mathrm{W} \mathrm{m}^{-2}\right)$ & -56.6 & -65.7 & -64.5 & -71.4 \\
Net radiation $\left(\mathrm{W} \mathrm{m}^{-2}\right)$ & -12.8 & 50.7 & 76.4 & 68.7 \\
Net radiation-surface $\left(\mathrm{W} \mathrm{m}^{-2}\right)$ & -20.8 & 29.4 & 50.6 & 43.1 \\
Sensible heat $\left(\mathrm{W} \mathrm{m}^{-2}\right)$ & 31.5 & 2.6 & 1.8 & 5.2 \\
Latent heat $\left(\mathrm{W} \mathrm{m} \mathrm{m}^{-2}\right)$ & -14.8 & -37.3 & -36.4 & -44.7 \\
Turbulent heat $\left(\mathrm{W} \mathrm{m}^{-2}\right)$ & 16.7 & -34.7 & -34.6 & -39.5 \\
Conduction $\left(\mathrm{W} \mathrm{m}^{-2}\right)$ & 4.2 & 6.3 & 0 & 3.7 \\
Melt $\left(\mathrm{W} \mathrm{m} \mathrm{m}^{-2}\right)$ & -0.2 & -1.0 & -16.8 & -7.3 \\
\hline
\end{tabular}




\subsubsection{Subsurface Melt}

According to the model, subsurface melting occurred in ten of eleven summers, often without surface melt, and occurred at depths of $0-50 \mathrm{~cm}$. During predicted surface melt periods, subsurface melt was present $79 \%$ of the time, and less ice melted in the subsurface than at the surface. Overall, subsurface melt was present about three times more often than surface melt (Table 4.1), and the subsurface was actively melting (positive subsurface melt flux) twice as often as the surface. During the warmest summer, 2001-2002, subsurface melt was modeled continuously at depths $>30 \mathrm{~cm}$ for nearly six weeks and the partially melted layer spanned $50 \mathrm{~cm}$ in thickness. However, even in the warmest summer, subsurface melt never exceeded $8 \%$ by mass (Figure 4.8 ). Subsurface melt was predicted to be present over a wide range of conditions - at air temperatures as low as $\sim-8^{\circ} \mathrm{C}$ and wind speeds as high as $15 \mathrm{~m} \mathrm{~s}^{-1}$. Total subsurface water expressed as a column of water varied dramatically between summers (Table 4.2); five summers exceed $0.1 \mathrm{~cm}$ and in the warmest summer (2001-2002) the maximum value is $1.6 \mathrm{~cm}$ (Figure 4.9).

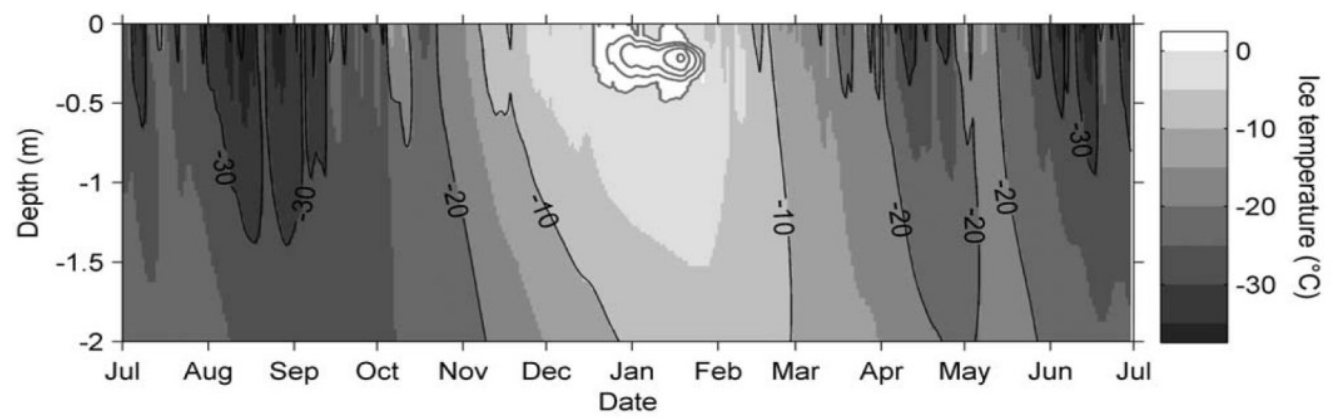

Figure 4.8: Ice temperature and meltwater fraction (2\% water fraction contours in gray) for 2001-2002. 


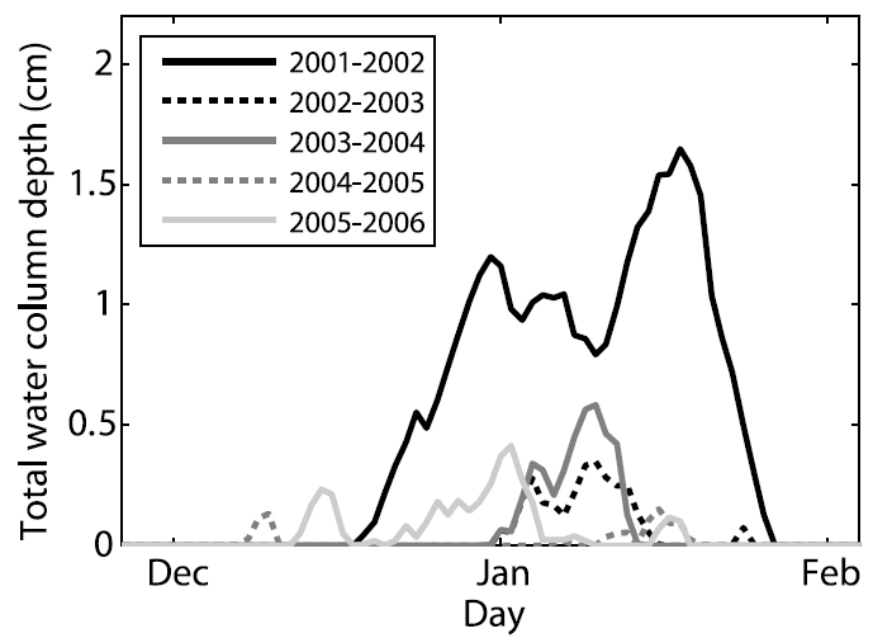

Figure 4.9: Total water column depth for summers with a maximum total water column depth greater than $0.1 \mathrm{~cm}$.

We have yet to deploy a practical method for systematically observing subsurface melt, but the good match between measured and modeled ice temperatures provides some confidence to my calculations of subsurface melt. Additionally, the modeled subsurface melt is consistent with our anecdotal observations that subsurface heating is not particularly important for melt within the white, bubbly ice of Dry Valley glaciers. We have looked for subsurface melt on Taylor Glacier on days when we observed partial melting across the glacier surface. No subsurface melt was observed during repeated drilling of holes to $50 \mathrm{~cm}$ depth between the meteorological station and the terminus, except in cryoconite holes or debris-rich ice. However, small fractions of partial melt along grain boundaries may be undetectable during drilling, so the modeled maximum values of subsurface melt seem reasonable based on our qualitative observations. In comparison, substantial liquid water has been observed in cryoconite holes (not modeled) when the surrounding glacier surface and subsurface appear dry (Fountain et al. 2004b). 


\subsection{Discussion}

\subsubsection{Energy Balance}

Within Taylor Valley, and the Dry Valleys in general, ablation is quite variable at many spatial scales. On decimeter scales, ablation varies due to albedo variations imposed by patches of snow and sediment. On scales of $\sim 10 \mathrm{~m}$, ablation changes dramatically due to topographic roughness that generates microclimates, most important of which is reduced wind speed (Lewis et al. 1999, Johnston et al. 2005). Under these conditions, the energy balance shifts to favor melting over sublimation due to the suppression of the heat losses to the turbulent fluxes, anecdotally observed since the early explorers (Taylor 1916). Therefore, my discussion here applies to the broad expanse of smooth and nearly level ice of Taylor Glacier and not to the interior of the deeply incised channels farther down glacier, the occasional hollows found on the glacier surface, or the terminal cliffs.

Over the entire year, solar radiation $\left(+44 \mathrm{~W} \mathrm{~m}^{-2}\right)$ and sensible heat $\left(+32 \mathrm{~W} \mathrm{~m}^{-2}\right)$ provide most energy to the glacier, $55 \%$ and $40 \%$, respectively, while most energy is lost to longwave radiation $\left(-57 \mathrm{~W} \mathrm{~m}^{-2}\right)$ and latent heat $\left(-15 \mathrm{~W} \mathrm{~m}^{-2}\right), 79 \%$ and $21 \%$, respectively (Table 4.2). These annual values differ somewhat from other Antarctic sites where energy balance modeling has also included internal heating by transmission of solar radiation within the glacier ice. For blue ice at Svea, Dronning Maud Land, Bintanja et al. (1997) found similar radiation magnitudes, but the turbulent fluxes at Taylor Glacier are each three times larger in magnitude, possibly due to larger surface roughness. For blue ice at Jutulgryta, Dronning Maud Land, Liston et al. (1999) report 
similar magnitudes of shortwave radiation and latent heat, but with one-third the losses to longwave radiation and a slightly negative sensible heat flux. All of the terms of the annual energy balance of Antarctic snow have the same sign as at Taylor Glacier, but generally have much smaller magnitude (e.g. Liston et al. 1999, Reijmer et al. 1999).

The summer (defined here as December-January) energy balance (Table 4.2) is similar to other glaciers in Taylor Valley (Lewis et al. 1998, Johnston et al. 2005) and at blue ice areas (Wendler et al. 1988, Bintanja and van den Broeke 1995b), but latent heat loss is much larger at Taylor Glacier than the other sites. The Taylor Glacier surface is generally cooler than the air (positive sensible heat flux), despite the subsurface heating of the ice. This contrasts with the blue ice at Svea, but is similar to the snow (Bintanja and van den Broeke 1995b). The average summer conductive flux at Taylor Glacier (+6 $\left.\mathrm{W} \mathrm{m}^{-2}\right)$ is greater than that for snow $\left(+5 \mathrm{~W} \mathrm{~m}^{-2}\right)$ but smaller than that for blue ice at Svea $\left(+19 \mathrm{~W} \mathrm{~m}^{-2}\right)$ (Bintanja and van den Broeke 1995b), suggesting subsurface scattering of solar radiation on Taylor Glacier ice is between that for blue ice and snow. Melt is less than $1 \%$ of the energy lost, and the conditions favorable for melt on Taylor Glacier (large radiation flux, smaller turbulent fluxes, Table 4.2) mirror conditions in the microclimate of basins and channels on MDV glaciers that generate enhanced melt (Chinn 1987, Lewis et al. 1999, Johnston et al. 2005). Interestingly, the energy balance of the tropical Kibo Northern Ice Field on Mount Kilimanjaro, 5794 m a.s.l. (Mölg and Hardy 2004), is a close analog to the Taylor Glacier summer energy balance. During a 7-month period of low snow cover at Kibo, all of the energy balance terms are of same sign as and similar magnitude to the summer energy balance at Taylor Glacier, but with more melt energy at 
Kilimanjaro, $-16 \mathrm{~W} \mathrm{~m}^{-2}$ versus $-1 \mathrm{~W} \mathrm{~m}^{-2}$. The ice surface roughness element shape of the glaciers is also similar (Mölg and Hardy 2004), as well as the morphology, with near-flat horizontal glacier surfaces and vertical ice cliffs forming the glacier margins.

The energy balance for days that the model calculates surface melt (Table 4.2) is similar to the summer (December-January) average, except with significantly greater $(+21 \%)$ net shortwave radiation and a relatively large fraction of the energy lost due to melting ( $14 \%$ on melt days, $1 \%$ for summer average). The increase in average solar radiation absorbed at the surface on melt days $\left(20 \mathrm{~W} \mathrm{~m}^{-2}\right)$ is nearly balanced by the increase in energy lost to melting $\left(16 \mathrm{~W} \mathrm{~m}^{-2}\right)$. This suggests that solar radiation drives melt, provided the ice surface reaches the melting temperature. A $10 \%$ increase in net solar radiation (either by decreased cloudiness or decreased albedo) under these conditions could approximately double the quantity of melt. Similarly, a $10 \%$ reduction in the turbulent fluxes on days with melt could increase the melt by $20 \%$. While the sensitivity of the energy balance is not as simple as this, this demonstrates how Taylor Glacier only marginally crosses the threshold of melt in summer, and modest increases of energy to the surface could increase melt substantially. As expected, days on which the subsurface was actively melting (positive subsurface melt flux) were characterized by high absorbed solar radiation and slightly larger turbulent fluxes than on days with surface melt (Table 4.2).

The momentum surface roughness determined by calibration of the model ( 2.5 $\mathrm{mm}$ ) is two orders of magnitude larger than that estimated for blue ice by measured wind speed profiles $(0.003 \mathrm{~mm})$ (Bintanja and van den Broeke 1995a). Our calibration 
roughness value is consistent with occasional melting that roughens the ice in ways that are not aerodynamically efficient (Bintanja 1999). Blue ice, as defined by Bintanja (1999), is not influenced by melt and may be the smoothest permanent, natural surface. Based on the summary of measured aerodynamic roughness lengths compiled by Brock et al. (2006), the calibrated value at Taylor Glacier is greater than Antarctic blue ice and Arctic 'smooth' ice $(0.007-0.17 \mathrm{~mm})$, but smaller than typical Arctic ice subject to melting $(0.6-6.7 \mathrm{~mm})$. Therefore, our calibrated roughness is consistent with occasionally melting glacier ice. However, the roughness on Taylor and other glaciers in the Dry Valleys is probably not constant due to the roughness elements that begin to form by the occasional melt events being erased by $\sim 10 \mathrm{~cm}$ w.e. of sublimation in winter. If this effect is indeed significant, our assumption of a constant surface roughness may lead to errors in estimated turbulent fluxes and ablation.

\subsubsection{Ablation and Surface Melt}

The measurements and modeling of annual ablation over the 11-year period average $17.7 \mathrm{~cm} \mathrm{a}^{-1}$ w.e. and $18.4 \mathrm{~cm} \mathrm{a}^{-1}$ w.e., respectively. In comparison, coastal blue ice at Reeves Glacier, Victoria Land, $26 \mathrm{~cm} \mathrm{a}^{-1}$ (Stearns and Weidner 1993), and Sør Rondane Mountains, Dronning Maud Land, 20-28 $\mathrm{cm} \mathrm{a}^{-1}$ w.e. (Takahashi et al. 1992), are similar. Most other blue ice regions have lower ablation rates, 2-15 $\mathrm{cm} \mathrm{a}^{-1}$ w.e. (Bintanja 1999, Genthon et al. 2007), as does Antarctic snow (1-10 $\mathrm{cm} \mathrm{a}^{-1}$ w.e.) (Stearns and Weidner 1993). Much of this variation is due to local climate conditions and ice albedo. About $9 \%$ of ablation on Taylor Glacier is caused by melt, a fraction intermediate amongst blue ice areas in Antarctica. Melting accounts for 15-30\% of ablation elsewhere 
in the Dry Valleys (Fountain et al. 1998), and may account for up to 39\% of ablation on coastal blue ice in Terre Adélie (Genthon et al. 2007). True blue ice areas, as defined by Bintanja (1999), experience no melt and are typically found at higher and colder elevations on the ice sheets.

The seasonal distribution of sublimation at Taylor Glacier is similar to other Antarctic ice locations. At Lake Hoare, $23 \mathrm{~km}$ away but still in Taylor Valley, $73 \%$ of the $35 \mathrm{~cm}$ of annual sublimation occurs during the October 15-April 1 summer period (Clow et al. 1988), at Taylor Glacier 75\%. At Svea, Dronning Maud Land (1170 m a.s.1.), $71 \%$ of the $14 \mathrm{~cm}$ of annual sublimation occurred during the summer (NovemberFebruary) (Bintanja and Reijmer 2001), similar to 69\% at Taylor Glacier for the same period.

Surface melt was estimated to occur on only 42 days over the 11 year period of study, supporting anecdotal observations of the paucity of melt and the relatively low runoff from Taylor Glacier, despite being the largest glacier in the valley. In comparison to Canada Glacier, $24 \mathrm{~km}$ down valley towards the coast, during the 1995-1996 summer Taylor Glacier had $0.87 \mathrm{~cm}$ w.e. of melt compared to Canada, which had $4.46 \mathrm{~cm}$ w.e. (Lewis et al. 1998). Air temperatures between the sites were similar and averaged around $-2.5^{\circ} \mathrm{C}$, and the primary difference was wind speed $\left(4.3 \mathrm{~m} \mathrm{~s}^{-1}\right.$ at Taylor vs. $2.9 \mathrm{~m} \mathrm{~s}^{-1}$ at Canada) that caused the latent heat flux at Taylor Glacier $\left(-37 \mathrm{~W} \mathrm{~m}^{-2}\right)$ to be $17 \mathrm{~W} \mathrm{~m}^{-2}$ larger than at Canada Glacier $\left(-20 \mathrm{~W} \mathrm{~m}^{-2}\right)$. Summer drainage winds occur twice as often at Taylor Glacier as Canada Glacier (Nylen et al. 2004). Also affecting the latent flux, the surface roughness used by Lewis et al. (1998), $1 \times 10^{-4} \mathrm{~m}$, is the same order of 
magnitude but half as small as I use here at Taylor. This rough comparison of different modeling results suggests that a reduction in wind speed at Taylor Glacier comparable to what is experienced elsewhere in the valley could increase melt fivefold. The sensitivity of melt on Taylor Glacier to wind speed may not be as simple as this, as a reduction in drainage wind events would also reduce the associated higher temperatures, but this example demonstrates how small changes in the meteorological conditions on MDV glaciers can cause large changes in melt and the resulting streamflow.

My results contrast strongly with Johnston et al. (2005) who calculated $3.4 \mathrm{~cm}$ w.e. of melt at Taylor Glacier for the 1994-1995 summer, an extremely large value compared to our estimates over the 11 years, and contrasts with the relatively low melt summer that year at Canada Glacier (Lewis et al. 1998), despite similar air temperatures. I suspect the problem may be the transfer coefficient method Johnston et al. (2005) used for calculating turbulent fluxes, which appears to underestimate latent heat flux. Johnston et al. (2005) estimated the summer average latent heat at $-22 \mathrm{~W} \mathrm{~m}^{-2}$, the same value estimated for Canada Glacier (Lewis et al. 1998) despite wind speeds $40 \%$ higher at Taylor Glacier. While the transfer coefficient method may provide satisfactory results for relative melt rates between the flat surface and incised channels, the purpose of Johnston's study, the approach here provides more robust estimates of sublimation and melt given the use of 22 seasonal measurements for model calibration.

The ability of the model to reasonably predict surface melt is important for its application to predict stream flow. Using daily time steps, however, may underestimate surface melt. I compared daily and hourly time step models for the 2005-2006 summer, 
and the daily model predicts $3.3 \mathrm{~cm}$ w.e. surface melt ( $28 \%$ of summer ablation) for 5 days when melt occurred, while the hourly model predicts $5.7 \mathrm{~cm}$ w.e. ( $48 \%$ of ablation) occurring over 29 days in which melt occurred. Expressing the results differently, the hourly model produces $40 \%$ of the seasonal surface melt in the same five days that the daily model predicts $100 \%$ of the seasonal surface melt, suggesting that the daily model is capturing only the most significant surface melt days. The reason may be that the summer energy balance is typically close to producing melt, and transient excursions that momentarily produce melt are suppressed within the daily average values of the meteorological conditions. However, such transient conditions have been observed with ice melt being generated for an hour or so. The melt occurs in patches on the glacier surface and these thin pools do not flow significant distances $(\sim<10 \mathrm{~m})$ before refreezing (Figure 4.2). In some cases, it was unclear whether the water froze due to its migration into a less favorable microclimate or temporal meteorological conditions changed. It may be that only the most significant melt days constitute runoff, whereas the smaller transient melt events indicated by the hourly model do not.

\subsubsection{Subsurface melt}

Comparisons between subsurface melt at Taylor Glacier and other locations are more difficult because few studies calculate subsurface melt and methods vary. Bintanja and van den Broeke (1995b) did not observe or model subsurface melting at the blue ice region of Svea, but did model "occasional" subsurface temperatures of $0^{\circ} \mathrm{C}$. Subsurface melting has been observed at depths up to $1 \mathrm{~m}$ in the blue ice of Jutulgryta, Dronning Maud Land (Winther et al. 1996), and Liston et al. (1999) calculated that melting may 
occur up to $1.7 \mathrm{~m}$ deep, with a maximum melt fraction of $25 \%$. Our calculations for Taylor Glacier show melting occurs at depths half that as Jutulgryta and much lower melt fractions, $0.5 \mathrm{~m}$ and $<10 \%$ respectively. Instead, modeled subsurface melt depth and water fraction at Taylor Glacier are more similar to that calculated for snow at Jutulgryta, $0.75 \mathrm{~m}$ and $4 \%$, respectively (Liston et al. 1999). Indeed, the grain radius I employ is smaller than Liston et al. (1999) used for the snow, suggesting that the scattering properties of ice at Taylor Glacier (grain radius, density, and void size) are more similar to that of snow than blue ice. Exceptions on Taylor Glacier include cryoconite holes and refrozen fractures, which have a 20\% lower albedo (Lewis 2001) and less bubbly ice, more similar to blue ice. Indeed, surface melt in the holes and refrozen fractures has been commonly observed (Fountain et al. 2004b). It may be that subsurface melt is only common where debris melts into the ice (forming cryoconite holes). This contrasts with the results of Liston et al. (1999) who found widespread subsurface melting.

\subsection{Conclusions}

The energy balance model based on Liston et al. (1999) performed well in estimating both the ablation and ice temperatures over the 11 year record on Taylor Glacier. The inclusion of solar-radiation transmission into the ice significantly improves model performance over a 'traditional' energy balance approach. The daily melt model captures the large melt events but in comparison to the hourly model it misses melt events of shorter time scales. Because the conditions on the glacier surface during summer are on the threshold of melting, using daily average meteorological variables 
essentially masks the high frequency transient conditions that may produce melt. However, it is unclear if these transient events produce runoff from regions like that around the meteorological station on Taylor Glacier because field observations suggest that they flow for short distances before refreezing on the surface.

According to the model, while daily surface melt is usually accompanied by subsurface melt, the reverse is not true, and little correspondence exists from season to season between the magnitudes of the two. Subsurface melt is generally small (never exceeding $2 \mathrm{~cm}$ w.e.) and is completely absent in some years. However, the calibrated daily model required a surface layer thickness of $13 \mathrm{~cm}$, and any melt modeled for that layer is assumed to be surface melt. Therefore, the daily model is unable to provide information on subsurface melt for that depth range, which is a limitation. Both the energy balance and magnitude of subsurface melting indicate that Taylor Glacier is composed of 'white' ice, intermediate in optical properties between snow and blue ice.

Results confirm previous studies that Taylor and other glaciers in the Dry Valleys are dominated by sublimation in all seasons and surface melt is a significant contribution only during some summers. Surface melt does not typically occur at our study site on Taylor Glacier. Its occurrence requires low wind speeds, and air temperatures near freezing. Positive air temperatures are neither necessary for nor a reliable indicator of surface melt. The windy conditions at Taylor Glacier suppress melt while it occurs elsewhere in the MDV where winds are calmer. I conclude that the energy balance in the MDV environment is on the threshold of generating substantial melt. Small changes in the balance can produce significant increases in melt on the surface and in the subsurface. 
In particular, deduction of wind speed and increases in absorbed solar radiation create favorable conditions for melt. 


\section{Chapter 5: Hourly Model Calibration: Importance of Internal Melting on Dry Valley Glaciers}

\subsection{Introduction and Background}

In the previous chapter, I found that both surface and subsurface melt predicted by the daily time step energy balance model are small on Taylor Glacier. However, the daily time step model was unable to resolve short duration melt events on the surface and the details of the melt process in the upper $13 \mathrm{~cm}$. Additionally, comparison to other studies indicated that other locations in Taylor Valley have substantially more melt. In this chapter I use the model with an hourly time step to investigate subsurface melting in detail at multiple locations within Taylor Valley. I also consider the development of a near-surface weathering crust through drainage of subsurface melt, which is typically observed on melting glacier surfaces around the world.

Polycrystalline ice near $0^{\circ} \mathrm{C}$ contains liquid water along grain boundaries (Raymond and Harrison 1975). These veins at the intersection of three or more crystals have a diameter on the order of $0.01 \mathrm{~mm}$ (Raymond and Harrison 1975), but can grow to a few tenths of a mm over time, a process termed as 'rotting' (Nye 1991). Intergranular water flux is assumed to be very small $\left(<0.1 \mathrm{~m} \mathrm{a}^{-1}\right)$, particularly when bubbles are present that can block the flow through veins (Raymond and Harrison 1975). However, when ice near the surface has been influenced to a high degree by surface and internal melting, a weakened weathered layer some $\mathrm{cm}$ to tens of $\mathrm{cm}$ thick is formed with reduced 
density and stored meltwater (Müller and Keeler 1969, Larson 1977, Braithwaite and Olesen 1990, Hubbard and Glasser 2005).

The reduction of ice density in a weathered crust can impact measurements of mass balance of bare ice surfaces (Müller and Keeler 1969, Braithwaite and Olesen 1990). The glaciological method for estimating specific mass balance commonly uses the difference in the glacier surface level between two dates, measured on a stake drilled into the glacier (Østrem and Brugman 1991, Kaser et al. 2002). To obtain changes in mass, the difference in level is multiplied by the near-surface density, which is typically assumed constant at $900 \mathrm{~kg} \mathrm{~m}^{-3}$ (Kaser et al. 2002). Using this method, measurements of surface lowering over periods of time during which a weathering crust develops will underestimate actual ablation because some mass has been lost below the ice surface (Müller and Keeler 1969). Similarly, surface lowering will overestimate actual ablation during time periods when the weathering crust is reduced or eliminated, because the nearsurface ice has a reduced density.

These density variations are generally ignored for all but short-term periods since their effects are typically small relative to ablation at the surface on most glaciers (Müller and Keeler 1969, Braithwaite and Olesen 1990). However, these density variations may be significant on Dry Valley glaciers, where summer ablation is small $(<15 \mathrm{~cm}$ weq, Fountain et al. 2006). Müller and Keeler (1969) estimated the melting and draining of $1.3 \mathrm{~cm}$ water equivalent (weq) of subsurface ice over 12 hours in the upper $10 \mathrm{~cm}$ of White Glacier in the Canadian Arctic. The drainage of this amount of subsurface melt over an entire summer on Taylor Glacier would create an error of $\sim 10 \%$ in ablation 
measured by the glaciological mass balance method assuming a constant ice density. Localized subsurface melt is observed in cryoconite holes and the blue ice of refrozen fractures on Dry Valley glaciers (Fountain et al. 2004b), and modeling predicts subsurface melt in the bubbly white ice that makes up the bulk of the glacier surfaces (Hoffman et al. 2008).

Internal ablation will only occur if melt is able to drain out of the ice; if it refreezes in place, no mass loss occurs (Figure 5.1). Because ice melts preferentially along grain boundaries, a drainage network of channels and sheets should develop with minimal internal melt. Once channels become large enough to overcome blocking bubbles and capillary tension, water can drain. Wakahama et al. (1973) observed a network of tubes 1-1.5 $\mathrm{mm}$ in diameter transporting water and capillary tubes less than $0.1 \mathrm{~mm}$ in diameter along grain intersections of weathered ice on Mendenhall Glacier, Alaska. A water table was present at about $40 \mathrm{~cm}$ depth that exhibited diurnal variations, presumably due to variations in melting. They measured hydraulic conductivity of weathered glacier ice to be $10^{-8}$ to $10^{-5} \mathrm{~m} \mathrm{~s}^{-1}$, comparable to silt or sand. Similarly, the hydraulic conductivity of highly weathered stagnant ice is estimated to be $4 \times 10^{-5} \mathrm{~m} \mathrm{~s}^{-1}$ (Larson 1978), and for seawater through brine channels in sea ice is estimated to be $10^{-8}$ to $10^{-4} \mathrm{~m} \mathrm{~s}^{-1}$ (Reeburgh 1984).

The near surface drainage system within the weathering crust is complex and spatially and temporally variable. Factors affecting the hydraulic head in the drainage network include proximity to a subsurface channel, surface slope, depth and degree of subsurface melt, and length of time that the passages remains interconnected. Ice 
affected by internal melting appears to act like an unconfined aquifer, with surface melt percolating down to the water table (Wakahama et al. 1973, Larson 1977). Though on temperature glaciers the water flux through the near-surface layer is negligible compared to that of supraglacial streams (Fountain and Walder 1998), near-surface drainage may be important on areas of Dry Valley glaciers lacking well-developed supraglacial streams. On Dry Valley glaciers, a near-surface drainage system has been observed in refrozen fractures that contain blue ice and melt preferentially (Fountain et al. 2004b). However, the spatial extent, temporal evolution, and connectivity within this system are unclear.

In this work I investigate internal melting on Dry Valley glaciers and assess its impact on mass balance. To estimate subsurface melting, I use the surface energy balance model described in Chapter 4 forced with fourteen years of hourly meteorological observations (Chapter 2). The model uses a one-dimensional heat transfer equation for calculating the heat flux into (or out of) the glacier that includes a source term for solar radiation absorbed beneath the surface. I tune the model to observations of ice temperature and surface ablation, which allows me to constrain the magnitudes of surface and subsurface melt. 


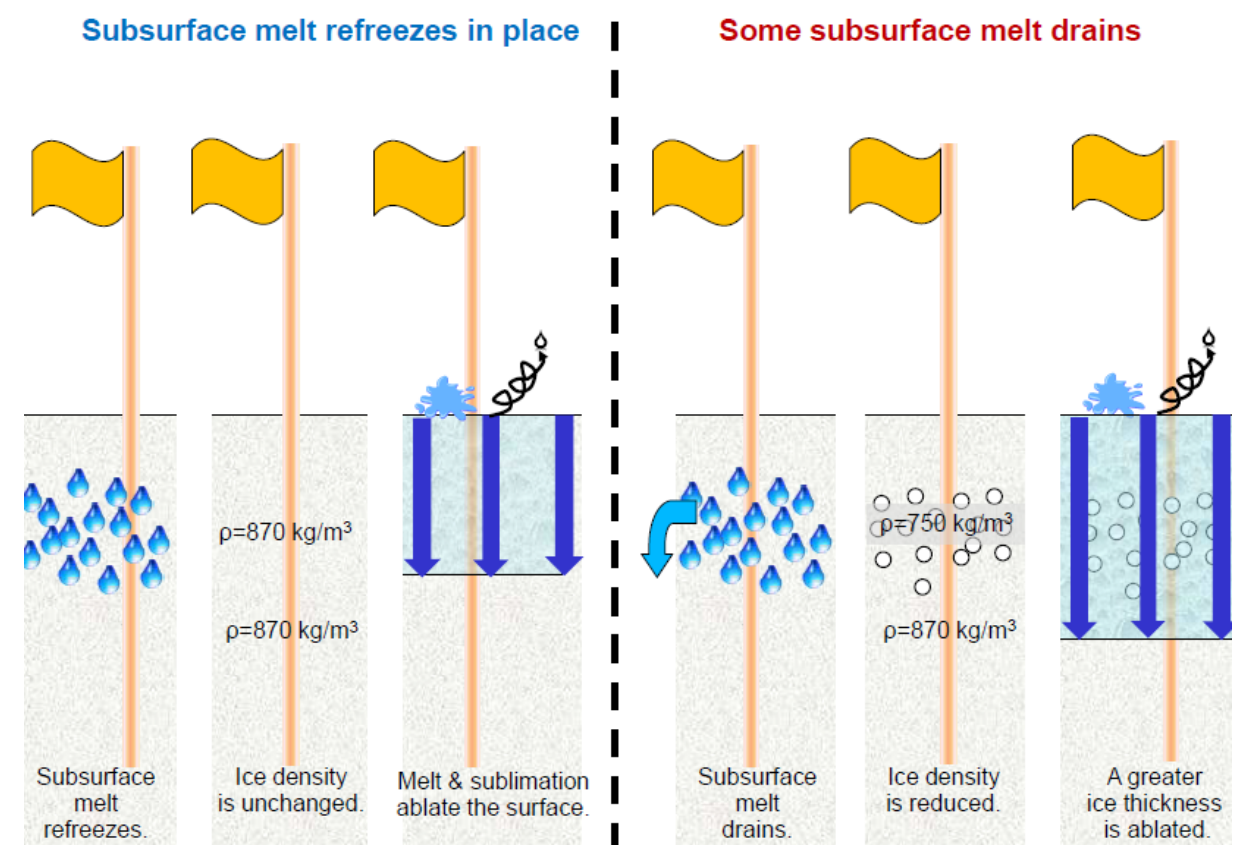

Figure 5.1: Schematic of how drainage of subsurface melt can reduce ice density and increase the thickness of ice subsequently ablated at the surface. The left panel shows the case of all subsurface melt refreezing in place, and the right panel shows the case of some subsurface melt draining. The pole and flag represent an ablation stake, and the arrows represent ablation at the surface due to sublimation and/or melt. Features are not to scale.

\subsection{Site Description}

Within Taylor Valley, the McMurdo Dry Valley Long Term Ecological Research project has maintained meteorological stations (Doran et al. 1995) and mass balance stake networks (Fountain et al. 2006) on four glaciers continuously since 1994 (Figure 2.2). I use each of these locations as a study site, using local meteorological, ablation, and ice temperatures at each site (Table 5.1). As a convention, I use abbreviations (Table 5.1) to refer to the study sites, and unabbreviated glacier names when referring to the glaciers generally. In order to consider the higher ablation environments that exist near the termini of Dry Valley glaciers, I include an additional site (TAR2) near the terminus of Taylor Glacier that experiences more melting than the other sites. This location was 
chosen because the consistently rare snowcover on Taylor Glacier meant that I could confidently apply timing of snowcover and albedo from TAR to TAR2. MicroMet output is used for meteorological forcing at TAR2 (Chapter 3).

All study sites have a similar mean annual air temperature, but mean summer temperature ranges from $-2^{\circ} \mathrm{C}$ at the low elevation TAR2 site to near $-5^{\circ} \mathrm{C}$ at $\mathrm{HOD}$ and $\mathrm{COH}$ (Table 5.1). The two Taylor Glacier locations are substantially windier than the other sites. HOD and $\mathrm{COH}$ are snow covered more than half of the time and have low ablation rates, but snow cover is rare at the other sites and ablation is higher. Most locations experience comparable amounts of mass loss during the two month long summer as the ten month long winter. The low elevation TAR2 site has higher mass loss than the other sites. The four sites located by meteorological stations are located on gently slopes, but TAR2 is in a region of well-developed surface channels with more than $20 \mathrm{~m}$ of local relief (Johnston et al. 2005).

Table 5.1: Summary of study sites. Climate and mass balance statistics are for the period December 2004 through January 2009. Summer is defined as December and January, and winter is the remainder of the year.

\begin{tabular}{|c|c|c|c|c|c|}
\hline Study site & TAR & TAR2 & CAA & HOD & COH \\
\hline Glacier & $\begin{array}{l}\text { Taylor } \\
\text { (met. station) }\end{array}$ & $\begin{array}{l}\text { Taylor } \\
\text { (terminus) }\end{array}$ & Canada & Howard & $\begin{array}{l}\text { Common- } \\
\text { wealth }\end{array}$ \\
\hline Distance from coast $(\mathrm{km})$ & 37 & 35 & 13 & 14 & 9 \\
\hline Elevation $(\mathrm{m})$ & 334 & 198 & 264 & 472 & 290 \\
\hline Mean annual air temperature $\left({ }^{\circ} \mathrm{C}\right)$ & -17.0 & -17.2 & -17.1 & -17.4 & -17.9 \\
\hline Mean summer air temperature $\left({ }^{\circ} \mathrm{C}\right)$ & -3.0 & -2.0 & -3.3 & -5.0 & -4.7 \\
\hline Mean annual wind speed $\left(\mathrm{m} \mathrm{s}^{-1}\right)$ & 5.2 & 4.4 & 3.2 & 3.1 & 3.9 \\
\hline Mean summer wind speed $\left(\mathrm{m} \mathrm{s}^{-1}\right)$ & 4.3 & 4.3 & 3.0 & 2.6 & 3.4 \\
\hline Snowcover frequency & $12 \%$ & $\mathrm{n} / \mathrm{a}$ & $24 \%$ & $67 \%$ & $70 \%$ \\
\hline Mean winter mass balance (cm weq) & -10.7 & -16.9 & -5.9 & -4.6 & -2.8 \\
\hline Mean summer mass balance ( $\mathrm{cm}$ weq) & -9.1 & -16.6 & -7.7 & -6.0 & -4.8 \\
\hline
\end{tabular}




\subsection{Model Description}

To investigate surface and subsurface melting, I apply the melt model described in Chapter 4 to the five study locations. I change the daily time step used in that study to an hourly time step forced by hourly averaged meteorological data measured locally at TAR, CAA, HOD, and $\mathrm{COH}$, and calculated using MicroMet for TAR2. I retain daily values of albedo.

Calculation of the turbulent fluxes has been modified from the previous model descriptions to use scalar roughness lengths for temperature and water vapor following the surface renewal theory of Andreas (1987), which should provide a more accurate estimate of the turbulent fluxes over rougher surfaces. In this theory, the bulk aerodynamic transfer coefficients for sensible and latent heat increase with the momentum surface roughness length, $\mathrm{z}_{0}$, and decrease with increasing wind speed. In an additional modification from the model described by Hoffman et al. (2008) (Chapter 4), the ice temperature profile is not recomputed when subsurface melt is calculated, because this procedure was found to violate conservation of energy.

\subsubsection{Treatment of Snow}

I apply a simple treatment of snow, because snowfall in Taylor Valley is generally infrequent (Fountain et al. 2010), and there are few data regarding snow duration and thickness on the glaciers for much of the period of record prior to the placement of sonic rangers at some sites in 2003 and 2004. Therefore I use the albedo threshold of 0.10 above the bare ice albedo identified in Chapter 2 to indicate the presence of snow in the model on each day. When albedo cannot be calculated because the sun is below the 
horizon ( April-September), snowcover is ignored. Snowfall in the Dry Valleys tends to remain on the ground longer during winter than during summer (Fountain et al. 2010), so ignoring snow in winter may be a limitation for applying the model during winter. When snow is present in the model, I ignore modeled ablation for the purposes of calculating ice ablation. However, I do not attempt to model snow ablation given the large uncertainties in snow depth and density, but instead rely on the albedo record to indicate when bare ice is once again exposed. Thus, the model does not allow for the possibility of snow melt, which is of minor importance. Most snow on the warmer and less windy valley floors sublimates prior to melting (Chinn 1981, Gooseff et al. 2003a), and because snow accumulation is observed to nearly eliminate runoff from the glaciers (Fountain et al. 1999b), snow is not expected to make a significant hydrologic contribution. Furthermore, some snow that accumulates on the glaciers may be removed from the glaciers by wind and deposited on the valley floor (Fountain et al. 2010), so that a proper treatment of snow ablation in the model would require accurate modeling of wind transport. Indeed, the sonic ranger record at TAR shows multiple instances of abrupt disappearance of all snow within a day, coinciding with high wind speed.

For simplicity, thermal and optical properties and surface roughness are left unchanged in the model when snow is present, but net solar radiation is reduced due to the increased albedo. Snow insulates the ice below from temperature changes at the surface, but will also reduce the solar radiation reaching the ice, so the effect of snowcover on subsurface ice temperatures depends on the relative magnitude of these processes. This simple treatment of snow should have little effect at Taylor where 
snowcover is infrequent (Table 5.1), but may cause significant errors at the other sites, particularly $\mathrm{COH}$ and $\mathrm{HOD}$, which are close to the equilibrium line of their respective glaciers. The effects of snowcover are explored more carefully in the Results section.

\subsubsection{Treatment of Drainage of Subsurface Melt}

The original model formulation assumes the water fraction within the subsurface ice to be in steady state - any water that drains out of a grid cell is replaced by water flowing in (Liston et al. 1999). In this application, I investigate drainage of subsurface melt by comparing two versions of the model: the "Refreezing Model" where all modeled subsurface melt in effect refreezes in place as described previously in Chapter 4 and the "Drainage Model" where a portion of the modeled subsurface melt is removed from the ice column. In the Drainage Model, any subsurface melt fraction that exceeds a 10\% threshold in each time step is assumed to drain and water fraction is set back to $10 \%$. However, I do not account for an air fraction within the grid cell, and therefore ice density does not change explicitly over time. This approach conserves energy by removing the heat stored in water from the model domain when drainage occurs, but does not conserve mass because the mass of any drained water is replaced with ice at $0^{\circ} \mathrm{C}$. Thus I employ a simple representation of subsurface drainage that avoids requiring the model state to dictate changes in the optical and thermal properties of ice, which is undesirable because errors in model state could trigger feedbacks that would lead to larger errors. I choose the fairly low threshold of $10 \%$ water fraction for drainage because of observations elsewhere that drainage tubes develop along grain boundaries - a connected drainage network develops at low porosity. Additionally, a fraction of water is 
held in capillary tension and is unable to drain. This irreducible water fraction has not been reported for weathered glacier ice, but varies from $5-15 \%$ for snow and is dependent on porosity (Coléou and Lesaffre 1998). In reality, the drainage of subsurface melt is likely to be slope dependent and dependent on the extent of cavity formation (from previous drainage). Lacking observations with which to quantify these effects, I impose a constant drainage threshold in the model. In the Drainage Model all drained water is assumed to become runoff. All surface melt is assumed to become runoff for both the Refreezing Model and the Drainage Model.

In order to use the Drainage Model to approximate the effect that drainage of subsurface melt has on density, and, in turn, ablation at the surface, I calculate the total mass lost through drainage at each depth at the end of each summer and adjust ice density accordingly. Then modeled summer ablation at the surface is adjusted to account for mass previously lost below the surface, which effectively increases the thickness of ice removed for the season. This allows me to compare values of modeled ablation (which are calculated by mass) with values of ablation measured with stakes (which are volume measurements converted to mass assuming a constant density). Again, this is a simple representation that ignores the lowering of the glacier surface into the ice column as ablation occurs, as well as the relative timing of ablation at the surface and weathering of the subsurface. However, I expect it to affect the qualitative performance of the model at predicting seasonal ablation and ice temperatures, allowing me to assess the importance of weathering on Dry Valley glaciers. 


\subsection{Model Calibration}

Within the model the effective ice grain radius, $r_{\text {eff }}$, the surface roughness length, $z_{0}$, and the solar radiation surface fraction (SRSF), $(\chi$ in Equation 10), are only known approximately (Table 5.2). The effective ice grain radius strongly affects the absorption of solar radiation beneath the surface and consequently, subsurface ice temperature and melt. The surface roughness length modifies the magnitude of the turbulent fluxes, and therefore sublimation. The SRSF partitions net solar radiation between the surface and subsurface, greatly affecting temperatures and melt at both the surface and subsurface. Both $r_{\text {eff }}$ and $z_{0}$ have physical significance and can be constrained to some degree by values from the literature for similar ice conditions. SRSF is a numerical consequence of discretizing the ice column, and there is less previous work to suggest a reasonable range of values. SRSF is a function of the effective grain radius and a specified surface layer thickness within which the solar radiation source term is eliminated.

Though none of these parameters can be easily or accurately measured, they each are a major control on processes affecting properties that are measured. Thus, measurements of ice temperature are used to constrain $r_{\text {eff }}$, and measurements of ablation are used to constrain $\mathrm{z}_{0}$ and SRSF. Additionally, I explore how proglacial streamflow measurements can provide additional information on these three parameters in Chapter 6 . These three parameters interact in such a way that a single simple solution is not attainable, but a range of possible values can be estimated. For example, a large ablation value may be fit by increasing $\mathrm{z}_{0}$ to achieve a high sublimation rate or by increasing SRSF to cause the model to generate higher melt rates. In such a case it may not be 
possible to determine true parameter values, but much information may be gained by eliminating a large range of unlikely parameter values.

To investigate the range of likely parameter values, I investigate each parameter in turn and explore effects on ice temperature and ablation, isolating the interactions of the remaining parameters where possible. Having constrained each parameter, I then estimate optimal parameter values by examining the entire parameter space for both the Refreezing and Drainage models. I begin with $\mathrm{r}_{\mathrm{eff}}$ because it is least affected by the other parameters. This is followed by $\mathrm{z}_{0}$ which can be constrained for winter conditions independently of the other parameters, but includes additional complexity for summer. Lastly I consider SRSF which is strongly influenced by the other two parameters, and lacking a simple physical significance is more difficult to constrain. This process uses output from $\sim 500$ simulations of each model at each of the five study locations for the period July 1995-January 2009. The quality of fit for both ice temperature and ablation is routinely assessed using the mean absolute error calculated as:

$$
M A E=\frac{1}{n} \sum_{i=1}^{n}\left|x_{o i}-x_{m i}\right|
$$

where $\mathrm{n}$ is the number of observations, and $\mathrm{x}_{\mathrm{oi}}$ and $\mathrm{x}_{\mathrm{mi}}$ are individual observations and modeled values, respectively, of ice temperature or ablation. The mean absolute error statistic was chosen over the more commonly used root mean square error, because the former is less sensitive to outliers. Since there is a relatively high degree of uncertainty in our observations, in particular with ablation (Chapter 2), I wish to minimize overfitting outliers which may be erroneous data. 
Table 5.2: Summary of model parameters used for calibration.

\begin{tabular}{llll}
\hline \hline Parameter & Name & $\begin{array}{l}\text { Primarily affects } \\
\text { mass loss by: }\end{array}$ & $\begin{array}{l}\text { Calibrated using } \\
\text { observations of: }\end{array}$ \\
\hline $\mathrm{r}_{\text {eff }}$ & $\begin{array}{l}\text { effective ice grain radius } \\
\mathrm{z}_{0}\end{array}$ & $\begin{array}{l}\text { subsurface melt } \\
\text { sublimation }\end{array}$ & $\begin{array}{l}\text { subsurface ice temperatures } \\
\text { ablation in winter and } \\
\text { early/late summer }\end{array}$ \\
$\mathrm{SRSF}$ & $\begin{array}{l}\text { solar radiation surface fraction } \\
\text { thickness of the surface layer } \\
\text { (used to calculate SRSF in }\end{array}$ & surface melt & ablation in summer \\
& $\begin{array}{l}\text { conjunction with } \mathrm{r}_{\mathrm{eff}} \text { ) } \\
\end{array}$ & & \\
\hline
\end{tabular}

\subsubsection{Effective Ice Grain Radius}

In conjunction with the ice density and albedo, the effective ice grain radius ( $\left.\mathrm{r}_{\mathrm{eff}}\right)$ determines the distribution of absorbed solar radiation with depth through the extinction coefficient (Brandt and Warren 1993). Density and albedo are well-constrained through direct measurements, but the appropriate value to use for the ice grain radius is uncertain. The effective ice grain radius is not in reference to the physical ice grain radius but represents the radius of spherical ice grains with equivalent optical properties, ignoring bubbles and impurities (Brandt and Warren 1993, Liston et al. 1999). Since Dry Valley glacier ice has high bubble content, $\mathrm{r}_{\mathrm{eff}}$ is likely to be substantially lower than the measured grain radius (Hoffman et al. 2008 / Chapter 4).

The Refreezing and Drainage models were run with 25 different values for $r_{\text {eff }}$ varying between 0.005 and $1.0 \mathrm{~mm}$. The effective ice grain radius is calibrated to summer ice temperatures measured by thermistors frozen within the ice for periods where the thermistor depth is well-known and the glacier surface is snow-free. A separate calculation of mean absolute error in hourly ice temperatures is made for each thermistor for each of the 39 time periods used. The average optimal $r_{\text {eff }}$ is about $0.1 \mathrm{~mm}$, and the range is 0.01 to $0.2 \mathrm{~mm}$, with slightly smaller values for TAR and CAA and slightly 
larger values for $\mathrm{HOD}$ and $\mathrm{COH}$. Optimal $\mathrm{r}_{\text {eff }}$ is largely independent of surface roughness length and the thickness of the surface layer because those parameters specify properties of the surface (Appendix B).

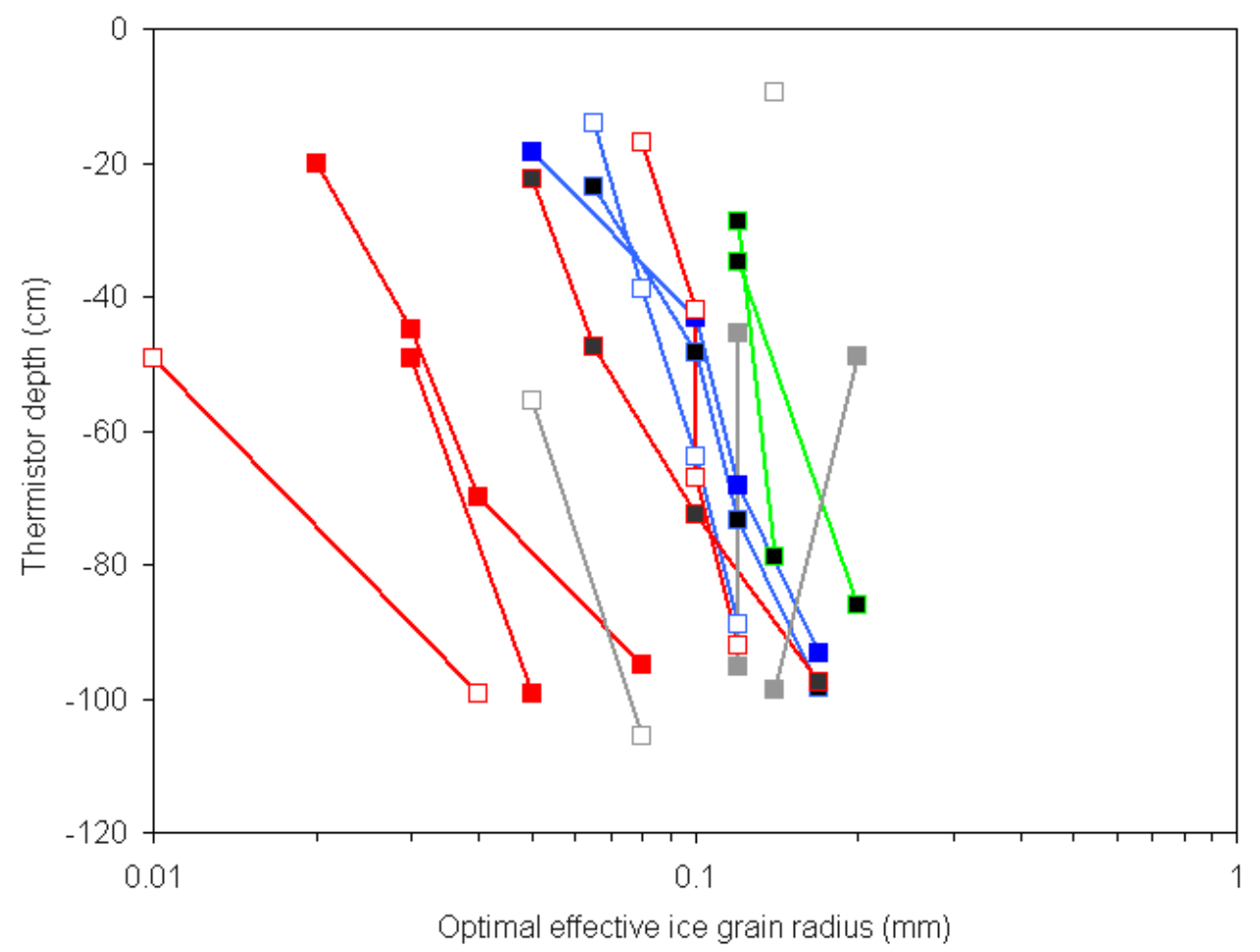

Figure 5.2: Optimal effective ice grain radii for the Refreezing Model at TAR (blue), CAA (red), $\mathrm{HOD}$ (green), and $\mathrm{COH}$ (gray). Black markers indicate periods of time from early summer, colored markers mid summer, and white markers late summer. Markers connected by lines indicate thermistor strings with measurements at multiple depths during the same time period. All strings with thermistors at four depths are from summer 2004-2005.

Comparisons made at different depths during the same time period indicate smaller effective grain radii tend to be optimal at shallower depths (Figure 5.2). The most likely explanation for this pattern is a depth-dependent bias in the extinction coefficient, while alternative explanations (drainage of subsurface melt changing the optical properties of the ice; thermal conductivity error; measurement error from radiative heating of thermistors) are not consistent with the pattern observed (Appendix B). 
Because I am most concerned with reproducing ice temperatures in the upper $25 \mathrm{~cm}$ where observations indicate subsurface melt occurs, I consider the shallowest ice temperature comparisons to be most valuable for calibrating effective grain radius.

For most time periods there is little difference in the optimal grain radius between the Refreezing and Drainage Models. However, for a few notable time periods the Refreezing model requires lower $r_{\text {eff }}$ than the Drain Model (e.g. late summers 2004-2005 and 2005-2006 at TAR and mid-summers 2002-2003 and 2004-2005 at CAA, see Appendix B, Figures B.3-B.4). In these cases the optimal grain radius is sensitive to the duration of subsurface melt. The timing of fall freezeup depends on the amount of heat stored in water - the Drainage Model has a maximum water fraction of $10 \%$ so subsurface melt is able to freeze quickly in the fall, but the Refreezing Model may reach water fractions up to $100 \%$, potentially providing a large heat reservoir that will delay freezeup. This is similar to the sea ice modeling study of Semtner (1984) where the length of the melt season was found to be largely governed by latent heat stored in brine pockets in the sea ice. As an example, using $\mathrm{r}_{\mathrm{eff}}=0.1 \mathrm{~mm}$ reproduces ice temperatures at $\sim 50 \mathrm{~cm}$ well during midsummer 2005-2006 at TAR, but in late summer the Refreezing Model produces ice temperatures that erroneously remain near $-1^{\circ} \mathrm{C}$ for about three weeks while all of the subsurface melt refreezes (Figure 5.3). The Drainage Model is able to accurately reproduce the timing of freezeup. When using a smaller grain radius of $0.01 \mathrm{~mm}$ there is little difference between the Refreezing and Drainage Models, because water fractions greater than $10 \%$ are rarely produced. 

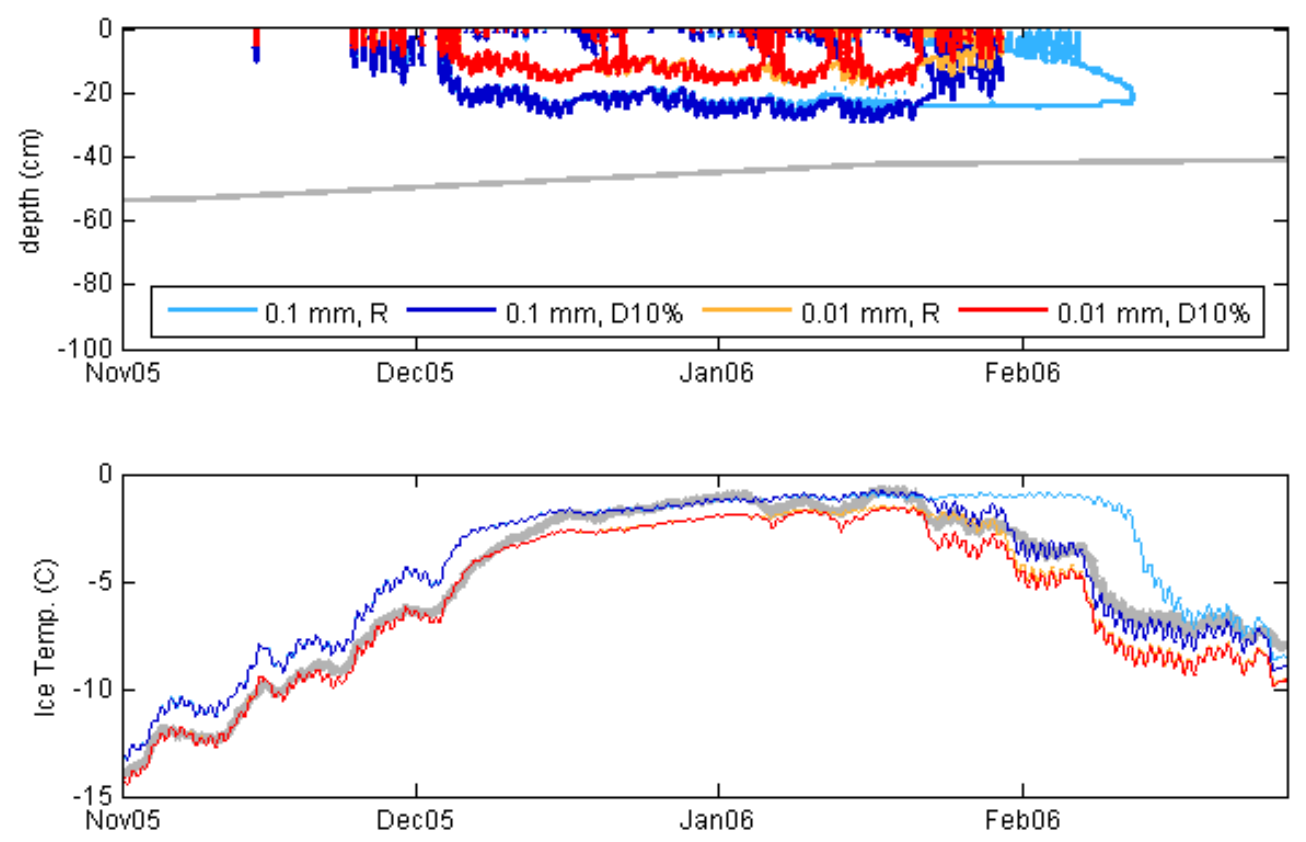

Figure 5.3: Subsurface melt and ice temperatures at TAR in summer 2005-2006. Upper panel: Depth and duration of modeled subsurface melt. Model results using two different grain radii for both the Refreezing and Drainage Models are shown. The gray line indicates the depth of the thermistor shown in the bottom panel. Bottom panel: Measured (gray) and modeled (colors) ice temperatures. The colors represent the same model versions as in the upper panel.

Thermistor data is not available for the summers with the greatest modeled subsurface melt, so it is more difficult to assess the optimal grain radius for high melt summers. Despite this limitation, I assess the reasonableness of modeled subsurface melt for a year with exceptional subsurface melt. In the 2001-2002 summer at TAR, the Refreezing Model predicts a $10 \mathrm{~cm}$ layer with $100 \%$ water fraction that lasts for a few weeks, for all $\mathrm{r}_{\mathrm{eff}}$ in the 0.01 to $0.1 \mathrm{~mm}$ range (Figure 5.4). As this represents an unrealistic situation of an areally extensive subsurface pond overlain by an ice lid, it is clear that the Refreezing Model has limited applicability in the biggest melt years. Over the range of $r_{\text {eff }}$ considered, subsurface melt for the 2001-2002 has similar duration, but the depth of melting increases with larger grain radius (Figure 5.4). Though the Drainage 
Model seems more reasonable than the Refreezing Model for this extreme summer, the appropriate choice of $r_{\text {eff }}$ for this season is unclear.
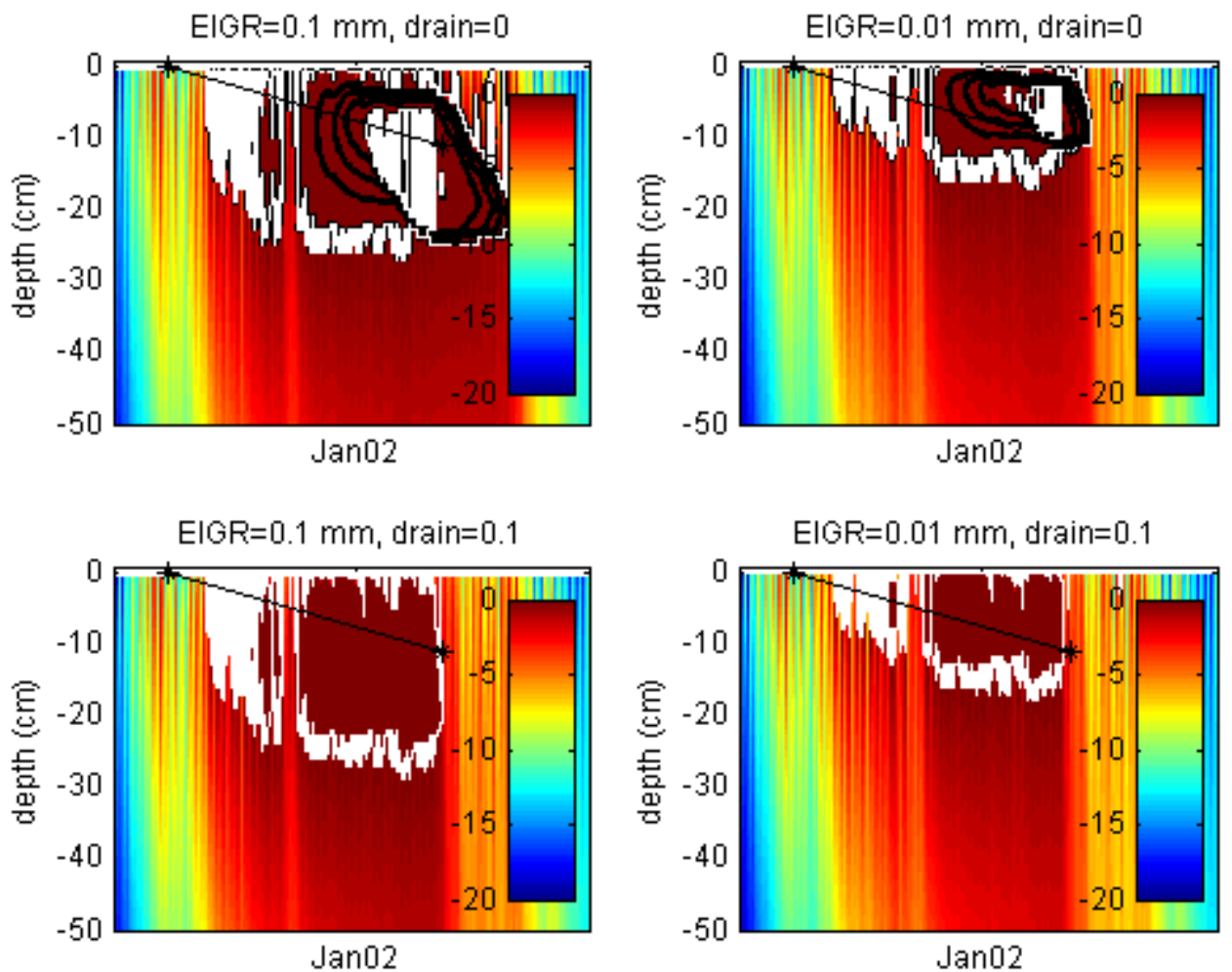

Figure 5.4: Modeled ice temperatures and subsurface melt for 2001-2002 at TAR. The upper row shows the Refreeze Model, while the lower row shows the Drain Model. The left column shows $E I G R=0.1 \mathrm{~mm}$, while the right column shows $E I G R=0.01 \mathrm{~mm}$. Colors show ice temperature in ${ }^{\circ} \mathrm{C}$. White contours indicate water fractions of $0 \%$ and $100 \%$ and black contours indicate water fractions at $25 \%$ intervals. The thin black line represents the amount of ablation that was measured at the surface during this summer.

Based on these analyses, $r_{\text {eff }}$ on the order of $10^{-2}$ to $10^{-1} \mathrm{~mm}$ is needed to reproduce measured ice temperatures. Because of the large range of acceptable values and large interseasonal variability (Appendix B), it is difficult to constrain the optimal value further. In Chapter 4 I calibrated an effective grain radius of $0.24 \mathrm{~mm}$ using measurements of the downward solar flux within the ice (Hoffman et al. 2008), which is at the maximum of the range of values obtained through calibration to measured ice 
temperatures (Figure 5.2). Given the uncertainty of these two calibration methods, I consider them compatible (Figure 5.5). However, it is worth noting that ice on Taylor and Canada Glaciers contains bubbles of 0.05 to $0.5 \mathrm{~mm}$ in radius (Hoffman et al. 2008), which is very similar to the range of optimal $r_{\text {eff }}$ values that I find here. This is consistent with a modeling study that shows that scattering within lake ice is controlled by the number and size of air bubbles trapped within the ice (Mullen and Warren 1988). Though the optimal effective ice grain radius may vary from glacier to glacier, from summer to summer, and over the course of each summer, for further calibration and modeling I assume it is a constant but uncertain value for lack of a robust way to characterize these variations. Lastly, the ice temperature observations suggest that the Drainage Model may be more realistic than the Refreezing Model by better reproducing the timing of freezeup in years with extensive subsurface melt.

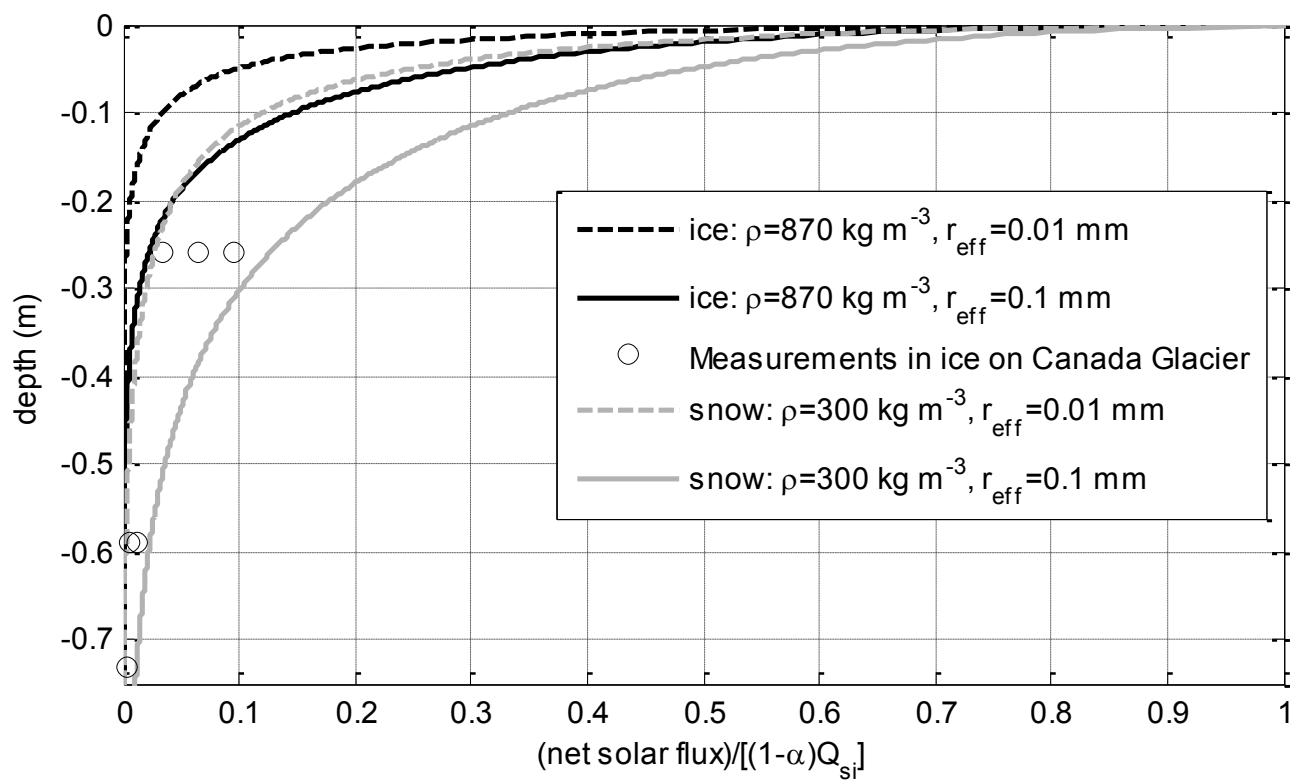

Figure 5.5: Calculations of net solar flux in the upper $75 \mathrm{~cm}$ for snow and ice. Measurements are from lower Canada Glacier, November 22, 2006 (Hoffman et al. 2008 / Chapter 4). 


\subsubsection{Surface Roughness Length}

The surface roughness length (or momentum roughness length), $\mathrm{z}_{0}$, is defined as the height at which the wind speed profile would reach zero if extrapolated towards the surface (Brock et al. 2006). Along with wind speed (friction velocity) and the gradients in temperature and vapor pressure near the surface, it is a major control on the magnitude of the turbulent fluxes, and, through the latent flux, the magnitude of sublimation. The magnitude of the turbulent fluxes more than doubles with an order of magnitude increase in $\mathrm{z}_{0}$ (Brock et al. 2000b), yet $\mathrm{z}_{0}$ varies over nearly five orders of magnitude on glacier surfaces (Brock et al. 2006). Under turbulent conditions that are typical of glacier surfaces, $z_{0}$ depends on the form drag of surface roughness elements (Andreas 1987, Smeets and van den Broeke 2008). However, air flow over Antarctic blue ice areas can be aerodynamically smooth, conditions that cause turbulent exchange to instead be governed by molecular diffusion (Bintanja 1999). The surface roughness length can be calculated from eddy-correlation measurements or from wind speed measured at multiple levels (Brock et al. 2006, Smeets and van den Broeke 2008). However, these methods require long periods of monitoring and careful processing (Brock et al. 2006) and have not been routinely collected in Taylor Valley. Temporal and spatial variations in $\mathrm{z}_{0}$ over two orders of magnitude have been reported on glaciers surfaces (Brock et al. 2006, Smeets and van den Broeke 2008), but in most studies a constant value is assumed (Brock et al. 2006).

Without measurements to calculate $\mathrm{z}_{0}$, I use ablation measurements to calibrate it within the melt model. In order to calibrate surface roughness length unambiguously, I 
chose time periods when I was confident that melt did not occur so that sublimation was the only ablative process. By choosing these periods, optimal surface roughness length is almost completely independent of parameter choices for effective ice grain radius and SRSF, and differences between the Refreezing and Drainage Models are negligible. In fact, I was able to identify, and subsequently eliminate, time periods that were 'contaminated' with melt by a dependence on the other parameters.

I tuned the surface roughness length by matching modeled ablation to measured ablation for periods in winter and in early or late summer (Table 5.3). The model was run with eight different values for surface roughness varying by half orders of magnitude between 0.01 and $5 \mathrm{~mm}$, which cover the range of smooth blue ice to melting ice for polar glaciers and ice sheets (Brock et al. 2006). Winter mass balance measurements were used for those seasons that were snow-free based on sonic ranger measurements. Snow-free winters at HOD were assumed to also apply to CAA, which does not have a sonic ranger, due to their close locations and the lower elevation of CAA. Similarly, snow-free winters at TAR were assumed to also apply to TAR2. For winter measurements, surface roughness length was calibrated to the mean absolute error in ablation for the available seasons at each study site. Additionally, I used sonic ranger measurements to identify time periods in early (October-December) and late summer (January-February) that were both snow-free and did not have rapid surface lowering that would indicate melt. For each of these time periods, ranging in duration from 10 to 30 days, I determined the surface roughness length value that would allow the model to best match the ablation recorded by the sonic ranger. These short-duration ablation 
measurements by sonic ranger have high uncertainty, as do the resulting calibration values of surface roughness. No eligible time periods existed at $\mathrm{COH}$ for winter or summer.

Table 5.3: Optimal values of surface roughness in mm for various time periods. Numbers in parentheses indicate the number of seasons used to calculate MAE in seasonal ablation. Explanation of low and high ablation summers is in the following section.

\begin{tabular}{|c|c|c|c|c|c|}
\hline Time Period & TAR & TAR2 & HOD & CAA & COH \\
\hline \multicolumn{6}{|c|}{ Calibrating $z_{0}$ independently of other parameters (Section 5.4.2) } \\
\hline Snow-free winters & $\begin{array}{l}0.15 \\
(5)\end{array}$ & $\begin{array}{l}1.0 \\
(5)\end{array}$ & $\begin{array}{l}0.5 \\
(3)\end{array}$ & $\begin{array}{l}0.3 \\
(3)\end{array}$ & $\begin{array}{l}2.0 \\
(1)\end{array}$ \\
\hline 2003-2004: early/late summer & $-1-$ & $-1-$ & $-/ 5.0$ & $-1-$ & $-1-$ \\
\hline 2004-2005: early/late summer & $0.01 / 0.03$ & $-1-$ & $0.3 /-$ & $-1-$ & $-1-$ \\
\hline 2005-2006: early/late summer & $0.01 / 0.03$ & $-1-$ & $0.08 /-$ & $-1-$ & $-1-$ \\
\hline 2006-2007: early/late summer & $0.01 /-$ & $-1-$ & $-1-$ & $-1-$ & $-1-$ \\
\hline 2007-2008: early/late summer & $0.01 / 0.03$ & $-1-$ & $-1-$ & $-1-$ & $-1-$ \\
\hline \multicolumn{6}{|c|}{ Calibrating $\mathrm{z}_{0}$ together with other parameters (Section 5.4.4) } \\
\hline Low ablation summers & $\begin{array}{l}0.05 \\
(9)\end{array}$ & $\begin{array}{l}0.5 \\
(1)\end{array}$ & $--/-$ & $\begin{array}{l}0.5 \\
(8)\end{array}$ & $-1-$ \\
\hline $\begin{array}{l}\text { High ablation summers, } \\
\text { Refreeze Model/Drain Model }\end{array}$ & $\begin{array}{l}1.0 / 0.05 \\
\text { (3) }\end{array}$ & $\begin{array}{l}1.0 / 1.0 \\
(11)\end{array}$ & $-1-$ & $\begin{array}{l}5.0+/ 5.0+ \\
\quad(3)\end{array}$ & $-1-$ \\
\hline
\end{tabular}

The optimal surface roughness length values for winters and early/late summer range from 0.01 to $2.0 \mathrm{~mm}$ (Table 5.3). Optimal surface roughness length during winter is lowest at TAR, two to three times larger at HOD, and CAA, and an order of magnitude larger at TAR2 and $\mathrm{COH}$. The glacier surfaces near HOD and CAA have more relief than in the vicinity of TAR, and the larger roughness values may be related to increased drag that would occur from the proximity to domes and gullies and the cliffs at those glaciers' edges. The value of $1.0 \mathrm{~mm}$ at the low-elevation TAR2 site is consistent with 
the surface roughness of a melt-dominated environment (Bintanja 1999, Brock et al. 2006). The large value at $\mathrm{COH}$ may be unreliable given that it is based on a single ablation measurement. Because TAR2 is in a relatively high melt environment, caution should be used in considering the calibrated surface roughness for winter there of 1.0 $\mathrm{mm}$, as it is possible that melt occurs on the shoulders of the mass balance time period, which would artificially increase the calibrated value of $\mathrm{z}_{0}$.

Surface roughness length during the early summer periods appears to be about an order of magnitude less than during winter, with the exception of one time period at HOD (Table 5.3). This seasonal difference may indicate errors in the calculation of the stability correction, as opposed to a physical change in roughness, as the atmosphere in winter is generally very stably stratified, while unstable conditions are more common in summer. An alternative explanation is if the density of the ice is reduced during summer through drainage of subsurface melt, winter ablation measurements assuming a constant unaltered density would be too high. This would force the calibration process to select for higher $\mathrm{z}_{0}$ values to match the inflated measurements of winter mass loss.

Surface roughness length during the late summer periods at TAR is slightly larger than during early summer, while the one late summer time period at HOD is one to two orders of magnitude larger than early summer values. Melting glacier ice generally has greater surface roughness than sublimation-dominated ice (Bintanja 1999, Brock et al. 2006), and it is possible that the observed increases in surface roughness are the result of summer melt roughening the surface. However, the late summer surface roughness values at TAR are still well below that of glacier surfaces dominated by melt $(\sim 1 \mathrm{~mm})$ 
(Brock et al. 2006), suggesting that if melt occurs, it does not significantly roughen the surface at TAR. The high value of $5 \mathrm{~mm}$ on HOD from late summer 2003-2004 occurs after a low ablation year and may be unrelated to melt effects.

\subsubsection{Solar Radiation Surface Fraction}

The solar radiation surface fraction (SRSF) represents the fraction of net solar radiation absorbed by the surface layer represented in the surface energy balance, with the remaining net solar radiation absorbed volumetrically within the subsurface. The SRSF is required to satisfy conservation of energy when radiative processes are included in both the surface energy balance and the subsurface source term. Its value is a function of the effective ice grain radius used and a specified surface layer thickness, within which the solar radiation source term is eliminated. The surface layer thickness can be thought of as the thickness of the air-ice interface or 'surface' that interacts with the atmosphere over the duration of the time step (Chapter 4 / Hoffman et al. 2008). It is possible that it varies over time as the temperature gradient near the surface changes, affecting the depth from which heat can be conducted to the surface over the span of the chosen time step.

Because solar radiation is the dominant energy source for the surface in summer and a large contributor of energy to melt events (Paterson 1994, Hock 2005, Hoffman et al. 2008), the value of SRSF strongly affects surface melting. Therefore, I vary SRSF and compare calculations of ablation from the Refreezing Model to measurements of ice ablation in summer. Ten surface layer thickness values between 0.1 and $9 \mathrm{~cm}$ and nine

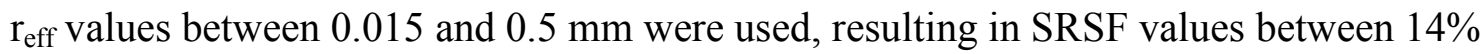
and $94 \%$. Surface roughness length was held constant at $0.01 \mathrm{~mm}$ at TAR and TAR2 and 
$0.1 \mathrm{~mm}$ at the other sites, yielding a total of 72 parameter combinations for the SRSF calibration. Because optimal SRSF in the Drainage Model is a function of grain radius, calibration of that model is conducted using all three parameters.

Optimal SRSF values for the Refreezing Model for the fourteen summer seasons at the four study sites range from $14-78 \%$. However, the range and uncertainty of values is much larger in low ablation summers than in high ablation summers (Figure 5.6). Low ablation summers $\left(<\sim 0.13 \mathrm{~cm}\right.$ weq day ${ }^{-1}$ of ablation, Table 5.4) have a much larger range of adequate values that can reproduce measured ablation to within $2 \mathrm{~cm}$ weq, the approximate uncertainty (Figure 5.6). I interpret these low ablation summers as having very little or no melt, and sublimation is the dominant ablative process. Because SRSF primarily affects ice surface temperature, ablation is relatively independent of SRSF in these years. Sublimation is calculated by the vapor pressure gradient between air at the ice surface and the air above, but the air at the ice surface is assumed to be saturated, regardless of surface temperature, yielding only a weak dependence of sublimation on surface temperature. In contrast, melt requires that the ice surface temperature reach $0^{\circ} \mathrm{C}$, and any additional energy goes directly to melting. Thus, changes in SRSF are directly converted into changes in melt at times when the surface temperature is at $0{ }^{\circ} \mathrm{C}$.

Presumably for this reason, I see small ranges of permissible SRSF values for summers with ablation rates greater than $0.13 \mathrm{~cm}$ weq day ${ }^{-1}$, which I infer indicates significant contributions to ablation from melting. 


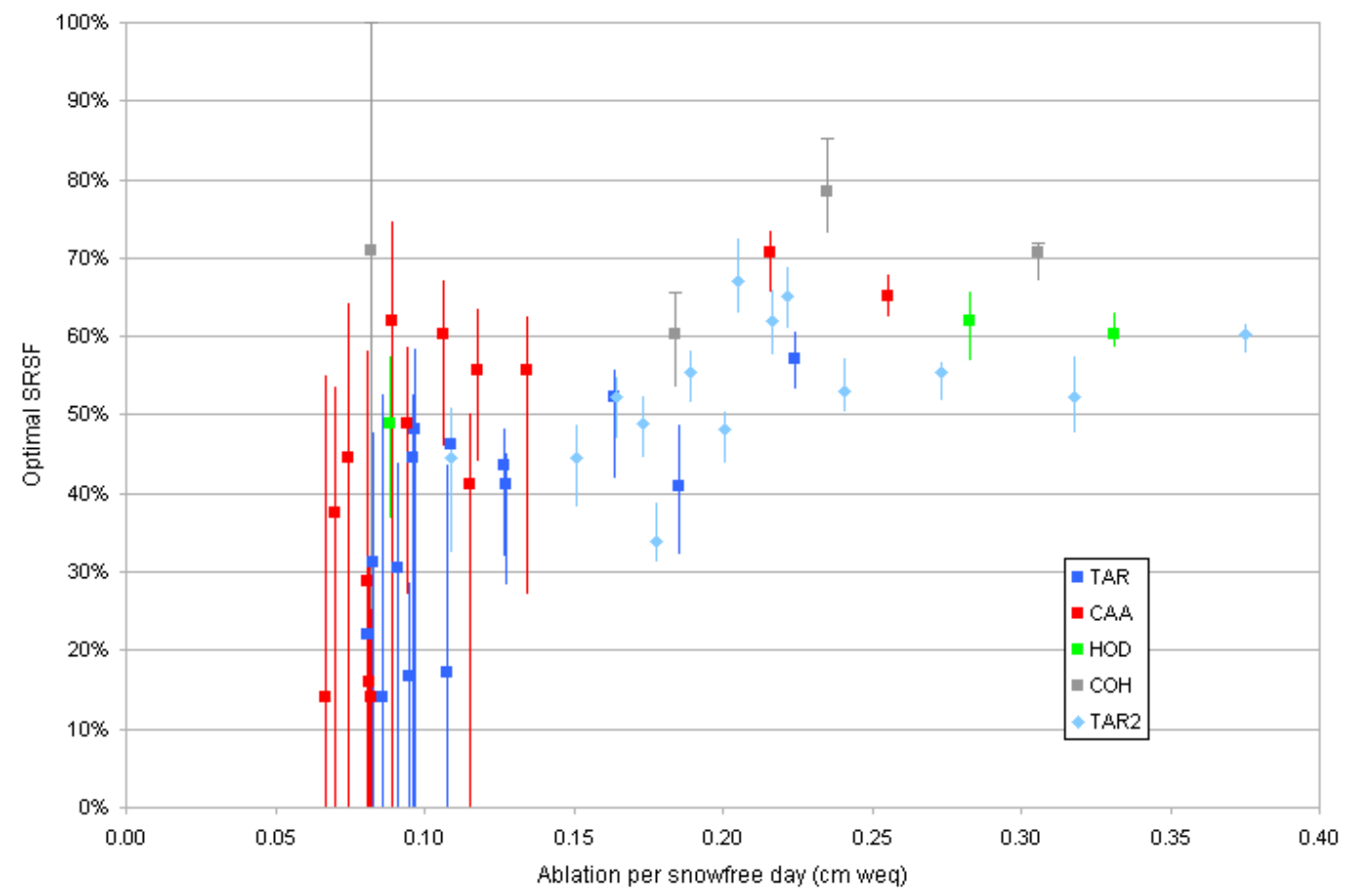

Figure 5.6: Optimal SRSF for each summer. Ablation per snowfree day is calculated from measured summer ablation (mass balance stakes) divided by the number of days identified as snowfree based on albedo value. Only summers with a fraction of days with snowcover less than $50 \%$ are shown. Vertical lines for each point represent the range of SRSF values that can reproduce observed ablation within $2 \mathrm{~cm}$ weq.

Considering all five sites, most low ablation summers can be fit using any SRSF between 14\% and 50\% (Figure 5.6). The SRSF required by high ablation summers increases from about $40 \%$ to a range between $50 \%$ and $70 \%$ for ablation rates $>0.20 \mathrm{~cm}$ weq day $^{-1}$. However, there is no sound theoretical reason for SRSF to change between low and high melt years. During most summers, ice temperatures $\sim 10 \mathrm{~cm}$ below the surface stay at or near $0^{\circ} \mathrm{C}$ for much of midsummer over the range of permissible grain radii. Thus, no large differences in the temperature gradient exist between years near the surface during midsummer, and consequently there is little reason to expect different SRSF values to be required. Using a constant SRSF value (e.g. 55\%) for all summers 
reproduces neither low nor high ablation summers particularly well. Instead, I

hypothesize that different physical processes are important in high ablation years that are mapping into higher SRSF values. For example, if subsurface melt is contributing to surface lowering through density reduction, a model that does not include this process (e.g. the Refreezing Model shown in Figure 5.6) would need to generate higher surface melt rates to match observations.

Table 5.4: Classification of summer seasons at each site. $L=$ low ablation rate summer; $H=$ high ablation rate summer; --=not used because snowcover lasted more than half of season; $a=n o t$ used because season has gaps in or issues with measured albedo.

\begin{tabular}{lccccc}
\hline \hline Summer & TAR & TAR2 & HOD & CAA & COH \\
\hline $1995-1996$ & L, a & H, a & -- & L, a & -- \\
$1996-1997$ & L & H & -- & L, a & -- \\
$1997-1998$ & H & H & -- & L, a & -- \\
$1998-1999$ & L & H & -- & L & -- \\
$1999-2000$ & L & H & -- & L, a & -- \\
$2000-2001$ & L & L & -- & L & -- \\
$2001-2002$ & H & H & H & H & H \\
$2002-2003$ & L & H & -- & L & -- \\
$2003-2004$ & L & H & -- & L & -- \\
$2004-2005$ & L & H & -- & L & H \\
$2005-2006$ & L & H & L & L & L \\
$2006-2007$ & L, a & H, a & -- & L & -- \\
$2007-2008$ & L & H & -- & H & -- \\
$2008-2009$ & H & H & H & H, a & H \\
\hline
\end{tabular}

\subsubsection{Multiparameter Calibration}

Having considered each of the three parameters separately, I estimate optimal parameter values by examining the entire parameter space for both the Refreezing and Drainage models. In order to investigate causes for the higher SRSF values in summers with high ablation rates (Figure 5.6), I explore parameter space for low and high ablation 
rate summers separately and compare the results. I use the analyses of previous sections to constrain possible values for $\mathrm{r}_{\mathrm{eff}}$ and $\mathrm{z}_{0}$, and I ignore data for $\mathrm{HOD}$ and $\mathrm{COH}$ because of complications from frequent snowcover.

As shown in the previous section, when using the Refreezing Model for low ablation rate summers (Figures 5.70 - 5.90: a), modeled ablation is extremely insensitive to variations in grain radius and insensitive to variations in SRSF below a threshold of about $50 \%$. For low ablation rate summers there is little difference in parameter space between the Refreezing and Drainage Models (Figures 5.70 - 5.90: a, c). This is not surprising as low ablation summers are likely to also have low subsurface melt, conditions that result in little difference between the two models. At all three sites considered, the optimal $\mathrm{z}_{0}$ for low ablation summers using either model $(5.70-5.90: \mathrm{a}, \mathrm{c})$ is within a half order of magnitude of the values for early/late summer and winter periods identified (cf. Table 5.3).

In high ablation rate summers substantial differences in optimal parameters exist between the Refreezing and Drainage Models (Figures 5.70 - 5.90: b, d). A possible explanation for the difference is the contribution of the drainage of subsurface melt to ablation during high ablation rate years. When using the Drainage Model, the same values for all three parameters can be used for both the low and high ablation rate summers at each site and provide near optimal fits for ablation (Figures 5.70 - 5.90: c, d). For example, at TAR2, a surface roughness length of $0.5 \mathrm{~mm}$, a grain radius of $0.03 \mathrm{~mm}$, and SRSF of $30 \%$ results in error in ablation for both low and high ablation rate summers that is very close to the lowest possible, even if the different classes of summers were 
allowed to have different parameters (Figure 5.8: c, d). Similar parameter values can be used at the other two sites shown. Additionally, at TAR2 and CAA the minimum error in high ablation rate years using the Drainage Model is lower than with the Refreezing Model; at TAR both models can achieve very low error for high melt rate years. Thus, with the Drainage Model a single set of parameters can be used for all years.

An alternate explanation of a physical change in high ablation rate summers is that surface roughness increases with melting. Considering the Refreezing Model, optimal surface roughness lengths increase by an order of magnitude or more between the low and high ablation rate summers (Figures 5.70 - 5.90: a, b; Table 5.3). At both TAR and CAA, ablation can be equally well reproduced (mean absolute error of $\sim 1 \mathrm{~cm}$ weq) for the low and high ablation rate summers if $\mathrm{z}_{0}$ is allowed to vary between the two classes of summers. With the Drainage Model, there also appears the possibility that surface roughness length increases in high ablation rate summers, but the increase suggested by the modeling is smaller, at about a half order of magnitude.

An increase in surface roughness in high ablation rate years is consistent with surface roughness transitioning from that of a sublimation dominated environment to a melt dominated environment (Bintanja 1999). While melt-free blue ice areas can have surface roughness lengths as low as $10^{-3} \mathrm{~mm}$ (Bintanja and van den Broeke 1995a), melt dominated glacier surfaces have a surface roughness length of $\sim 1 \mathrm{~mm}$ or greater, and melt-dominated Arctic ice can achieve a surface roughness length of close to $10 \mathrm{~mm}$ (Brock et al. 2006). This range of values is comparable to the range of optimal surface roughness values for TAR, TAR2, and CAA over all summers (Table 5.3). 
It should be pointed out that drag exerted on a rough surface by turbulent boundary-layer flow results from form drag of roughness elements and skin friction (Raupach 1992). If the aerodynamic surface roughness is dominated by form drag from macro-scale roughness elements (e.g. gulleys, hummocks), changes to skin friction (subcentimeter scale roughness elements) caused by melting may have little effect on $z_{0}$. While the glacier surface at TAR is free of larger roughness elements, the surface near CAA includes some small gulleys, and TAR2 is in a region of $\sim 20 \mathrm{~m}$ deep canyons (Johnston et al. 2005). Accordingly, changes in $\mathrm{z}_{0}$ as an explanation for differences between low and high ablation rate summers may not be valid at those locations. In the previous section it was noted that an SRSF of $50 \%$ to $70 \%$ reproduces ablation well for the high ablation rate summers using the Refreezing Model (Figure 5.6), and this region of parameter space is prominent as a horizontal band in Figures 5.7b 5.9b. There is no theoretical justification for using different SRSF values in different summers, so I consider possible physical explanations for higher SRSF values in high ablation summers. One possible explanation is that SRSF is not an appropriate choice of parameter, but instead, the thickness of the surface layer should be used. Because SRSF is a function of the thickness of the surface layer and the ice grain radius, a reduction in grain radius would increase SRSF for a given surface layer thickness. For example, reducing $\mathrm{r}_{\text {eff }}$ from $0.1 \mathrm{~mm}$ to $0.01 \mathrm{~mm}$ increases SRSF from $26 \%$ to $43 \%$ using a constant surface layer thickness of $0.5 \mathrm{~cm}$. A plausible mechanism for decreasing effective ice grain radius is the drainage of subsurface melt (Buckley and Trodahl 1987), but my calibration process is inconclusive regarding such a process (Appendix B). Furthermore, 
subsurface drainage is not represented in the Refreezing Model, so I interpret this region of parameter space with relatively good fits at $\mathrm{SRSF}=\sim 50 \%$ (Figures $5.7-5.9: \mathrm{b}$ ) to be an artifact. I hypothesize that these higher optimal SRSF values in high ablation rate summers allow the Refreezing Model to somewhat compensate for the lack of subsurface mass loss within the model. 


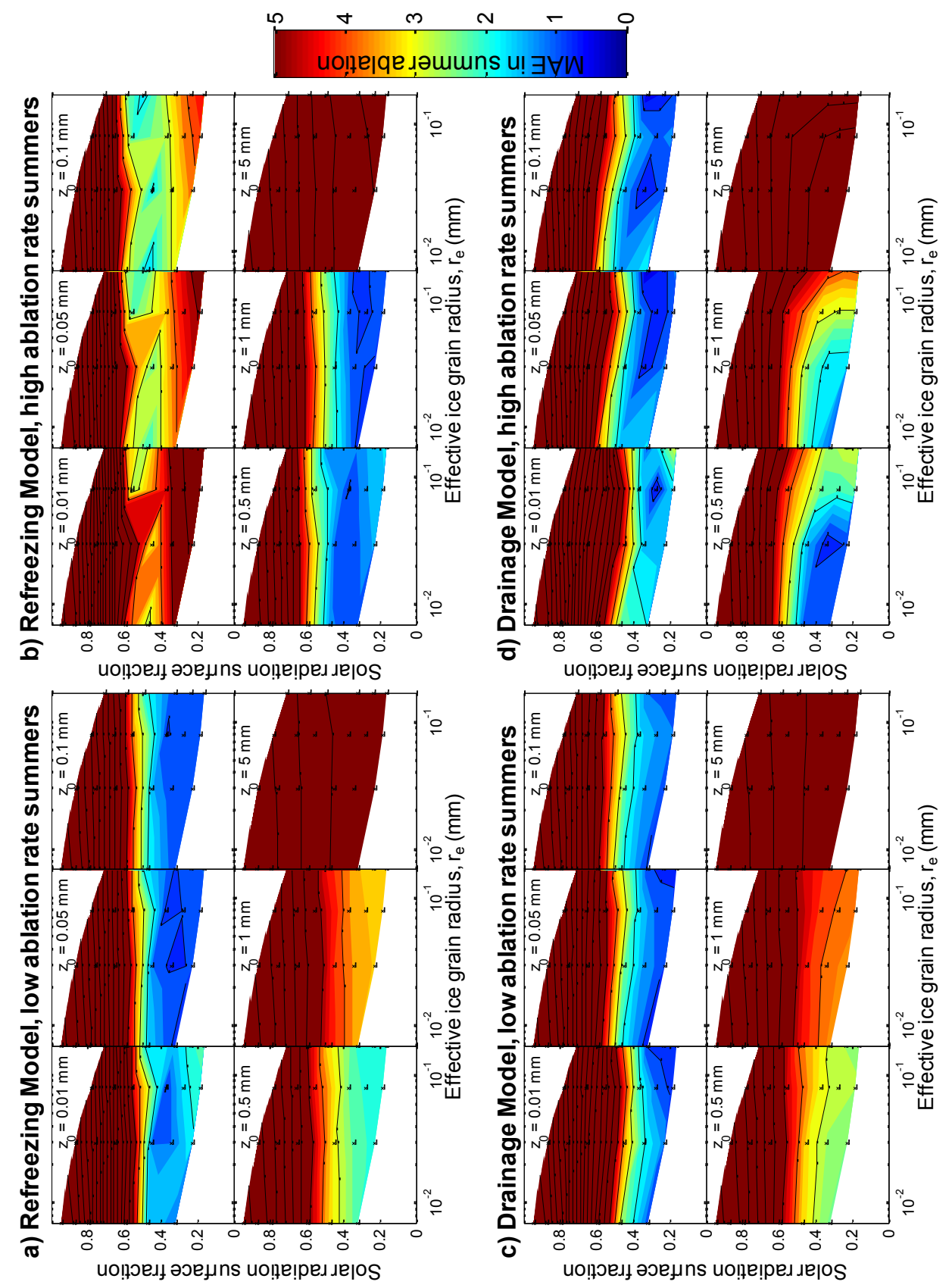

Figure 5.7: Variations in mean absolute error (MAE) in summer ablation at TAR. The upper half shows the Refreezing Model and the lower half shows the Drainage Model. The left half shows $M A E$ for the nine low ablation rate years and the right half shows MAE for the three high ablation rate years (Table 5.4). For each subfigure, each of the six plots show variations in MAE in summer ablation over a range of $r_{\text {eff }}$ and SRSF values for different surface roughness lengths. Small black X's indicate the parameter combinations sampled. Black contours have intervals of 1 cm weq. 

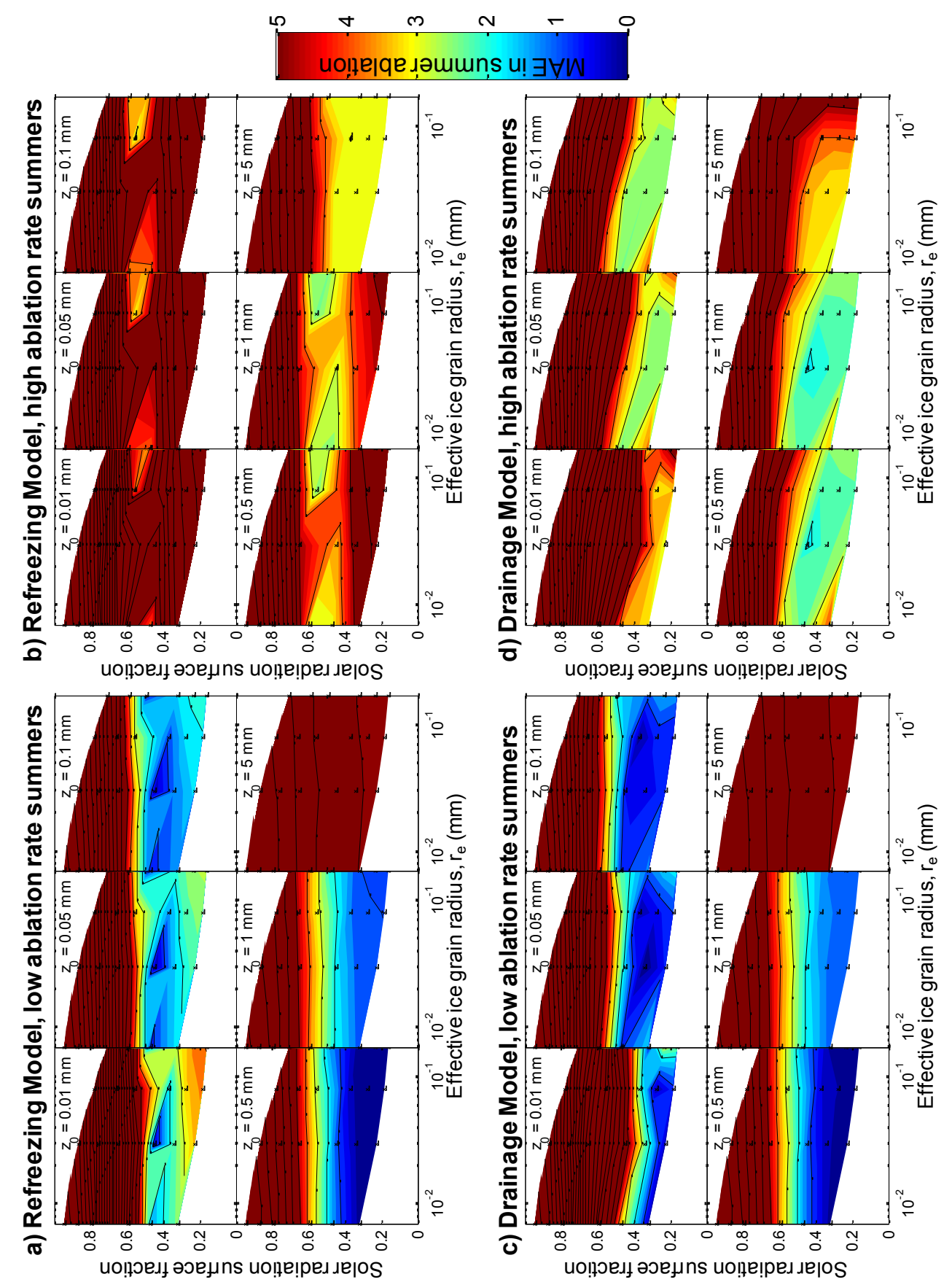

Figure 5.8: Variations in mean absolute error (MAE) in summer ablation at TAR2. The upper half shows the Refreezing Model and the lower half shows the Drainage Model. The left half shows MAE for the one low ablation rate year and the right half shows MAE for the eleven high ablation rate years (Table 5.4). For each subfigure, each of the six plots show variations in MAE in summer ablation over a range of $r_{\text {eff }}$ and SRSF values for different surface roughness lengths. Small black x's indicate the parameter combinations sampled. Black contours have intervals of 1 $\mathrm{cm}$ weq. 


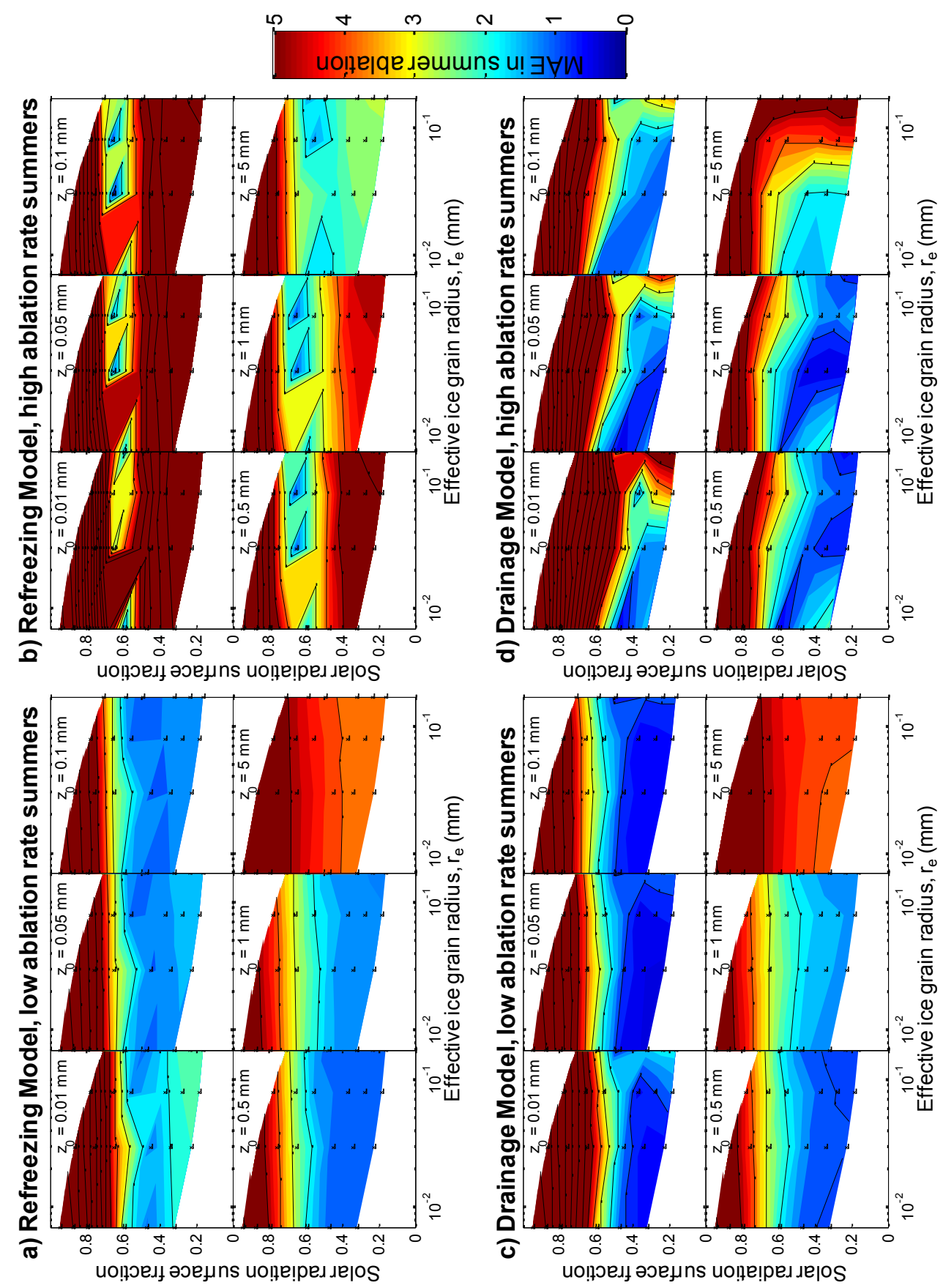

Figure 5.9: Variations in mean absolute error (MAE) in summer ablation at CAA. The upper half shows the Refreezing Model and the lower half shows the Drainage Model. The left half shows MAE for the seven low ablation rate years and the right half shows MAE for the two high ablation rate years (Table 5.4). For each subfigure, each of the six plots show variations in MAE in summer ablation over a range of $r_{\text {eff }}$ and SRSF values for different surface roughness lengths. Small black x's indicate the parameter combinations sampled. Black contours have intervals of 1 $\mathrm{cm}$ weq. 


\subsubsection{Calibration Summary}

Based on this exploration of parameter space, I am able to propose a few different possible model configurations. Analysis of effective ice grain radius ( $\left.\mathrm{r}_{\mathrm{eff}}\right)$ indicated that optimal values range between $10^{-2}$ and $10^{-1} \mathrm{~mm}$, though there is high temporal variability. To match the timing of fall freezeup in summers with extensive subsurface melting, the Drainage Model works well over that range of grain radii. For the Refreezing Model, however, it is necessary to use a small $\mathrm{r}_{\text {eff }}$ value $\left(\sim 10^{-2} \mathrm{~mm}\right)$. Reduction of effective grain radius could occur due to draining of subsurface melt creating air voids. However, a smaller effective grain radius is not needed when using the Drainage Model, suggesting that changes in ice optical properties are of secondary importance relative to the removal of latent heat stored in water.

Accurate modeling of high ablation rate summers requires either using the Refreezing Model with changes in surface roughness from summer to summer or using the Drainage Model without such adjustments. To employ the Refreezing Model in a predictive fashion would require allowing the surface roughness to increase dynamically after the model has predicted a certain amount of melt within a season. However, a better understanding of the processes involved is necessary to define the relationship between cumulative melt magnitude and surface roughening. Additionally, errors in the calculation of melt could lead to erroneous changes in surface roughness. Lastly, the optimal surface roughness for high ablation summers at TAR2 and CAA is at the upper limit of what is realistic for melting polar ice. This may suggest that both subsurface 
melt drainage and surface roughening occur in high ablation summers, which is consistent with observations.

A concern with the drainage explanation for high ablation summers is the relatively simplistic treatment that I have employed for drainage of subsurface melt and estimation of changes in ice density. The $10 \%$ threshold I have used is guided by observations of ice weathering but may be incorrect and is likely to vary in space and time. Additionally, should subsurface melting and drainage be extensive, the structural integrity of the ice may be reduced to the extent that the ice surface lowers due to settlement or collapse of the ice grain matrix. In that situation, some component of subsurface melting transfers directly to surface ablation, rather than merely decreasing ice density, as I assume. Weak ice layers near the surface have been observed to collapse in some areas during the extreme melt summer of 2001-2002 (Fountain et al. 2004b).

I define final model configurations that best represent these two explanations for the differences between low and high ablation rate summers to explore in more detail (Table 5.5). For the Refreezing Model, I use different surface roughness for different summers, but all other parameters remain constant at each site. For the Drainage Model, the same parameters are used for all years at each site. In both model versions, I allow parameters to differ between sites. 
Table 5.5: Summary of final model configurations. Where multiple parameter values are listed, they correspond to values used for TAR / TAR2 / CAA.

\begin{tabular}{llcccc}
\hline $\begin{array}{l}\text { Model } \\
\text { configuration }\end{array}$ & Abbreviation & $\begin{array}{c}\mathbf{r}_{\text {eff }} \\
(\mathbf{m m})\end{array}$ & $\begin{array}{c}\mathbf{z}_{\mathbf{0}} \\
(\mathbf{m m})\end{array}$ & $\begin{array}{c}\text { SRSF } \\
(\mathbf{\%})\end{array}$ & $\begin{array}{c}\mathbf{d z}(\mathbf{1}) \\
(\mathbf{c m})\end{array}$ \\
\hline $\begin{array}{l}\text { Refreezing } \\
\begin{array}{l}\text { Model: low } \\
\text { ablation summers }\end{array}\end{array}$ & R-L & $0.08 / 0.08 / 0.03$ & $0.05 / 0.5 / 0.5$ & $27 / 27 / 34$ & $0.5 / 0.5 / 0.5$ \\
$\begin{array}{l}\text { Refreezing } \\
\begin{array}{l}\text { Model: high } \\
\text { ablation summers }\end{array}\end{array}$ & R-H & $0.08 / 0.08 / 0.03$ & $1.0 / 5.0 / 5.0$ & $27 / 27 / 34$ & $0.5 / 0.5 / 0.5$ \\
$\begin{array}{l}\text { Drainage Model: } \\
\text { all summers }\end{array}$ & D-A & $0.08 / 0.03 / 0.03$ & $0.05 / 1.0 / 1.0$ & $23 / 34 / 34$ & $0.5 / 0.5 / 0.5$ \\
\hline
\end{tabular}

\subsection{Results}

\subsubsection{Ablation and Energy Balance}

Using the final model configurations (Table 5.5), I calculate ablation for all summers at each site (Figure 5.10). Both model versions perform well at each site, as expected by the low mean absolute error in summer ablation for these model configurations. The best fit are at TAR where snowcover and surface melt are rare. At TAR2 there is considerably more error for both model versions, and both under-predict the high ablation year of 2001-2002 by over $10 \mathrm{~cm}$ weq. At CAA both model versions have about the same skill, and both under-predict ablation in the 2008-2009 summer.

Both model versions suggest that surface melt is a small fraction of ablation at all sites in all summers. With the optimal Refreezing Model configuration much of the additional ablation in high ablation rate summers comes from increased sublimation. In contrast, with the optimal Drainage Model configuration, additional ablation in high ablation rate summers is caused by the drainage of subsurface melt. The Drainage Model shows this effect most frequently at TAR2 where most years have high ablation rates. 
Though subsurface drainage impacts ablation estimates in both high and low ablation rate summers, sublimation is still the largest mass loss in all years at all sites.

Considering TAR, the final model configurations have similar surface energy balances during summer (Figure 5.11a). Net shortwave radiation is the largest contribution of energy to the glacier, but most of it penetrates below the surface. On average during summer, conduction brings about $80 \mathrm{~W} \mathrm{~m}^{-2}$ of energy to the surface, making up for nearly all of the shortwave radiation that penetrated the surface. However, during surface melting, conduction goes to zero, and at those times penetrated solar radiation is not compensated for. Thus, the choice of SRSF appears to be of little significance when the surface temperature remains below freezing, but has a major impact on the magnitude of melt calculated when the surface reaches $0^{\circ} \mathrm{C}$. Hours with surface melting or subsurface melting have substantially higher net shortwave radiation than the summer average conditions. Additionally, hours with surface melt occurring have smaller losses due to net longwave radiation. The only substantial difference from summer average conditions for hours with subsurface melt occurring is higher net solar radiation, which reflects the role of subsurface solar heating in driving subsurface melt. 

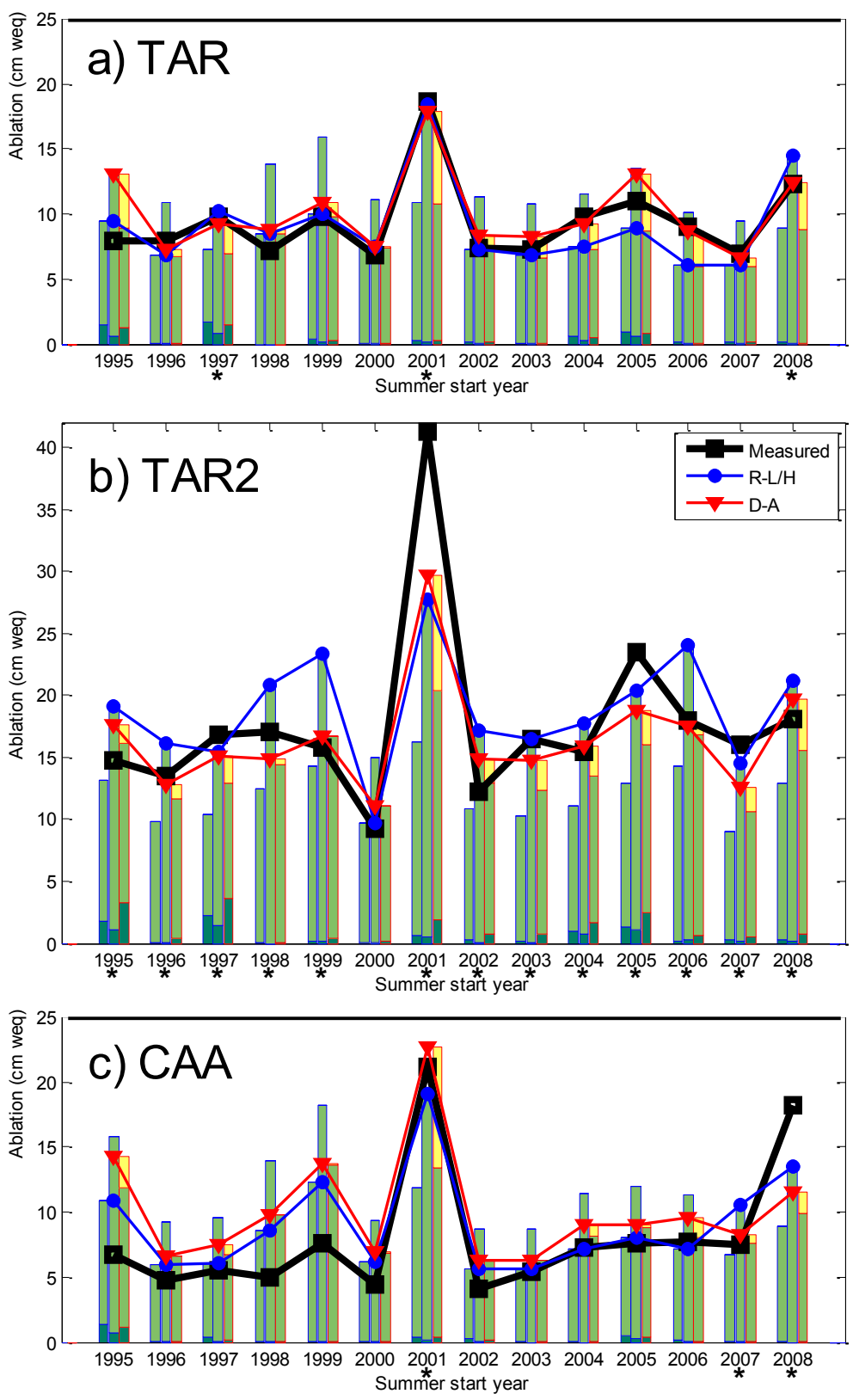

Figure 5.10: Model ablation results at a) TAR, b) TAR2, and c) CAA. Black line is measured summer ablation, blue is the optimal Refreezing Model configuration, and red line is the optimal Drainage Model configuration. The blue line uses the $R-L$ model version for low ablation rate summers and the $R$-H model version for high ablation rate summers. The three stacked columns for each season indicate the processes contributing to ablation for the $R$-L model (left of three columns), $R$-H model (center), and D-A model (right). Dark green is surface melt, light green is sublimation, and yellow is the component due to density reduction from drainage of subsurface melt. Stars next to year labels indicate summers classified as having a high ablation rate (Table 5.4). Explanation of model names is in Table 5.5. There are notable problems with measured albedo for summers 1995 and 1999. 
In addition to penetrating net solar radiation, net longwave radiation and latent heat are large energy losses to the surface during summer. Sensible heat is a small term in the summer energy balance and may be positive or negative depending on choice of parameters. This arises from both summer air temperature and ice surface temperature being close to $0^{\circ} \mathrm{C}$ throughout much of the summer. The R-H configuration uses a larger surface roughness length, and this version differs somewhat from the others by having larger magnitude sensible and latent heat fluxes. Melt is a small energy loss to the surface, even if considering only times when melt occurs.

The summer surface energy balance at TAR2 and CAA is similar to that at TAR, with a few slight differences (Figure 5.11b,c). TAR2 gains more energy from sensible heat, particularly during times that the surface is melting, reflecting warmer air temperatures that more frequently exceed $0^{\circ} \mathrm{C}$ at this low elevation site. TAR2 has larger magnitude turbulent fluxes than TAR because larger surface roughness lengths are used at TAR2. Larger surface roughness lengths are also used at CAA, but lower wind speeds there compensate for the difference. 

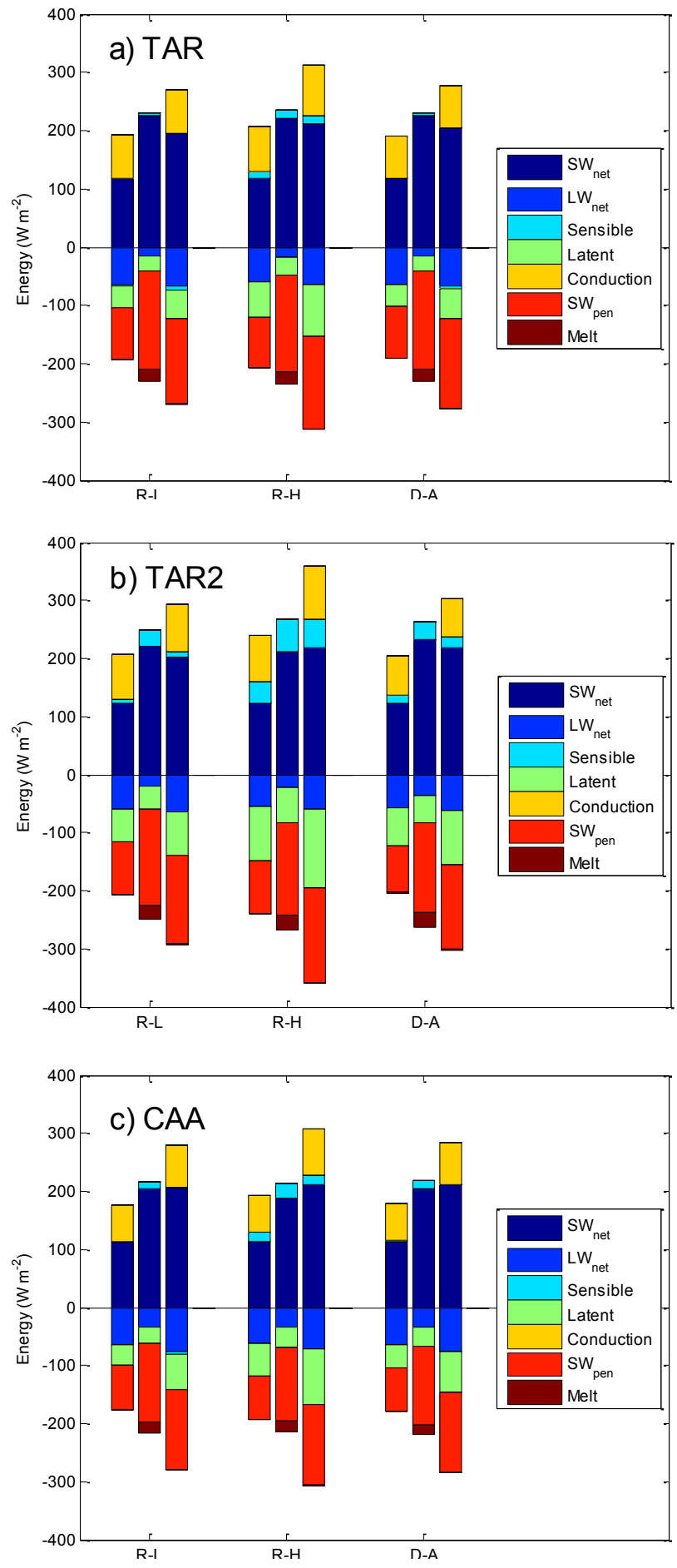

Figure 5.11: Surface energy balance terms at a) TAR, b) TAR2, and c) CAA for different model configurations. Within each grouping, the left column is the average for the entire summer, the middle column is the average for hours when surface melt occurred, and the right column is the average for hours when subsurface melt occurred. $S W_{\text {pen }}$ is penetrated net solar radiation. 


\subsubsection{Ablation Partitioning}

The final model configurations (Table 5.5) result in very low melting, even in high ablation years. To assess the possibility that a different parameter choice would lead to greater melting, I developed histograms of melt generation for all parameter combinations (Figure 5.12). Considering high and low ablation rate summers separately, I calculate the fraction of total ablation from melt or drainage of subsurface melt for all parameter combinations using both the Refreezing and Drainage models. I assign a likelihood to each model run that is proportional to the squared inverse of the goodness of fit (mean absolute error in summer ablation). The likelihood of each model is also weighted by the "volume" it fills in our three-dimensional parameter space. In this way I can summarize the range of plausible ways that ablation may be partitioned into sublimation, surface melt, and drainage of subsurface melt.

For all three sites there is a low likelihood that surface melt (blue and red lines in Figure 5.12) makes up more than $10 \%$ of total ablation during low ablation rate years, supporting my interpretation that ablation during these summers is composed almost entirely of sublimation. For the high ablation rate summers, similarly low melt fractions are most likely at all sites, consistent with the low melt rates predicted by our final model configurations. However, the distribution of the fraction of total ablation from surface melt for the Refreezing Model (blue lines) is bimodal at each site, with a secondary peak between $30 \%$ and $50 \%$. This secondary peak has a low likelihood at TAR but at the other two sites is almost equally likely as the peak near $10 \%$. These peaks correspond to the 
band of lower error parameter combinations with a SRSF of around 40\%-60\% (Figures 5.7 - 5.9: b) that I hypothesized to be artifacts in Section 5.4.4.

Using the Drainage Model, the role of surface melt during high ablation rate summers (thick red lines) is harder to constrain. At TAR it is most likely that surface melt composes no more than $20 \%$ of total ablation during high ablation rate summers, and drainage of subsurface melt makes up nearly half of all ablation. In contrast, at TAR2 it is likely that both surface melt and subsurface melt are not large fractions of ablation, but there the distributions are fairly flat so there is considerable uncertainty. At CAA there is a bimodal distribution of surface melt contribution to ablation using the Drainage Model in high ablation rate summers, with likely values near $0 \%$ and $30 \%$. The peak at 30\% corresponds to small grain radii in Figure 5.9d. It may represent reduction of the effective ice grain radius due to drainage of subsurface melt, resulting in more energy absorbed within the surface layer (increase of SRSF). Though evidence for such a process is inconclusive (Appendix B), if it occurs it would create a negative to feedback to additional subsurface melting but a positive feedback to melting at the surface.

The fraction of ablation from subsurface drainage (yellow lines in Figure 5.12), particularly at CAA, is interesting in that it has a very high likelihood near $90 \%$. It is unclear what the physical significance of this is, but it may be interpreted as sufficient reduction in density due to drainage as to cause collapse of the overlying ice in the surface layers. During the highest melt summer on record (2001-2002), a thin crust was observed that could not support the weight of a person overlying a void space filled with air, water, and slush (Andrew Fountain, pers. comm.). These conditions occurred on 
Canada Glacier but not on Taylor Glacier, suggesting that such a high fraction of ablation from subsurface melt may be possible. 

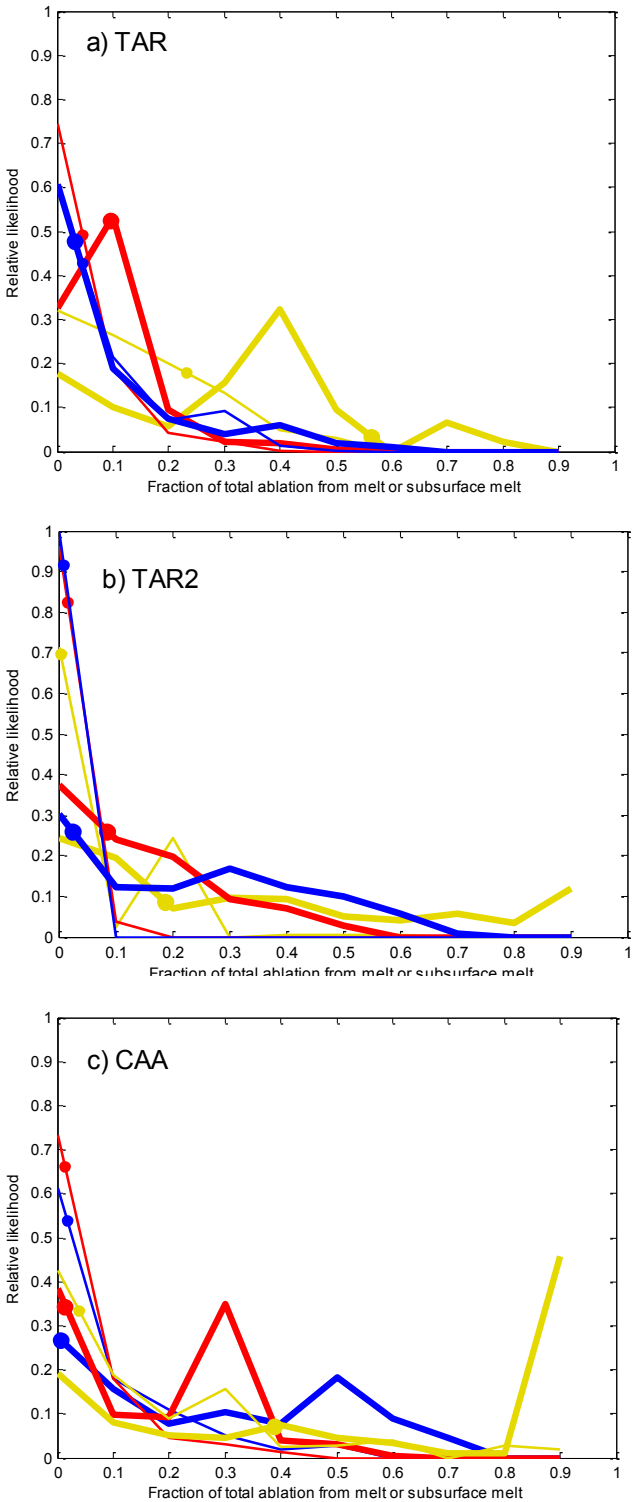

Figure 5.12: Fraction of total ablation from melt or subsurface melt at a) TAR, b) TAR2, and c) $C A A$. Each line is a histogram of relative likelihood over the range of parameters considered. Blue is surface melt for the Refreezing Model, red is surface melt for the Drainage Model, and yellow is the contribution from drainage of subsurface melt for the Drainage Model. Thin lines are for low ablation rate years, and thick lines are for high ablation rate years. The circles on each line mark the location of the final model configurations used (Table 5.5). The ranges of parameters shown in Figures 5.7 - 5.9 are used to calculate the relative likelihood values, considering variations in $z_{0}$ and $r_{\text {eff }}$ in log space. The relative likelihood estimated from each model run is weighted proportionally by the volume of parameter space the run represents and inversely by the square of the mean absolute error in summer ablation associated with the run. Runs with mean absolute error of greater than $5 \mathrm{~cm}$ weq are ignored. Bin size of histograms is 0.1 , and relative likelihood is plotted at the left edge of each bin. 


\subsubsection{Effects of Snowcover}

As described previously, the model uses a simplistic treatment of snow, merely ignoring ablation that occurs when snow is present without including the thermal and optical effects of snowcover. To explore the limitations of that approach, I developed another version of the model that explicitly includes these effects. The presence of snowcover has two competing effects on the temperature of the ice underneath the snow. Snow has a lower thermal conductivity than ice, which reduces the rate of heat exchange between the atmosphere and the ice. The thermal effect of snowcover during summer will be to trap heat within the solar-heated ice, resulting in higher ice temperatures than without snow. The thermal effect may be offset by snow albedo which reduces solar radiation flux to the ice. Snow has higher rates of extinction of solar radiation than ice due to smaller effective grain radii and lower density, such that more solar radiation is absorbed near the surface of snow than ice (Brandt and Warren 1993). These optical effects can greatly reduce the solar radiation flux reaching the ice underneath a snowcover and may result in lower ice temperatures than without snow. The relative impact of these two competing effects is a complex interaction of the depth, density, thermal conductivity, albedo, and effective snow grain radius, all of which change over time.

For the model version that explicitly includes snowcover, a new model layer for snow is introduced above the ice layers when snow is present on the glacier surface. The snow layer is assigned the following properties that differ from those of the underlying ice: thickness, density, thermal conductivity, effective snow grain radius, albedo, surface 
roughness length and initial temperature. After assigning values for each of these properties, I assess the importance of thermal and optical properties of snow by comparing modeled ice temperatures to temperatures measured by thermistors in the upper $50 \mathrm{~cm}$ of the ice when snow is present on the surface.

The snow layer has a thickness prescribed by sonic ranger measurements when available, or a constant value of $5 \mathrm{~cm}$ when sonic ranger measurements are unavailable but albedo is above the snow threshold (Chapter 2). The snow layer uses a density of 300 $\mathrm{kg} \mathrm{m}^{-3}$, the average value measured in mass balance measurements on Taylor Glacier. Though snow density is highly variable in space and time (Fountain et al. 2010), I use a constant value due to lack of knowledge about the variability. In conjunction with thermal conductivity, snow density affects thermal diffusivity, and it affects radiation penetration in conjunction with effective grain radius and albedo. I use a surface roughness length of $0.1 \mathrm{~mm}$ for snow, which is typical for Antarctic snow (Brock et al. 2006). For simplicity, a new snow layer is given an initial temperature equal to the temperature of the top ice layer.

Thermal conductivity can vary over an order of magnitude and is dependent on snow density and temperature (Fukusako 1990, Paterson 1994). Because snow thermal conductivity is poorly constrained, I run the model using the range of plausible values, from 0.05 to $0.4 \mathrm{~W} \mathrm{~m}^{-1} \mathrm{~K}^{-1}$. This represents the approximate range of values for snow with density between 100 and $400 \mathrm{~kg} \mathrm{~m}^{-3}$ (Fukusako 1990), the range of densities measured in the Dry Valleys. These values are valid for snow temperatures between -10 to $0^{\circ} \mathrm{C}$, which is appropriate for summer. 
Albedo is well-known through pyranometer measurements, but there is uncertainty in effective snow grain radius. The net bulk-extinction coefficient increases with effective grain radius and density (Brandt and Warren 1993, Liston et al. 1999). The optical grain size of snow varies from $0.05 \mathrm{~mm}$ to $1 \mathrm{~mm}$ (Warren 1982), and previous researchers using derivations of the Brandt and Warren (1993) model have used a range of values between 0.1 and $0.35 \mathrm{~mm}$ for snow (Brandt and Warren 1993, Liston et al. 1999, Kuipers Munneke et al. 2009), which is comparable to the values I calibrated for ice. Note that because of the difference in density, snow will have lower extinction coefficient than ice with the same effective grain radius (Figure 5.5). Even so, the higher albedo of snow reduces the radiative heating of snowpacks relative to ice with the same effective grain radius. I consider a range of effective snow grain radii within the model of 0.005 to $0.12 \mathrm{~mm}$.

Within the model I calculate the flux divergence of solar radiation (radiative heating) for a theoretical $15 \mathrm{~m}$ column of snow with the chosen optical properties. I use this profile to calculate the fraction of net solar radiation absorbed within a given snow depth, rather than explicitly calculating a two-layer optical model with snow over ice. Then, when snow is present on the surface in the melt model, the model determines how much solar radiation would be absorbed within the snow layer using the snow depth and the flux divergence profile. That amount of energy is used in the surface energy balance at the snow surface, temporarily replacing the SRSF used for ice. This approach does not require that the SRSF for snow be consistent with the values found for ice during 
calibration. However, the purpose of this exercise is to assess the effect of snowcover on ice temperatures which should be largely independent of the SRSF used for the snow.

The remainder of solar radiation that reaches the ice column is distributed with depth using the ice bulk extinction coefficient (with $\mathrm{r}_{\text {eff }}=0.1 \mathrm{~mm}$ ) as before. This is a somewhat simplistic treatment of a complicated process - the solar radiation profiles in the snow and ice are not independent. For example, the snow will absorb most of the infrared radiation, which changes the solar spectrum at the ice surface. However, I consider this a reasonable approximation without modifying the two-stream radiative transfer model to allow depth variant optical properties, particularly given the degree of uncertainty in parameter values. This approach is also computationally efficient because it avoids having to recalculate extinction coefficients every time the snow depth changes.

To assess the effects of snow, I identified four time periods when snow depth is known from sonic ranger measurements and ice temperatures are measured by thermistors with well-known depths (Figures 5.13-5.16). Though only four such periods are available, there is a wide range of effects from snowcover on ice temperatures. In the first example, at TAR, the original model version that ignores thermal and optical effects of snow matches measured ice temperatures well under a snowcover of about $5 \mathrm{~cm}$ (Figure 5.13). Adding in the thermal and optical effects of snow produces little change in ice temperature when snow thermal conductivity is high $\left(0.4 \mathrm{~W} \mathrm{~m}^{-1} \mathrm{~K}^{-1}\right)$, but results in ice temperatures that are up to $5^{\circ} \mathrm{C}$ higher than measured when thermal conductivity is at the low end of plausible values. In contrast, for the two time periods investigated at HOD (Figures 5.14-5.15), the original model version that ignores thermal and optical effects of 
snow produces ice temperatures that are substantially lower than measured. To reproduce measured ice temperatures requires including snow with low thermal conductivity and large effective grain radius. This holds for both thin (1-5 cm, Figure 5.15) and thick (5-10 cm, Figure 5.14) snowcover. The last example, at $\mathrm{COH}$ (Figure 5.16), is a little more difficult to interpret because modeled ice temperatures do not match measured ice temperatures well prior to the arrival of snow. However, this appears to be a case where the thermal and optical effects of snow largely cancel - the original model version that ignores thermal and optical effects of snow matches measured ice temperatures well during a thin snowcover. In this case, a moderate value of snow thermal conductivity is needed to reproduce measured ice temperatures.

Thus, including the thermal and optical properties of snow generally results in modeled ice temperatures that are higher than if snow is ignored, but there are also situations where inclusion of these effects results in substantially lower modeled ice temperatures if snow thermal conductivity is high (Figures 5.15 and 5.16). In most cases, variations in effective snow grain radius have negligible effect on ice temperatures when snow thermal conductivity is high (Figures 5.13-5.15). However, when snow thermal conductivity is low, the choice of effective snow grain radius can alter ice temperatures by $1-4^{\circ} \mathrm{C}$ through variations in the amount of solar radiation that is able to penetrate the snow. In the last example (Figure 5.16) the effect of variations in effective snow grain radius are similar at high and low thermal conductivities. These differences may be a function of incoming solar radiation and albedo (which vary between and during these examples), for when net solar radiation is low, variations in solar heating have less 
impact. Similarly, variations in thermal conductivity of snow are less important during times when the snow surface temperature is close to the ice temperature beneath the surface and conduction is low.

These examples show that for the relatively thin snow depths that are common for the Dry Valleys $(2-10 \mathrm{~cm})$ (Fountain et al. 2010), the effect of snow on ice temperatures is equivocal. Furthermore, the effect of modeling the thermal and optical effects of snow is equivocal - resulting modeled ice temperatures can be higher, lower or the same as when ignoring these effects. The variability in the response is likely largely due to the variability in time and space of the physical properties of snow. As discussed in Chapter 2, I observe differences in snow presence (and by extension, snow depth) over the $\sim 1 \mathrm{~m}$ between the sonic rangers measuring snow depth and pyranometers measuring albedo, and I expect similar differences between the sonic rangers and thermistors measuring ice temperature. The physical properties of snow also vary in time: density and grain size tend to increase, and albedo tends to decrease over time. These examples show that given such high variability, it is difficult to model snow properly even when snow depth is well-known at one location. In some cases, ignoring the thermal and optical properties of snow performs as well or better than attempting to include those effects.

Given this, and the fact that snow depth is unmeasured for the majority of the time period I consider and for the entire time period at CAA, I consider the original model version that ignores snow to be adequate. I concede that this can result in errors in ice temperature of $5-10^{\circ} \mathrm{C}$ under thick $(>10 \mathrm{~cm})$ or extended $(>2$ weeks) snowcover. 


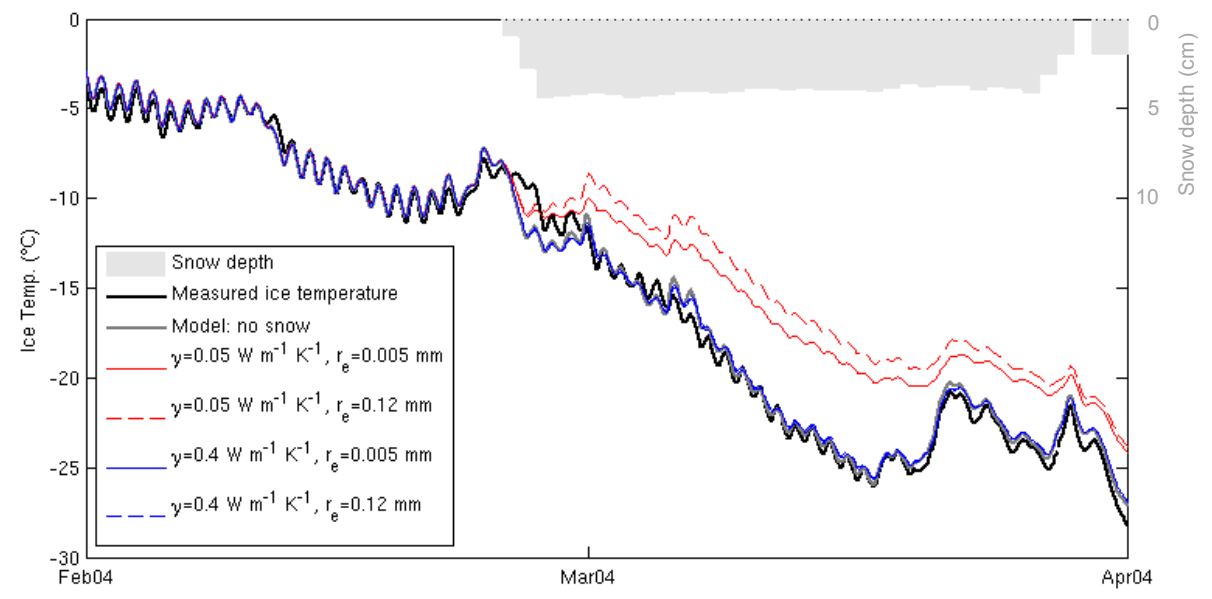

Figure 5.13: Ice temperatures at TAR, fall 2004, 30 cm depth. Black line is ice temperature measured by a thermistor. Ice temperatures were modeled ignoring thermal and optical effects of snow (gray line), and using the range of plausible values for snow thermal conductivity and snow effective grain radius (red and blue lines). Snow depth as measured by sonic ranger is shown with light gray shading.

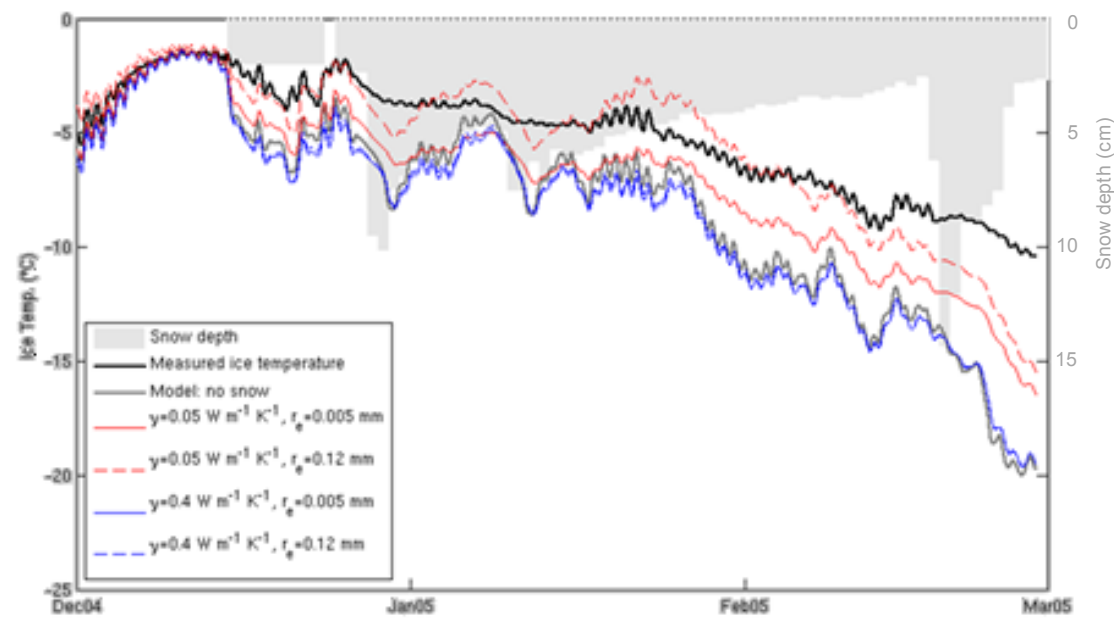

Figure 5.14: Ice temperatures at HOD, summer 2004-2005, 32 cm depth. Black line is ice temperature measured by a thermistor. Ice temperatures were modeled ignoring thermal and optical effects of snow (gray line), and using the range of plausible values for snow thermal conductivity and snow effective grain radius (red and blue lines). Snow depth as measured by sonic ranger is shown with light gray shading. 


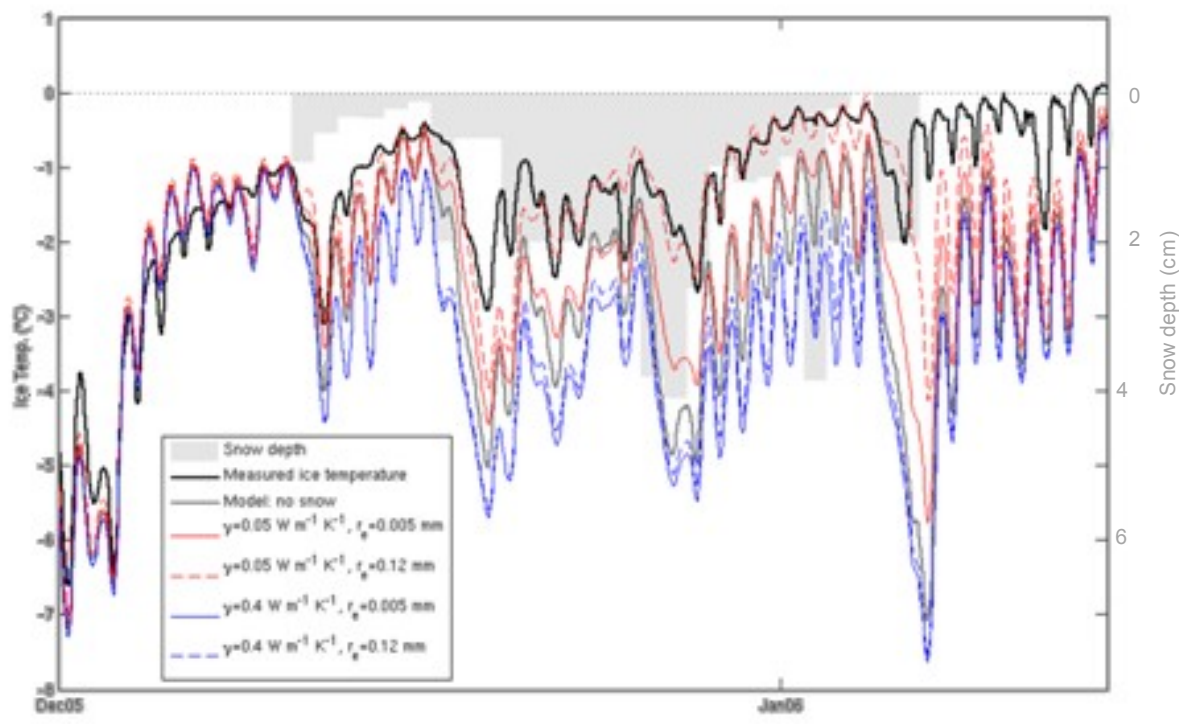

Figure 5.15: Ice temperatures at HOD, summer 2005-2006, 27 cm depth. Black line is ice temperature measured by a thermistor. Ice temperatures were modeled ignoring thermal and optical effects of snow (gray line), and using the range of plausible values for snow thermal conductivity and snow effective grain radius (red and blue lines). Snow depth as measured by sonic ranger is shown with light gray shading.

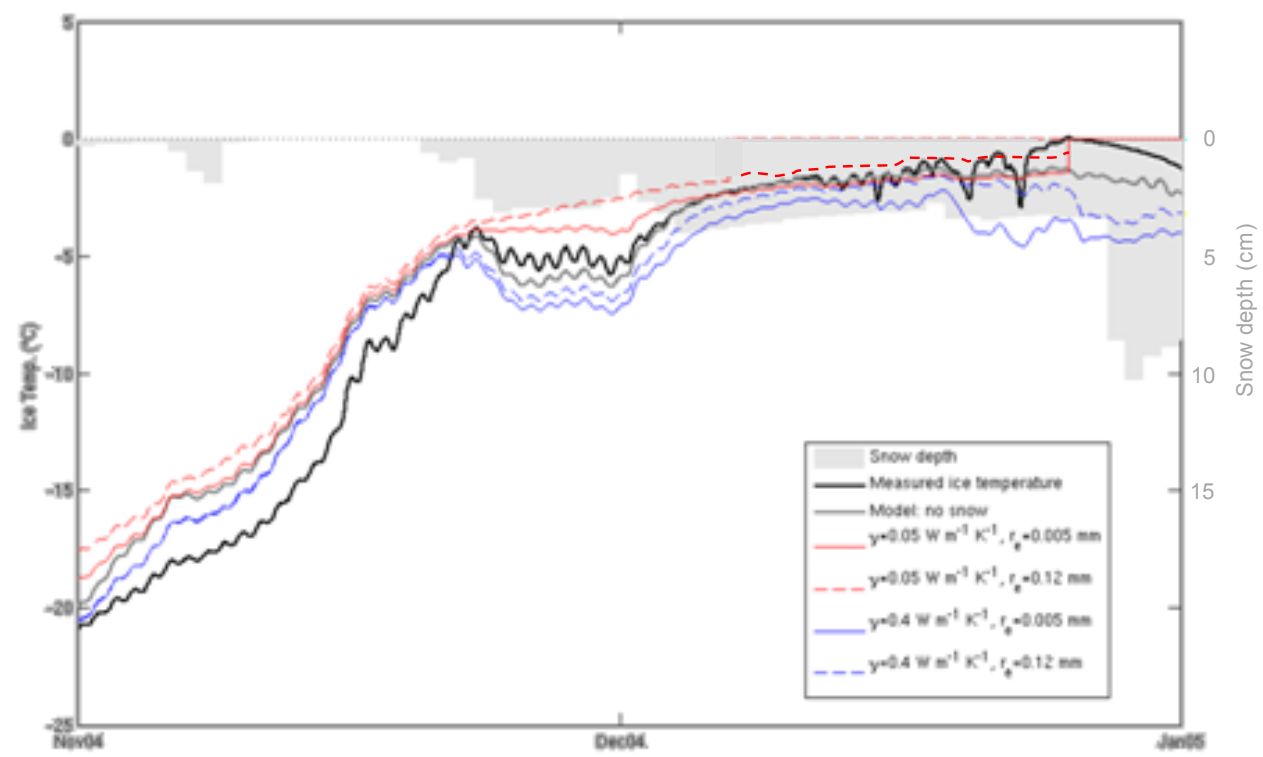

Figure 5.16: Ice temperatures at COH, summer 2004-2005, 40 cm depth. Black line is ice temperature measured by a thermistor. Ice temperatures were modeled ignoring thermal and optical effects of snow (gray line), and using the range of plausible values for snow thermal conductivity and snow effective grain radius (red and blue lines). Snow depth as measured by sonic ranger is shown with light gray shading. 


\subsection{Discussion}

\subsubsection{Energy Balance and Melt Characteristics}

The summer energy balance at Taylor Glacier calculated with our hourly timestep model is consistent with the energy balance calculated with the daily time-step model (Hoffman et al. 2008). Both have net shortwave radiation as the primary source of energy to the surface, and net longwave radiation and latent heat as the primary energy losses. However, the hourly model uses a much smaller SRSF value, so most of the net solar radiation penetrates the surface layer in the hourly model, but is absorbed within the surface layer in the daily model. Accordingly, conduction to the surface is an order of magnitude larger with the hourly model, as much of the solar radiation absorbed internally is returned to the surface.

As discussed in Chapter 4, the summer energy balance I calculate is similar to that calculated previously for ice surfaces at Taylor (Johnston et al. 2005) and Canada (Lewis et al. 1998) glaciers, as well as Antarctic blue ice areas (Bintanja and van den Broeke 1995b) and glaciers on Mount Kilimanjaro (Mölg and Hardy 2004). The energy balance at these polar and high elevation locations differs from that at temperate glaciers where sensible heat, and to a lesser extent, latent heat provide energy to the surface (Hock 2005).

The hourly and daily models calculate very different magnitudes of surface and subsurface melt at TAR. Averaged over all summers, the daily model calculates $1.7 \mathrm{~cm}$ weq of surface melt and a maximum water column depth of $0.3 \mathrm{~cm}$ (Chapter 4 / Hoffman et al. 2008). In contrast, with an hourly time step the Refreezing Model calculates $0.5 \mathrm{~cm}$ 
weq of surface melt and a maximum water column depth of $9.4 \mathrm{~cm}$. The Drainage Model calculates a similar amount of surface melt plus $2.6 \mathrm{~cm}$ of drained subsurface melt contributing to ablation during the average summer. However, the daily model uses a surface layer thickness of $13 \mathrm{~cm}$, while the hourly model uses $0.5 \mathrm{~cm}$, making a direct comparison inappropriate. With the hourly model, $72 \%$ of subsurface melt occurs in the upper $13 \mathrm{~cm}$. Thus, when considering over the same depths, the two models are roughly consistent. The daily model has too coarse of a vertical resolution to resolve the internal melt occurring in the upper $13 \mathrm{~cm}$, but the mass of ice lost in that layer broadly agrees with the more detailed calculations using the hourly model with finer vertical resolution. As the surface layer thickness was calibrated in both models based on the SRSF, it appears that if one wishes to adjust the vertical resolution of melt prediction near the surface, the time step must be adjusted accordingly, and it is not possible to resolve fine vertical structure with a coarse time step.

\subsubsection{Drainage of Subsurface Melt}

Subsurface melting is difficult to observe directly in the field due to the difficulty of uninvasively accessing the subsurface. However, ice density measurements of lower ice density near the surface in summer (Figure 2.9) suggest that subsurface melting occurs and that some fraction of it drains. In addition to the field evidence, this is supported by the model. Of the final model configurations (Table 5.5), I consider the Drainage Model to be more probable based on four lines of reasoning:

In calibrating effective ice grain radius, I showed that the Refreezing Model generated ice temperatures that were too high late in some summers due to storage of 
latent heat in subsurface melt, unless a small ice grain radius was used $(\sim 0.01 \mathrm{~mm})$. However, a larger grain radius is supported by comparison to thermistors during early and midsummer (Appendix B) and by comparison to measurements of downwelling solar radiation within the ice (Figure 5.5). Thus, a more plausible explanation of late summer ice temperatures is through removal of latent heat stored in subsurface meltwater through drainage. This drain-cooling of the ice is analogous to the refreeze-warming of melting snowpacks.

Similarly, the Refreezing Model predicts unrealistically high subsurface water fractions in extreme years (e.g. 2001-2002), even with a small grain radius (Figure 5.4). This is additional evidence that some water must drain, removing latent heat.

Fitting ablation with the Refreezing Model in high ablation rate summers requires assuming that melt roughens the surface, increasing $\mathrm{z}_{0}$ and, in turn, sublimation. However, the magnitude of surface melt modeled is very small, even for the high ablation rate summers with low $\mathrm{z}_{0}$. Such small amounts of melt are unlikely to be sufficient to roughen the surface, unless localized melt in blue or dirty ice is sufficient to change the aerodynamic properties of the glacier surface at the fetch scale. Alternatively, the surface is roughened as internally weathered ice is revealed through sublimation at the surface. Such an explanation requires drainage of subsurface melt.

An alternate explanation of high ablation rate summers is that grain radius decreases, increasing SRSF, and therefore melt. The most plausible mechanism for decreasing effective grain radius is drainage of subsurface meltwater introducing air voids that increase scattering. 
It is possible that there are multiple differences between low and high ablation rate summers. For instance, it may be that surface roughness increases, and drainage of subsurface melt decreases ice density resulting in decreased effective grain radius and increased SRSF. However, I feel there is sufficient evidence to support the drainage of subsurface melt, and this explanation is attractive in that it does not require changing model parameters for different years.

Because the ice column in the model does not adjust as ablation lowers the surface, I see a maximum density reduction at 5-15 cm depth (Figures 5.3 - 5.4, Appendix B), depending on grain radius used. Additionally, because density does not evolve with the model, but density adjustments are post-processed, in some extreme cases I calculate densities below 0 , which is physically impossible (Figure 5.17). However, if the calculation of ice density includes the effect of ice surface lowering, more reasonable values of minimum summer density are obtained. For the extreme melt year of 20012002, a minimum density of about $200 \mathrm{~kg} \mathrm{~m}^{-3}$ is achieved in late December before being largely excavated by surface ablation within a few weeks (Figure 5.17). Ice with such a low density may not be structurally coherent, and is consistent with observations on Canada Glacier of a thin surface layer of ice overlying a mixture of air, ice, and water during that summer. In a more typical year, ice density is not reduced below $750 \mathrm{~kg} \mathrm{~m}^{-3}$, and a density profile is obtained that is very similar to that observed (Figure 5.18).

Reduced density ice may remain in the upper $5-10 \mathrm{~cm}$ at the start of winter in most years (e.g. Figure 5.18). Given that total winter ablation is on the order of $5-15 \mathrm{~cm}$ weq (Table 5.1), failure to account for this may be overestimating winter mass loss. In 
calibrating surface roughness length, I found that winter needed values almost an order of magnitude higher than early summer or low ablation rate summers at some sites (Table 5.3). However if I adjust the winter mass balance measurements to an ice density of 750 $\mathrm{kg} \mathrm{m}^{-3}$ from the assumed value of $870 \mathrm{~kg} \mathrm{~m}^{-3}$, the calibrated surface roughness value for winter at TAR reduces from $0.15 \mathrm{~mm}$ to $0.06 \mathrm{~mm}$, in line with the $\mathrm{z}_{0}$ values calibrated for low ablation summers.

Thus the modeling suggests an annual cycle of ice density variations in the nearsurface layer (upper $\sim 20 \mathrm{~cm}$ ) of the ice on the Dry Valley glaciers. Ice far below the surface has a density of about $870 \mathrm{~kg} \mathrm{~m}^{-3}$, and at the beginning of summer ice at the surface has this density. During summer, drainage of subsurface melt gradually lowers the density in the near-surface layer. This mass loss is centered on a depth between 5 and $10 \mathrm{~cm}$ below the surface where subsurface melting is greatest. However, the ice often develops a density profile that increases with depth below the surface because ablation at the surface lowers the surface into the zone of reduced density while the depth of subsurface mass loss remains fixed. Unaltered ice from below achieves shallower depths as the surface lowers as the process continues over the course of the summer. Subsurface melt appears to continue through much of summer, but when it ceases for extended periods and at the end of the summer, a layer of reduced density ice remains until ablation at the surface is sufficient to eliminate it. The rate of surface ablation is low enough for that to require most of winter to occur, but high enough that all of the weathered ice is sublimated away before subsurface melt begins again the following summer. This is comparable to the cycles of weathering crust development and 
elimination observed over the course of days by Müller and Keeler (1969) on White Glacier in the Canadian Arctic, but it occurs over an annual cycle in Taylor Valley due to lower ablation rates. 


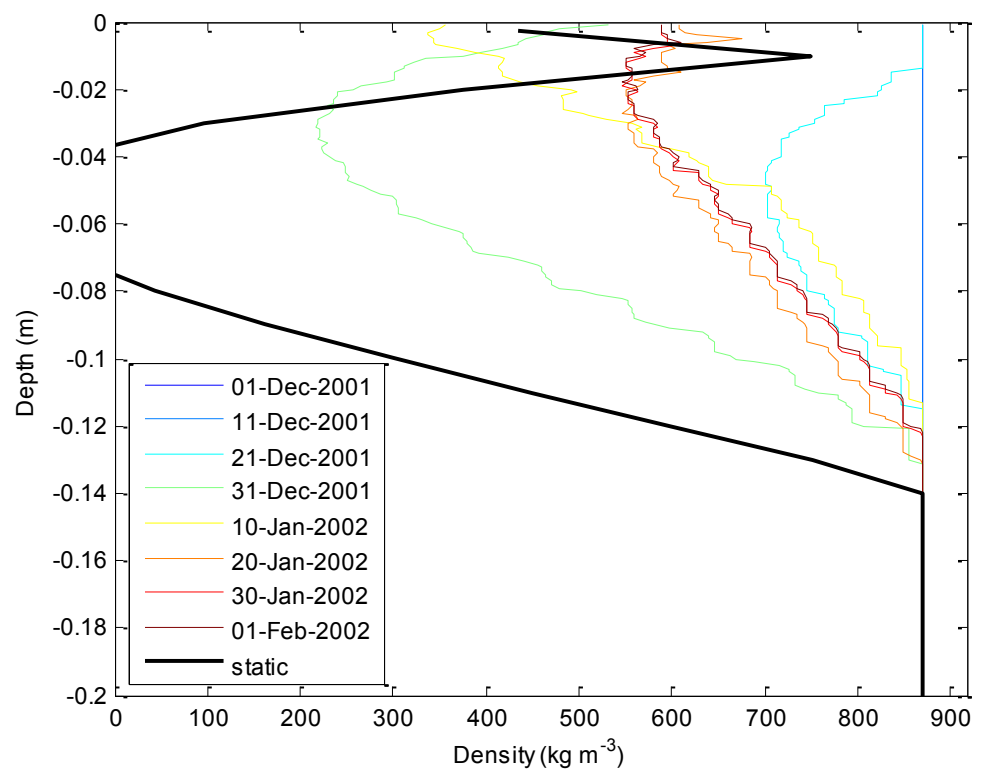

Figure 5.17: Density evolution at CAA in 2001-2002. The static case corresponds to a calculated density on February 1 without accounting for lowering of the ice surface through ablation.

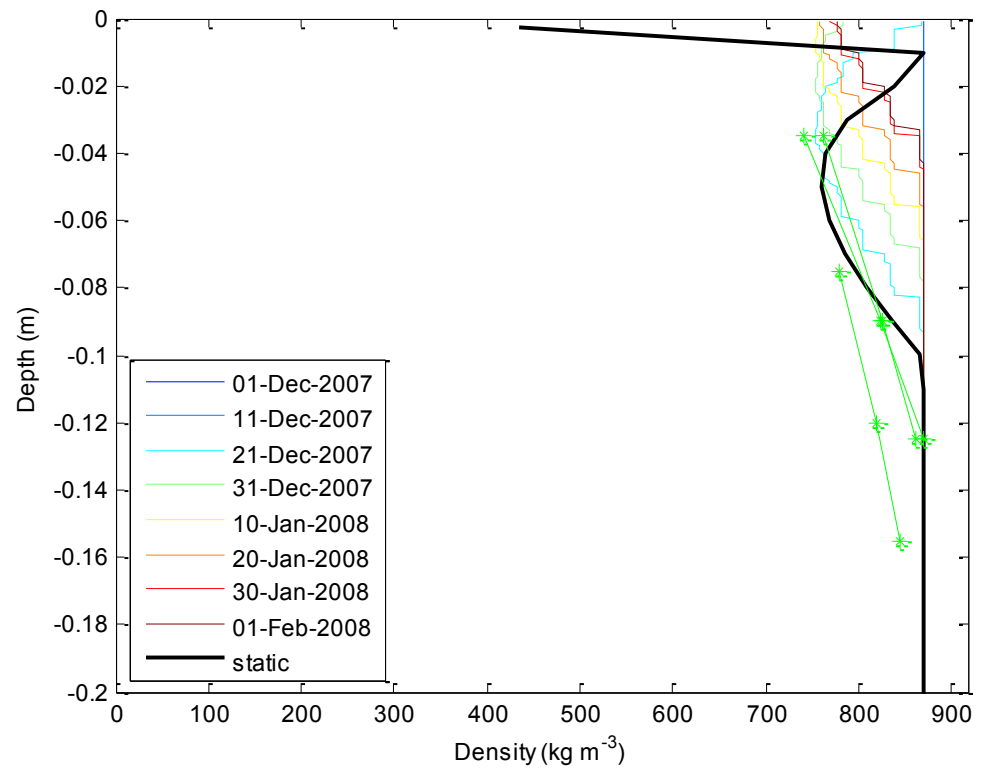

Figure 5.18: Density evolution at CAA in 2007-2008. The static case corresponds to a calculated density on February 1 without accounting for lowering of the ice surface through ablation. The green lines with asterisks are density profiles measured on December 17, 2007 on lower Canada Glacier. 


\subsubsection{Partitioning of Net Shortwave Radiation}

Little agreement exists on the proper partitioning of net shortwave radiation between the surface and the subsurface. Many glacier energy balance studies assume that all net shortwave radiation is absorbed at the surface (i.e. SRSF=100\%). For glaciers with a high degree of melting and isothermal temperatures this may be a reasonable simplification. Rapid ablation quickly exhumes ice with density reduced due to internal melting, so there is little net difference between including radiation penetration or not (van den Broeke et al. 2008).

When the surface ice may be below the melting point, many energy balance studies divide the net shortwave radiation into a surface fraction and a penetrated fraction, as I have done. However, the partitioning used varies significantly, as do the surface layer thickness and time steps in the associated models. Most studies use solar penetration methods based on Greuell and Oerlemans (1989) who divided the net shortwave radiation into two wavelength bands. The infrared portion (wavelengths $>800$ $\mathrm{nm}$ ) was assumed to be completely absorbed in a constant $6 \mathrm{~cm}$ thick surface layer, yielding $\mathrm{SRSF}=36 \%$. The remainder was assumed to decay exponentially with depth according to Bier's law using a broadband extinction coefficient. This SRSF value of $36 \%$ has been adopted by other studies using a range of surface layer thicknesses from 3 to $12 \mathrm{~cm}$ and time steps ranging from 1 minute to 1 hour, while other studies have used the same approach but with a SRSF of $80 \%$ (Table 5.6). More recently, van den Broeke et al. (2008) and Kuipers Munneke et al. (2009) applied the model of Brandt and Warren 
(1993) in a similar fashion to what I have done for snow and ice in Greenland (Table $5.6)$.

The SRSF can be compared to the practice commonly used in sea ice models of specifying the flux of radiative energy that passes through the surface into the ice, commonly represented as $\mathrm{I}_{0}$, and removing that flux from the surface energy balance (Maykut and Untersteiner 1971, Launiainen and Cheng 1998). In sea ice modeling, the surface layer is typically defined to be $10 \mathrm{~cm}$ thick, as this is the depth by which most shortwave infrared energy has been absorbed, leaving only visible light with a spectrally more uniform extinction coefficient. Thus, the broadband extinction coefficient becomes relatively constant with depth below this point (Grenfell and Maykut 1977). Using this fact, sea ice models typically use an exponential decay for the penetrated solar radiation below $10 \mathrm{~cm}$ (Maykut and Untersteiner 1971, Launiainen and Cheng 1998), as done by Greuell and Oerlemans (1989) for glacier ice. Most sea ice models use either the single value of $\mathrm{I}_{0}$ deduced by Maykut and Untersteiner (1971) based on two sets of previous measurements $\left(\mathrm{I}_{0}=17 \%\right.$; SRSF $\left.=83 \%\right)$ or the set of values calculated by Grenfell and Maykut (1977) for different ice types and cloud conditions ( $\mathrm{I}_{0}=18-63 \%$; $\left.\mathrm{SRSF}=82-47 \%\right)$. Most sea ice applications use a time step on the order of 8 hours, but a range of time steps have been used with these standard $\mathrm{I}_{0}$ values.

Little discussion exists in the glacier or sea ice energy balance literature regarding the uncertainty or variability of SRSF or $\mathrm{I}_{0}$, despite the conclusion by the authors of the original $\mathrm{I}_{0}$ model formulation that more careful studies of $\mathrm{I}_{0}$ were needed (Maykut and Untersteiner 1971). This is justifiable for sea ice because long-term coordinated 
measurements of ablation and meteorological variables with which to calibrate surface energy balance models is logistically difficult on sea ice. The most detailed sensitivity analysis was done in the original study. Maykut and Untersteiner (1971) found that modeled sea ice thickness increases as more solar radiation is partitioned into the subsurface because less energy is available at the surface for melting. The additional energy stored within the ice does not increase the conductive flux to the surface appreciably because the summer temperature gradient cannot change much since ice temperatures cannot increase above the melting temperature. This is similar to what I find in my calibration process. Semtner (1984) also found that increasing the fraction of shortwave radiation penetrating into the subsurface increased modeled sea ice thickness. In addition, he found that while the fraction of penetrating shortwave radiation does not affect the timing of maximum ice thickness, increasing the penetrating fraction results in a significantly later date of minimum ice thickness - the length of the melt season is largely governed by latent heat stored in brine pockets in the ice, an effect that I see as well.

Based on this review, it appears that most applications of radiation penetration are based on a few early studies, with variations that differ markedly from the original formulations. The fact that most of the energy balance studies perform well suggests that accurate partitioning of shortwave radiation is not crucial for many of these applications. Most of the studies mentioned consider conditions where melt is substantial (e.g. van den Broeke et al. 2008) or not observed at all (e.g. Bintanja and van den Broeke 1995b). However, I have shown here that ablation calculations for glaciers in the Dry Valleys are 
very sensitive to SRSF for summers when melt occurs, and this is presumably because ablation is low enough that accounting for mass loss below the surface is important. For the optimal model configurations, I find $\mathrm{SRSF}=\sim 30 \%$ (Table 5.5), and in no case would SRSF greater than $60 \%$ provide reasonable ablation estimates (Figures 5.7 - 5.9).

However, with the daily time step model I used SRSF=82\% (Chapter 4 / Hoffman et al. 2008). As discussed previously, I find the melt estimates of the two models to be broadly consistent, and I infer that the appropriate SRSF value is dependent on the chosen time step. In fact, surface layer thickness may be a more appropriate parameter than SRSF, as a constant surface layer thickness could more easily accommodate changes in ice optical properties.

Table 5.6: Summary of SRSF values used by selected glacier energy balance studies. G89= Greuell and Oerlemans (1989); B95=Bintanja and van den Broeke (1995b); vdB08=van den Broeke et al. (2008)

\begin{tabular}{|c|c|c|c|c|c|}
\hline Study & Location & SRSF & $\mathrm{dz}(1)$ & dt & Source \\
\hline $\begin{array}{l}\text { Greuell and Oerlemans } \\
\text { (1989) }\end{array}$ & $\begin{array}{l}\text { Laika Ice Cap, Canadian } \\
\text { Arctic }\end{array}$ & $36 \%$ & $6 \mathrm{~cm}$ & $30 \mathrm{~min}$ & G89 \\
\hline Greuell and Konzelmann & West Greenland & $36 \%$ & $3-12 \mathrm{~cm}$ & $1-30 \mathrm{~min}$ & G89 \\
\hline $\begin{array}{l}\text { Bintanja and van den } \\
\text { Broeke }(1995 b)\end{array}$ & $\begin{array}{l}\text { Dronning Maud Land, } \\
\text { Antarctica }\end{array}$ & $80 \%$ & $0.5 \mathrm{~cm}$ & $7.5 \mathrm{~s}$ & B95 \\
\hline Mölg and Hardy (2004) & Kilimanjaro & $80 \%$ & $?$ & $1 \mathrm{hr}$ & B95 \\
\hline Johnston et al. (2005) & Taylor Glacier, Antarctica & $80 \%$ & $1 \mathrm{~m}$ & $1 \mathrm{hr}$ ? & \\
\hline $\begin{array}{l}\text { van den Broeke et al. } \\
\text { (2008) }\end{array}$ & West Greenland & $?$ & $4 \mathrm{~cm}$ & $?$ & vdB08 \\
\hline $\begin{array}{l}\text { Kuipers Munneke et al. } \\
\text { (2009) }\end{array}$ & Summit Greenland, snow & $63 \%$ & $4 \mathrm{~cm}$ & $1 \mathrm{~min}$ & vdB08 \\
\hline Pellicciotti et al. (2009) & various & $36 \%$ & ? & $1 \mathrm{hr}$ ? & G89 \\
\hline $\begin{array}{l}\text { Wheler and Flowers } \\
\text { (2011) }\end{array}$ & $\begin{array}{l}\text { St. Elias Mountains, } \\
\text { Canada }\end{array}$ & $36 \%$ & $4 \mathrm{~cm}$ & $1 \mathrm{hr}$ ? & G89 \\
\hline
\end{tabular}




\subsection{Conclusion}

I have applied a surface energy balance model that explicitly includes penetration of solar radiation into the ice to glaciers in Taylor Valley, Antarctica. Inclusion of penetration of solar radiation beneath the surface is necessary to match observations of ablation and subsurface melting. By comparing a version of the model that assumes that all subsurface melt refreezes with one where some subsurface melt is able to drain, I am able to assess the role of internal melt and associated reductions in ice density (weathering). In contrast to temperate glaciers where internal melt is insignificant relative to surface melt, the glaciers in the Dry Valleys appear to have a summer energy balance where internal melting is of great importance. In extreme summers, drainage of subsurface melt may contribute up to half of the observed surface lowering through reduction of ice density and possibly through collapse of highly weathered ice. My modeling indicates that surface melt makes a small contribution to ablation, and sublimation is the dominant method of mass loss during summer, even at low elevations near the glacier termini. Where snowcover is thin, the effect of snow on ice temperatures is equivocal due to competing thermal and optical effects of the snowcover. On the Dry Valley glacier ablation zones where snowcover is rare and thin, a simpler model that essentially ignores snow performs about as well as a more complicated version that explicitly accounts for the thermal insulation provided by snow and the scattering of solar radiation within the snowpack.

My model version that assumes all subsurface melt refreezes in place requires different parameter values for summers with low and high ablation rates, while the 
version of the model that assumes some subsurface melt drains does not. I conclude that drainage of subsurface melt decreases ice density, allowing the ablation energy at the surface (primarily sublimation) to produce greater surface lowering, and this process is largely responsible for the higher ablation rates observed in some summers. Alternative hypotheses for summers with higher ablation rates are that melt roughening of the surface causes higher rates of turbulent heat losses to the atmosphere (sublimation) and suppresses further melt, or that drainage of subsurface melt decreases effective ice grain radius leading to more solar radiation scattering near the surface and enhanced surface melt. However, model support for these alternative hypotheses is inconclusive or inconsistent.

Although the contribution of internal melting to ablation measured at the surface is small in most summers, it appears that it may be as large as $40 \%$ in extreme summers. Most subsurface melting occurs between 5 and $15 \mathrm{~cm}$ below the surface, and ice below about $30 \mathrm{~cm}$ is largely unaffected by internal melting. Though subsurface melting is rare in the immediate few cm below the surface, ablation at the surface lower the ice surface into the zone of weathered ice beneath the surface. This commonly results in a density profile that increases with depth rather than having a minimum at the depth of maximum subsurface melting. On the Dry Valley glaciers, the reduction in density due to internal melting lasts through much of the following winter before sublimation is able to completely eliminate the reduced density ice. This is comparable to the cycles of weathering crust development and elimination observed over days by Müller and Keeler (1969) in the Canadian Arctic, but it occurs over an annual cycle in Taylor Valley. I also 
find that the drainage of internal melt cools the ice by removing latent heat and is an important process for ice temperatures at the end of the melt season, as has been described for sea ice (Semtner 1984).

My surface energy balance modeling was particularly sensitive to the choice of solar radiation surface fraction. I find optimal values of about $30 \%$ with a surface layer thickness of $0.5 \mathrm{~cm}$. Previous values used in the literature vary significantly, but my study indicates that determining the proper value requires careful consideration of the solar radiation extinction profile of the ice and the time step chosen. The choice of solar radiation surface fraction may be of little consequence for high ablation rate environments where ice weathered beneath the surface is quickly exhumed by surface ablation, but it has a significant effect on predicted glacier melt in a polar climate where ablation rates are low. 


\section{Chapter 6: Patterns of Meltwater Production and Runoff on Dry Valley Glaciers}

\subsection{Introduction}

The availability of liquid water is a limit to life in the McMurdo Dry Valleys, and glacial melt is the dominant source of water to the streams and lakes found there (McKnight et al. 1999). The streams in the Dry Valleys convey water from the melting glaciers to the lakes for up to 10 weeks each summer, but streamflow is highly variable at both interannual and daily timescales (McKnight et al. 1999). The Dry Valley landscape and ecosystems are sensitive to variations in water availability, yet predicting streamflow is difficult because small changes in atmospheric forcing lead to large changes in meltwater production (Dana and Wharton 1998, Fountain et al. 1998).

Previous efforts to model the glacial meltwater streams have been restricted spatially or temporally. Statistically based models (e.g. temperature index models) have been most successful at the seasonal scale and have examined the relation between temperature, solar radiation, and runoff (Bomblies 1998, Dana et al. 2002, Jaros 2003, Ebnet et al. 2005). However, because the energy balance of the Dry Valley glaciers is often near the threshold of melt during summer (Hoffman et al. 2008), statistical methods are problematic and may perform poorly if extrapolated outside of the current climate (Hock 2005).

Energy balance models, however, should be applicable across a wider range of climate forcings because they are based on physical processes. They have been 
employed successfully to investigate differences in the energy balance at a few locations on Taylor and Canada glaciers (Lewis et al. 1998, Lewis et al. 1999, Johnston et al. 2005). However, previous applications have been limited to a few summer weeks, precluding understanding of the day-to-day variation over the seasonal cycle, including the onset and termination of the melt season. Additionally, these studies do not adequately address the subsurface heating of the ice which can lead to subsurface melting and water flow (Liston et al. 1999, Fountain et al. 2004b).

In this chapter, I apply a surface energy balance model that includes detailed treatment of subsurface melting to the glaciers of Taylor Valley (Figure 6.1). To explore spatial and temporal melt variations, I apply the model over 14 years using an hourly time step and at a spatial resolution of $250 \mathrm{~m}$. Previously, in depth application of this model to a few well-studied locations revealed differences in ablation between summers with low and high ablation rates; surface melt alone cannot explain high ablation summers without invoking a change in some physical parameter (Chapter 5). I hypothesized three possible changes in high ablation summers that would allow the model to adequately predict ablation: 1) surface melt roughens the glacier surface, resulting in increased sublimation rates; 2) drainage of subsurface melt reduces ice density resulting in increased rates of surface lowering; and 3) drainage of subsurface melt increases scattering of solar radiation near the surface leading to increased rates of surface melt, with the second scenario listed here being the one I felt was most likely. These three explanations point to higher ablation rates resulting primarily from sublimation, subsurface melt, or surface melt, respectively. Here, I explore the effect that each of these scenarios has on 
meltwater runoff by comparing modeled runoff to proglacial streamflow measurements. Through this comparison I am able to highlight the importance of subsurface melt on Dry Valley glaciers, which in turn allows us to improve our ability to model the glacial meltwater streams. Though runoff routing is treated in a simple manner, the relatively good performance of the model suggests that routing is fast and losses are small.

\subsection{Site Description}

The streams in the Dry Valleys are 1 to $30 \mathrm{~m}$ wide and run for 4 to 10 weeks each summer (McKnight et al. 1999). Streamflow can vary interannually and diurnally by two to three orders of magnitude (Conovitz et al. 1998, McKnight et al. 1999). This high variability is due to the high temporal variability in source water production from melting glaciers and the lack of baseflow in the traditional sense. Groundwater flow in the Dry Valleys has been observed to be localized (Chinn 1993, Harris et al. 2005), and streamflow recession is instead dominated by water stored temporarily in the hyporheic zone (Conovitz et al. 1998). Hyporheic exchange is dependent on stream length and bank slope. On the longest streams, the hyporheic zones are capable of storing the entire seasonal flow during low runoff seasons (Bomblies 1998, Conovitz et al. 2006). The hyporheic zones expand vertically by up to $0.5 \mathrm{~m}$ over the summer season as the permafrost active layer thaws (Conovitz et al. 2006). Streamflow may be stored temporarily in the hyporheic zones or may be lost to refreezing or evaporation, contributing to high interannual variability of streamflow (Conovitz et al. 2006). 
The timing of peak flow appears controlled by the timing of peak solar radiation on glacier surfaces; the lag of the timing of peak streamflow after peak solar radiation can largely be explained by in-stream travel time (Conovitz et al. 1998). Within each catchment the horizontal glacier surfaces and the vertical glacier cliffs have similar topographic aspects, so it is difficult to determine which region of the glaciers controls the timing of peak discharge. However, because surface runoff on glaciers is rarely seen, diurnal peaks are steep, and there tend to be high peakflow to baseflow ratios, it has been suggested that the cliffs control the diurnal timing of peak runoff (Fountain et al. 1998).

I first test the spatially distributed melt model in detail at Canada Glacier (Figure 6.2) before applying it to the remainder of Taylor Valley (Figure 6.1). Canada Glacier is a valley glacier that terminates in a piedmont lobe approximately $4 \mathrm{~km}$ in diameter. The equilibrium line altitude is approximately $400 \mathrm{~m}$ (Fountain et al. 1999a). Much of the lower ablation zone is covered by high relief basins (Johnston 2004). Segments of the glacier drain into five catchments: Canada Stream, Lake Fryxell, Green Creek, Lake Hoare, and Andersen Creek (Ebnet et al. 2005) (Figure 6.2). All three streams are less than $2 \mathrm{~km}$ long and experience relatively little hyporheic storage (Conovitz et al. 1998), making them good candidates for comparing to modeled runoff. However, Canada Stream and Green Creek have ponds at the base of the glacier's terminal cliffs which likely attenuate the runoff hydrographs (Conovitz et al. 1998). 


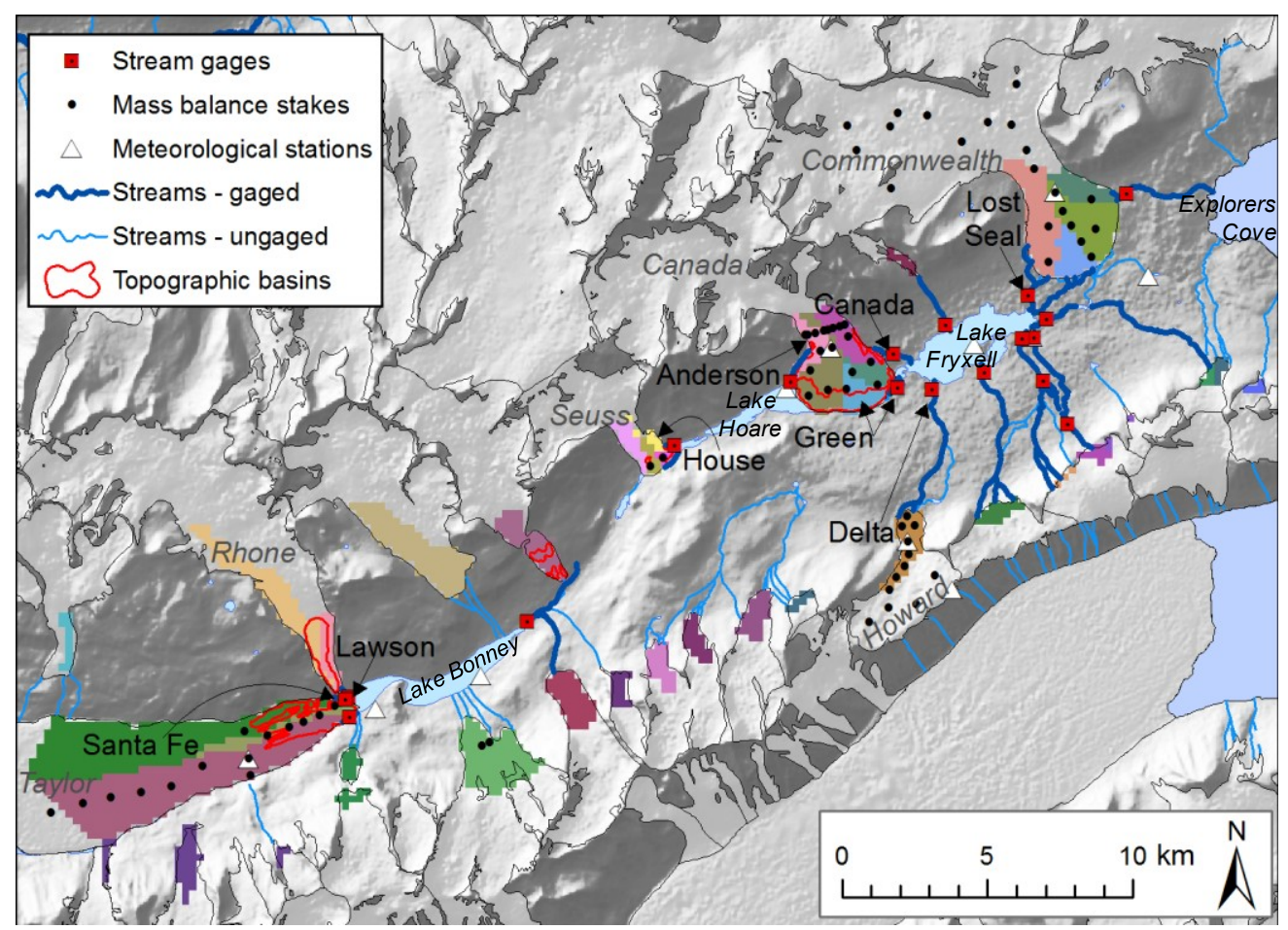

Figure 6.1: Shaded relief map of stream catchments modeled (colored areas) in Taylor Valley. Streams discussed in text and lakes are labeled in black, and glaciers are labeled in gray. Lakes and ocean are shown in light blue.

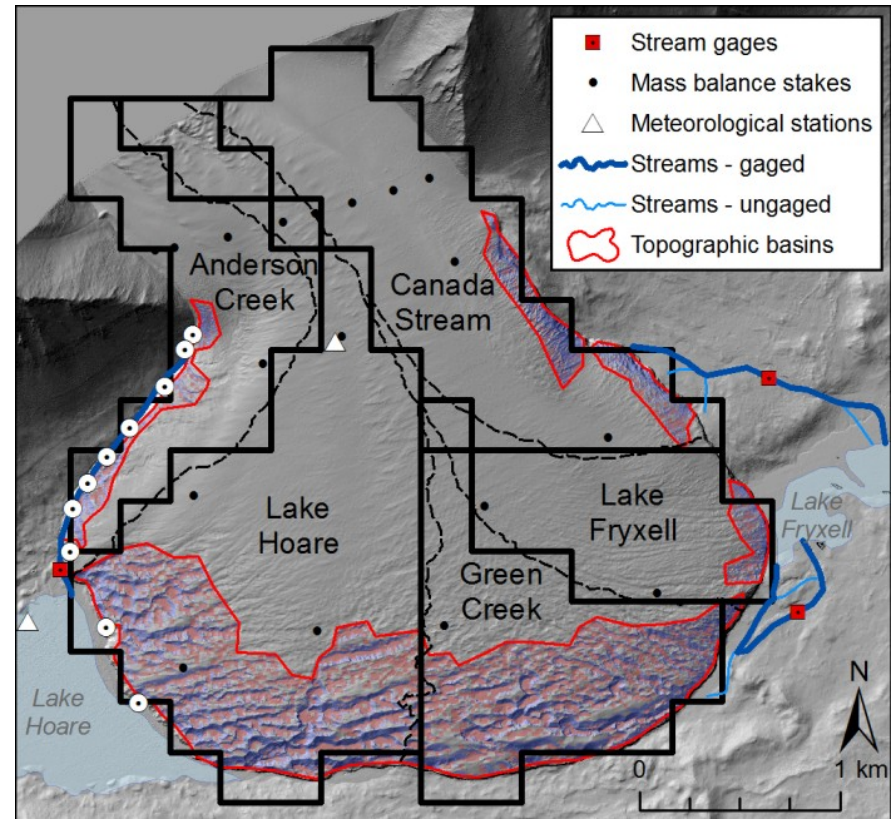

Figure 6.2: Shaded relief map of Canada Glacier showing actual (dotted black lines) and modeled (solid black lines) catchment boundaries. Basin floors are shown in red and basin walls in dark blue. Mass balance stakes installed in cliff faces are shown surrounded by a white circle. 


\subsection{Spatial Melt Model Description}

For runoff prediction I spatially distribute the hourly Drainage Model described in Chapter 5 across a $250 \mathrm{~m}$ grid (Figure 6.1). I test three configurations of the Drainage Model that reasonably reproduce ablation measurements at the Canada Glacier meteorological station. Each configuration is an end-member of the region of parameter space with low ablation error (Figure 5.9), and they are chosen to emphasize sublimation, subsurface melt, or surface melt (Table 6.1). The High Sublimation model configuration uses larger surface roughness $\left(\mathrm{z}_{0}\right)$ and results in more sublimation than the other versions. The High Internal Melt model configuration uses a larger ice grain radius ( $\left.\mathrm{r}_{\text {eff }}\right)$ and a lower solar radiation surface fraction (SRSF), resulting in more subsurface melt than the other versions. The High Surface Melt model configuration uses a smaller ice grain radius $\left(\mathrm{r}_{\text {eff }}\right)$ and higher solar radiation surface fraction (SRSF), resulting in more surface melt than the other versions.

All three of these model configurations can successfully predict high ablation summers, but I found the High Internal Melt version to be most plausible (Chapter 5). Also, the High Internal Melt model was the only version that could explain both low and high ablation summers with a single set of parameters; the other two overpredict low ablation summers. However, at Taylor Glacier I found that "high ablation" conditions were rare higher in the ablation zone but occurred nearly every summer near the glacier terminus (site TAR2), and I expect the same may apply to other glaciers. To avoid having to delineate where and when "high ablation" conditions occur, I apply the three 
configurations uniformly to the entire glacier over all summers. I consider the biases introduced by such an approach as I assess the model results.

Table 6.1: Parameter values used for each model configuration.

\begin{tabular}{lcccc}
\hline \hline Model Version & $\begin{array}{c}\text { Roughness length, } \\
\mathbf{z}_{\mathbf{0}}(\mathbf{m m})\end{array}$ & $\begin{array}{c}\text { Effective ice grain } \\
\text { radius, } \mathbf{r}_{\text {eff }}(\mathbf{m m})\end{array}$ & $\begin{array}{c}\text { Solar radiation } \\
\text { surface fraction, SRSF }\end{array}$ & $\begin{array}{c}\text { Surface layer } \\
\text { thickness }(\mathbf{c m})\end{array}$ \\
\hline High Sublimation & 5.0 & 0.03 & $34 \%$ & 0.5 \\
High Internal Melt & 0.1 & 0.08 & $19 \%$ & 0.1 \\
High Surface Melt & 0.1 & 0.01 & $55 \%$ & 1.0 \\
\hline
\end{tabular}

I restrict the modeling domain to the typically snow-free ice of the glacier ablation zones, because snowmelt in the accumulation zone generally refreezes at depth (Fountain et al. 1998). The model is applied over the 250-m grid described in Chapter 3, and for each grid cell the initial ice temperature profile is determined by assuming an isothermal temperature profile equal to the local mean annual air temperature and then running the model once over the 14 model years (spin-up). The resulting ice temperature profile is used as the initial condition for the actual model run. To apply the melt model over the entire ablation zone, I identify a number of different regions with different ice compositions (bubbly white ice; bubble-free blue ice; dirty ice; cryoconite holes) and topographic morphologies (smooth surfaces; high-relief basins; near-vertical terminal cliffs).

The dominant surface morphology and ice composition over most of the glacier surfaces is that of gently sloping, smooth glacier surfaces (Figure 6.3) composed of bubbly, white ice (Figure 4.2), which was considered for the point model applications in Chapter 4 and 5. Additionally, cryoconite holes and refrozen fractures composed of bubble-free blue ice cover about 4-6\% of the smooth glacier surfaces in Taylor Valley 
(Fountain et al. 2004b). Concentrated sediment is found within cryoconite holes, but is otherwise rare on the smooth glacier surfaces.

Near-vertical cliffs form the terminal and lateral boundaries of the glacier ablation zones (Figure 6.3). White ice is the dominant ice composition of the cliffs, except for the lower few meters of some cliffs which include exposures of entrained basal till (e.g. Taylor Glacier).

The basins are topographically rough regions with local relief up to $20 \mathrm{~m}$ (Figure 6.4). On Taylor Glacier channels oriented along-flow make up most of the lower $4 \mathrm{~km}$, while the terminus of Canada Glacier is covered with features that are oriented generally transverse to flow (Johnston 2004) (Figure 6.1). Increased melt from the presence of low-albedo debris appears to be the cause of the topographically rough areas, although the debris source can vary - medial moraines on Taylor Glacier, windblown sand and silt on Canada Glacier, or rock avalanche debris elsewhere. For purposes of melt modeling, I do not differentiate the morphology, orientation, or causal mechanism of channels and basins, and for simplicity I refer to all topographically rough regions as "basins." Basins typically have increased temperature and reduced wind speed and albedo relative to the smooth surfaces (Lewis 2001, Johnston et al. 2005). Basin walls are generally composed of white ice, although the steeper walls may be dirty from scavenged cryoconite holes (Fountain et al. 2004b, Johnston 2004). Basin floors typically contain much sediment and blue ice. Sediment often initiates basin formation, but once basins enlarge, additional sediment is collected within them from scavenged cryoconite holes along the walls and deposition from the wind (Fountain et al. 2004b). Blue ice forms from refrozen streams 
and ponds that form in the basin areas, in some cases forming ice-topped pools 10-50 m in diameter (Bagshaw et al. 2010).

To account for these variations, I establish four submodels for the most prevalent combinations of topographic morphology and ice composition.

\subsubsection{Smooth Surfaces}

Smooth surfaces (Figure 6.3) use distributed meteorological data (Chapter 3) without adjustment and apply the parameter values listed in Table 6.1. The smooth surfaces are the only areas to which the High Sublimation model is applied; roughness on the other regions is dominated by large scale form drag, and changes in mm-scale roughness elements due to melting is unlikely to affect them.

The spatial distribution of albedo is a major uncertainty. The major factor in albedo variation is the presence/absence of snow. Accurately tracking the spatial distribution of snow would require near-daily imagery of the entire valley, which presents numerous challenges (Appendix C). Instead, I apply a constant albedo across the smooth surfaces equal to the albedo measured at the glacier meteorological stations. I use measured albedo at Canada Glacier meteorological station for all glacier ablation zones in the Hoare and Fryxell basins, and at Taylor Glacier meteorological station for the Bonney basin, as previous observations have shown an abrupt decrease in snow accumulation upvalley of the Nussbaum Riegel that divides Taylor Valley (Fountain et al. 2006, Fountain et al. 2010). Albedo measured at the $\mathrm{COH}$ and HOD stations is not used because those stations are close to the equilibrium line, and experience substantially longer snow cover than most of the ablation zones on their respective glaciers. This 
approach accounts for the major spatial control on snow accumulation in Taylor Valley, but fails to resolve the general upvalley decrease in snow accumulation within each half of the valley. It also ignores snow cover variation with elevation, but as the glacier ablation zones span relatively small elevation ranges this may be a reasonable simplification.

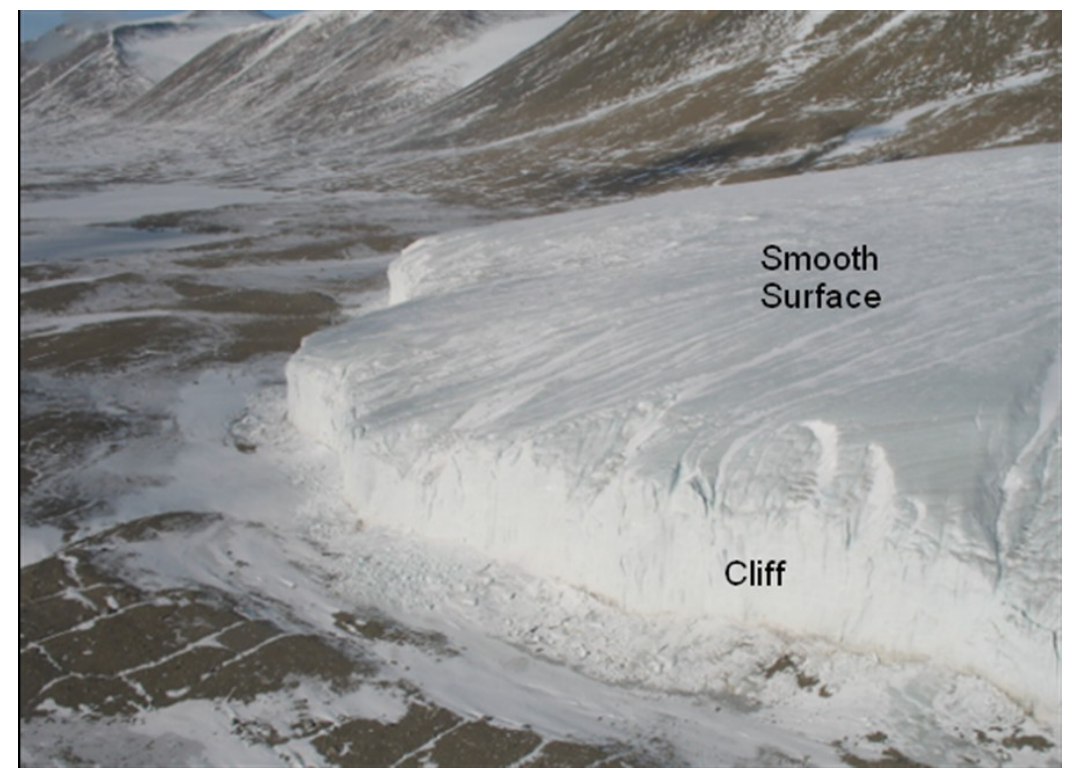

Figure 6.3: Photograph of the Smooth Surface and Cliff topographic morphologies on Howard Glacier. The cliff here is about $25 \mathrm{~m}$ high.

\subsubsection{Cryoconite Holes}

Cryoconite holes on the smooth surfaces are assumed to melt internally at a rate equal to surface ablation, such that they maintain a constant depth. This may underestimate seasonal melt of the cryoconite holes, as they melt-deepen at a more rapid rate during early season because winter ablation has exhumed the sediment layer to a depth shallower than the equilibrium depth (Fountain et al. 2008). On the other hand, in most years about half of the cryoconite holes are isolated from the near-surface hydrologic system (Fountain et al. 2004b), and thus cannot contribute to runoff. The 
assumed melt rate within the cryoconite holes is multiplied by the fractional area they cover, which varies by glacier and is lowest at Taylor Glacier (3.4\%) and highest at Howard Glacier (6.4\%) (Fountain et al. 2004b). Cryoconite hole lids are assumed to melt at the same rate as the surrounding white ice. This is a simplification as there is less scattering of solar radiation within the blue ice of the lids, and the lids are less likely to melt at shallow depths.

\subsubsection{Basins}

Basins on the glacier surfaces are identified empirically as regions with relief of greater than $3 \mathrm{~m}$ within a 10 by $10 \mathrm{~m}$ area using a $2 \mathrm{~m}$ resolution digital elevation model, which roughly corresponds to slopes $>15^{\circ}$. The regions were manually delineated to ensure that smooth surfaces with high slope were not included and that basin floors and intervening ridges with low slope were included (Figures 6.1-6.2). The area within the basin regions is divided into three components: the walls, the floors, and the intervening ridges (Figure 6.4). Each component is modeled separately, and the melt rate for each is distributed by each component's fractional area within each grid cell (Table 6.4). The fractional area for each component is identified from slope and curvature calculations using the $2 \mathrm{~m}$ resolution digital elevation model as described below.

Smeets and van den Broeke (2008) measured a surface roughness length $\left(\mathrm{z}_{0}\right)$ of $\sim 10 \mathrm{~mm}$ for a location in the ablation zone of the Greenland Ice Sheet covered by hummock $\left(\sim 10^{0} \mathrm{~m}\right)$ and dome $\left(\sim 10^{1} \mathrm{~m}\right)$ features, but observations and drag-partition modeling indicated that the surface drag of the smaller scale hummocks dominated over the larger features which had a $\mathrm{z}_{0}$ of $\sim 1 \mathrm{~mm}$. Based on the topographic similarity of the 
basins on Taylor Valley glaciers to the dome features, I assign basin floor and basin wall regions a $\mathrm{z}_{0}$ of $1 \mathrm{~mm}$, and I ignore the possibility that meter-scale roughness elements could increase $\mathrm{z}_{0}$ by an order of magnitude if present.

Basin floors are identified by slopes $<15^{\circ}$ with concave-up curvature (curvature is calculated over distances of $20 \mathrm{~m}$ ). Within basin floors, meteorological values are adjusted based on reported comparisons between simultaneous measurements in basins and adjacent surfaces at three basins on Canada Glacier (Lewis 2001) and three locations with channels on Taylor Glacier (Johnston 2004) (Table 6.2). Air temperature is increased by $1.5^{\circ} \mathrm{C}$ (when incoming solar radiation is greater than $50 \mathrm{~W} \mathrm{~m}^{-2}$ ), and wind speed is reduced by $67 \%$.

Values of incoming solar radiation are unaltered, as observations indicate that the effects of radiation reflecting off of or being blocked by basin walls have opposing net effects at different basin locations (Lewis 2001). These geometric effects would have to be modeled at high resolution $(\sim 5 \mathrm{~m})$ to resolve these local variations. However, net radiation on basin floors is substantially increased due to lower albedo. Basin floor albedo is highly spatially variable as the basin floors are a patchwork of white ice, blue ice, and sediment. Resolving such variations is not practical, so I apply a constant albedo adjustment to the basin floors of -0.2 relative to the values measured at the meteorological stations (making typical basin floor albedo $\sim 0.4$ ), which is the average difference observed for basins on both Canada and Taylor glaciers (Lewis 2001, Johnston 2004). 
Basin walls are identified by slopes $>15^{\circ}$. Johnston (2004) measured an increase in temperature of $0.5^{\circ} \mathrm{C}$ along channel walls on Taylor Glacier, so I apply this adjustment. Wind speed was not measured for the channel walls, so I arbitrarily reduce the wind reduction used for basin walls by half (Table 6.2). This is certainly a simplification, but should capture the expected behavior that the walls of the basins are subject to higher wind speeds than the basin floors but lower wind speeds than the unobstructed ridges above. These adjustments are very close to those determined independently for the cliffs along the terminus of Canada Glacier, a similar topographic situation.

As with the basin floors, I do not alter incoming solar radiation, though in reality the steeply sloping basin walls will experience brief periods during each day of intense solar radiation as well as extended periods of low solar radiation, similar to the terminal cliffs. I reduce the albedo of basin walls by 0.05 , the average reduction observed within the channels on Taylor Glacier (Johnston 2004). The reduction in average albedo is presumably due to sediment from scavenged cryoconite holes, which tends to be highly localized. When calculating melt volume from basin walls, the planimetric area covered by basin walls is increased by $20 \%$ (Figure 6.4 ), based on calculations I made of the typical ratio of topographic surface area (Jenness 2004) to planimetric surface area for the relatively steep basin walls using the $2 \mathrm{~m}$ digital elevation model.

Basin ridges are identified by slopes $<15^{\circ}$ with convex curvature. The basin ridges are modeled the same as the smooth surfaces (Table 6.2). 


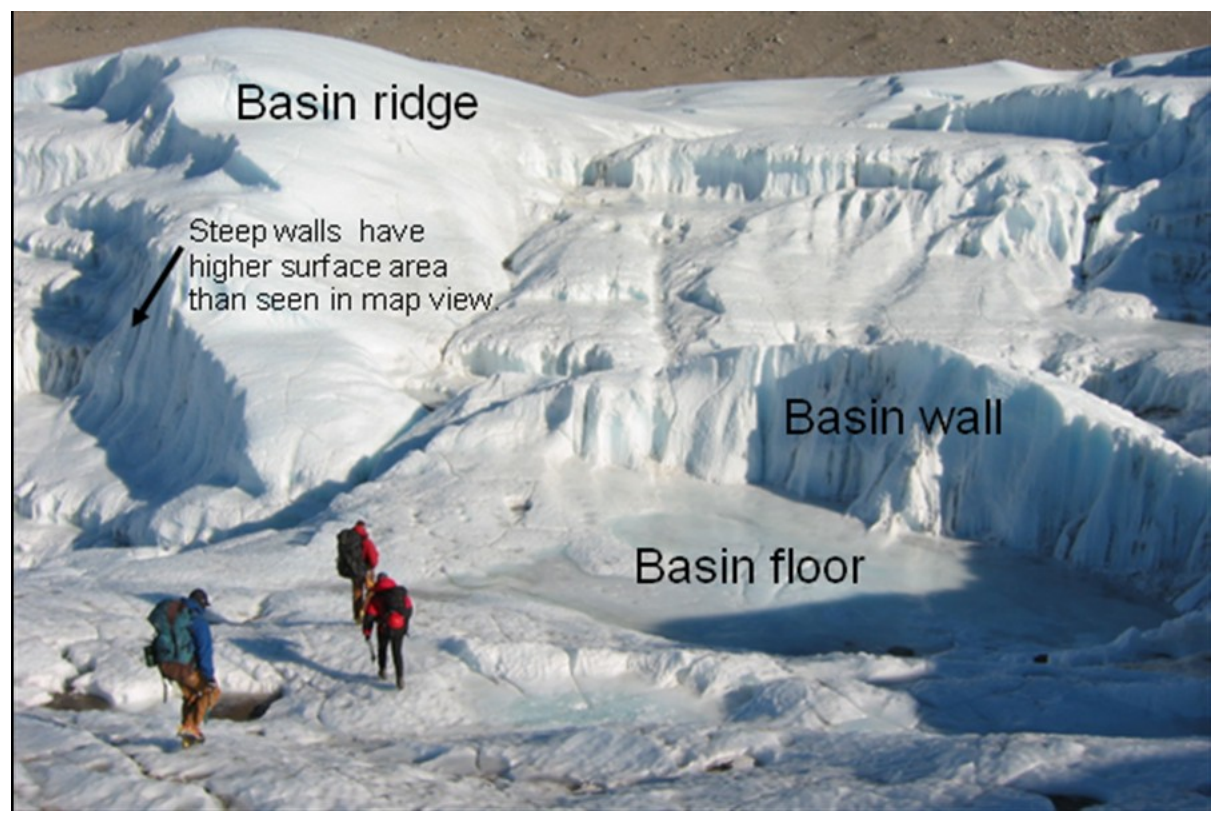

Figure 6.4: Photo of basin on Taylor Glacier showing the floor, wall, and ridge topographic morphologies.

Table 6.2: Summary of meteorological adjustments and parameters for each submodel. -- No adjustment made. ${ }^{*}$ Value used for High Sublimation model configuration.

\begin{tabular}{llllll}
\hline \hline & $\begin{array}{l}\text { Air } \\
\text { temperature }\end{array}$ & $\begin{array}{l}\text { Wind } \\
\text { speed }\end{array}$ & Albedo & $\mathbf{z}_{\mathbf{0}}$ & $\begin{array}{l}\text { Surface } \\
\text { area }\end{array}$ \\
\hline Smooth surfaces & -- & -- & -- & $0.1 / 5.0^{*} \mathrm{~mm}$ & -- \\
Cryoconite holes & $\mathrm{N} / \mathrm{A}$ & $\mathrm{N} / \mathrm{A}$ & $\mathrm{N} / \mathrm{A}$ & $\mathrm{N} / \mathrm{A}$ & -- \\
Basin floors & $+1.5^{\circ} \mathrm{C}$ & $-67 \%$ & -0.2 & $1 \mathrm{~mm}$ & -- \\
Basin walls & $+0.5^{\circ} \mathrm{C}$ & $-33 \%$ & -0.05 & $1 \mathrm{~mm}$ & $+20 \%$ \\
Basin ridges & -- & -- & -- & $0.1 \mathrm{~mm}$ & -- \\
Cliffs & $+0.5^{\circ} \mathrm{C}$ & $-32 \%$ & $=0.55$ & $1 \mathrm{~mm}$ & -- \\
\hline
\end{tabular}

\subsubsection{Terminal Cliffs}

Despite the terminal cliffs making up a small fraction of the surface area of the glacier ablation zones, they can generate a substantial fraction of total meltwater runoff. For example, on Canada Glacier the terminal cliffs account for $2 \%$ of the total ablation area but up to $15-20 \%$ of the runoff (Lewis et al. 1999). Thus any runoff model needs to consider the cliffs explicitly. 
To apply the melt model for the terminal cliffs, I establish a separate model domain that describes the geometry of the cliffs (Chapter 3). Using the same twodimensional 250-m grid that is used for the glacier surfaces, I identify grid cells that contain cliffs. Within each of those grid cells I calculate cliff length and mean aspect. Though cliff slope varies from $70-90^{\circ}$ from the horizontal (Fountain et al. 1998), the majority are near vertical, and I assume all cliffs to be vertical. I also apply a constant cliff height of $25 \mathrm{~m}$ (Fountain et al. 2006), though variation in height does exist.

The meteorological forcing for the cliffs is derived from MicroMet applied to the cliff domain (Chapter 3). This application of MicroMet explicitly considers cliff geometry for calculating incoming shortwave and longwave radiation, but does not consider the microclimate along the cliffs that results in higher air temperature and lowered wind speed relative to a horizontal glacier surface (Lewis et al. 1999). To account for that I apply adjustments to the MicroMet output: air temperature is increased by $0.5^{\circ}$ when solar radiation is greater than $50 \mathrm{~W} \mathrm{~m}^{-2}$, and wind speed is reduced by $32 \%$ (derived from Table 3.3).

The final input required to apply the melt model along the cliffs is cliff albedo. Because the cliffs are near vertical, snow does not stick to the cliff surfaces, and ice is continually exposed. For this reason, I applied a constant albedo for all cliff surfaces. This approach precludes adjusting albedo for solar incidence angle. The seasonal pattern of albedo variation observed on the near-horizontal glacier surfaces (Figure 2.21) does not apply to the near-vertical cliffs where solar incidence angles varies from $0^{\circ}$ to $90^{\circ}$ over the course of hours. I determine a representative cliff albedo through measurements 
of incoming and outgoing shortwave radiation on the Canada Glacier westside cliff (Figure 6.5). As expected, albedo decreases with increasing incoming solar radiation, which is when solar incidence angle is largest. Since I am more concerned with accurate albedo values when incoming solar radiation is large, I use an albedo value of 0.6 as a representative value. These observations were made with Licor pyranometers which have a bias in measurements of reflected shortwave radiation, so I apply the correction described in Chapter 3 of scaling albedo measurement by 0.92 . This results in an albedo value of 0.55 , which is similar to the value of 0.56 identified as the average of snow-free conditions at TAR meteorological station (Section 2.2.3). With this agreement, I use a constant albedo value of 0.55 for all cliffs.

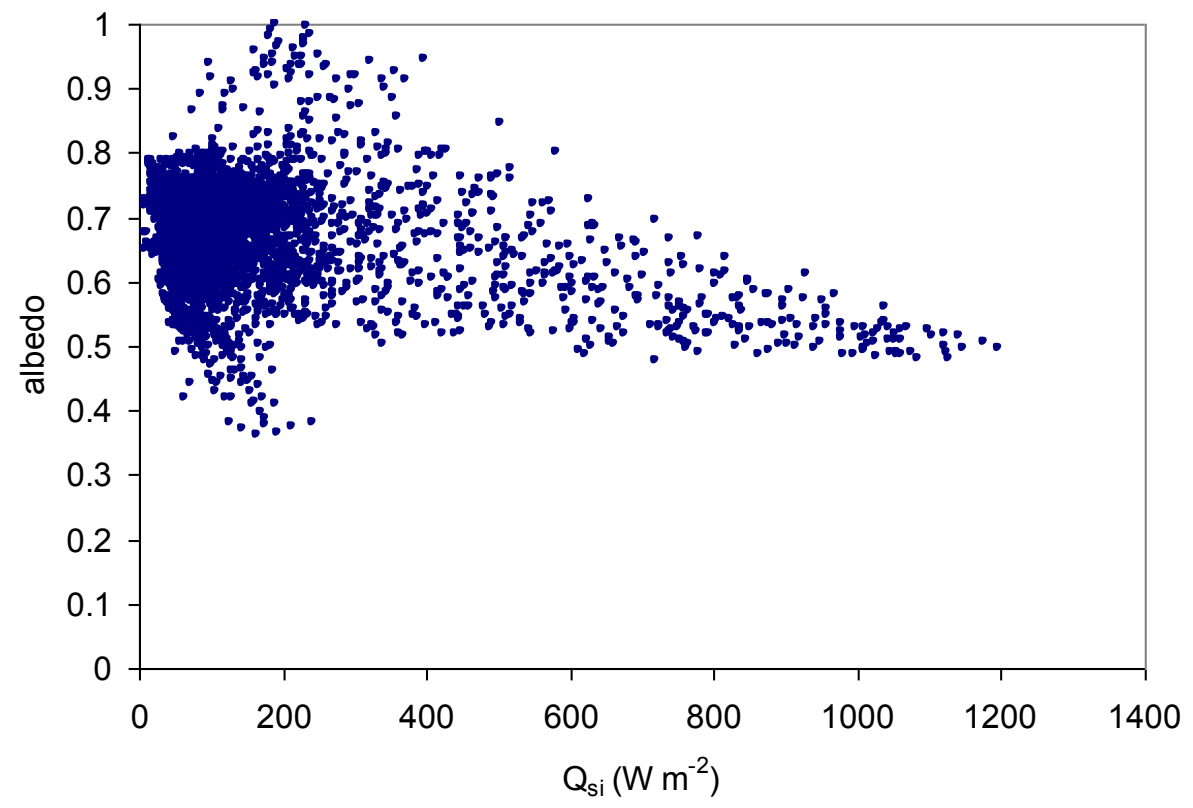

Figure 6.5: Measured albedo of Canada Glacier westside cliff as a function of incoming solar radiation for the period December 10, 1995 to January 22, 1996. Measurements were made with Licor LI-200 pyranometers. 
Because of lack of long-term observations, it is difficult to systematically calibrate the cliff model. Calibration is further limited by uncertainties unique to the cliff domain: considerable uncertainty in the corrections for cliff microclimate to air temperature, relative humidity, and wind speed (Section 3.4); deficiencies in MicroMet estimates of incoming shortwave and longwave radiation along cliff faces (Section 3.4); variations in albedo (Figure 6.5); and variations in weather and ablation with height along the cliffs (Sniffen 2008). Rather than performing a detailed calibration for the cliffs, I test the cliff model performance for several parameter combinations. Resulting estimates of summer and winter ablation are compared to ablation measurements from stakes installed in cliffs along the west side of Canada Glacier (Figure 6.2). Of particular concern is the proper value for $\mathrm{z}_{0}$ to use along cliffs whose shape violates a fundamental assumption of the bulk aerodynamic theory of a flat, homogenous surface that extends for $\sim 10^{2} \mathrm{~m}$ (Brutsaert 1982, Lewis et al. 1999). For this reason, I consider surface roughness lengths ranging from $0.1 \mathrm{~mm}$ to $20 \mathrm{~mm}$ for the cliffs.

\subsubsection{Runoff Routing}

Runoff routing from glaciers is often implemented as coupled linear reservoirs for firn, snow, and ice with differing hydraulic properties for each medium (Jansson et al. 2003). Storage coefficients used for bare ice on mountain glaciers range from 4-16 hours (e.g. Hock and Noetzli 1997, Hannah and Gurnell 2001). Those used for snow are two to three times larger, and for firn an order of magnitude larger yet. Because I only model ice melt and assume runoff contributions from firn and snow are insignificant, I only consider routing of runoff over bare ice. Most catchments have maximum travel 
distances of less than $2 \mathrm{~km}$ for water to leave the glacier. For modeling daily runoff volume, I assume that all melt runs off the glacier on the same day as which it melted, rather than attempting to explicitly route meltwater over the glacier surface.

Meltwater routing is complicated by a number of sinks, including evaporation (Cozzetto et al. 2006), and temporary storage or refreezing in the near surface drainage system (Fountain et al. 2004b), fractures, supraglacial lakes (Bagshaw et al. 2010), proglacial lakes (McKnight et al. 1999), and the proglacial stream hyporheic zones (McKnight et al. 1999, Gooseff et al. 2003b). Jaros (2003) estimated streamflow losses to evaporation and hyporheic zone storage to be $4-7 \times 10^{3} \mathrm{~m}^{3}$ per summer for the streams draining Canada Glacier, which corresponds to between $<1 \%$ and $18 \%$ of total seasonal runoff, depending on year. Unmodeled sources of water include melting from the aprons of calved ice blocks at the base of the terminal cliffs and releases from storage of the above-mentioned sinks, including melting of the proglacial stream hyporheic zones in early summer (Gooseff et al. 2003b).

Despite these complications, the streams draining Canada Glacier are well-suited to comparison with modeled meltwater runoff without explicitly modeling in-stream processes. Other than streamflow attenuation from a proglacial lake, Canada Stream has minimal hydrograph modification due to in-stream processes; the stream is short and steep, and the banks are steep, minimizing the width of the hyporheic zone (Conovitz et al. 1998). Andersen and Green creeks have similar physical characteristics.

In addition to uncertainty introduced by routing processes, uncertainty exists in mapping catchment boundaries and the spatial extent over which to apply the various 
submodels within each catchment. My assumption that melt occurs only below the equilibrium line may not be valid in extreme years. In the warmest summers the equilibrium line may move slightly upglacier and snow is likely melting in the lower accumulation zone, causing my defined constant catchment boundaries to be too small. Though field observations suggest that most snowmelt refreezes within the snowpack (Fountain et al. 1998), this may be a limitation of my approach in high melt summers.

All of these various uncertainties introduce possible parameters that could be calibrated to make modeled runoff match streamflow measurements. However, because there are too many possible parameters and additional unquantifiable uncertainty (including the streamflow measurements themselves), this is not practical. Instead I model glacier runoff with the prescribed parameter values, and explore the sensitivity of streamflow estimates to selected parameters for various watersheds. I also compare modeled ablation to ablation measured across the stake networks to help constrain ice property parameters for the smooth surfaces and cliffs.

\subsection{Results: Canada Glacier}

I first make an in-depth assessment of the spatial melt model for Canada Glacier before applying the model to the rest of the glaciers within Taylor Valley. First, mass balance stake measurements are used to assess modeled ablation for the smooth surfaces and terminal cliffs. Due to lack of systematic ablation measurements within the basins, no assessment is made for the basins. Secondly, modeled runoff is compared to streamflow measurements on the three gaged streams draining Canada Glacier. 


\subsubsection{Canada Glacier Surface Ablation}

Generally speaking, interannual variability in ablation is greater than spatial variation on Canada Glacier (Figures 6.6 - 6.8). The bulk of the ablation zone spans about $200 \mathrm{~m}$ in elevation and changes in weather over this elevation range tend to be smaller than changes from summer to summer. All three model versions (Table 6.1) substantially overpredict ablation during the 1995 and 1999 summers. These years had substantially lower albedo than other summers, which could be due to the field of view of the downward facing pyranometer not being representative of the ablation zone because of the presence of dirt or blue ice. I exclude these summers from further analysis.

Additionally, all model versions have trouble with summer 2008 which had much higher ablation rates on some stakes in the upper ablation zone than lower down on the glacier. The cause for this pattern is unclear, but it is consistent over multiple stakes. All three model versions do a reasonable job with the remaining stakes in this summer that do not exhibit this high ablation. All three versions also do a reasonable job with the other high ablation rate summer, 2001, although the High Internal Melt version underpredicts ablation slightly.

The High Sublimation model version overpredicts ablation for most years besides 2001 and 2008, particularly at higher elevations (Figure 6.6). This is not surprising as this model configuration was only found to work at the Canada Glacier meteorological station for the high ablation summers of 2001 and 2008 (Chapter 5). The High Internal Melt and High Surface Melt model versions match stake measurements well across the range of elevations for most summers. They predict similar magnitudes of total ablation, 
but the distribution between ablative processes differs. With the High Internal Melt version, surface melt is insignificant (Figure 6.7). Sublimation makes up nearly the entirety of ablation in some summers, while in others the reduction of density due to the drainage of subsurface melt makes up more than half of total surface lowering. With the High Surface Melt version (Figure 6.8), surface melt is a substantial fraction of total ablation in all summers. The contribution of internal melting is generally insignificant, except at lower elevations during extreme summers when sublimation, surface melt, and internal melt make about equal contributions to surface lowering.

Based on these comparisons, I find the High Sublimation model configuration to only be plausible for high ablation summers and moderate ablation summers at the lowest elevations. For predicting ablation, the other two model versions work well across the glacier in most summers. 


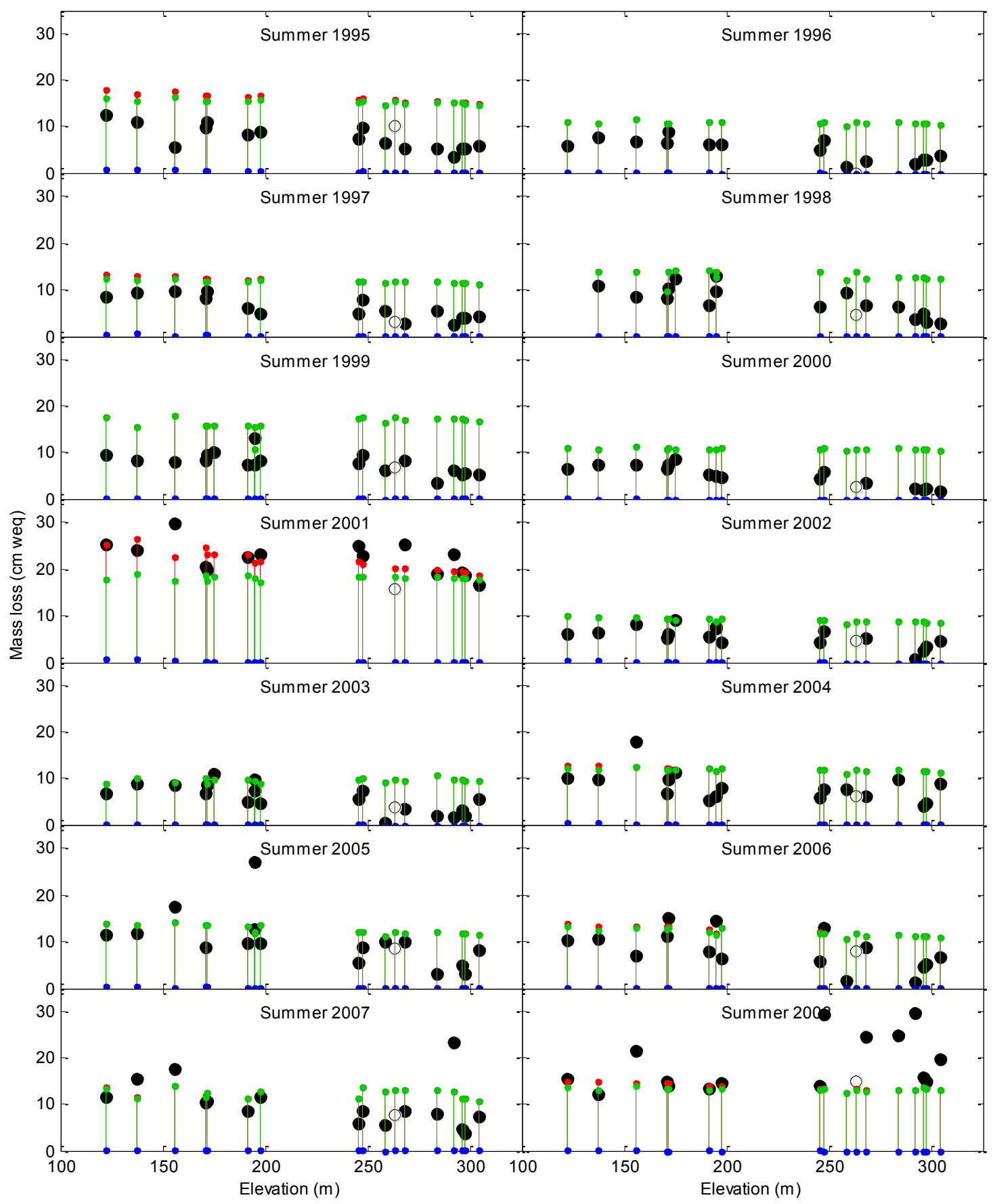

Figure 6.6: Ablation with elevation for Canada Glacier using the High Sublimation model configuration. Black dots are measured mass balance values. The open black dot is the stake located at the CAA meteorological station. Each colored column shows surface melt (blue), sublimation (green), and the contribution of subsurface melt to density reduction (red). Summers are identified by their start year. 


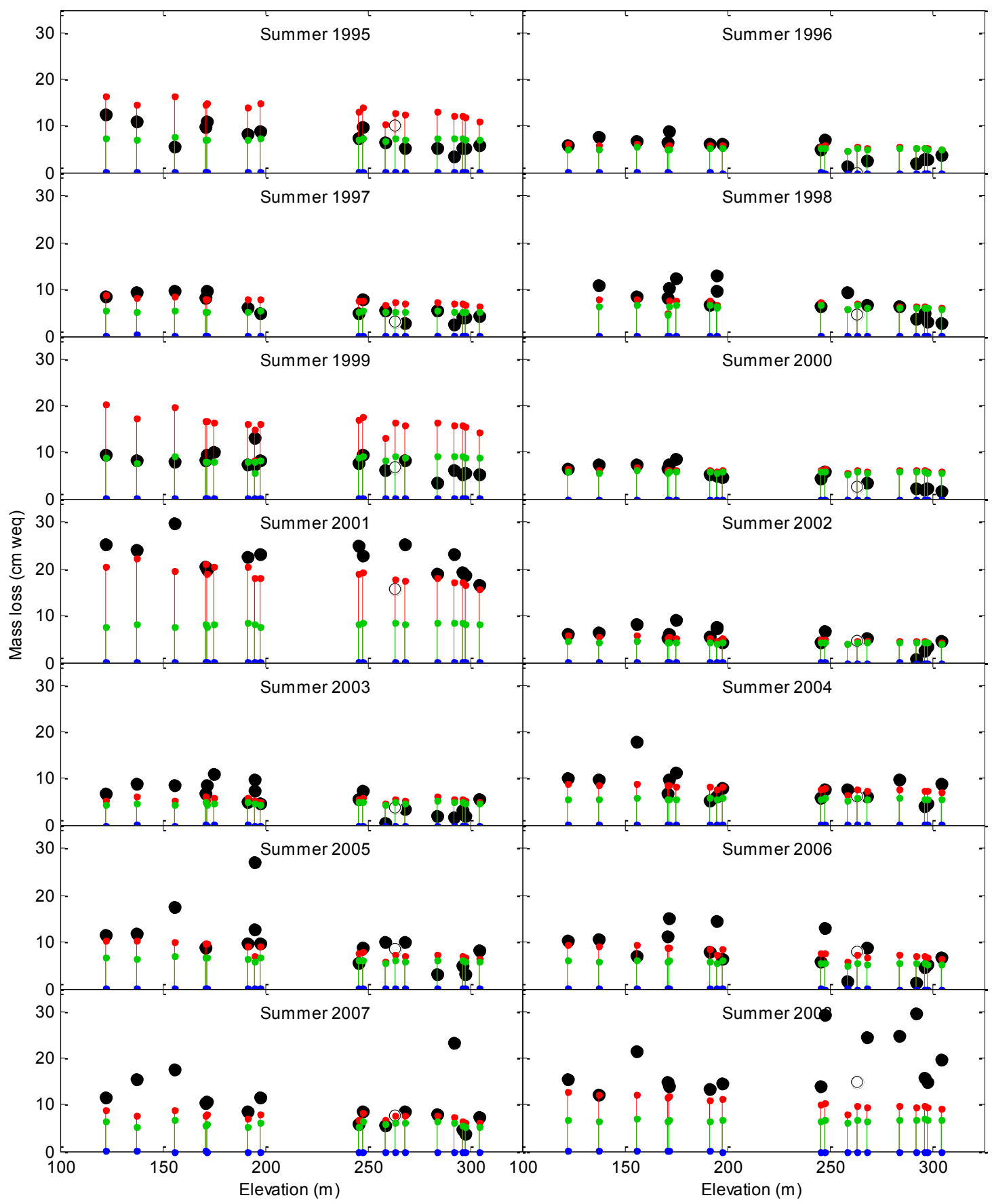

Figure 6.7: Ablation with elevation for Canada Glacier using the High Internal Melt model configuration. Black dots are measured mass balance values. The open black dot is the stake located at the CAA meteorological station. Each colored column shows surface melt (blue), sublimation (green), and the contribution of subsurface melt to density reduction (red). Summers are identified by their start year. 


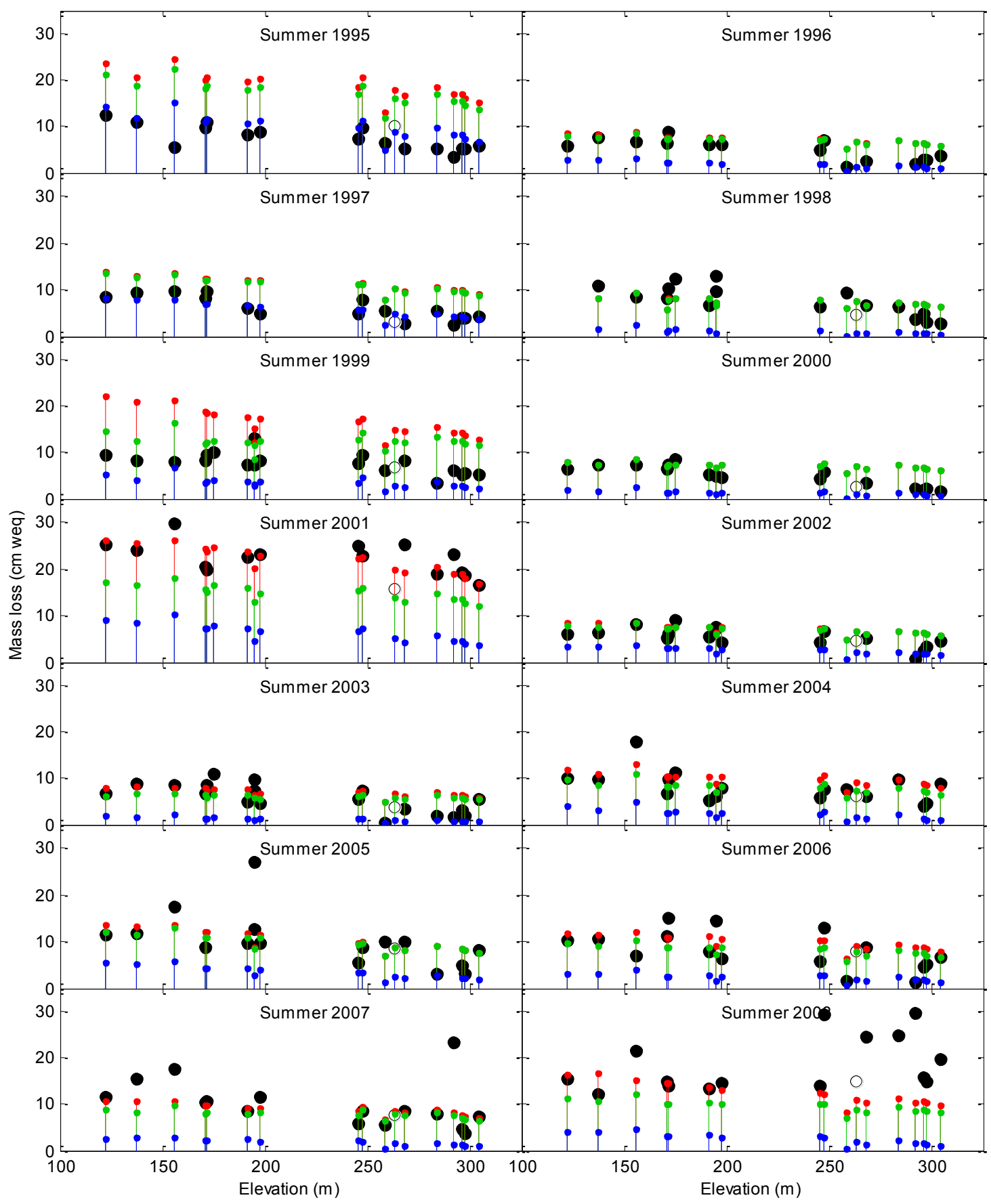

Figure 6.8: Ablation with elevation for Canada Glacier using the High Surface Melt model configuration. Black dots are measured mass balance values. The open black dot is the stake located at the CAA meteorological station. Each colored column shows surface melt (blue), sublimation (green), and the contribution of subsurface melt to density reduction (red). Summers are identified by their start year. 


\subsubsection{Canada Glacier Cliff Ablation}

I tested the cliff submodel using cliff ablation measurements on Canada Glacier. Eleven ablation stakes have been variously maintained over eleven years along the cliffs on the westside of Canada Glacier. These stakes are drilled horizontally into the cliff face about $1.5 \mathrm{~m}$ off the ground (Lewis et al. 1999), and record ablation of the cliff surface at seasonal intervals. Because of high spatial variability in the observations of cliff ablation, I average all stake measurements for each season and compare the cliffwide average ablation to the average ablation of all model grid cells over the length of the cliff (Figure 6.2). The number of stakes with observations in a given season varies between 2 and 11, but most seasons have at least 5 .

I use the observations to test the cliff submodel with the High Internal Melt and High Surface Melt model configurations using surface roughness $\left(\mathrm{z}_{0}\right)$ values between 0.1 and $20 \mathrm{~mm}$. The High Surface Melt model estimates summer ablation for the cliffs that is two to three times too large over the range of surface roughness values and is not discussed further. The High Internal Melt model with $\mathrm{z}_{0}=1 \mathrm{~mm}$ provides a good match to ablation measurements during summer (Figure 6.9a). Using $\mathrm{z}_{0}=0.1 \mathrm{~mm}$ (the value used for the glacier surface, Table 6.2) results in summer ablation that is $57 \%$ too high on average. The higher surface roughness value of $\mathrm{z}_{0}=20 \mathrm{~mm}$ also does a good job of predicting ablation in summer, but most ablation is sublimation (Figure 6.9b). Only the smaller $\mathrm{z}_{0}=1 \mathrm{~mm}$ value reasonably predicts ablation in winter (Figure 6.10), and I consider $\mathrm{z}_{0}=1 \mathrm{~mm}$ to be a more appropriate value to use in the cliff model. It is worth noting that although both model runs capture total ablation well, melt (surface and 
subsurface) predicted using $\mathrm{z}_{0}=1 \mathrm{~mm}$ is $65 \%$ greater than for the high $\mathrm{z}_{0}$ case. Lewis et al. (1999) estimated that sublimation accounted for $5 \%$ of total cliff ablation during the 1995-1996 summer (using $\mathrm{z}_{0}=0.1 \mathrm{~mm}$ ), but my modeling suggests a larger value (33\% for $\mathrm{z}_{0}=1 \mathrm{~mm}$ ). Though the cliff model performs well at Canada Glacier, results are mixed at a different cliff site on Taylor Glacier (Appendix D). 

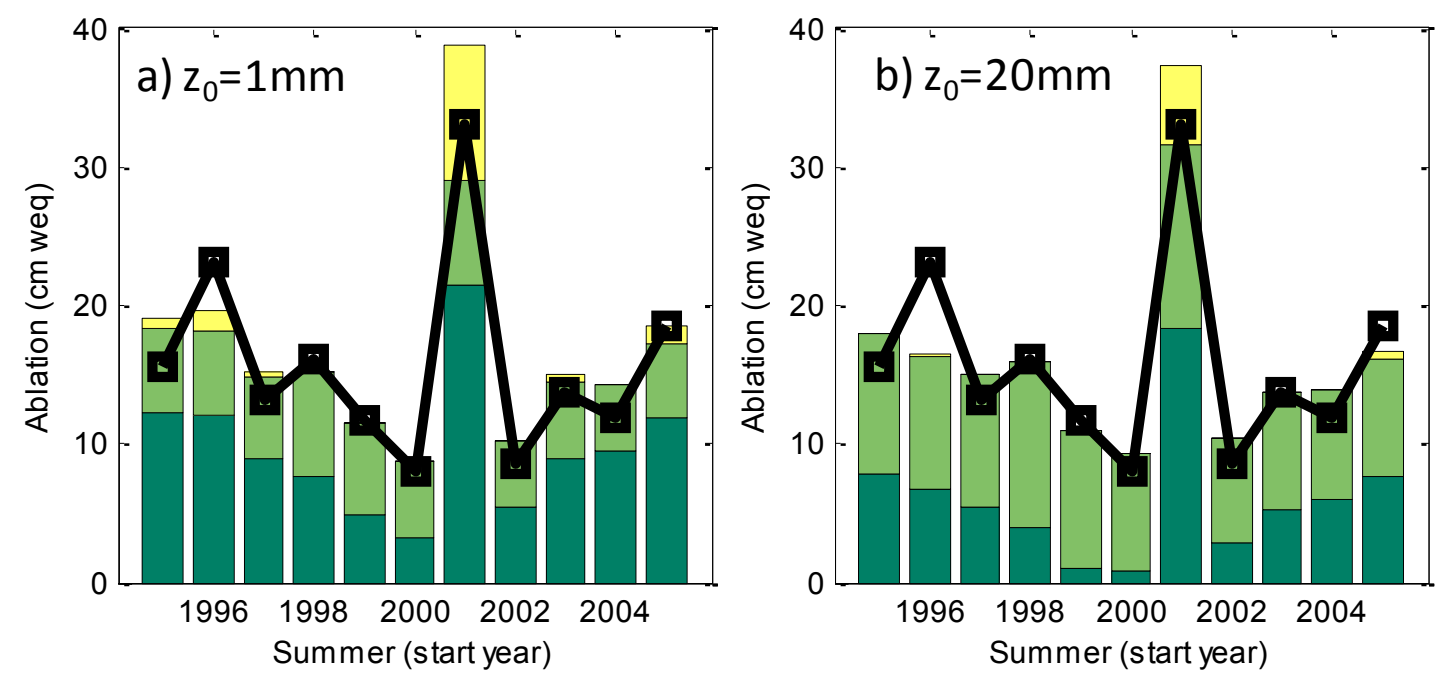

Figure 6.9: Cliff submodel results for summer along Canada Glacier westside cliff. Black line is measured ablation averaged over 3-11 cliff stakes. Stacked bars show modeled ablation using a) $z_{0}=1 \mathrm{~mm}$ and $\left.b\right) z_{0}=20 \mathrm{~mm}$. Both runs use $r_{\text {eff }}=0.03 \mathrm{~mm}$ and $S R S F=34 \%$. Dark green is melt, light green is sublimation, and yellow is the component due to density reduction from drainage of subsurface melt.
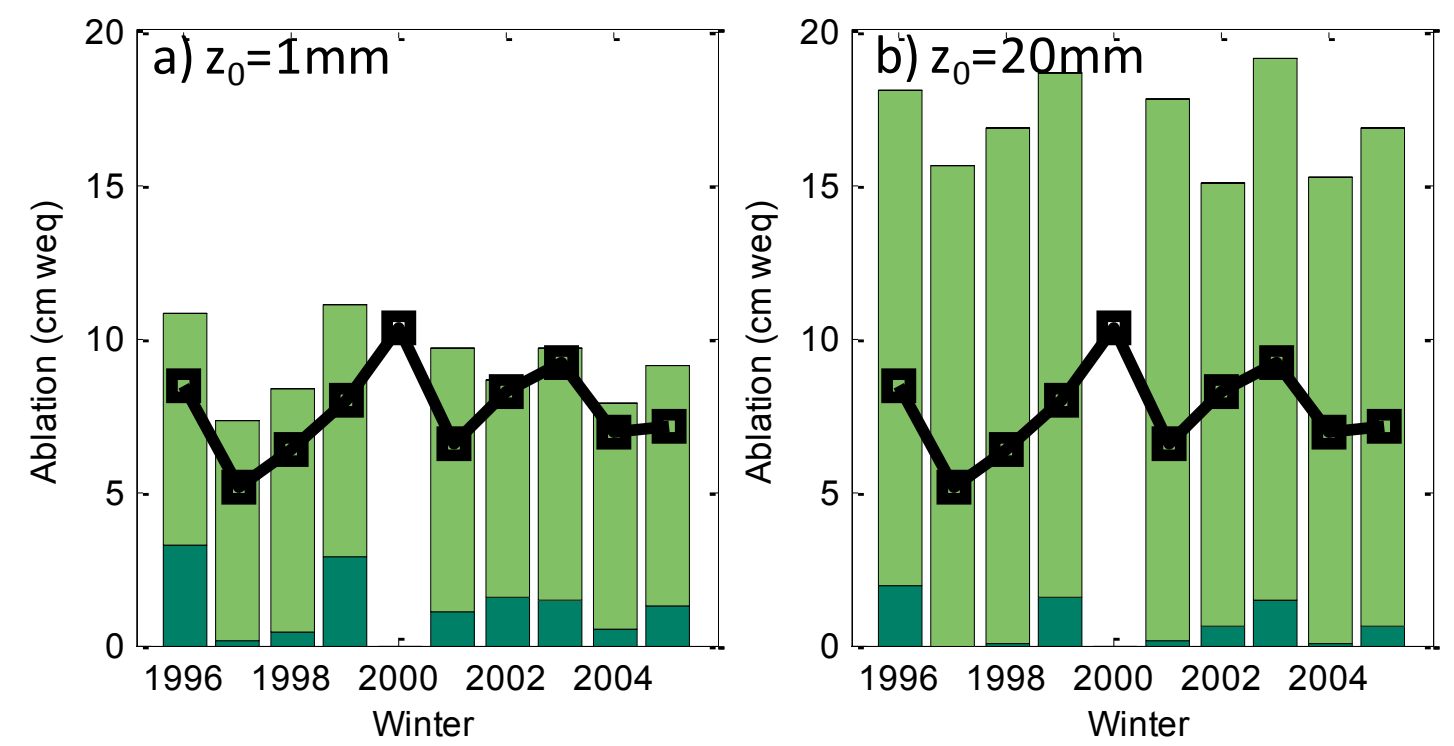

Figure 6.10: Cliff submodel results for winter along Canada Glacier westside cliff. Black line is measured ablation averaged over 3-11 cliff stakes. Stacked bars show modeled ablation using a) $z_{0}=1 \mathrm{~mm}$ and b) $z_{0}=20 \mathrm{~mm}$. Both runs use $r_{\text {eff }}=0.03 \mathrm{~mm}$ and $S R S F=34 \%$. Dark green is melt, light green is sublimation, and yellow is the component due to density reduction from drainage of subsurface melt. 


\subsubsection{Canada Glacier Seasonal Runoff}

Based on my assessment of modeled ablation, I next consider the model's skill at predicting runoff from Canada Glacier. I eliminate the High Sublimation model version from further detailed analysis due to its poor performance in modeling ablation. Indeed, the High Sublimation model predicts no melt on the smooth surfaces in most years, and consequently seasonal streamflow volume estimates are over three times too small. Runoff estimates combine contributions from all glacier submodels (smooth surfaces, cryoconite holes, basins, and terminal cliffs), and due to the inability to assess these components separately, they are considered in total in this section.

The High Internal Melt model predicts melt rates about 30\% higher than the High Surface Melt model, though both models predict similar spatial patterns of meltwater production (Figure 6.11). The higher melt rate from the High Internal Melt model is expected, as both model versions predict similar magnitudes of summer ablation (surface lowering), but the High Internal Melt model includes greater mass loss beneath the surface, in addition to that expressed as surface lowering. The basins are responsible for the much higher melt rates along the glacier edges, particularly in the south where the basins have more floor area, which favors melt.

In the average summer, melt near the equilibrium line is small (a few $\mathrm{cm}$ weq). Though I did not model the accumulation zone, the higher albedo of snow would likely prevent it from melting significantly, as assumed previously (Fountain et al. 1998). However, for the high melt 2001 summer, seasonal meltwater production near the equilibrium line for both model versions is up to $15 \mathrm{~cm}$ weq. Though the higher albedo 
of snow will result in lower melt rates for snow at the same elevation as the ice that I have modeled, these high melt rates suggest that a runoff contribution from the lower accumulation zone during high melt years may be possible.
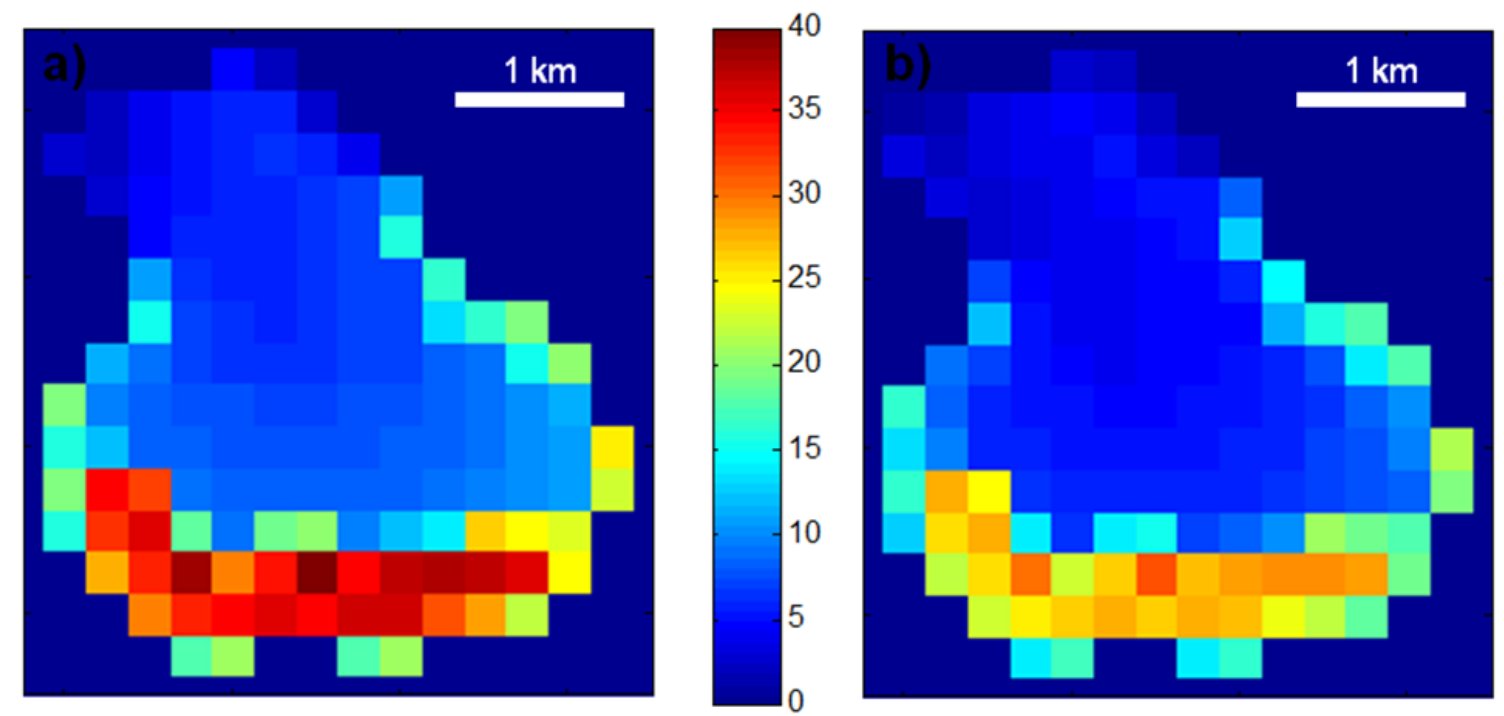

Figure 6.11: Average summer meltwater production (cm) for Canada Glacier with the a) High Internal Melt and b) High Surface Melt model configurations. The total of surface and internal melt from the smooth surfaces and basins is spatially averaged for each grid cell. Melt from the cryoconite holes and terminal cliffs is not represented.

Both the High Internal Melt and High Surface Melt models generally capture the interannual variability in total summer runoff volume (Figures 6.12 - 6.13). Runoff from the High Internal Melt model version is almost entirely due to subsurface melt, with surface melt comprising $<5 \%$ in most summers. In contrast, surface melt makes up $>75 \%$ of runoff from the High Surface Melt model in most summers. However, for many summers at Green Creek and in high melt summers at the other two streams, subsurface melt contributes substantially to runoff with the High Surface Melt model. The additional meltwater generated by subsurface melt greatly improves the interannual variability of the High Surface Melt Model (Figures 6.12 - 6.13). 
Both model versions underpredict summer runoff volume for all but low volume years at Andersen Creek and Canada Stream (Figures 6.12 - 6.13). The low volume years may be underpredictions as well, because I have not accounted for any routing losses, which are likely to be highest during colder summers due to refreezing of meltwater on the glacier surface. As estimated by Jaros (2003), streamflow losses to evaporation and hyporheic zone storage of $4-7 \times 10^{3} \mathrm{~m}^{3}$ per summer would be insignificant on these streams for all but the lowest flow years. Of the two models, the High Internal Melt model performs slightly better at reproducing seasonal runoff volume and interannual variability for Andersen Creek and Canada Stream, particularly for the high melt summers of 2001 and 2008 (Figures $6.12-6.13$ ).

For Green Creek, both model versions reproduce seasonal streamflow volume well (Figures $6.12-6.13$ ). The High Surface Melt model version predicts runoff volumes that are very close to measured streamflow. The High Internal Melt model version tends to be almost $50 \%$ too high, but this may not be unreasonable given the potential for refreezing of meltwater in the extensive basin system that occurs in the Green Creek catchment. Large ice-topped pools 10-50 $\mathrm{m}$ in diameter that drain and fill episodically occur on this part of the glacier (Bagshaw et al. 2010), and they would have the capacity to store large volumes of meltwater. However, because individual basins are not modeled in detail, significant errors could exist in meltwater production for basins that differ from those used to define meteorological adjustments used in the model.

The High Internal Melt model version reproduces day-to-day variability in runoff somewhat better than the High Surface Melt model for all three streams (Figures 6.14 - 
6.15). The correlation coefficient between modeled and measured streamflow varies widely from year to year, but is always positive for both model versions. The correlation coefficient tends to be smaller in lower melt years when source area and in-stream routing losses are likely to be bigger. Additionally, some low melt years are affected by the presence of snowcover which the model treats rather crudely. On the whole, inclusion of subsurface melt improves the correlation coefficient for both model versions. This is particularly the case for Green Creek, and less so for Canada Stream. 


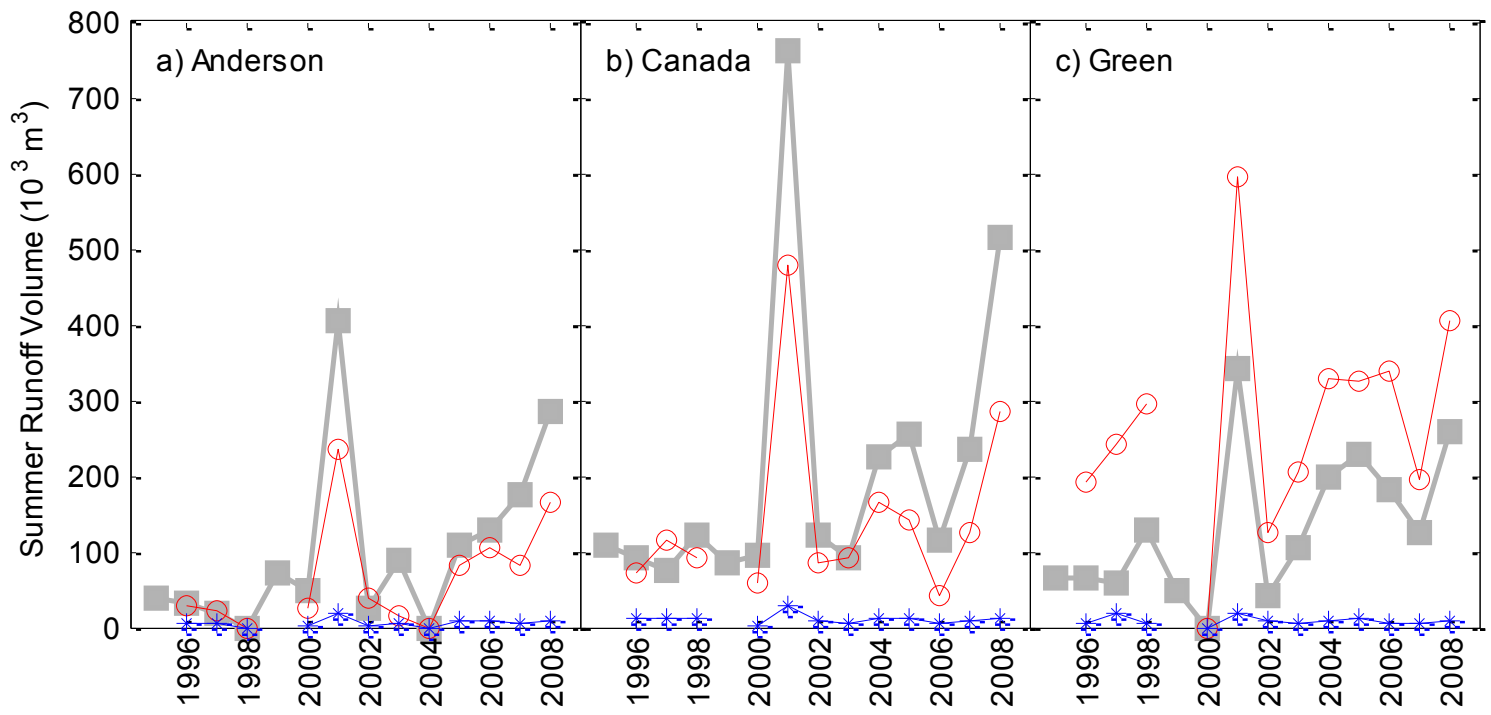

Figure 6.12: Measured (squares) and modeled (circles) summer runoff volume using the High Internal Melt model configuration for a) Andersen Creek, b) Canada Stream, and c) Green Creek. Modeled runoff is the sum of surface and internal melt from smooth surfaces, basins, cryoconite holes, and cliffs. The component of runoff from surface melt is shown with asterisks.

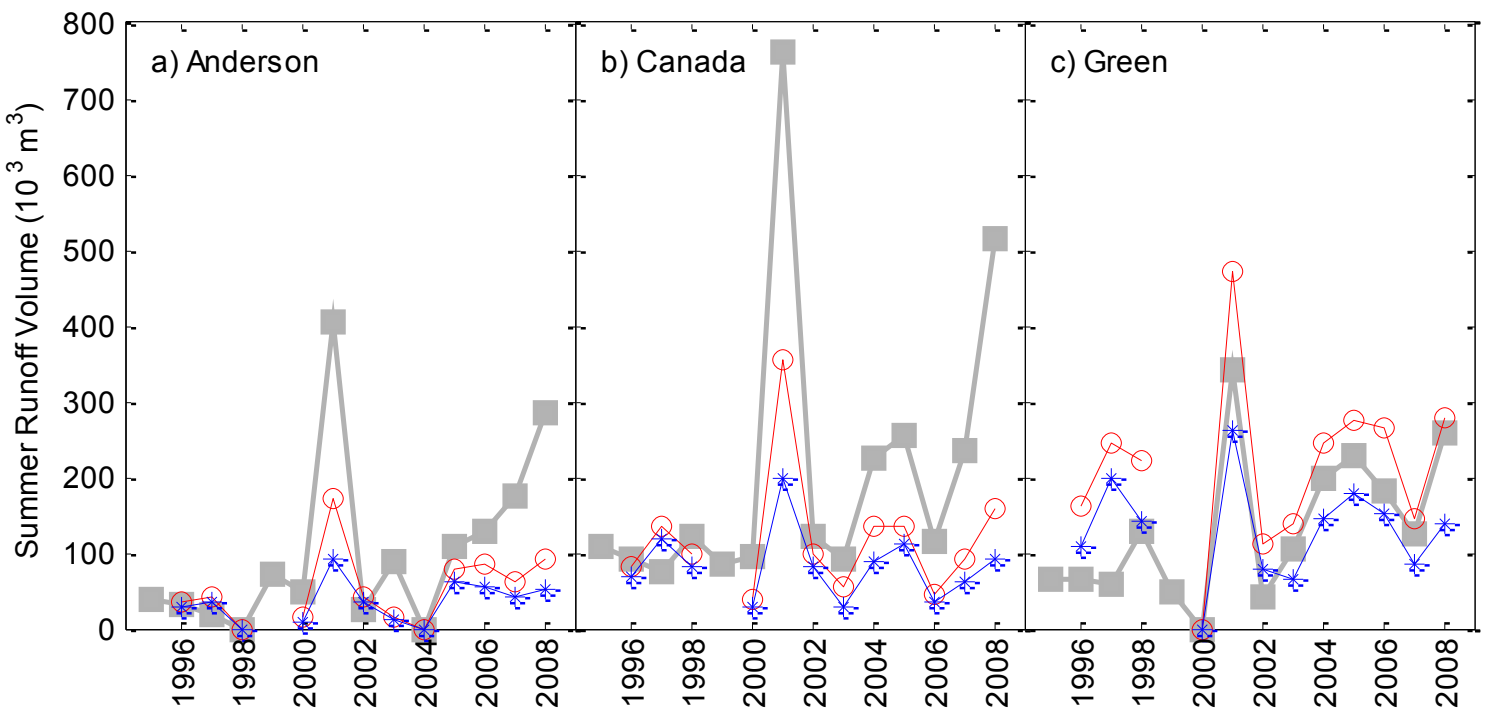

Figure 6.13: Measured (squares) and modeled (circles) summer runoff volume using the High Surface Melt model configuration for a) Andersen Creek, b) Canada Stream, and c) Green Creek. Modeled runoff is the sum of surface and internal melt from smooth surfaces, basins, cryoconite holes, and cliffs. The component of runoff from surface melt is shown with asterisks. 


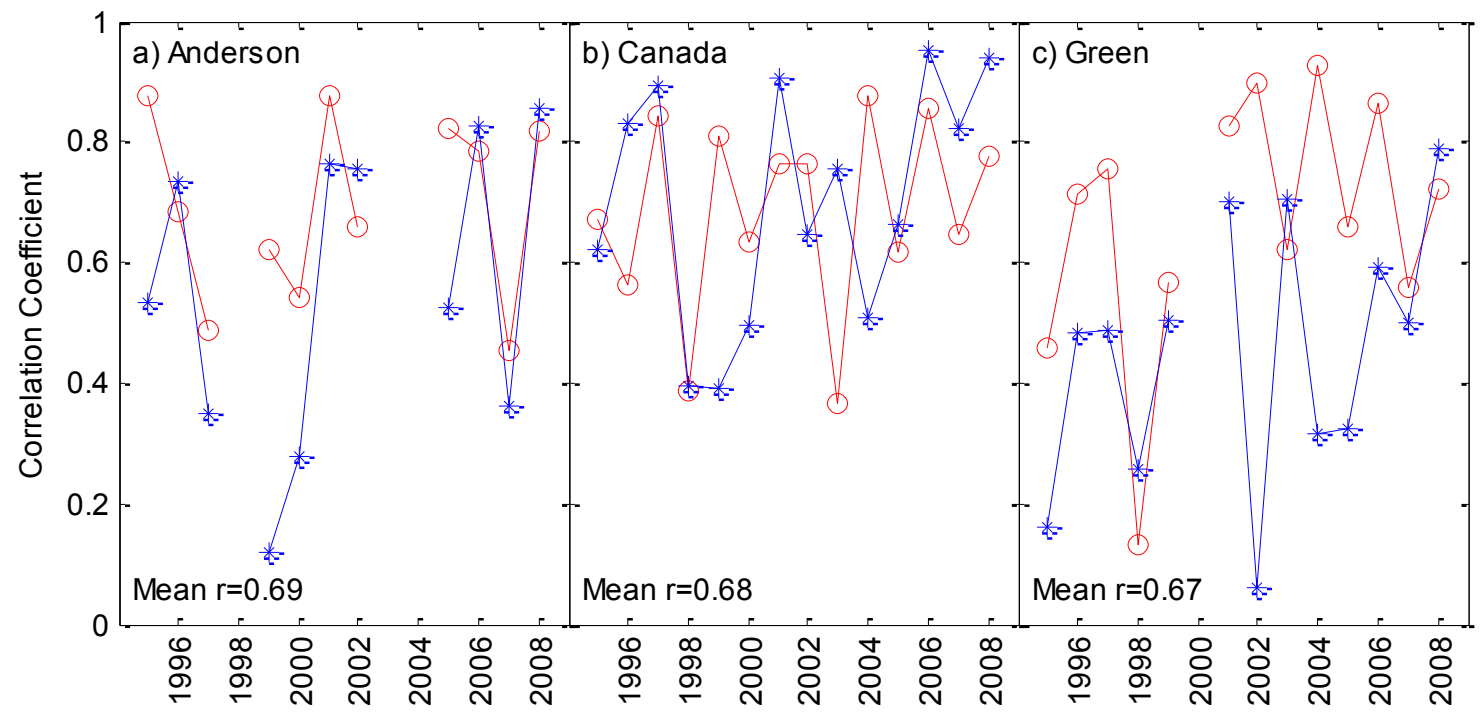

Figure 6.14: Correlation coefficient between measured and modeled daily runoff volume using the High Internal Melt model configuration for a) Andersen Creek, b) Canada Stream, and c) Green Creek. Modeled runoff is the sum melt from smooth surfaces, basins, cryoconite holes, and cliffs. Circles are for modeled runoff including both internal and surface melt. Asterisks are for modeled runoff including only surface melt.

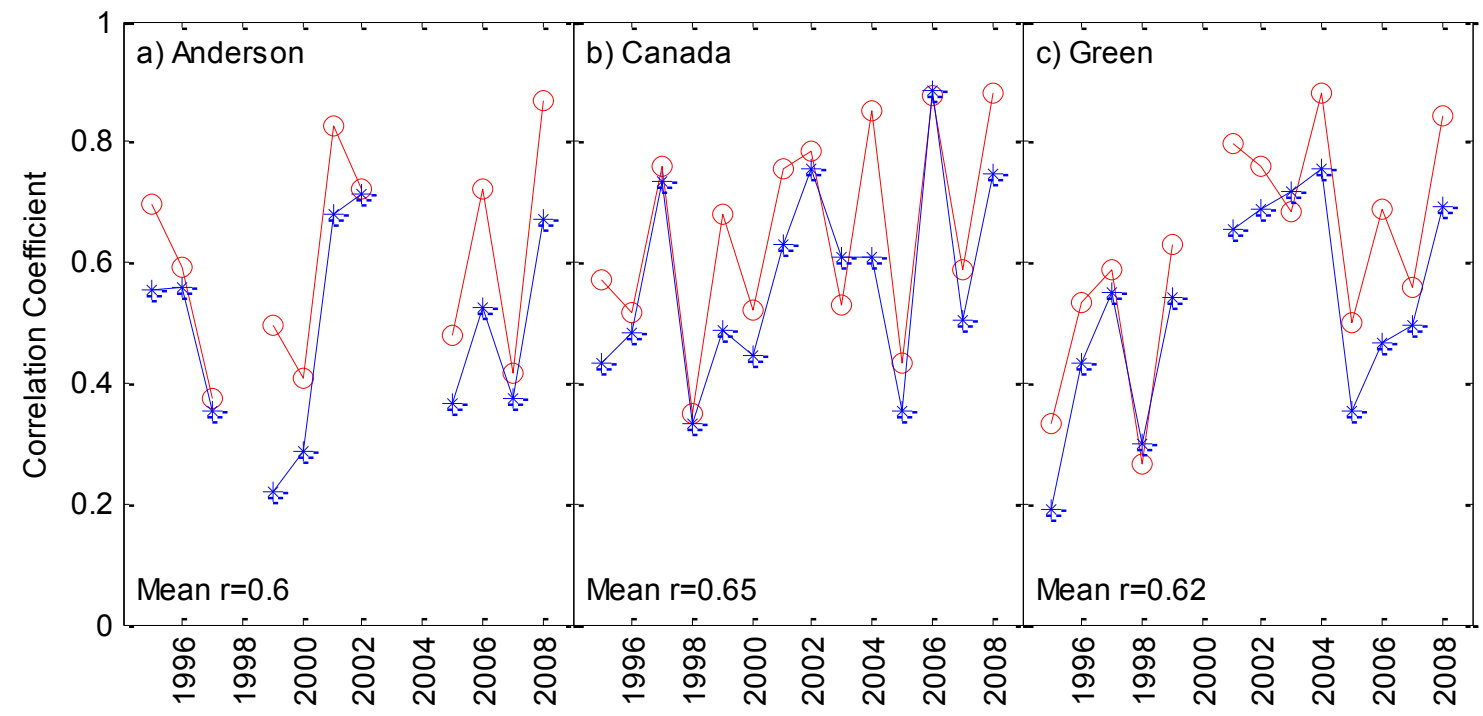

Figure 6.15: Correlation coefficient between measured and modeled daily runoff volume using the High Surface Melt model configuration for a) Andersen Creek, b) Canada Stream, and c) Green Creek. Modeled runoff is the sum melt from smooth surfaces, basins, cryoconite holes, and cliffs. Circles are for modeled runoff including both internal and surface melt. Asterisks are for modeled runoff including only surface melt. 


\subsubsection{Canada Glacier Daily Runoff}

Inspection of hydrographs of daily runoff is consistent with the seasonal statistics, but reveals additional information (Figures 6.16 - 6.18). The High Internal Melt model and the High Surface Melt model have similar hydrographs for the most part, but there are some notable differences. While most large flood events are represented by both models, some flood events in low to moderate melt years only appear in one or the other of the two model predictions. For example, a moderate flood peak in mid-January of 2006 is captured very well by the High Internal Melt model at Andersen Creek and Canada Stream, but the High Surface Melt model greatly underpredicts it (Figures 6.16 and $6.17,2005)$. In contrast, the High Surface Melt model reproduces a moderate flood peak that the High Internal Melt model largely misses in early December 2006 at Andersen Creek (Figure 6.16, 2006). At Green Creek, both models produce similar magnitudes for both of these events, in one case matching the observations (January 2006), and in the other overpredicting it (December 2006) (Figure 6.18, 2005 and 2006).

While either model may predict larger magnitudes for small to medium sized flood events, the High Internal Melt model is generally higher for the largest events. As stated previously, the High Internal Melt model does a better job predicting both the magnitude and timing during the high melt summers of 2001 and 2008. The daily hydrographs demonstrate this well (Figures 6.16 - 6.17, 2001 and 2008). Additionally, the High Surface Melt model includes contributions from subsurface melt, a necessary addition to match observations. The flood peaks in early and mid January of 2002 at Green Creek are good examples (Figure 6.18, 2001). The flood peak recession without 
the contribution from subsurface melt is far too fast, but with subsurface melt included, the recession matches the observations well. It is conceivable that the slower recession is due to flow routing, however, that inclusion of subsurface melt allows the model to match the timing and volume of the observations is compelling.

In Chapter 1, I hypothesized that subsurface melt does not contribute substantially to runoff, but instead refreezes. Though the model largely refutes this hypothesis, there is some evidence for subsurface melt failing to contribute to runoff early in the summer when the ice is still cold. For example, the High Surface Melt model matches observations better without including contributions from subsurface melt during the first half of December in both 2001 and 2008 at Green Creek, but matches observations better for the remainder of those summers including subsurface melt (Figure 6.18). It is difficult to find similar examples at the other two streams, and this phenomenon may be unique to Green Creek where runoff is stored within the basins in supraglacial ponds. 

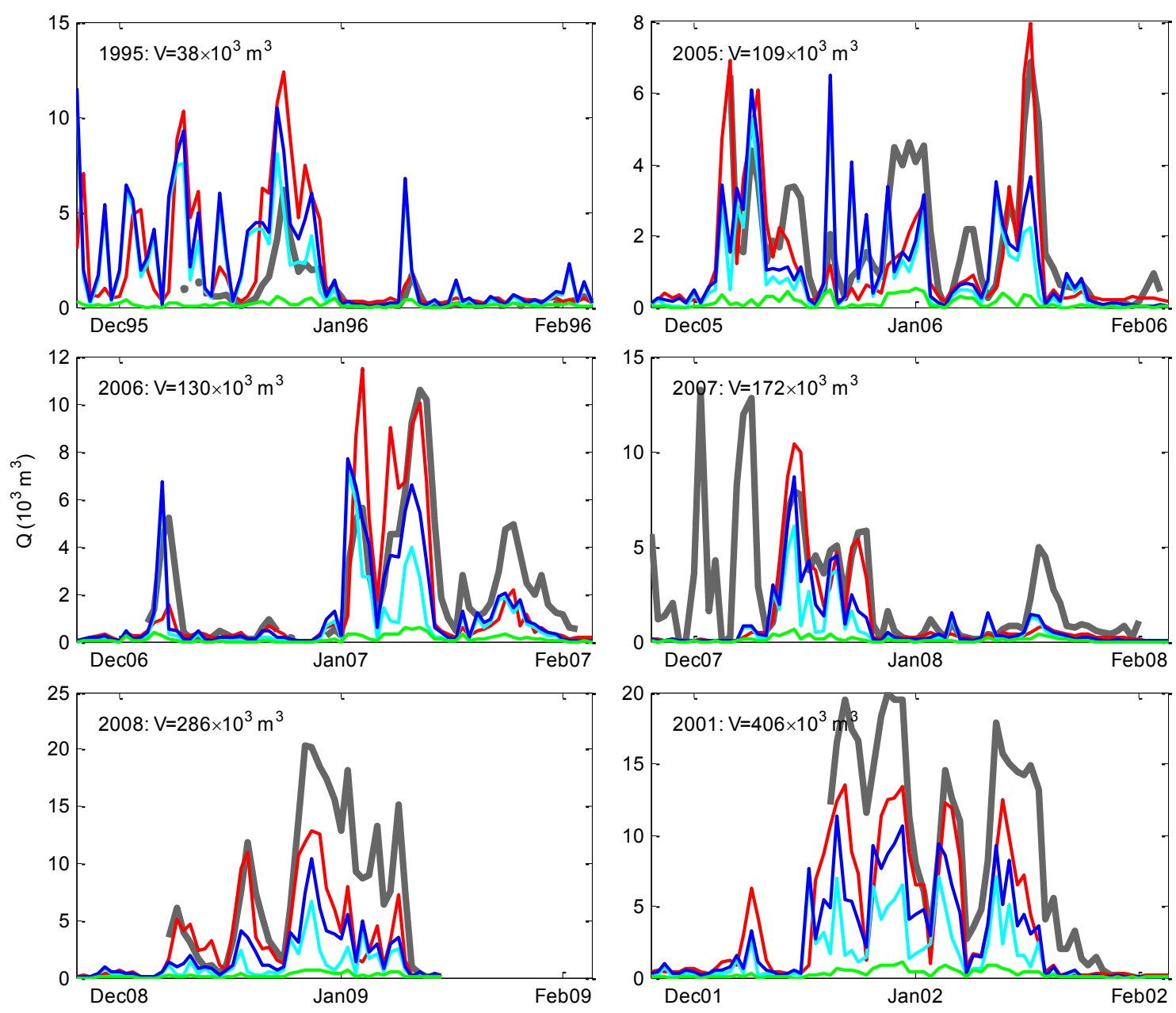

Figure 6.16: Measured and modeled daily streamflow at Andersen Creek for selected summers. Measured streamflow is shown in thick gray. The red line shows modeled runoff from the High Internal Melt model, and blue shows modeled runoff from the High Surface Melt model. The cyan line shows the surface melt contribution within the High Surface Melt model. The green line shows the contribution from the terminal cliffs, which is the same for both models. Only summers with reliable streamflow data are shown and they are identified by their start year. They are ordered by increasing measured seasonal streamflow volume, which is stated on each plot. Note that the y-axis scale varies between plots. 

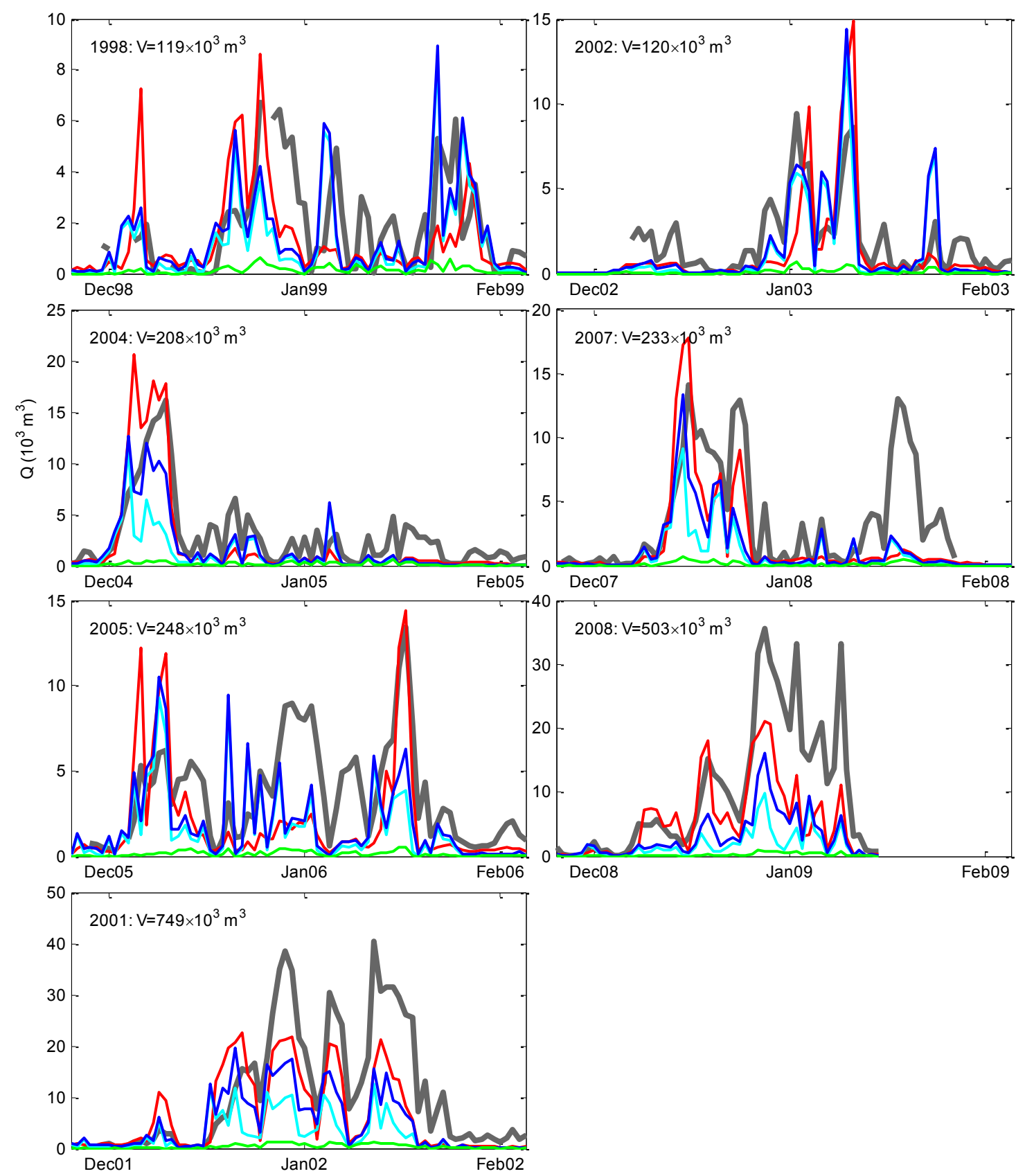

Figure 6.17: Measured and modeled daily streamflow at Canada Stream for selected summers. Measured streamflow is shown in thick gray. The red line shows modeled runoff from the High Internal Melt model, and blue shows modeled runoff from the High Surface Melt model. The cyan line shows the surface melt contribution within the High Surface Melt model. The green line shows the contribution from the terminal cliffs, which is the same for both models. Only summers with reliable streamflow data are shown and they are identified by their start year. They are ordered by increasing measured seasonal streamflow volume, which is stated on each plot. Note that the y-axis scale varies between plots. 

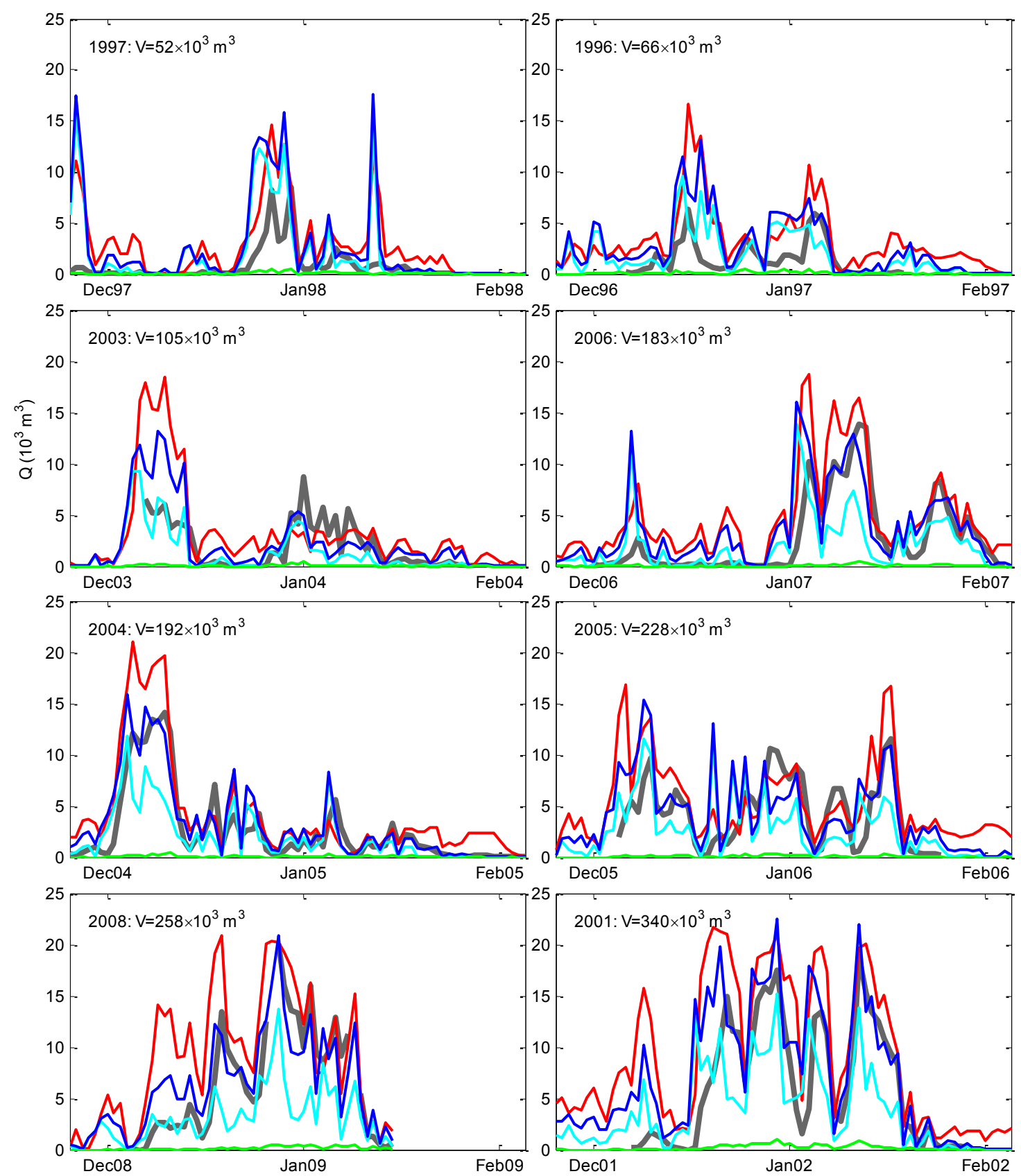

Figure 6.18: Measured and modeled daily streamflow at Green Creek for selected summers. Measured streamflow is shown in thick gray. The red line shows modeled runoff from the High Internal Melt model, and blue shows modeled runoff from the High Surface Melt model. The cyan line shows the surface melt contribution within the High Surface Melt model. The green line shows the contribution from the terminal cliffs, which is the same for both models. Only summers with reliable streamflow data are shown and they are identified by their start year. They are ordered by increasing measured seasonal streamflow volume, which is stated on each plot. Note that the $y$-axis scale is consistent between plots. 


\subsection{Results: Valleywide}

Based on the results for Canada Glacier, I apply the model to the rest of the glaciers in Taylor Valley. I use the High Internal Melt model; the High Surface Melt model provides similar results for ablation and runoff but with a greater fraction of total melt from the surface. For convenience, I restrict the analysis to six summers that are representative of the range of conditions exhibited over the fourteen year period (Table 6.3) and consider five representative streams from across the valley (

Table 6.4) in addition to the streams draining Canada Glacier described in the previous section.

Table 6.3: Summers used for valleywide model.

\begin{tabular}{ll}
\hline \hline Summer (start year) & Relative runoff magnitude \\
\hline 1997 & Low \\
2002 & Low \\
\hline 2004 & Medium \\
2006 & Medium \\
\hline 2001 & High \\
2008 & High \\
\hline
\end{tabular}

Table 6.4: Streams investigated with the valleywide model. Catchment area is bare ice area above the stream gage, and coverage of basin walls and floors is a percentage of that area. \# Stream considered in the previous section, included for reference.

\begin{tabular}{llclll}
\hline \hline Stream & Glacier drained & $\begin{array}{l}\text { Catchment } \\
\text { area }\left(\mathbf{k m}^{2}\right)\end{array}$ & $\begin{array}{l}\text { Coverage of } \\
\text { basin } \\
\text { walls/floors }\end{array}$ & $\begin{array}{l}\text { Primary } \\
\text { glacier aspect }\end{array}$ & Lake basin \\
\hline Santa Fe Stream & Taylor & 12.6 & $3 \% / 1 \%$ & East & Bonney \\
Lawson Creek & Rhone & 5.4 & $20 \% / 3 \%$ & South & Bonney \\
House Stream & Seuss & 0.5 & $10 \% / 0 \%$ & South & Hoare \\
Andersen Creek & Canada & 1.3 & $5 \% / 2 \%$ & South & Hoare \\
Green Creek $^{\#}$ & Canada & 1.5 & $21 \% / 17 \%$ & South & Fryxell \\
Canada Stream & Canada & 1.9 & $6 \% / 2 \%$ & South & Fryxell \\
Delta Stream & Howard & 1.9 & $0 \% / 0 \%$ & North & Fryxell \\
Lost Seal Stream & Commonwealth & 4.1 & $0 \% / 0 \%$ & South & Fryxell \\
\hline
\end{tabular}




\subsubsection{Valleywide Ablation}

Long-term mass balance measurements provide a test of model ablation on Taylor, Commonwealth, and Howard glaciers, in addition to those previously assessed on Canada Glacier (Figure 6.7). The model reproduces measured ablation very well over the range of elevations measured on Taylor Glacier (Figure 6.19). Sublimation is fairly uniform across this part of the glacier and from year to year, and the higher ablation observed at lower elevations in some summers is caused by increased melt. Above $\sim 350$ m elevation, melt is small in all years, so despite the large area of Taylor Glacier only the lower parts provide a substantial contribution to runoff. The model overpredicts ablation slightly at the highest elevations (e.g. in 2006), and this is likely due to the smooth ice on Taylor Glacier generating low sublimation rates; the optimal surface roughness length for Taylor Glacier $\left(\mathrm{z}_{0}=0.05\right.$, Chapter 5$)$ is smaller than the uniform value I have used for the spatial model $\left(\mathrm{z}_{0}=0.1\right)$.

Model performance at Commonwealth and Howard glaciers (Figure 6.20) is noticeably poorer than at Taylor and Canada glaciers. The difference may largely be attributed to spatial variations in albedo, as local albedo measurements are not used at Commonwealth and Howard glaciers. In some summers, the model overestimates ablation on Commonwealth Glacier (e.g. at high elevations in 1997 and everywhere in 2006), and this is likely due to the presence of snow on that glacier but not on Canada Glacier where albedo was measured. On the other hand, the model underestimates ablation in other summers, in some cases dramatically (e.g. 2001), and this may be due to variations in ice albedo between glaciers. Although bare ice is infrequently exposed at 
Commonwealth and Howard glacier meteorological stations due to their location near the equilibrium lines of their respective glaciers (Chapter 2), ice albedo was recorded at those sites in the high melt year of 2001. The minimum value measured at Canada Glacier during that summer (and used in the spatial model for the glaciers in the Hoare and Fryxell basins) was 0.52 , while the minimum albedo measured on Commonwealth and Howard glaciers was 0.49 and 0.45 , respectively. Indeed, reducing albedo for Commonwealth and Howard glaciers by 0.05 results in modeled ablation that matches the observations in the high melt summers (not shown).

Sublimation across the valley shows a marked break between the Bonney $(>9 \mathrm{~cm}$ weq summer $\left.{ }^{-1}\right)$ and Hoare $\left(<9 \mathrm{~cm}\right.$ weq summer $\left.{ }^{-1}\right)$ basins (Figure 6.21). This is likely due to the substantially higher wind speeds and drier conditions found in the Bonney Basin (Chapter 2). In actuality, the model is likely overestimating sublimation for some of the glaciers in the Bonney Basin as they tend to have smoother surfaces (e.g. Taylor, Hughes glaciers). Variations in sublimation from summer to summer are minor $(< \pm 25 \%)$ and the spatial patterns are consistent. 


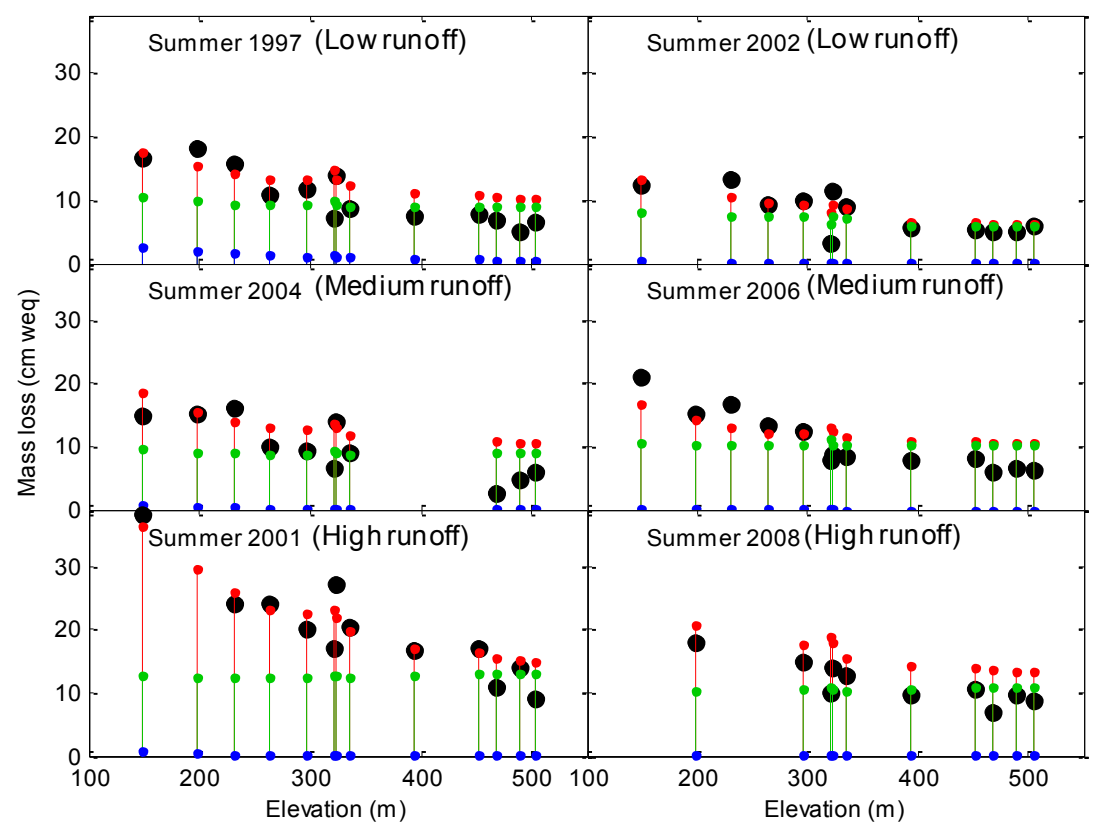

Figure 6.19: Ablation with elevation for Taylor Glacier using the High Internal Melt model configuration for selected summers. Black dots are measured mass balance values. Each colored column shows surface melt (blue), sublimation (green), and the contribution of subsurface melt to density reduction (red). Summers are identified by their start year.

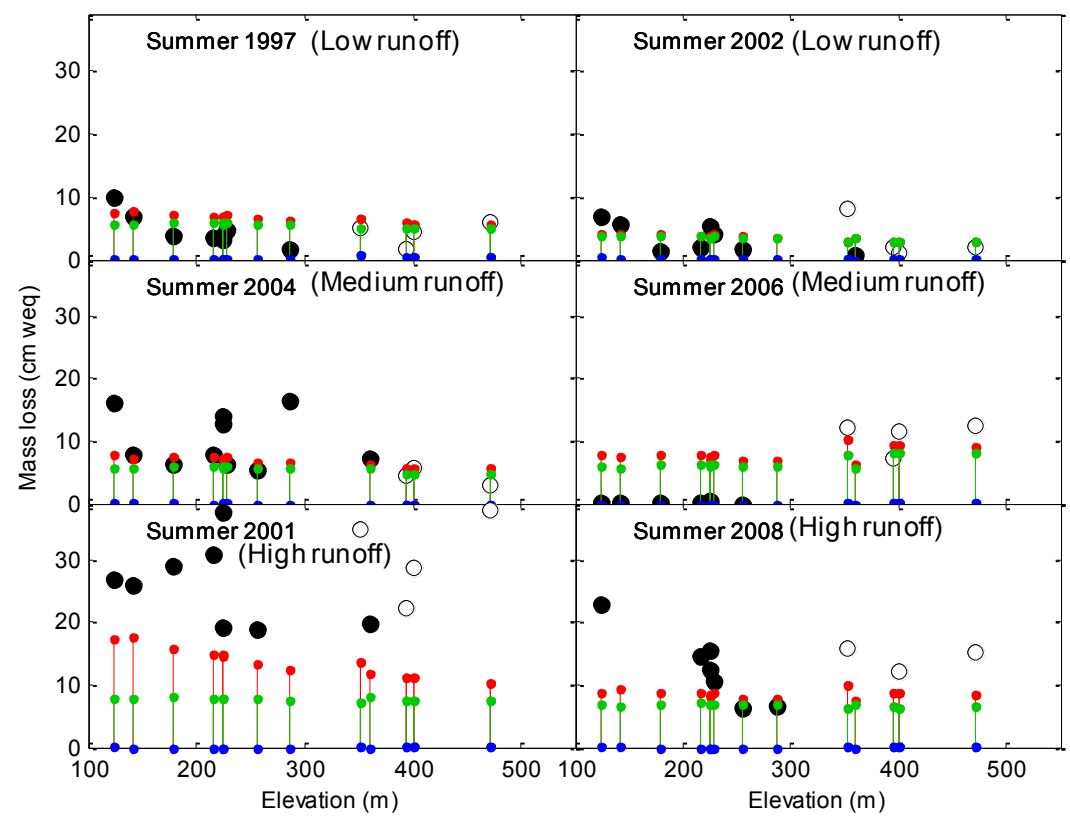

Figure 6.20: Ablation with elevation for Commonwealth Glacier (black dots) and Howard Glacier (white dots) using the High Internal Melt model configuration for selected summers. Black/white dots are measured mass balance values. Each colored column shows surface melt (blue), sublimation (green), and the contribution of subsurface melt to density reduction (red). Summers are identified by their start year. 

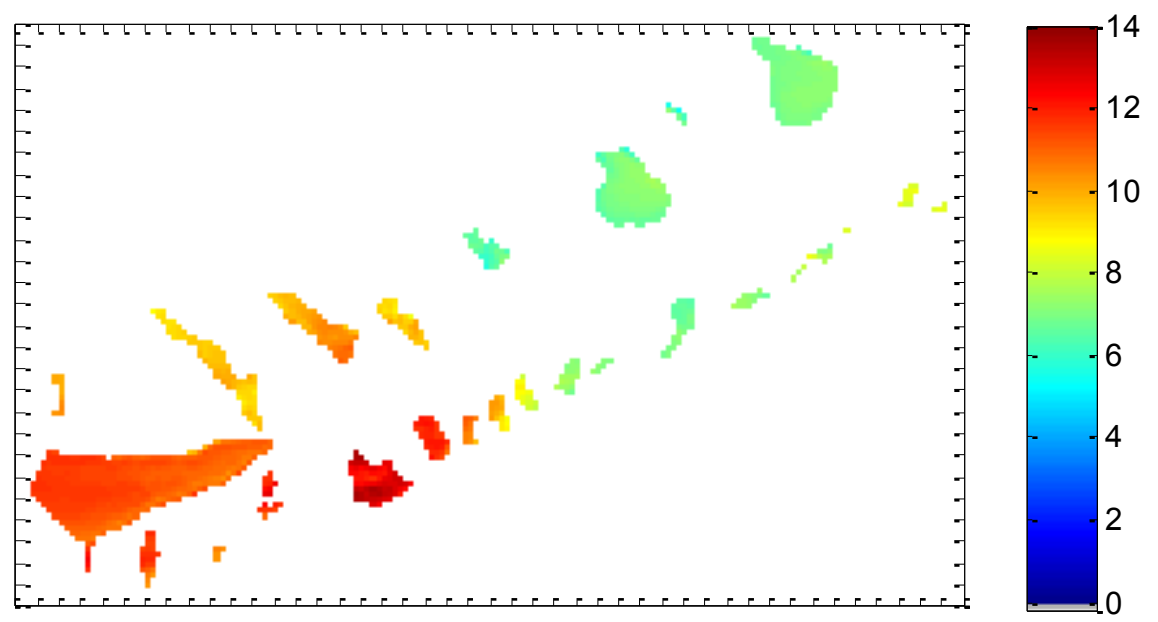

Figure 6.21: Map of average summer sublimation (cm weq) from the Smooth Surface submodel.

\subsubsection{Valleywide Runoff}

Spatial patterns of melt are similar in low, medium, and high melt years, with low melt over most glacier surfaces and melt in basin areas up to an order of magnitude greater (Figure 6.22). Basins with substantial floor area (lower Canada and Taylor glaciers) greatly out-produce basins composed primarily of walls (Rhone, and lower Seuss and Lacroix glaciers). Many of the smooth glacier surfaces consistently produce melt at low rates $\left(<5 \mathrm{~cm}\right.$ weq summer $\left.{ }^{-1}\right)$ that vary little between low and high runoff summers. Only certain regions of the smooth surfaces (e.g. Commonwealth, Canada glaciers) exhibit a marked increase in melt $(\sim 10 \mathrm{~cm}$ weq) during the 2001 summer over the other summers. The increase in melt in basin areas during the 2001 summer is greater $(\sim 20 \mathrm{~cm}$ weq).

Unlike the spatial pattern of sublimation, there is not a substantial difference in melt between the Bonney Basin and the Hoare and Fryxell basins. However, there is a pattern of higher melt on the glaciers flowing from the Asgard Range on the north side of 
the valley, particularly in high melt summers (Figure 6.22c), despite these glaciers receiving less solar radiation due to their southerly aspect. The Asgard Range reaches elevations up to $1000 \mathrm{~m}$ higher and is substantially wider than the Kukri Hills on the south side of the valley, and the glaciers flowing from the Asgard Range are significantly larger due to higher snowfall and larger basins for collecting snow. This allows these glaciers to flow further into Taylor Valley and terminate at lower elevations where the air is warmer in summer.

The model simulations show large expanses of exposed ice at high elevation in the Bonney Basin produce no melt, even in the high melt summer of 2001. In fact, the low runoff 1997 summer has a slightly higher melt limit in the Kukri Hills than the high runoff 2001 summer. The higher temperatures in the 2001 summer were associated with unusually strong and frequent drainage winds (Doran et al. 2008), and these winds may be suppressing melt in locations with lower temperatures despite the seasonally higher temperatures that summer. In the Hoare and Fryxell basins, the model predicts melt up to the limit of exposed ice on most glaciers which in the high melt summer is over $10 \mathrm{~cm}$ weq in places. This extends the observation made for Canada Glacier that a runoff contribution from the higher albedo accumulation zone during high melt years may be possible. This appears less likely in the Bonney Basin, perhaps because many of the glaciers there are steeper. 

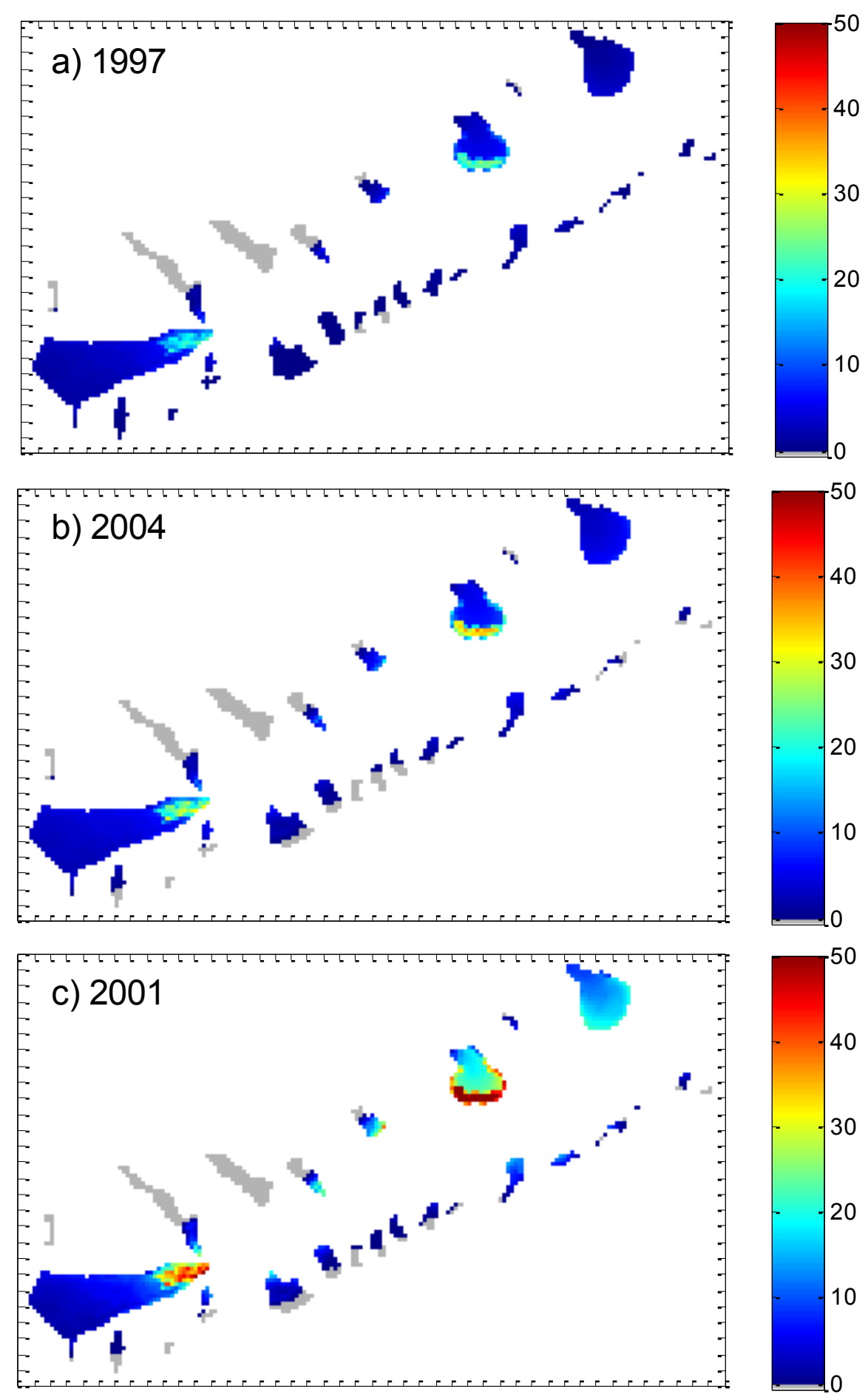

Figure 6.22: Maps of summer melt production (cm weq) for a) a low streamflow summer (1997), b) a medium streamflow summer (2004), and c) a high streamflow summer (2001). The total of surface and internal melt from the smooth surfaces and basins is spatially averaged for each grid cell. Melt from the cryoconite holes and terminal cliffs is not represented. 
The model predicts streamflow well for streams in the Bonney and Hoare basins where the albedo used in the model is likely to be representative (Figures 6.23-6.25), but tends to underpredict streamflow for streams in the Fryxell Basin in higher melt summers (Figures 6.26-6.27). For the large catchment Santa Fe Stream only one modeled summer has streamflow observations (1997), but the model does very well for the first part of this season (Figure 6.23). The model misses a large flood peak in late January of this summer because albedo measurements at the Taylor Glacier meteorological station indicated the presence of snow. The model suffers from similar missed flood peaks due to unrepresentative albedo measurements at most locations, some also of large magnitude (e.g. early January of summer 2008 on Lawson Creek, Figure 6.24) but typically of small magnitude (e.g. much of summer 2004 on House and Crescent streams, Figures 6.25 and $6.26)$.

The contribution of the various glacier surfaces to runoff varies from stream to stream. For Santa Fe stream, smooth surfaces make the dominant contribution to flood events due to their large contributing area (Figure 6.23). Basins and cliffs make large contributions relative to their surface areas, but have less variable runoff than the smooth surfaces and become insignificant during the largest flood peaks. On the neighboring Lawson Creek, large flood events are comprised of about equal parts from basin floors, basin walls, and smooth surfaces (Figure 6.24). Small and medium flood peaks come almost entirely from basin melt, but contributions from the smooth surfaces are necessary to predict the large flood peaks (e.g. early December 2004). The small catchment House Stream is the only stream investigated where cliff melt makes a sizable contribution to 
flood events (Figure 6.25). This stream is similar to the much larger Santa Fe stream in that flood peaks are primarily comprised of melt from smooth surfaces, and the contribution from basins seems to plateau at some maximum level. For the two streams considered in the Fryxell Basin, I did not map any basin regions, and flood peaks come almost entirely from the smooth surfaces (Figures 6.26-6.27).
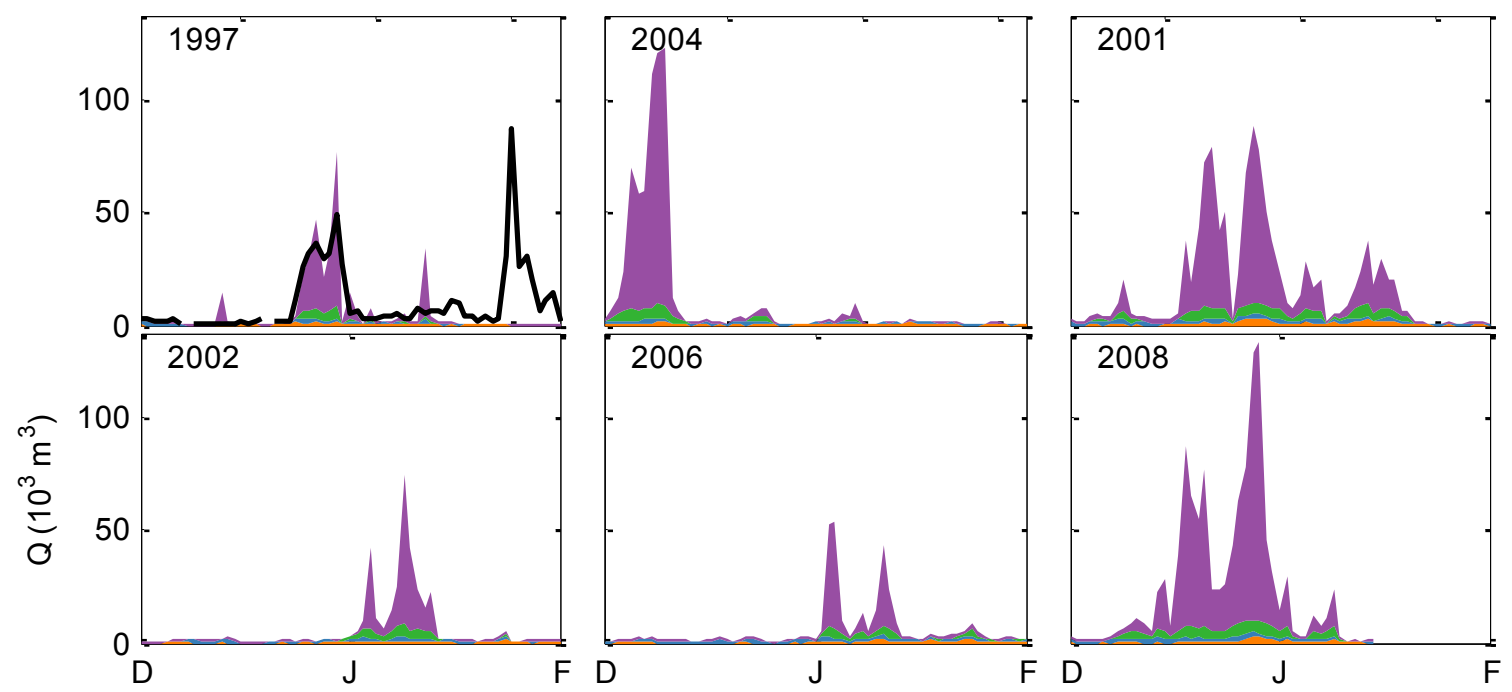

Figure 6.23: Measured (black) and modeled daily streamflow at Santa Fe Stream for selected summers. Modeled runoff from the High Internal Melt model is shown with stacked colors representing contributions from cliffs (orange), basin floors (blue), basin walls (green), and glacier surface and cryoconite holes (purple). Surface and subsurface melt are not differentiated. 

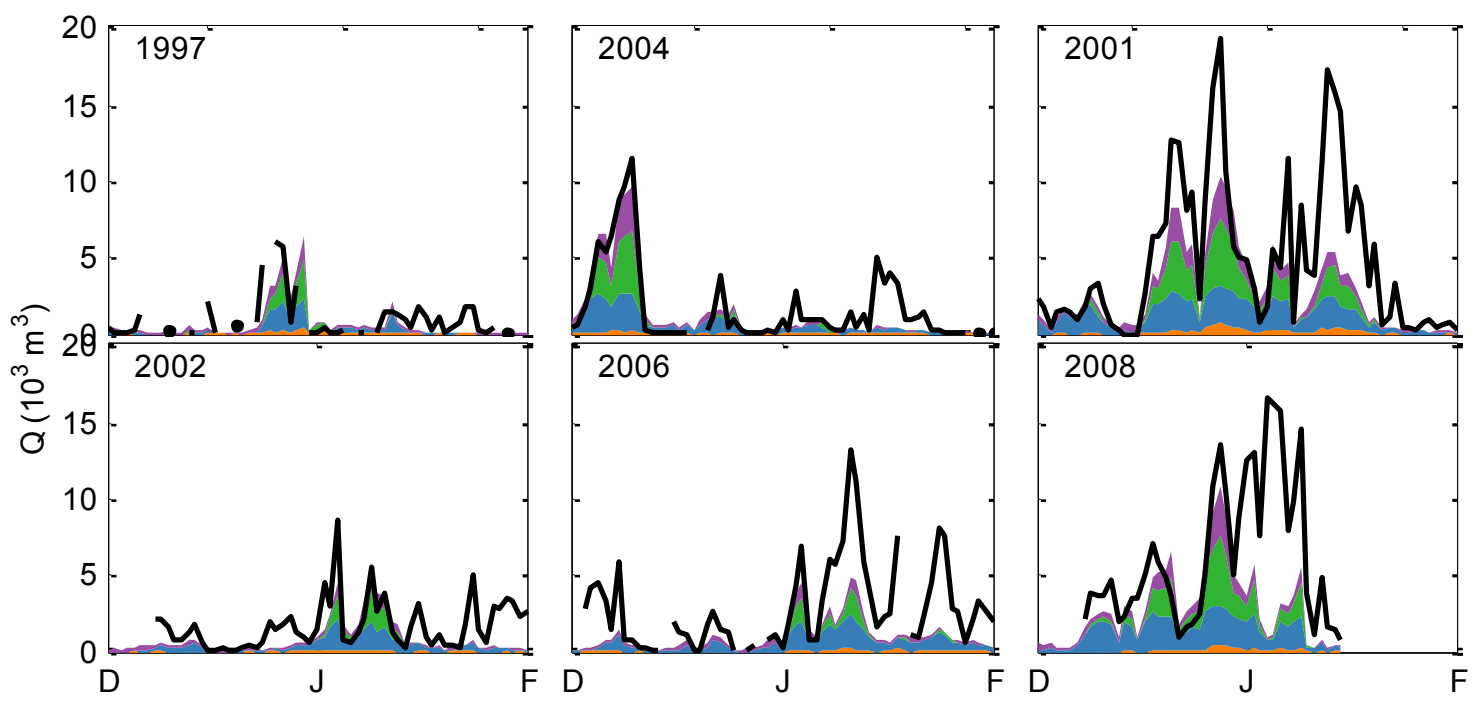

Figure 6.24: Measured (black) and modeled daily streamflow at Lawson Creek for selected summers. Modeled runoff from the High Internal Melt model is shown with stacked colors representing contributions from cliffs (orange), basin floors (blue), basin walls (green), and glacier surface and cryoconite holes (purple). Surface and subsurface melt are not differentiated.
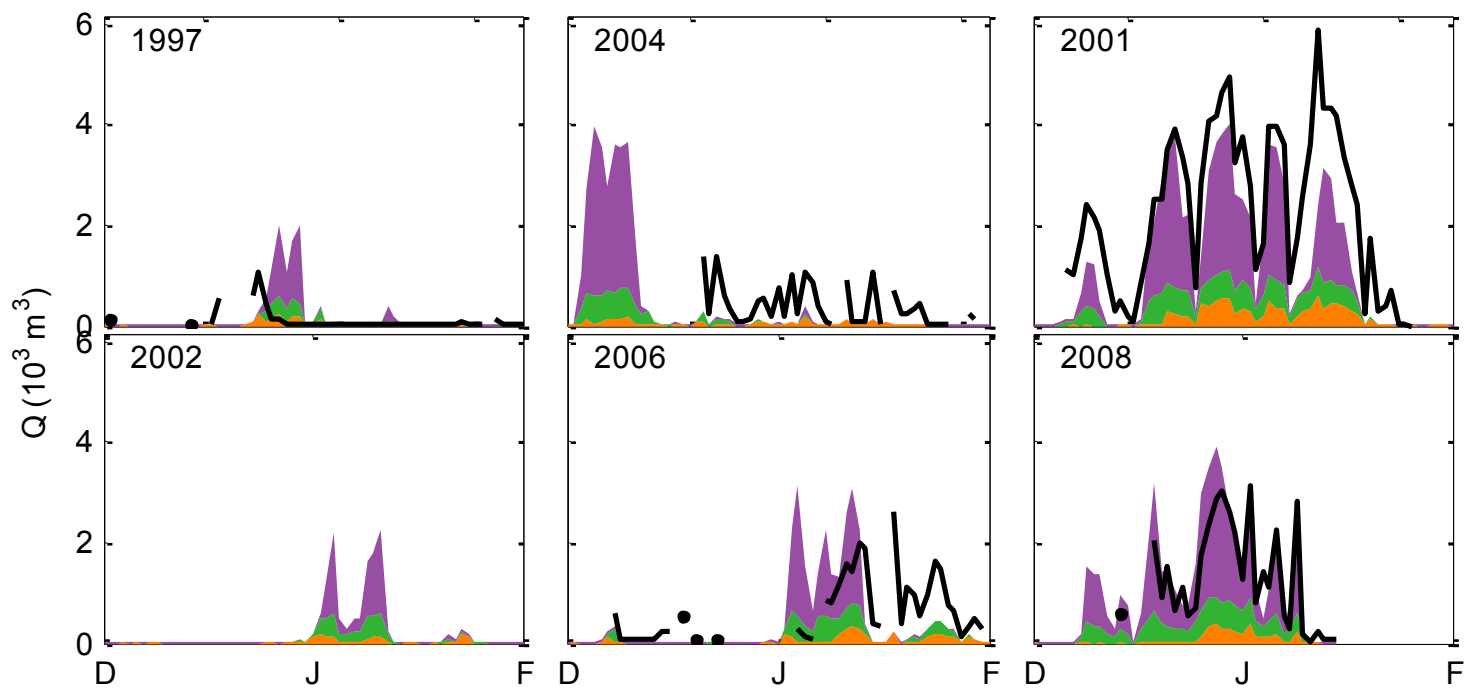

Figure 6.25: Measured (black) and modeled daily streamflow at House Stream for selected summers. Modeled runoff from the High Internal Melt model is shown with stacked colors representing contributions from cliffs (orange), basin floors (blue), basin walls (green), and glacier surface and cryoconite holes (purple). Surface and subsurface melt are not differentiated. 

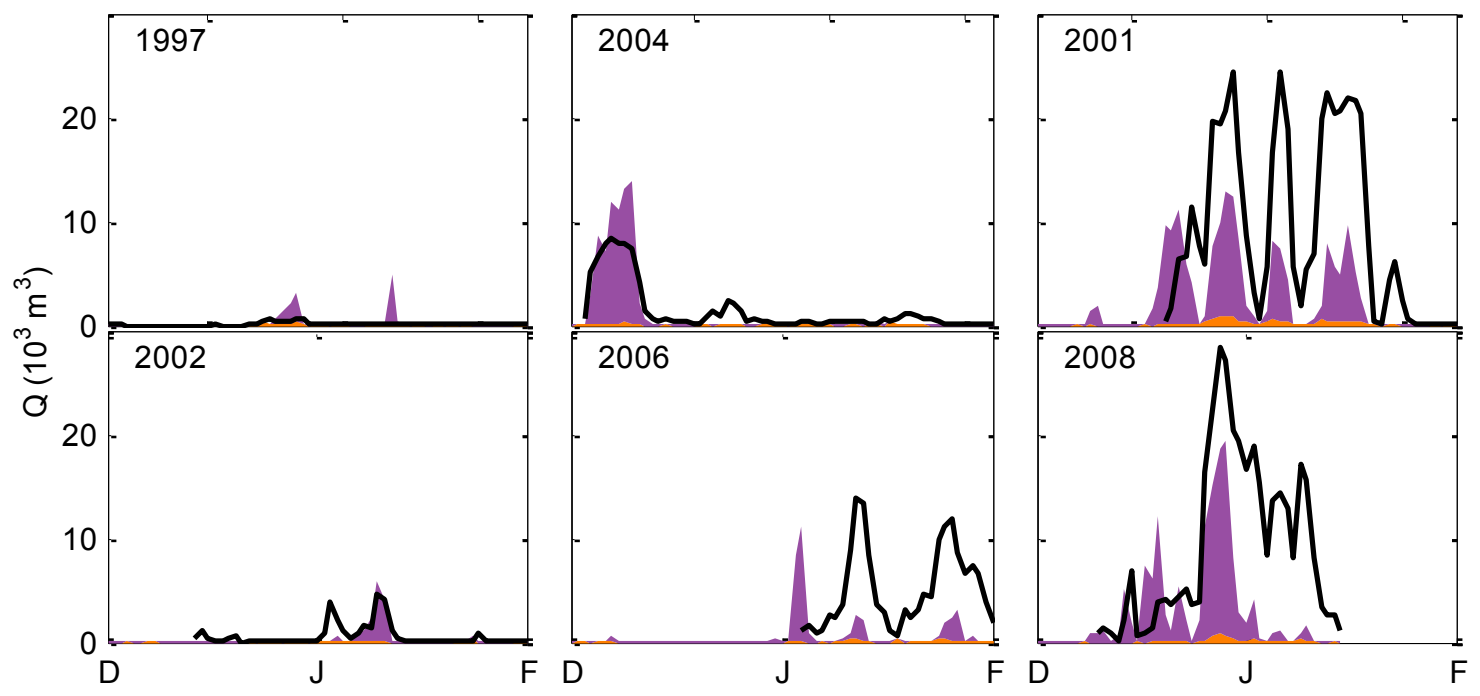

Figure 6.26: Measured (black) and modeled daily streamflow at Delta Stream for selected summers. Modeled runoff from the High Internal Melt model is shown with stacked colors representing contributions from cliffs (orange), basin floors (blue), basin walls (green), and glacier surface and cryoconite holes (purple). Surface and subsurface melt are not differentiated.
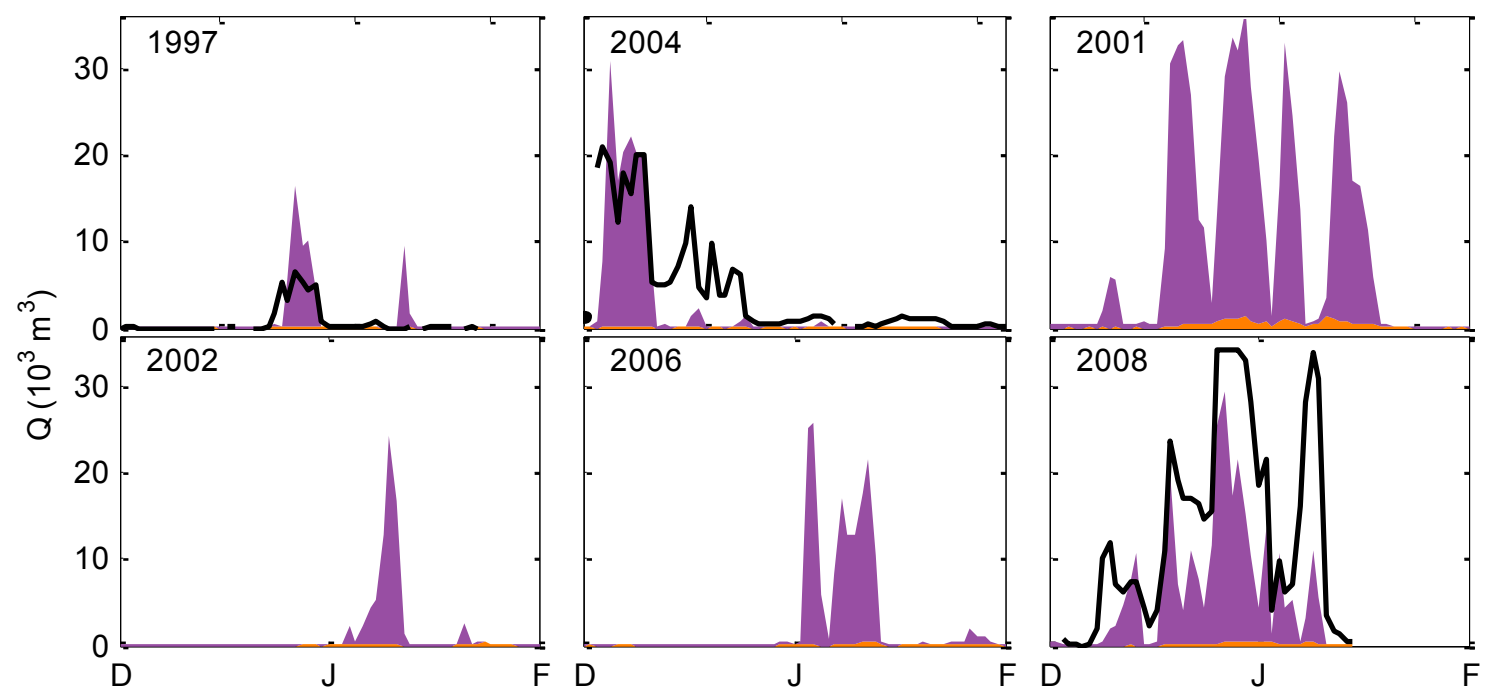

Figure 6.27: Measured (black) and modeled daily streamflow at Lost Seal Stream for selected summers. Modeled runoff from the High Internal Melt model is shown with stacked colors representing contributions from cliffs (orange), basin floors (blue), basin walls (green), and glacier surface and cryoconite holes (purple). Surface and subsurface melt are not differentiated. 


\subsection{Discussion}

\subsubsection{Assessment of Modeled Runoff Volumes}

Each streamflow measurement includes a data quality flag (good=most data accurate within $10 \%$, fair $=$ most data accurate within $25 \%$, poor $=$ significant amounts of data may be $>25 \%$ off) determined by the hydrologists collecting the measurements based on the condition of the gage (Ebnet et al. 2005). These quality flags change over the course of the season and between seasons, but some gages tend to provide higher quality data than others due gage type, channel configuration, and sediment loads. Canada Stream has one of the most reliable gages, which is categorized as producing good quality data most of the time. Based on this, the High Internal Melt model performs significantly better than the High Surface Melt in moderate summers (e.g. in 2004, 2005, and 2007) and is within measurement error a large part of the time in those summers (Figure 6.17). However, in extreme summers $(2001,2008)$ both model significantly underpredict the observations, even considering that part of the seasons may have had errors in excess of $25 \%$. The same pattern also applies at streams that often have poor data quality (e.g. Andersen Creek).

The model predicts streamflow well for some streams (e.g. Green Creek, Santa Fe Stream, House Stream), but significantly underestimates most seasons for other streams (e.g. Andersen Creek, Canada Stream, Crescent Stream, Lost Seal Stream). Many of the streams for which the model performs well have substantial melt contributions from basin areas. Given the simplifications in the basin submodel, it is possible that overproduction of melt in the basin submodel is compensating for deficiencies in other submodels. Many 
of the streams that the model underpredicts have little to no catchment area covered with basins, and therefore on these glaciers the model either underpredicts melt over the glacier surface or is missing important melt sources. Alternatively, it is possible that the streamflow measurements are biased at higher flows, but this would have to be a systematic problem.

For the glaciers in the Fryxell Basin, there is evidence that melt on the smooth surfaces is underpredicted. Modeled ablation for Commonwealth and Howard glaciers is low in high ablation summers (Figure 6.20), and the deficit of ablation is likely to be primarily melt as sublimation appears to be modeled well (Chapter 5) and cannot reasonably be invoked to explain the high ablation rates observed. In the Results section I noted that Commonwealth and Howard glaciers have a lower bare ice albedo than Canada Glacier, at least in high melt summers, and that adjusting for the difference allows the model to match the ablation observations. This adjustment also allows the model to match the streamflow observations in the high streamflow summers (Figure 6.28). During the high melt summer of 2001, extensive sediment was revealed on the surfaces of many glaciers due to the surface melting faster than the sediment could melt into the ice (Fountain et al. 2004b). The additional sediment on the surface lowered the ice albedo, but the effect was not uniform between and across glaciers.

The original, higher albedo model run works better in low streamflow summers and early in the season during high streamflow summers, and this may be due to the substantial in-stream losses that occur on longer streams such as Delta (Conovitz et al. 1998) or snowcover over all or parts of these glaciers during those times. Jaros (2003) 
estimates about $40 \times 10^{3} \mathrm{~m}^{3}$ of hyporheic zone and evaporation losses for Delta Stream, which would primarily occur early in the season as the hyporheic zone fills with water. The excess modeled runoff in low melt summers and early in high melt summers (Figure $6.28)$ is of the same order of magnitude as that estimate.
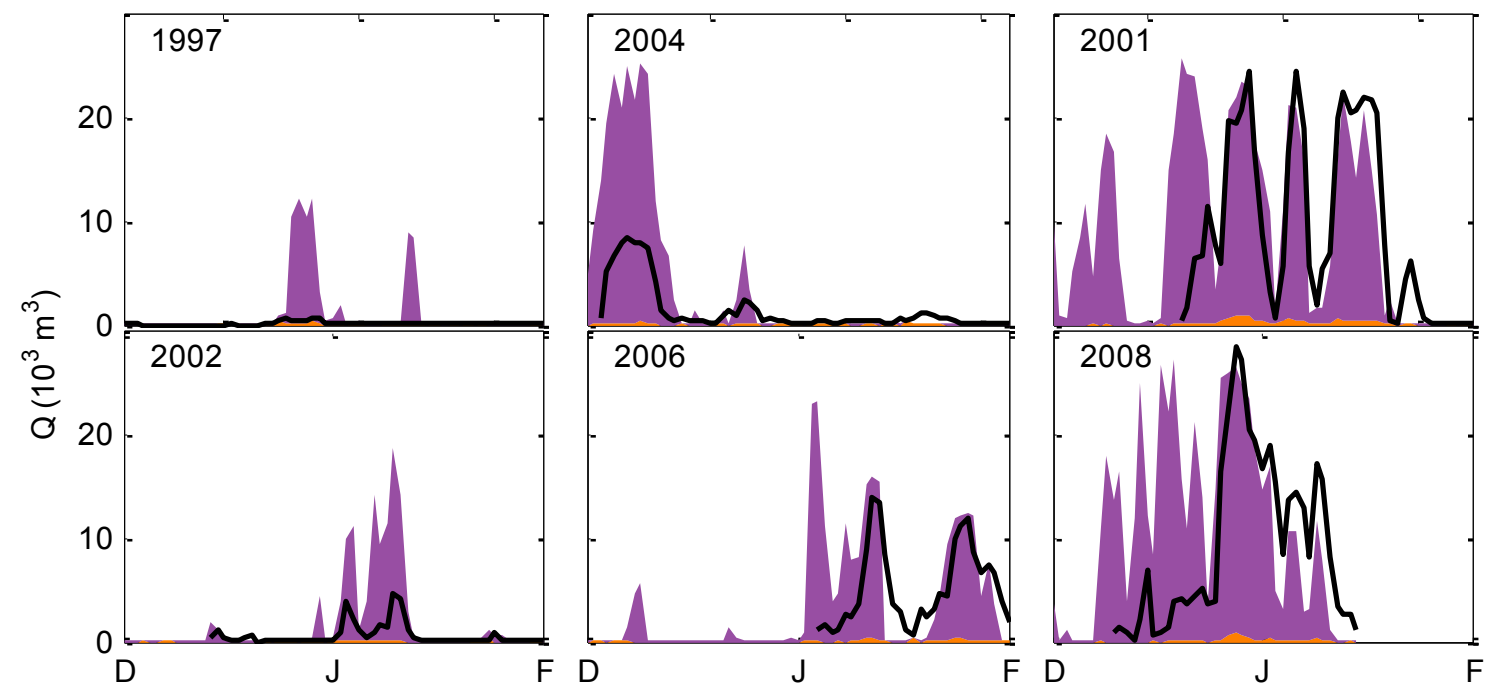

Figure 6.28: Measured (black) and modeled (colors) daily streamflow at Delta Stream for selected summers using albedo reduced by 0.05 to match the bare ice albedo measured on Howard Glacier. See Figure 6.26 for explanation of symbology.

It is not clear if variations in ice albedo can explain low modeled runoff for other streams, particularly Andersen Creek and Canada Stream, since the source of the albedo values used to model them (Canada Glacier meteorological station) is within a few $100 \mathrm{~m}$ of their catchments. The debris content of ice can vary over short distances, but ice albedo lower than that at the meteorological station would have to be restricted to the margins because melt rates over the interior of Canada Glacier are constrained by ablation measured from the mass balance stake network. Reducing sublimation allows for additional melt while matching ablation observations, however the surface roughness 
length used $(0.1 \mathrm{~mm})$ is already near the lower limit of plausible values, making a reduction in sublimation unlikely. Similarly, the cliffs on Canada Glacier are well constrained by ablation measurements, and even if cliff melt rates were doubled or tripled, the small surface area of the cliffs would fail to significantly increase runoff. Melt from cryoconite holes is also constrained by the small fraction of the surface they occupy, and the approach used to model cryoconite holes likely overpredicts melt. It is possible that the model may underpredict basin melt in some locations, although the catchment with the most basins (Green Creek) is slightly overpredicted in most summers. However, basin floors cover a much higher fraction of the basins in the catchment of Green Creek than elsewhere, and the simple division of basins into floors and walls may be inadequate. Despite uncertainties, none of these explanations seem likely for the low modeled runoff.

Snow melt is another possible source of additional runoff. Snowmelt in Taylor Valley is considered rare (Chinn 1981, Gooseff et al. 2003a), and when it does occur it refreezes at depth in the snowpack (Fountain et al. 1998). However, modeling of ice near the equilibrium line on Canada Glacier indicates up to $15 \mathrm{~cm}$ weq of melt there over the high melt summer of 2001. Despite having a higher albedo than the ice modeled, it is possible that snowmelt in the lower elevations of the accumulation zone does contribute to runoff in the warmest summers. The lowest parts of the accumulation zone would be less susceptible to snowmelt refreezing at depth because the impermeable ice surface is close to the surface. It is intriguing that of the three streams on Canada Glacier, Green Creek is the only one that does not suffer from underprediction during high melt years. 
This may be because Green Creek is the only gaged stream in Taylor Valley whose topographic catchment is contained entirely within the ablation zone, so that the contributing catchment area cannot enlarge to include melting snow-covered areas in high melt years. However, the high fraction of that catchment covered by basins makes a direct comparison to the other streams on Canada Glacier difficult. In some cases the degree to which the model underpredicts streamflow increases over the course of the summer (e.g. Andersen Creek 2008, Figure 6.16). This would be consistent with expansion of bare ice area as the snowline moves upglacier, or alternatively, the formation of impermeable ice lenses in the snowpack during early summer melt events that facilitate runoff of snowmelt from subsequent melt events.

The presence of any routing losses would further increase the extent to which the model underpredicts streamflow for many streams. The in-stream sinks of evaporation and hyporheic zone storage are likely to be relatively insignificant for the short streams draining Canada Glacier, but can be large on the longer streams (e.g. Delta Stream). For all catchments, the fraction of melt refreezing before it leaves the glacier could be substantial, particularly in low melt years and early summer when the ice is cold. Apart from basins and the very periphery, overland flow is uncommon on Dry Valley glaciers (Fountain et al. 1998), and we observe that when subsurface melt drains downslope onto the surface it often refreezes (Figure 4.2). However, a subsurface network of flow paths has been observed to link cryoconite holes (Fountain et al. 2004b). The extent to which this type of connection occurs in the bulk white ice of the glaciers is unclear. However, modeling of subsurface ice temperatures indicated that subsurface melt is able remain 
unfrozen continually for much of the summer at about $10 \mathrm{~cm}$ depth during many seasons (e.g. Figure 5.3). If this melted zone maintains permeability, it is conceivable that the primary routing pathway over much of the glacier surface is actually beneath the surface, and the refreezing of melt is less than would occur for melt traveling across the surface.

\subsubsection{Runoff Source Areas}

To investigate the role of different parts of the glacier to meltwater production, I calculate the fractional contribution of melt from each submodel. The results are summarized for Andersen and Green creeks (Figure 6.29) using the High Surface Melt model. The results for Canada Stream are similar to those for Andersen Creek. The fractions for each component using the High Internal Melt model are similar to the High Surface Melt model, except that the fractions from surface melt are nearly entirely replaced by additional subsurface melt. I assume that all melt becomes runoff.

Smooth surfaces make up $85 \%$ of the glacier surface area of the Andersen Creek catchment, while basins make up 6\%, and the cliffs 5\% (Figure 6.29a). Cryoconite hole area is set at $3.4 \%$ of the smooth glacier surface (Fountain et al. 2004b). The relative contribution from the smooth surfaces increases as total runoff increases, while the fraction from the other meltwater sources decreases. The smooth surfaces exhibit the smallest melt rates, and even in the highest melt summers they provide only $65 \%$ of the modeled runoff. On the other hand, the basins experience the highest melt rates and can contribute nearly half of the runoff in low melt summers, despite occupying only $6 \%$ of the catchment's surface area. Their relative contribution shrinks in the highest melt years to about $20 \%$, but this is still large for their area. The basin floors dominate over the 
basin walls, despite occupying less area. Net solar radiation is the largest component of the energy balance (Chapters 4 and 5), and the high melt rates of the basin floors are due to the low albedo surface.

For Green Creek, basins comprise about one-third of the catchment area, and basin meltwater dominates all other sources (Figure $6.29 \mathrm{~b}$ ). The basins generate $90 \%$ of the meltwater in the lowest runoff summer, and in the highest runoff year, they provide $65 \%$ of the total runoff. Despite this difference from the Andersen Creek catchment, there is a similar pattern at Green Creek of melt production from the smooth surfaces becoming increasingly important as total summer runoff increases. The relative contributions from the terminal cliffs and cryoconite holes on the surface are both small (approximately equal to their surface area fraction) and are relatively constant from year to year.

These comparisons underscore the importance of the basins in the melt model. Melt from the basins is a sizable contribution to runoff in all years, even in catchments where they occupy a small fraction of the total surface area. Given this, improvements to the model treatment of the basins may be warranted. The modeling also indicates that even though melt rates on the smooth surfaces are much lower than elsewhere, their contribution to runoff should not be ignored even in low melt summers.

Previous studies have suggested that cliffs contribute up to $15-20 \%$ (Lewis et al. 1999) and cryoconite holes contribute up to $13 \%$ (Fountain et al. 2004b) of runoff to Andersen Creek. These previous studies used similar methods for modeling melt production from these regions of the glacier for summers 1994 through 1996, and I find 
similar fractions here for those summers and other years with similar streamflow volumes. However, those summers are among the lowest in runoff volume of the fourteen summers included in my model. Considering this longer period of record, the contributions to runoff from cryoconite holes and terminal cliffs is less than reported previously. Also, these meltwater sources are insignificant for Green Creek and other streams whose catchment includes extensive basin areas.

The differences in source area contributions between catchments are largely due to the fraction of the total surface area that is occupied by each type of glacier surface. When the contribution to runoff from each type of glacier surface is scaled by the area of each surface, the areally averaged melt production rates are similar between nearby catchments are very similar (Figure 6.30), as expected. Melt rates for smooth surfaces are the lowest. Melt rates from cliffs, cryoconite holes, and basin walls are similar to one another and up to a few times larger than for smooth surfaces. Melt rates for basin floors are up to a few times larger yet. 
a) Andersen Creek

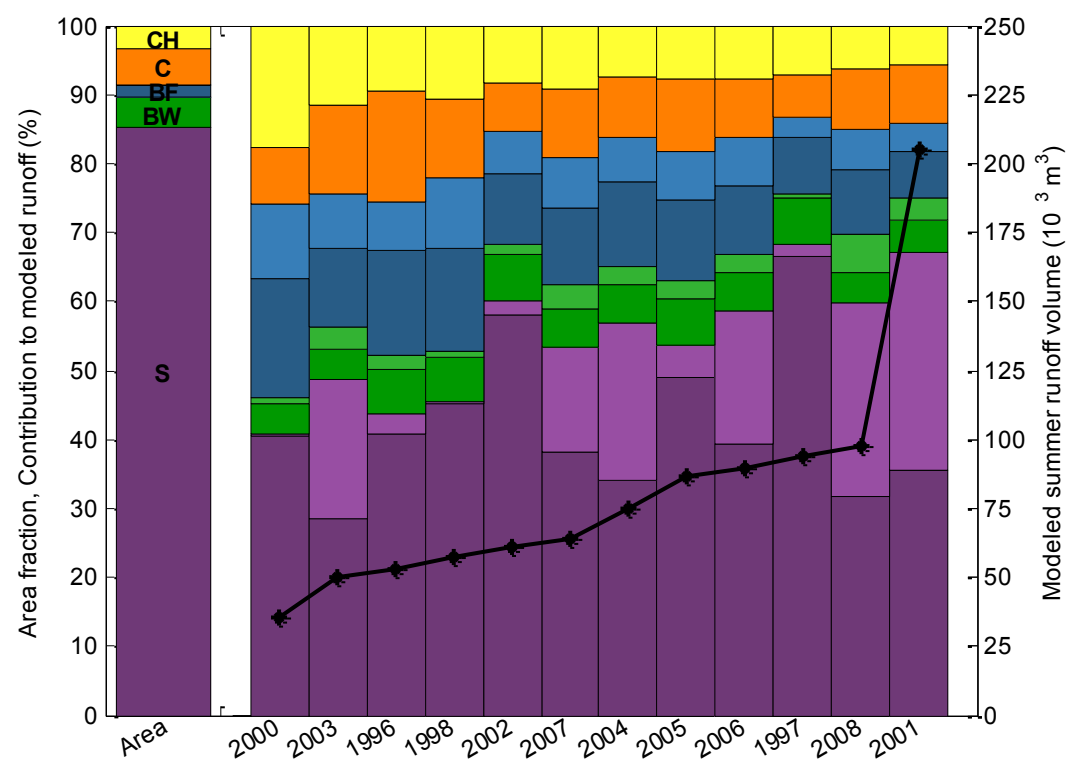

b) Green Creek

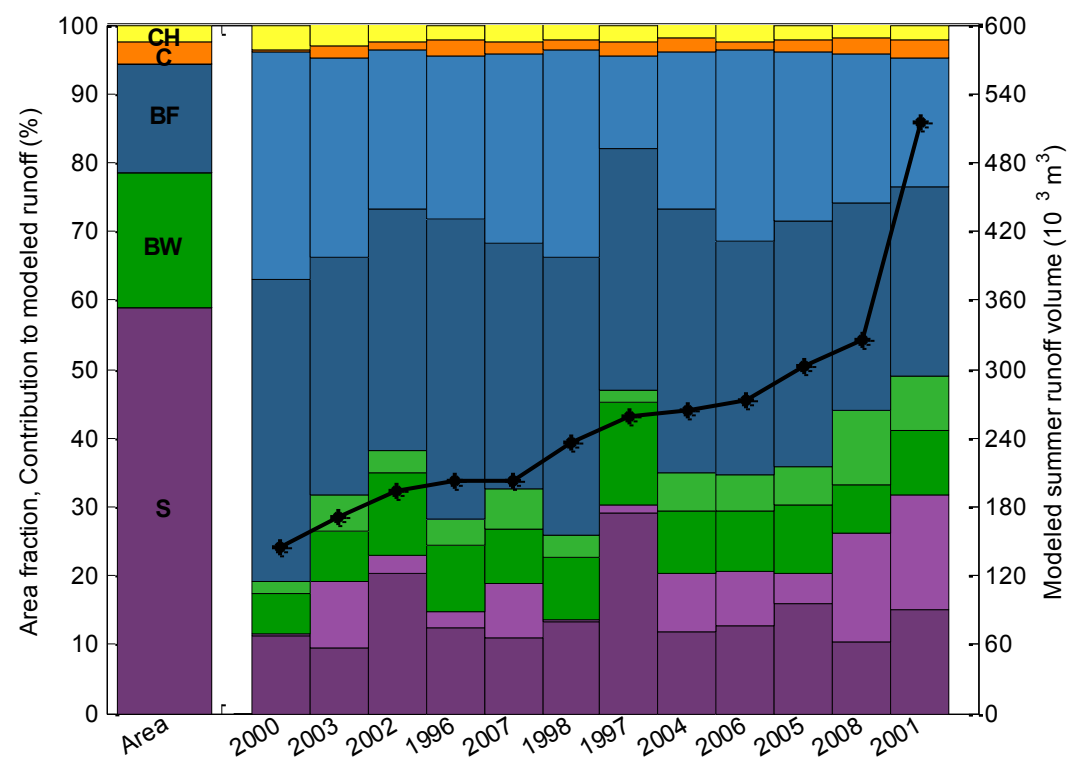

Figure 6.29: Contribution of different glacier surfaces to modeled summer runoff for a) Andersen Creek and b) Green Creek catchment using the High Surface Melt model. The contribution of smooth surfaces (S, purple), basin walls (BW, green), basin floors $(B F$, blue), terminal cliffs $(C$, orange), and cryoconite holes ( $\mathrm{CH}$, yellow) are shown for each summer (designated by start year). For the smooth surfaces, basin walls, and basin floors, surface melt is shown in a darker shade and subsurface melt is shown in a lighter shade. Also shown is the fraction of the surface area of the catchment that each surface type comprises (left bar), and the total modeled runoff volume for each summer (black line). The years are ordered by increasing modeled runoff volume. See Figure 6.2 for map of stream catchments. 

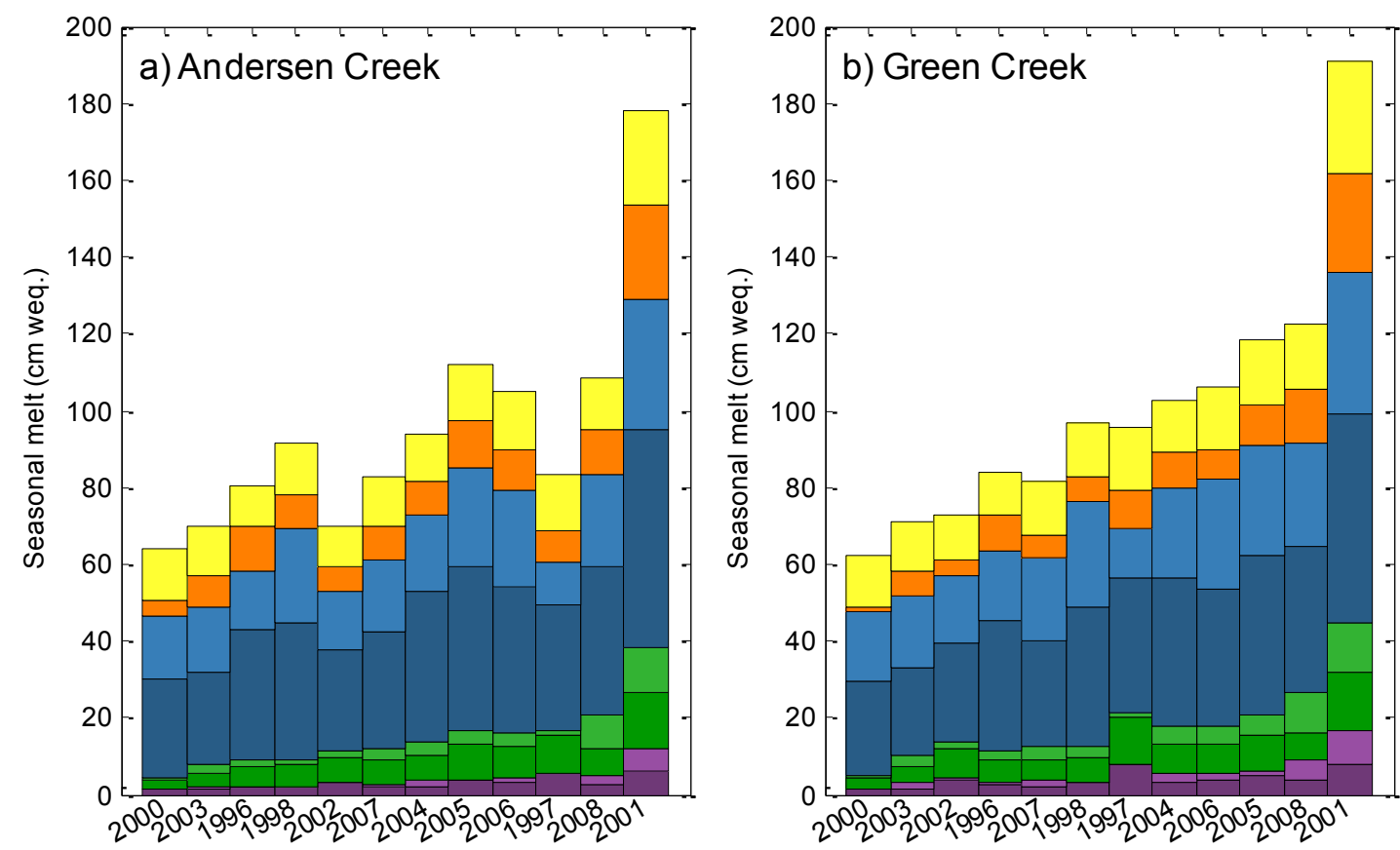

Figure 6.30: Summer melt from different glacier surfaces scaled by surface area for a) Andersen Creek and b) Green Creek. See Figure 6.29 for explanation of colors.

To better assess the role of the cliffs in maintaining streamflow during cool periods, as suggested by (Lewis et al. 1999), I recalculate the relative contributions of the various glacier surfaces using daily runoff instead of seasonal totals (Figure 6.31). Because the crude method for modeling runoff from cryoconite holes is not appropriate for short-term application, cryoconite holes are excluded. For the days with greatest modeled melt, the fraction of melt from each source is similar to that calculated at the seasonal scale (Figure 6.29). However, the daily calculations reveal that most melt days have no runoff contribution from the smooth surfaces or basin walls. On these low melt days, basin floors at Andersen Creek (and Canada Stream, not shown) contribute about 
equally to runoff as the cliffs, while at Green Creek melt from the basin floors dominates all but the smallest melt days (those with less than $100 \mathrm{~m}^{3}$ of total melt).

This suggests that cliffs are not as important for maintaining low streamflows as previously suggested. The previous work by Lewis et al. (1999) came to this conclusion by comparing observations on the terminal cliff faces with those at the Canada Glacier meteorological station in the upper ablation zone. However I find that the elevation difference between those locations alone, without considering different geometry and microclimates, accounts for much of the difference in melt (Figure 6.11). Furthermore, Lewis et al. (1999) did not consider the basin areas in the Andersen Creek and Canada Stream catchments, presumably because they cover such small areas. However, they are at low elevations, and the microclimate adjustments for basin floors suggested by previous studies (temperature, wind speed, and albedo) are more favorable for melt than those found for the cliffs (Table 6.2). Thus it is reasonable to consider that the basin floors play a role in maintaining low flows that is equal to or greater than that provided by the terminal cliffs. However, more careful modeling of the basin areas that makes spatially distributed calculations within each basin, particularly for albedo, would help clarify the role of the basins during low flow periods. Additionally, meltwater generated in basins may be stored within supraglacial ponds during low flow conditions, but cliff melt is likely to immediately drain into the stream. Therefore actual runoff from the basins may be substantially less than meltwater production during cooler, low flow conditions. 
Comparing the relative contributions of the various glacier surfaces to $\sim 3-\mathrm{m}$ air temperature shows that melt from the cliffs and basin floors begins at about $-5^{\circ} \mathrm{C}$, and melt from the basin walls and smooth surfaces begins at about $-2^{\circ} \mathrm{C}$ (Figure 6.31). This relationship exists for both Andersen and Green creeks, and generally holds for other streams within Taylor Valley (not shown). However, there is about $5^{\circ} \mathrm{C}$ of scatter in this relationship, which emphasizes the complexity of the energy balance and underscores the mixed results found using statistical melt models (Ebnet 2005). Runoff increases exponentially while temperature increases linearly, evidence that these glaciers remain near the threshold of generating substantial melt during much of summer. 
a) Andersen Creek

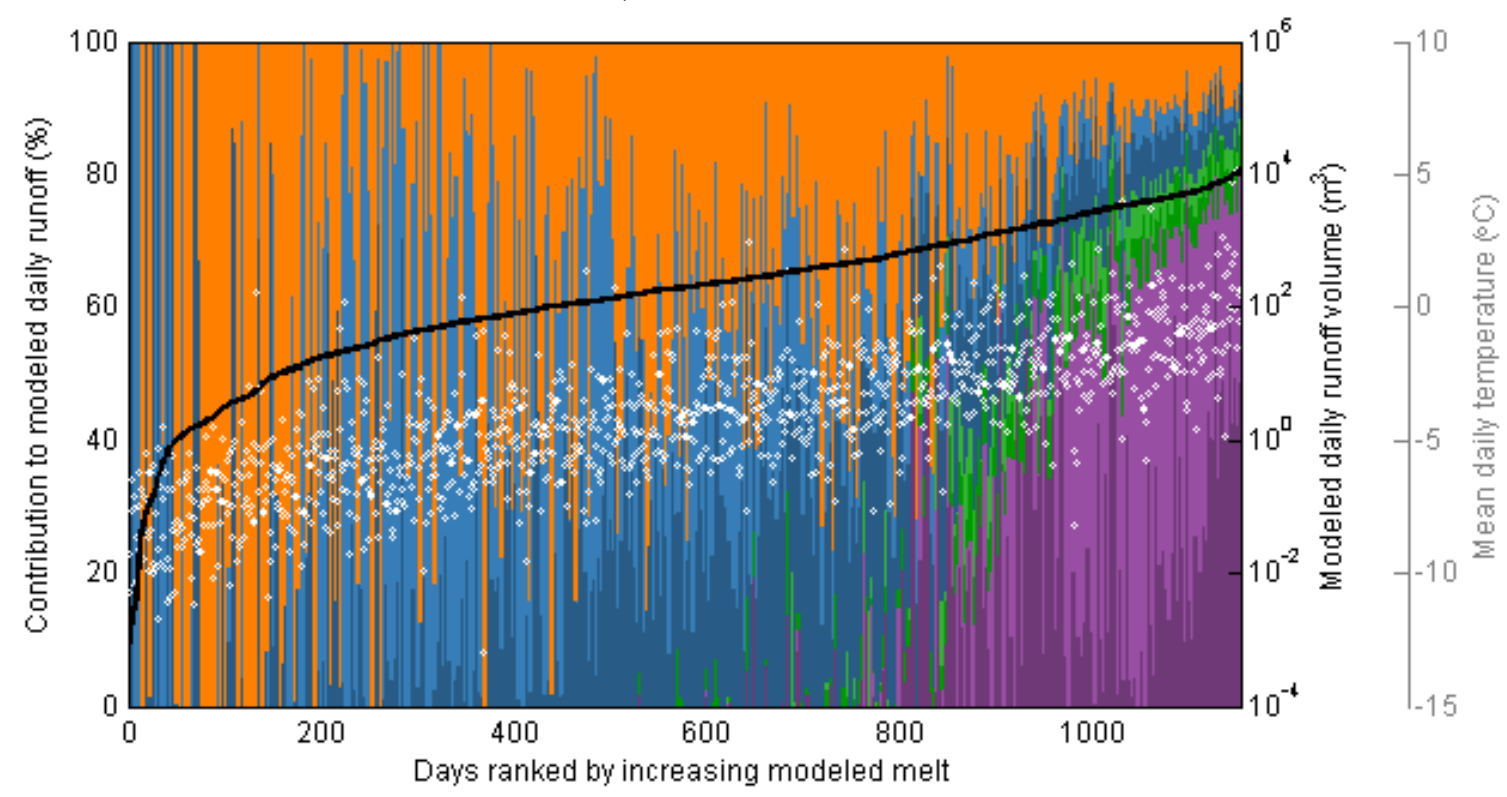

b) Green Creek

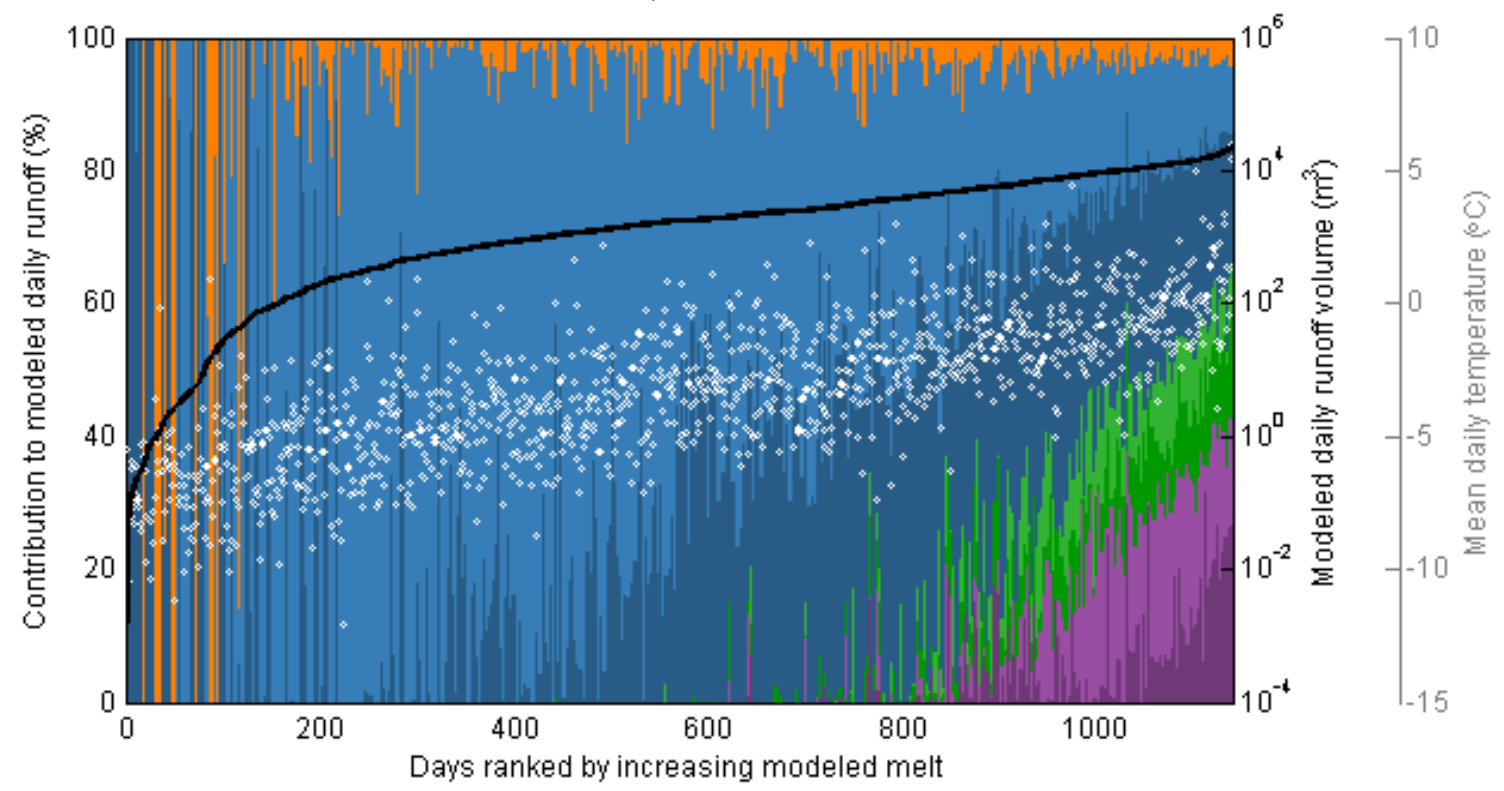

Figure 6.31: Contribution of different glacier surfaces to modeled daily runoff for a) Andersen Creek and b) Green Creek catchment using the High Surface Melt model. The contribution of smooth surfaces (purple), basin walls (green), basin floors (blue), and terminal cliffs (orange) are shown for each day with modeled runoff. For the smooth surfaces, basin walls, and basin floors, surface melt is shown in a darker shade and subsurface melt is shown in a lighter shade. Also shown is the total modeled runoff volume for each day (black line) and mean daily temperature at the center of the catchment (white dots) ordered by increasing modeled runoff volume. 


\subsection{Conclusion}

Using a melt model that includes contributions from subsurface melt, runoff from Canada Glacier can be reasonably well modeled at the seasonal and daily scales. In Chapter 5, I found that inclusion of the effects of ice density reduction from drainage of subsurface melt improved modeling of surface lowering on Taylor Valley glaciers, and here I find that it also improves estimates of runoff. Using a model version that favors subsurface melting produces better predictions of runoff volume and timing than using a model version that favors surface melt. Even when using the version that favors surface melt, contributions from subsurface melt improve the interseasonal variation in runoff volume and the recession of large flood peaks. Constraints on surface melt from observations of surface lowering suggest that it may be necessary to appeal to subsurface melt to achieve accurate runoff volumes in high melt summers.

The model works best on glaciers where albedo is measured locally, and develops some problems when applied to glaciers further away from albedo measurements, particularly in the Fryxell Basin where snowcover is more frequent. In some cases albedo errors result in overestimates of ablation and runoff in cases where a glacier surface is assumed to be snow-free but is actually snow covered. Spatial variations in albedo due to dirt and algae on the ice appears to cause high melt rates on glaciers in the Fryxell Basin, relative to the other basins, when those glaciers are snowfree. In most cases, the model supports the existing assumption that snowmelt is insignificant, but in extreme melt years, snowmelt in the accumulation area may be contributing significantly to runoff in some locations. It has been shown previously that high temperatures in 
extreme melt years are largely due to an increased frequency of drainage winds (Doran et al. 2008), and the model indicates that in locations where these winds are strong (e.g. Bonney Basin), they may suppress melt despite advecting higher temperatures.

Despite omitting a routing scheme, and instead assuming that all melt generated exits the glacier on the same day, the model performs well at seasonal and daily time scales. The fact that the model does not overestimate runoff on short streams suggests that refreezing is not substantial. I have witnessed melt on several glaciers refreezing after flowing 10s of $\mathrm{cm}$ on the surface (Figure 4.2). To account for this apparent contradiction, I speculate that runoff may be predominantly transported beneath the surface in a partially melted permeable layer. The modeling in Chapter 5 suggests such a layer exists continually over much of the summer at a depth of $5-10 \mathrm{~cm}$, and is considerably less prone to refreezing than the ice surface.

Topographic basins, particularly the low albedo basin floors, appear to play a prominent role in runoff production, even when basins cover a small fraction of the glaciated catchment area. The smooth surfaces exhibit the lowest melt rates of any glacier surface type, but are important during high melt conditions due to their large surface area. The estimated contributions from cliffs and cryoconite holes are somewhat smaller than suggested in previous studies because I am able to consider a wider range of flow conditions. It has previously been assumed that the terminal cliffs maintain streamflow during colder conditions (Lewis et al. 1999), but their role may actually be overshadowed by the topographic basins on the glacier surface. Expansion or shrinkage of basin areas may produce changes in runoff that are greater than changes in climate. 


\section{Chapter 7: Conclusions and Future Work}

In this dissertation I have used a surface energy balance model combined with long-term observational records of weather, glacier mass balance, and streamflow to explore melt generation in Taylor Valley, Antarctica. In this chapter I summarize conclusions from the previous chapters and suggest directions for future work.

\subsection{Collection and Analysis of Climate and Glacier Data}

In Chapters 2 and 3 I summarized the meteorological and glacier datasets that have been collected in the McMurdo Dry Valleys. Though these datasets have been described and analyzed in detail previously (Doran et al. 2002a, Nylen et al. 2004, Fountain et al. 2006), I presented new analysis and highlighted some methodological aspects that may be of interest to others collecting or using the data.

\subsubsection{Data Collection}

Albedo data needs to be considered carefully because some pyranometers (e.g.

LI-COR LI-200) have a nonuniform spectral response which will introduce bias into measurements of reflected solar radiation. Given the importance of net solar radiation to the energy balance shown in Chapters 4 and 5, small biases can be important. I also anticipated an instrumental source of error in air temperature measurements using gill radiation shields on calm, sunny days, but initial comparisons to measurements taken using actively aspirated radiation shields suggested that the errors introduced are small. 
Mass balance measurements in the ablation zone of Dry Valley glaciers have a measurement uncertainty of about $0.7 \mathrm{~cm}$ weq (Fountain et al. 2006), but here I estimate that local variations in ablation result in uncertainty of about $2 \mathrm{~cm}$ weq. Additional uncertainty is introduced by variations in ice density. I measured ice density on the Dry Valley glaciers to be about $870 \mathrm{~kg} \mathrm{~m}^{-3}$, similar to that found for Antarctic blue ice (Bintanja 1999). Near-surface ice density varies with depth and location over the course of summer, presumably from drainage of subsurface melt.

\subsubsection{Data Analysis}

Though previous studies have presented comprehensive summaries of Dry Valley climate (Doran et al. 2002a, Nylen et al. 2004), I have extended and updated these analyses. Strong inversions persist the majority of time throughout winter in Taylor Valley and result in an increase in mean annual temperature with elevation. During winter these inversions are interrupted by drainage winds that mix the air. These winds are most frequent and strongest upvalley, occurring at Taylor Glacier over 50\% of the time in winter. Drainage wind events last up to 6 days, but typical events are less than one day. In addition to breaking the inversions, the drainage winds carry adiabatically warmed air that can raise air temperatures by up to $30^{\circ} \mathrm{C}$, but warming ceases quickly after the cessation of the wind. The warming affects the valley floor more than the glaciers.

The surfaces of the glacier ablation zones are typically bare ice with intermittent snowcover. The albedo of the exposed ice is over 0.65 in spring and fall when sun angles are very low, but drops to below 0.55 early summer. In addition to the substantial effect 
of sun angle on albedo which is inline with theoretical calculations (Warren 1982, Gardner and Sharp 2010), albedo often rises prior to the solstice, resulting in an asymmetrical seasonal albedo time-series over summer. This is presumably due to changes in ice properties due to melt processes, which is well-documented for temperate glaciers (Brock et al. 2000a). Snowfall raises albedo, but snow can be difficult to identify conclusively, even using both albedo and surface height records, because it is typically thin and patchy. However, an albedo threshold of 0.15 above bare ice albedo does a reasonable job at indicating snow, which is substantially lower than the value of 0.42 found for thin snow cover on a glacier in the Alps (Brock et al. 2000a). It is unclear if this difference is universal to polar and temperate glaciers and if it is related to differences in solar geometry or snow and ice properties. Commonwealth and Howard glacier meteorological stations are typically snow covered during summer, while Taylor and Canada glacier meteorological stations are not.

Because of the wealth of meteorological observations within Taylor Valley, the model MicroMet performs well at developing gridded weather fields. However, the frequency of inversions complicates parameterization of the lapse rate. This and other parameter choices may need to be adjusted if applying MicroMet to applications beyond the glaciers. I introduced a new routine for distributing solar radiation that treats direct and diffuse radiation differently and accounts for topographic shading. I also explored a wide range of parameterizations of incoming longwave radiation for both clear-sky and all-sky conditions. I found that the formulation presented by Konzelmann et al. (1994) 
and used previously for glacier studies worked best and only required minor adjustments from its original formulation.

\subsection{Energy Balance and Melt Generation}

\subsubsection{Energy Balance}

Chapters 4 and 5 used an energy balance model to investigate melt generation on and below the glacier surface. I found generally good agreement between versions of the model with a daily and an hourly time step, but only the hourly model is able to resolve short duration melt events and subsurface melting within the upper $10 \mathrm{~cm}$ of ice. Both the daily and hourly time step models required partitioning net solar radiation between the surface and a subsurface source term in order to get reasonable results for ablation and for subsurface ice temperatures, as has been found in other locations with cold ice near the surface (Bintanja and van den Broeke 1995b, van den Broeke et al. 2008) and at high elevation on temperate glaciers during early summer (Greuell and Oerlemans 1986).

The choice of time step appears to determine the appropriate thickness of the modeled surface layer that interacts with the atmosphere. This, in turn, defines how much net solar radiation is part of the surface energy balance; with a daily time step I find that the majority of net solar radiation interacts with the atmosphere, while with an hourly time step the majority penetrates beneath the surface layer. This consideration that has not been explored in glacier energy balance studies, and while some studies do partition solar radiation into surface and penetrated fractions (e.g. Greuell and Oerlemans 1989, 
Bintanja and van den Broeke 1995b, van den Broeke et al. 2008), there has been little exploration into the sensitivity of the patitioning chosen.

Model results confirm previous studies that Taylor and other glaciers in the Dry Valleys are dominated by sublimation in all seasons and melt is a significant contribution only during some summers. For example, surface melt does not typically occur at the Taylor Glacier meteorological station, and it is likely a small fraction of total ablation lower on the glacier. Its occurrence requires low wind speeds, and air temperatures near freezing. Because of the complexity of the surface energy budget, above freezing air temperatures are neither necessary for nor a reliable indicator of surface melt. The windy conditions at Taylor Glacier suppress melt while it occurs elsewhere in Taylor Valley where winds are calmer. My modeling supports Hypothesis 1 (Chapter 1) that the energy balance of Dry Valley glaciers nears or reaches the threshold of generating substantial melt in summer. Small changes in the balance can produce significant increases in melt on the surface and in the subsurface. In particular, reduction of wind speed and increases in absorbed solar radiation create favorable conditions for melt. Both the energy balance and magnitude of subsurface melting indicate that Taylor Valley glaciers are composed of 'white' ice, intermediate in optical properties between Antarctic snow and blue ice (Bintanja and van den Broeke 1995b, Liston et al. 1999).

I found that modeling snowcover in the ablation zone was difficult due to uncertainty and spatiotemporal variability in the density, thickness, and thermal and optical properties of snow. The modeling revealed that for thin snowcovers, the presence of snow can result in higher or lower temperatures in the ice below, and ignoring the 
thermal and optical properties of a thin snowcover can perform about as well as including them, due to these uncertainties.

\subsubsection{Subsurface Melt}

According to the model, while daily surface melt is usually accompanied by subsurface melt, the reverse is not true, and little correspondence exists from season to season between the magnitudes of the two. The daily model considered subsurface conditions only below $13 \mathrm{~cm}$, and at those depths, it predicted that subsurface melt is generally small and is completely absent in some years. The hourly model is in general agreement with this, but predicts substantial melt in the ice shallower than $13 \mathrm{~cm}$ depth, in many summers continuously for up to six weeks.

By comparing a version of the model that assumes that all subsurface melt refreezes with one where some subsurface melt is able to drain, I have been able to assess the extent of internal melt and ice weathering. In contrast to high melt environments where internal melt is insignificant relative to surface melt such as temperate glaciers or west Greenland (van den Broeke et al. 2008), the glaciers in the Dry Valleys appear to have a summer energy balance where internal melting in the upper $15 \mathrm{~cm}$ is of great importance. Although the contribution of internal melting to surface lowering through reductions in ice density is small in most summers, it appears that it may be as large as $40 \%$ in extreme summers. My modeling suggests that the reduction in density due to internal melting lasts through much of the following winter before sublimation is able to completely eliminate the reduced-density ice. This is comparable to the cycles of weathering crust development and elimination observed over days by Müller and Keeler 
(1969) in the Canadian Arctic and Hock and Holmgren (1996) in Sweden, but it occurs over an annual cycle in Taylor Valley. I also find that the drainage of internal melt cools the ice by removing latent heat and is an important process for ice temperatures at the end of the melt season, as has been described for sea ice (Semtner 1984). The evidence from observations and modeling for density reduction and removal of latent heat contradict Hypothesis 2 (Chapter 1) that subsurface melt does not contribute significantly to runoff.

\subsection{Glacier Runoff}

In Chapter 6, I applied the melt model for estimation of runoff and streamflow throughout Taylor Valley, and the model is able to predict streamflow at the seasonal and flood event scales well. The model works best on glaciers where albedo is measured locally, and develops some problems when applied to glaciers further away from albedo measurements, particularly in the Fryxell Basin where snowcover is more frequent. Spatial variations in albedo due to snow, dirt, and algae on the ice play a dominant role in variations in melt production across the valley, a result commonly found in glacier studies (Paterson 1994, Konzelmann and Braithwaite 1995, Brock et al. 2000b), and these variations create a limitation on the ability of the model to predict runoff with point measurements of albedo. Using a model version that favors subsurface melting produces better predictions of runoff volume and timing than using a model version that favors surface melt. Even when using a version that favors surface melt, contributions from subsurface melt improve the interseasonal variation in runoff volume and the recession of large flood peaks. Few studies have explicitly considered the contribution of subsurface 
melt to runoff. Müller and Keeler (1969) found internal melting to be an important form of mass loss on glaciers in the Canadian Arctic, but measurements of surface runoff were not considered reliable enough for comparison to their ablation measurements.

Despite using a simplistic routing scheme that assumes that all melt generated exits the glacier on the same day, the model performs well seasonally and daily. The fact that the model does not overestimate runoff on short streams implies that refreezing is not substantial, but observations suggest that meltwater on the surface refreezes before flowing far at all but the lowest elevtions. Instead of flowing over the surface, runoff may travel through weathered ice in the upper $15 \mathrm{~cm}$ that modeling indicates is considerably less prone to refreezing than the ice surface. Thus, in addition to generating a substantial portion of runoff, the subsurface ice may also be the primary flowpath for runoff. This is analagous to the topographic channels on Taylor Glacier that largely generate the meltwater that they convey (Johnston et al. 2005). It appears that the use of storage coefficients for bare ice that are less than a day, as used for temperate glaciers (e.g. Hock and Noetzli 1997, Hannah and Gurnell 2001), is also appropriate for ice surfaces that commonly remain below the melting point due to the permeability of the weathering crust. Müller and Keeler (1969) found the permeability of the weathering crust to cause variations in the time lag between peak melt and runoff on the order of hours.

These topographic channels and basins, particularly the low albedo basin floors, appear to play a prominent role in runoff production, even when basins cover a small fraction of the glaciated catchment area. Smooth glacier surfaces exhibit the lowest melt 
rates of any parts of the glaciers, but are important during high melt conditions due to their large surface area. Cliffs and cryoconite holes make small contributions to runoff seasonally, but cliffs produce a large fraction of melt on the lowest flow days. Where basin areas exist, they overshadow cliffs at maintaining low flows, a modification to Hypothesis 3 that terminal cliffs are the major source of runoff on the shoulders of the season.

\subsection{Implications for Melting Glaciers}

The surface energy balance of temperate glaciers is simplified in that the conductive flux is nearly always zero, but for cold glacier ice, conduction into the ice is a substantial heat sink (Hock 2005). Energy balance studies of temperate glaciers often ignore the conductive heat flux and assume the surface is at the melting point, which has generally been successful for predicting melt for periods when melt is sustained, but less so in spring and fall (Pellicciotti et al. 2009). While it has become clear the extent to which conduction of heat into the ice reduces melt on glaciers with cold ice (Greuell and Oerlemans 1986, Konzelmann and Braithwaite 1995) and glaciers with seasonally cold ice (Hock and Holmgren 1996, Pellicciotti et al. 2009, Wheler and Flowers 2011), the specific role of radiation penetration in warming the ice has been more difficult to determine due to the paucity of models that consider it in detail.

Partitioning solar radiation between the surface and the subsurface has been shown to improve ice temperatures in Antarctic blue ice that experiences no melt (Bintanja and van den Broeke 1995b) and in ice in Greenland that experiences high melt 
rates (van den Broeke et al. 2008). For Dry Valley glaciers where melt is a small fraction of summer ablation, partitioning of solar radiation is critically important to successfully modeling both ice temperature and ablation. Small shifts in energy when ice temperature is just below the melting temperature translate to large changes in mass loss both above and below the surface. For ice in this thermal regime, I find that both surface melt and subsurface melt have to be modeled in detail, including changes in ice density, to best predict ablation. Van den Broeke et al. (2008) estimated that subsurface melt accounted for up to $30 \%$ of the melt in the ablation zone of west Greenland, but that surface lowering could be directly compared to modeled ice melt because surface lowering due to melt was large compared to the mass loss below the surface. In contrast, I find it critical to monitor ice density changes caused by internal melting in a low melt environment.

Thus, this work fills a critical gap in the understanding of glacier melt processes near the threshold of melt. On one end of the spectrum of melt conditions found on glaciers during summer are temperate glaciers where melting is near-constant and the conductive heat flux can be ignored (Hock 2005). Radiation penetration need not be explicitly considered because surface lowering (melt) rates are high enough that the distinction between surface and subsurface melt is inconsequential. Weathering crusts represent an insignificant mass loss and they form and erode within hours to days. On subpolar glaciers with cold ice or substantial winter cold waves (e.g. west Greenland, Storglaciären), the conductive heat flux can be important over all but the height of summer when melting becomes prevalent and the near surface temperatures are nearly isothermal (Greuell and Oerlemans 1986, Hock and Holmgren 1996). Internal melting is 
a substantial fraction of total melt, but the effect of ice density variations on surface lowering is small (van den Broeke et al. 2008). On polar glaciers (e.g. Canadian High Arctic), the conductive heat flux is a large heat sink that cannot be ignored, and internal melting due to radiation penetration can result in a detectable but small fraction of surface lowering (Müller and Keeler 1969). The Dry Valley glaciers fill a key niche where both the conductive heat flux and internal melting due to radiation penetration are critically important to ice temperature and ablation, and neither can be ignored in surface energy balance modeling. In climates even slightly colder (high altitude Antarctic blue ice areas), melting ceases altogether, and though the conductive heat flux and radiation penetration remain critically important, the lack of melt simplifies the energy balance (Bintanja and van den Broeke 1995b).

The complexity of glacier ablation near the threshold of melt is significant in considering the expansion of areas of melting ice on cold ice sheets and glaciers in a warming climate. Though temperatures at most snow-free blue ice areas in Antarctica would have to rise dramatically to allow melt (Bintanja 1999), some warmer areas near the coast do experience melt in summer (Liston et al. 1999, Genthon et al. 2007), and increased melt could lead to the expansion of these areas. Accurately predicting melt from these areas will require careful modeling of the role of solar radiation in both surface and subsurface melt. Current temperature-index models have limited success with these conditions (Ebnet et al. 2005), but analysis of detailed modeling studies such as this one may allow the development of reduced-complexity models for cold ice conditions that can be applied predictively with minimal meteorological inputs. 
In addition to detailing the role of radiation penetration in low melt environments, this work provides new insight into runoff processes in these environments. On temperate glaciers, the water flux through the ice weathering crust is negligible compared to that through supraglacial streams (Fountain and Walder 1998), and there is little delay between melting and transport of water into or off of the glacier (Jansson et al. 2003). The Dry Valley glaciers have relatively few supraglacial streams and an ice surface that typically remains below freezing. Despite this, I present evidence that runoff occurs within hours of melt production and refreezing is minimal. It seems likely that runoff travels some $\mathrm{cm}$ below the surface through a permeable weathering crust which remains partially melted for much of the summer. Weathering crusts commonly exist on temperate glaciers (Braithwaite and Olesen 1990, Hubbard and Glasser 2005), and, when present, runoff would be routed through them by gravity (Wakahama et al. 1973). Thus despite the differences in energy balance and melting, runoff routing on low melt glaciers may be similar to that on temperate glaciers. The gradual formation and erosion of the weathering crust on Dry Valley glaciers would facilitate careful study, and knowledge gained about water flow over and through porous glacier ice would have widespread application.

\subsection{Future Work}

Additional modifications can be made to the melt model that may yield more realistic results and additional insights. Ice density could be made to evolve within the model as subsurface melt drains, and the ice surface in the model could be made to lower 
with ablation to create dynamic ice density profiles. With this ability, thermal and optical properties of the ice could also adjust with the development of the weathering crust (Greuell and Konzelmann 1994), allowing the determination of melt feedbacks and model investigation into the increase in albedo that is observed in midsummer during many seasons. Additionally, adjusting the optical properties of the ice with sun angle and cloud cover may improve the representation of solar radiation within the model. One such simple adjustment would be to prescribe a diurnal albedo curve (van den Broeke et al. 2004), rather than assuming it is constant throughout the day. Cursory comparison of modeled ice surface temperatures to observations indicate that currently the model may produce nighttime temperatures in summer that are too high.

The spatial application of the model could also be refined. With more observations to better constrain the proper optical parameters to use for snow, the melt model could be extended to snow covered areas to test the validity of assuming snowmelt can be ignored. My model results suggest snowmelt may contribute to runoff in high melt years, and this could be assessed through modeling. Also, given the importance of the basin areas, high spatial resolution modeling of some basins may yield further insight into their behavior. High resolution topography ( $2 \mathrm{~m})$ is already available, and recently high resolution commercial optical imagey $(<2 \mathrm{~m})$, which would facilitate mapping debris and blue ice, has become available for the Dry Valleys. Testing a high resolution basin melt model would require observations of ablation and supraglacial streamflow within the basins. Because of high variability in basin ablation rates, stakes may provide inadequate spatial coverage, but recent tests of repeat lidar measurements within basins 
show promise for creating high resolution, high precision three-dimensional maps of ablation. I performed some testing of supraglacial streamflow measurements on small basin streams, and with regular maintenance an installation of a simple V-notch weir made out of plywood can successfully provide continuous measurements of streamflow without the need for a rating curve.

The spatial melt model shows potential for investigating past or future variations in Dry Valleys hydrology. Forecasting changes in melt production associated with expected future climate change would be of great interest to ecologists studying the Dry Valley ecosystems, and the model could also investigate the evolution of Lake Washburne, which filled much of Taylor Valley during the last glacial period. These applications would require additional testing to determine the feasibility of applying the model without direct meteorological observations. Due to the complexity of the energy balance, simply using the historical meteorological record with adjustments to air temperature may be inadequate. My modeling has shown that melt production is also sensitive to wind speed and net solar radiation, and variations in snow cover or dust and debris need to be considered.

Finally, the importance of subsurface melting and weathering crust development on Dry Valley glaciers identified by the model warrants a more detailed field investigation. Subsurface ice temperatures measured with thermistors indicate that ice near the surface reaches $0^{\circ} \mathrm{C}$, but these measurements cannot assess the degree of melt that occurs. Investigating subsurface melt through drilling has proved difficult because it provides limited information at a point and water content is difficult to quantify. 
However, high frequency radar may be able to provide information about water content beneath the surface. In particular, portable freqeuncy modulated continuous wave (FMCW) radars have proven capable of measuring snow pack properties such as depth and water content reliably and quickly at high resolution (Marshall and Koh 2008). This tool may be well-suited to obtaining water content observations within the upper $20 \mathrm{~cm}$ of the ice to test the model. My experiments using shallow ice cores to measure density worked well, but were fairly labor intensive and required rapid processing of the core. Combining such ice core density measurements with a non-invasive, portable method, such as neutron or gamma ray density, may provide a broader picture of ice density variations on Dry Valley glaciers. Additionally, controlled runoff experiments on the glacier surface could be created to assess the extent and timing of the runoff of subsurface melt (e.g. Müller and Keeler 1969, Wendler and Ishikawa 1973). An observational campaign could be planned to track the evolution of subsurface melting and density over the course of a summer at different locations. This could be contrasted with observations on a temperate glacier or cold-room experiments (e.g. Coléou and Lesaffre 1998). The ecological significance of meltwater would warrant a more detailed investigation into the importance of subsurface melt, and the knowledge gained on ice weathering crust development would be applicable to energy and mass balance studies on any glacier. 


\section{Bibliography}

Andreas, E. L. 1987. A Theory for the Scalar Roughness and the Scalar Transfer-

Coefficients over Snow and Sea Ice. Boundary-Layer Meteorology 38: 159-184.

Arck, M., and D. Scherer. 2001. A physically based method for correcting temperature data measured by naturally ventilated sensors over snow. Journal of Glaciology 47: 665-670.

Bagshaw, E. A., M. Tranter, A. G. Fountain, K. A. Welch, H. B. Basagic, and W. B. Lyons. 2007. Biogeochemical evolution of cryoconite holes on Canada Glacier, Taylor Valley, Antarctica. Journal of Geophysical Research-Biogeosciences 112: doi:10.1029/2007JG000442.

Bagshaw, E. A., M. Tranter, J. L. Wadham, A. G. Fountain, and H. B. Basagic. 2010. Dynamic behaviour of supraglacial lakes on cold polar glaciers: Canada Glacier, McMurdo Dry Valleys, Antarctica. Journal of Glaciology 56: 366-368.

Barnes, S. L. 1964. A technique for maximizing details in numerical weather map analysis. Journal of Applied Meteorology 3: 396-409.

Bintanja, R. 1999. On the glaciological, meteorological, and climatological significance of Antarctic blue ice areas. Reviews of Geophysics 37: 337-359.

Bintanja, R., S. Jonsson, and W. H. Knap. 1997. The annual cycle of the surface energy balance of Antarctic blue ice. Journal of Geophysical Research 102: 1867-1881.

Bintanja, R., and C. H. Reijmer. 2001. Meteorological conditions over Antarctic blue-ice areas and their influence on the local surface mass balance. Journal of Glaciology 47: 37-50.

Bintanja, R., and M. R. van den Broeke. 1995a. Momentum and scalar transfer coefficients over aerodynamically smooth Antarctic surfaces. Boundary-Layer Meteorology 74: 89-111.

- $1995 \mathrm{~b}$. The surface energy balance of Antarctic snow and blue ice. Journal of Applied Meteorology 34: 902-926.

Bomblies, A. 1998. Climatic controls on streamflow from Antarctic glaciers. University of Colorado.

Boresjo-Bronge, L. B., and C. Bronge. 1999. Ice and snow-type classification in the Vestfold Hills, East Antarctica, using Landsat-TM data and ground radiometer measurements. International Journal of Remote Sensing 20: 225-240.

Braithwaite, R. J., T. Konzelmann, C. Marty, and O. B. Olesen. 1998. Errors in daily ablation measurements in northern Greenland, 1993-94, and their implications for glacier climate studies. Journal of Glaciology 44: 583-588.

Braithwaite, R. J., and O. B. Olesen. 1990. A simple energy-balance model to calculate ice ablation at the margin of the Greenland Ice-Sheet. Journal of Glaciology 36: 222-228. 
Brandt, R. E., and S. G. Warren. 1993. Solar-heating rates and temperature profiles in Antarctic snow and ice. Journal of Glaciology 39: 99-110.

Brock, B. W., I. C. Willis, and M. J. Sharp. 2000a. Measurement and parameterization of albedo variations at Haut Glacier d'Arolla, Switzerland. Journal of Glaciology 46: 675-688.

—. 2006. Measurement and parameterization of aerodynamic roughness length variations at Haut Glacier d'Arolla, Switzerland. Journal of Glaciology 52: 281-297.

Brock, B. W., I. C. Willis, M. J. Sharp, and N. S. Arnold. 2000b. Modelling seasonal and spatial variations in the surface energy balance of Haut Glacier D'Arolla, Switzerland. Annals of Glaciology 31: 53-62.

Brutsaert, W. 1982. Evaporation into the atmosphere : theory, history, and applications. Kluwer Academic Press, Dordrecht, Holland.

Buckley, R. G., and H. J. Trodahl. 1987. Thermally driven changes in the optical properties of sea ice. Cold Regions Science and Technology 14: 201-204.

Chinn, T. J. 1993. Physical hydrology of the dry valley lakes. Pages 1-51 in W. J. Green and E. I. Friedman, eds. Physical and Biogeochemical Processes in Antarctic Lakes, Antarctic Research Series, v. 59, Washington, D.C.

- 1998. Recent fluctuations of the Dry Valleys glaciers, McMurdo Sound, Antarctica. Annals of Glaciology 27: 119-124.

Chinn, T. J. H. 1981. Hydrology and climate in the Ross Sea area. Journal of the Royal Society of New Zealand 11: 373-386.

-. 1987. Accelerated ablation at a glacier ice-cliff margin, Dry Valleys, Antarctica. Arctic and Alpine Research 19: 71-80.

Clow, G. D., C. P. McKay, G. M. Simmons, and R. A. Wharton. 1988. Climatological Observations and Predicted Sublimation Rates at Lake Hoare, Antarctica. Journal of Climate: 715-728.

Colbeck, S. C. 1979. Grain clusters in wet snow. Journal of Colloid and Interface Science 72: 371-384.

Coléou, C., and B. Lesaffre. 1998. Irreducible water saturation in snow: experimental results in a cold laboratory. Annals of Glaciology 26: 64-68.

Conovitz, P. A., L. H. MacDonald, and D. M. McKnight. 2006. Spatial and temporal active layer dynamics along three glacial meltwater streams in the McMurdo dry valleys, Antarctica. Arctic, Antarctic, and Alpine Research 38: 42-53.

Conovitz, P. A., D. M. McKnight, L. H. MacDonald, A. G. Fountain, and H. R. House. 1998. Hydrologic processes influencing streamflow variation in Fryxell Basin, Antarctica. Pages 93-108 in J. C. Priscu, ed. Ecosystem dynamics in a polar desert; the McMurdo dry valleys, Antarctica. American Geophysical Union, Washington (DC).

Cozzetto, K., D. McKnight, T. Nylen, and A. Fountain. 2006. Experimental investigations into processes controlling stream and hyporheic temperatures, Fryxell Basin, Antarctica. Advances in Water Resources 29: 130-153. 
Dana, G. L., R. E. Davis, A. G. Fountain, and R. A. Wharton, Jr. 2002. Satellite-derived indices of stream discharge in Taylor Valley, Antarctica. Hydrological Processes 16: 1603-1616.

Dana, G. L., and R. A. Wharton, Jr. 1998. Solar radiation in the McMurdo Dry Valleys, Antarctica. Pages 39-64 in J. C. Priscu, ed. Ecosystem dynamics in a polar desert; the McMurdo dry valleys, Antarctica.

Denton, G. H., J. G. Bockheim, S. C. Wilson, and M. Stuiver. 1989. Late Wisconsin and Early Holocene glacial history, inner Ross Embayment, Antarctica. Quaternary Research 31: 151-182.

Doran, P. T., G. L. Dana, J. T. Hastings, and R. A. Wharton, Jr. 1995. McMurdo Dry Valleys LTER: LTER automatic weather network (LAWN). Antarctic Journal of the United States Review 1995: 276-280.

Doran, P. T., C. P. McKay, G. D. Clow, G. L. Dana, A. G. Fountain, T. Nylen, and W. B. Lyons. 2002a. Valley floor climate observations from the McMurdo dry valleys, Antarctica, 1986-2000. Journal of Geophysical Research D: Atmospheres 107: 13-1 - 13-12.

Doran, P. T., C. P. McKay, A. G. Fountain, D. A. McKnight, and J. E. Barrett. 2008. Hydrologic response to extreme warm and cold summers in the McMurdo Dry Valleys, East Antarctica. Antarctic Science 20: 499-509.

Doran, P. T., J. C. Priscu, W. B. Lyons, J. E. Walsh, A. G. Fountain, D. M. McKnight, D. L. Moorhead, R. A. Virginia, D. H. Wall, G. D. Clow, C. H. Fritsen, C. P. McKay, and A. N. Parsons. 2002b. Antarctic climate cooling and terrestrial ecosystem response. Nature 415: 517-520.

Dozier, J., and J. Frew. 1990. Rapid calculation of terrain parameters for radiation modeling from digital elevation data. IEEE Transactions on geoscience and remote sensing 28: 963-969.

Drewry, D. J., S. R. Jordan, and E. Jankowski. 1982. Measured properties of the Antarctic ice sheet: surface configuration, ice thickness, volume, and bedrock characteristics. Annals of Glaciology 3: 83-91.

Dubayah, R., and S. Loechel. 1997. Modeling topographic solar radiation using GOES data. Journal of Applied Meteorology 36: 141-154.

Ebnet, A. F. 2005. Temperature-Index Model of Stream Flow in Taylor Valley, Antarctica. Pages 81. Geology. Portland State University, Portland, OR.

Ebnet, A. F., A. G. Fountain, T. H. Nylen, D. M. McKnight, and C. Jaros. 2005. A temperature-index model of stream flow at below-freezing temperatures in Taylor Valley, Antarctica. Annals of Glaciology 40: 76-82.

Flerchinger, G. N., W. Xaio, D. Marks, T. J. Sauer, and Q. Yu. 2009. Comparison of algorithms or incoming atmospheric long-wave radiation. Water Resources Research 45: W03423.

Foreman, C. M., C. F. Wolf, and J. C. Priscu. 2004. Impact of episodic warming events on the physical, chemical and biological relationships of lakes in the McMurdo dry valleys, Antarctica. Aquatic Geochemistry 10: 3-4. 
Fountain, A. G., G. L. Dana, K. J. Lewis, B. H. Vaughn, and D. M. McKnight. 1998. Glaciers of the McMurdo dry valleys, southern Victoria Land, Antarctica. Pages 65-75 in J. C. Priscu, ed. Ecosystem dynamics in a polar desert; the McMurdo dry valleys, Antarctica.

Fountain, A. G., K. J. Lewis, and P. T. Doran. 1999a. Spatial climatic variation and its control on glacier equilibrium line altitude in Taylor Valley, Antarctica. Global and Planetary Change 22: 1-10.

Fountain, A. G., W. B. Lyons, M. B. Burkins, G. L. Dana, P. T. Doran, K. J. Lewis, D. M. McKnight, D. L. Moorhead, A. N. Parsons, J. C. Priscu, D. H. Wall, R. A. Wharton, Jr., and R. A. Virginia. 1999b. Physical Controls on the Taylor Valley Ecosystem, Antarctica. BioScience 49: 961-971.

Fountain, A. G., T. A. Neumann, P. L. Glenn, and T. Chinn. 2004a. Can climate warming induce glacier advance in Taylor Valley, Antarctica? Journal of Glaciology 50: 556-564.

Fountain, A. G., T. H. Nylen, K. L. MacClune, and G. L. Dana. 2006. Glacier mass balances (1993-2001), Taylor Valley, McMurdo dry valleys, Antarctica. Journal of Glaciology 52: 451-462.

Fountain, A. G., T. H. Nylen, A. Monaghan, H. J. Basagic, and D. Bromwich. 2010. Snow in the McMurdo Dry Valleys, Antarctica. International Journal of Climatology 30: 633-642.

Fountain, A. G., T. H. Nylen, M. Tranter, and E. A. Bagshaw. 2008. Temporal variations in physical and chemical features of cryoconite holes on Canada Glacier, McMurdo Dry Valleys, Antarctica. Journal of Geophysical Research 113: G01S92.

Fountain, A. G., M. Tranter, T. H. Nylen, K. J. Lewis, and D. R. Mueller. 2004 b. Evolution of cryoconite holes and their contributions to meltwater runoff from glaciers in the McMurdo Dry Valleys, Antarctica. Journal of Glaciology 50: 3545.

Fountain, A. G., and J. S. Walder. 1998. Water flow through temperate glaciers. Reviews of Geophysics 36: 299-328.

Fukusako, S. 1990. Thermophysical properties of ice, snow, and sea ice. International Journal of Thermophysics 11: 353-372.

Gardner, A. S., and M. J. Sharp. 2010. A review of snow and ice albedo and the development of a new physically based broadband albedo parameterization. Journal of Geophysical Research 115: F01009.

Genthon, C., P. Lardeux, and G. Krinner. 2007. The surface accumulation and ablation of a coastal blue-ice area near Cap Prudhomme, Terre Adélie, Antarctica. Journal of Glaciology 53: 635-645.

Gooseff, M. N., J. E. Barrett, P. T. Doran, A. G. Fountain, W. B. Lyons, A. N. Parsons, D. L. Porazinska, R. A. Virginia, and D. H. Wall. 2003a. Snow-patch influence on soil biogeochemical processes and invertebrate distribution in the McMurdo dry valleys, Antarctica. [Serial] Arctic, Antarctic, and Alpine Research 35: 91-99. 
Gooseff, M. N., W. B. Lyons, D. M. McKnight, B. H. Vaughn, A. G. Fountain, and C. Dowling. 2006. A stable isotopic investigation of a polar desert hydrologic system, McMurdo dry valleys, Antarctica. Arctic, Antarctic, and Alpine Research 38: 60-71.

Gooseff, M. N., D. M. McKnight, R. L. Runkel, and B. H. Vaughn. 2003b. Determining long-timescale hyporheic zone flow paths in Antarctic streams. Hydrological Processes 17: 1691-1710.

Grenfell, T. C. 1983. A theoretical model of the optical properties of sea ice in the visible and near infrared. Journal of Geophysical Research 88: 9723-9735.

Grenfell, T. C., and G. A. Maykut. 1977. The optical properties of ice and snow in the Arctic Basin. Journal of Glaciology 18: 445-463.

Greuell, W., and T. Konzelmann. 1994. Numerical modelling of the energy balance and the englacial temperature of the Greenland Ice Sheet. Calculations for the ETHCamp location (West Greenland, $1155 \mathrm{~m}$ a.s.1.). Global and Planetary Change 9: 91-114.

Greuell, W., and J. Oerlemans. 1986. Sensitivity studies with a mass balance model including temperature profile calculations inside the glacier. Zeitschrift für Gletscherkunde und Glazialgeologie 22: 101-124.

- 1989. The evolution of the englacial temperature distribution in the superimposed ice zone of a polar ice cap during a summer season. Pages 289-304 in J. Oerlemans, ed. Glacier Fluctuations and Climatic Change. Kluwer, Dordrecht.

Ham, J. 2005. Useful equations and tables in micrometeorology. Pages 533-560 in J. L. H. a. J. M. Baker, ed. Micrometeorology in Agricultural Systems. Agronomy Monograph 47. ASA, CSSA, and SSSA, Madison, WI.

Hannah, D. M., and A. M. Gurnell. 2001. A conceptual, linear reservoir runoff model to investigate melt season changes in cirque glacier hydrology. Journal of Hydrology 246: 123-141.

Harris, K., B. Lyons, A. Carey, K. Welch, and A. Fountain. 2005. Solute and isotope geochemistry of near-surface ice melt seeps in Taylor Valley, Antarctica. Anonymous In: Geological Society of America 37: 356.

Henneman, H. E., and H. G. Stefan. 1998. Snow and ice albedo measured with two types of pyranometers. Journal of the American Water Resources Association 34: 14871494.

Hock, R. 2005. Glacier melt: A review of processes and their modelling. Progress in Physical Geography 29: 362-391.

Hock, R., and B. Holmgren. 1996. Some aspects of energy balance and ablation of Storglaciaren, northern Sweden. Geografiska Annaler, Series A 78A: 121-131.

Hock, R., and C. Noetzli. 1997. Areal melt and discharge modelling of Storglaciaren, Sweden. Annals of Glaciology 24: 211-216.

Hoffman, M. J., A. G. Fountain, and G. E. Liston. 2008. Surface energy balance and melt thresholds over 11 years at Taylor Glacier, Antarctica. J. Geophys. Res. 113: F04014. 
House, H. R., D. A. McKnight, and P. von Guerard. 1995. The influence of stream channel characteristics on stream flow and annual water budgets for lake in Taylor Valley. Antarctic Journal of the United States 30: 284-287.

Hubbard, B., and N. Glasser. 2005. Field techniques in glaciology and glacial geomorphology. John Wiley \& Sons.

IPCC. 2007. Climate Change 2007: The Physical Science Basis. Contribution of Working Group I to the Fourth Assessment Report of the Intergovernmental Panel on Climate Change. Cambridge University Press, Cambridge, United Kingdom and New York, NY, USA.

Iziomon, M. G., H. Mayer, and A. Matzarakis. 2003. Downward atmospheric longwave irradiance under clear and cloudy skies: Measurement and parameterization. Journal of Atmospheric and Solar-Terrestrial Physics 65: 1107-1116.

Jansson, P., R. Hock, and T. Schneider. 2003. The concept of glacier storage: A review. Journal of Hydrology 282: 116-129.

Jaros, C. 2003. Temperature-elevation effect on glacial meltwater generation in dry valley streams, University of Colorado.

Jenness, J. S. 2004. Calculating landscape surface area from digital elevation models. Wildlife Society Bulletin 32: 829-839.

Jin, Z., K. Stamnes, W. F. Weeks, and S.-C. Tsay. 1994. The effect of sea ice on the solar energy budget in the atmosphere-sea ice-ocean system: A model study. Journal of Geophysical Research 99: 25281-25294.

Johnston, R. R. 2004. Channel morphology and surface energy balance on Taylor Glacier, Taylor Valley, Antarctica. Pages 117. Department of Geology. Portland State University, Portland, OR.

Johnston, R. R., A. G. Fountain, and T. H. Nylen. 2005. The origin of channels on lower Taylor Glacier, McMurdo Dry Valleys, Antarctica, and their implication for water runoff. Annals of Glaciology 40: 1-7.

Kaser, G., A. Fountain, and P. Jansson, eds. 2002. A manual for monitoring the mass balance of mountain glaciers. UNESCO, International Hydrological Programme.

Kennedy, A. D. 1993. Water as a limiting factor in the Antarctic terrestrial environment: A biogeographical synthesis. Arctic and Alpine Research 25: 308-315.

Keys, J. R. 1980. Air Temperature, Wind, Precipitation and Atmospheric Humidity in the McMurdo Region, Victoria. Antarctic Data Series, Victoria University, Wellington.

Kimball, B. A., S. B. Idso, and J. K. Aase. 1982. A model of thermal radiation from partly cloudy and overcast skies. Water Resources Research 18: 931-936.

King, D. L., and D. R. Myers. 1997. Silicon-photodiode pyranometers: operational characteristics, historical experiences, and new calibration procedures. Pages 1285-1288. Photovoltaic Specialists Conference, 1997., Conference Record of the Twenty-Sixth IEEE, Anaheim, CA.

Klein, A. G. 2003. Determination of broadband albedos of partially snow-covered sites for validation of MODIS snow albedo retrievals. 60th Eastern Snow Conference, Sherbrooke, Québec, Canada. 
Koch, S. E., M. DesJardins, and P. J. Kocin. 1983. An interactive Barnes objective map analysis scheme for use with satellite and conventional data. Journal of Climate and Applied Meteorology 22: 1487-1503.

König-Langlo, G., and E. Augstein. 1994. Parameterization of the downward longwave radiation at the Earth's surface in polar regions. Meteorologische Zeitschrift 3: 343-347.

Konzelmann, T., and R. J. Braithwaite. 1995. Variations of ablation, albedo and energy balance at the margin of the Greenland ice sheet, Kronprins Christian Land, eastern North Greenland. Journal of Glaciology 41: 174-182.

Konzelmann, T., R. S. W. van de Wal, W. Greuell, R. Bintanja, E. A. C. Henneken, and A. Abe-Ouchi. 1994. Parameterization of global and longwave incoming radiation for the Greenland Ice Sheet. Global and Planetary Change 9: 143-164.

Kuipers Munneke, P., M. R. van den Broeke, C. H. Reijmer, M. M. Helsen, W. Boot, M. Schneebeli, and K. Steffen. 2009. The role of radiation penetration in the energy budget of the snowpack at Summit, Greenland. The Cryosphere 3: 155-165.

Kunkel, K. E. 1989. Simple procedures for extrapolation of humidity variables in the mountainous western United States. Journal of Climate 2: 656-669.

LaChapelle, E. 1959. Errors in ablation measurements from settlement and sub-surface melting. Journal of Glaciology 3: 458-467.

Larson, G. J. 1977. Internal drainage of stagnant ice: Burroughs Glacier, southeast Alaska, Rep. 65. Pages 33. Institute of Polar Studies, Ohio State University, Columbus, $\mathrm{OH}$.

—. 1978. Meltwater storage in a temperate glacier: Burroughs Glacier, southeast Alaska, Rep. 66. Pages 56. Institute of Polar Studies, Ohio State University, Columbus, $\mathrm{OH}$.

Launiainen, J., and B. Cheng. 1998. Modelling of ice thermodynamics in natural water bodies. Cold Regions Science and Technology 27: 153-178.

Lewis, K. J. 2001. Solar-forced roughening of Antarctic glaciers and the Martian icecaps; how surficial debris and roughness affect glacial melting in Taylor Valley, Antarctica and how this can be applied to the Martian icecaps. Pages 182. University of Colorado, Boulder, CO, United States.

Lewis, K. J., A. G. Fountain, and G. L. Dana. 1998. Surface energy balance and meltwater production for a Dry Valley glacier, Taylor Valley, Antarctica. Annals of Glaciology 27: 603-609.

-. 1999. How important is terminus cliff melt? A study of the Canada Glacier terminus, Taylor Valley, Antarctica. Global and Planetary Change 22: 1-4.

Liston, G. E., and K. Elder. 2006. A meteorological distribution system for highresolution terrestrial modeling (MicroMet). Journal of Hydrometeorology 7: 217234.

Liston, G. E., J.-G. Winther, O. Bruland, H. Elvehoy, and K. Sand. 1999. Below-surface ice melt on the coastal Antarctic ice sheet. Journal of Glaciology 45: 273-285.

Liu, B. Y. H., and R. C. Jordan. 1960. The interrelationship and characteristic distribution of direct, diffuse and total solar radiation. Solar Energy 4: 1-19. 
Marshall, H. P., and G. Koh. 2008. FMCW radars for snow research. Cold Regions Science and Technology 52: 118-131.

Maykut, G., and N. Untersteiner. 1971. Some results from a time-dependent thermodynamic model of Arctic sea ice. Journal of Geophysical Research 76: 1550-1575.

Maykut, G. A., and P. F. Church. 1973. Radiation climate of Barrow, Alaska, 1962-66. Journal of Applied Meteorology 12: 620-628.

McKnight, D. A., H. R. House, and P. von Guerard. 1994. McMurdo LTER: Streamflow Measurements in Taylor Valley. Antarctic Journal of the United States 29: 230232.

McKnight, D. M., D. K. Niyogi, A. S. Alger, A. Bomblies, P. A. Conovitz, and C. M. Tate. 1999. Dry Valley streams in Antarctica: Ecosystems waiting for water. BioScience 49: 985-995.

Mölg, T., and D. R. Hardy. 2004. Ablation and associated energy balance of a horizontal glacier surface on Kilimanjaro. Journal of Geophysical Research 109: D16104.

Monaghan, A. J., D. H. Bromwich, J. G. Powers, and K. W. Manning. 2005. The climate of the McMurdo, Antarctica region as represented by one year of forecasts from the Antarctic Mesoscale Prediction System. Journal of Climate 18: 1174-1189.

Müller, F., and C. M. Keeler. 1969. Errors in short-term ablation measurements on melting ice surfaces. Journal of Glaciology 8: 91-105.

Mullen, P. C., and S. G. Warren. 1988. Theory of the optical-properties of lake ice. Journal of Geophysical Research-Atmospheres 93: 8403-8414.

Nye, J. F. 1991. The rotting of temperate ice. Journal of Crystal Growth 113: 465-476.

Nylen, T. H., A. G. Fountain, and P. T. Doran. 2004. Climatology of katabatic winds in the McMurdo dry valleys, southern Victoria Land, Antarctica. Journal of Geophysical Research 109: D03114.

Orheim, O., and B. Lucchitta. 1990. Investigating climate change by digital analysis of blue ice extent on satellite images of Antarctica. Annals of Glaciology 14: 211215.

Østrem, G., and M. Brugman, eds. 1991. Glacier Mass-Balance Measurements. A manual for field and office work. National Hydrological Research Institute.

Paterson, W. S. B. 1994. The physics of glaciers. Pergamon Press, Oxford.

Pellicciotti, F., M. Carenzo, J. Helbing, S. Rimkus, and P. Burlando. 2009. On the role of subsurface heat conduction in glacier energy-balance modeling. Annals of Glaciology 50: 16-24.

Pirazzini, R., M. Nardino, A. Orsini, F. Calzolari, T. Georgiadis, and V. Levizzani. 2001. Parameterization of the downward longwave radiation from clear and cloudy skies at Ny Ålesund (Svalbard). Pages 559-562 in W. L. a. T. Smith, Y. M., ed. IRS 2000: Current Problems in Atmospheric Radiation. A. Deepack Publishing, Hampton, Virginia.

Priscu, J. C., C. F. Wolf, C. D. Takacs, C. H. Fritsen, J. Laybourn-Parry, E. C. Roberts, B. Sattler, and W. B. Lyons. 1999. Carbon transformations in a perennially icecovered Antarctic lake. Bioscience 49: 997-1008. 
Raupach, M. R. 1992. Drag and drag partition on rough surfaces. Boundary-Layer Meteorology 60: 375-395.

Raymond, C. F., and W. D. Harrison. 1975. Some observations on the behavior of the liquid and gas phases in temperate glacier ice. Journal of Glaciology 14: 213-233.

Reeburgh, W. S. 1984. Fluxes associated with brine motion in growing sea ice. Polar Biology 3: 29-33.

Reijmer, C., W. Greuell, and J. Oerlemans. 1999. The annual cycle of meteorological variables and the surface energy balance on Berkner Island, Antarctica. Annals of Glaciology 29: 49-54.

Reijmer, C. H., R. Bintanja, and W. Greuell. 2001. Surface albedo measurements over snow and blue ice in thematic mapper bands 2 and 4 in Dronning Maud Land, Antarctica. Journal of Geophysical Research - D Atmospheres 106: 9661-9672.

Schmidt, R. A. 1982. Vertical profiles of wind speed, snow concentration and humidity in blowing snow. Boundary-Layer Meteorology 23: 223-246.

Sedlar, J., and R. Hock. 2009. Testing longwave radiation parameterizations under clear and overcast skies at Storglaciären, Sweden. The Cryosphere 3: 75-84.

Semtner, A. J., Jr. 1984. On modelling the seasonal thermodynamic cycle of sea ice in studies of climatic change. Climatic Change 6: 27-37.

Skartveit, A., and J. A. Olseth. 1987. A model for the diffuse fraction of hourly global radiation. Solar Energy 38: 271-274.

Skartveit, A., J. A. Olseth, and M. E. Tuft. 1998. An hourly diffuse fraction model with correction for variability and surface albedo. Solar Energy 63: 173-183.

Smeets, P. 2006. Assessing unaspirated temperature measurements using a thermocouple and a physically based model. Pages 99-101 in J. Oerlemans and C. H. TijmReijmer, eds. The Mass Budget of Arctic Glaciers, Workshop and GLACIODYN planning meeting. IASC Working group on Arctic Glaciology, Obergurgl, Austria.

Smeets, P., and M. van den Broeke. 2008. Temporal and Spatial Variations of the Aerodynamic Roughness Length in the Ablation Zone of the Greenland Ice Sheet. Boundary-Layer Meteorology 128: 315-338.

Sniffen, P. J. 2008. Dry calving at the terminus of a polar glacier, Taylor Glacier, McMurdo Dry Valleys, Antarctica. Pages 68. Department of Geology. Portland State University, Portland, OR.

Speirs, J. C., D. F. Steinhoff, H. A. McGowan, D. H. Bromwich, and A. J. Monaghan. 2010. Foehn winds in the McMurdo Dry Valleys, Antarctica: The origin of extreme warming events. Journal of Climate 23: 3577-3598.

Stearns, C. R., and G. A. Weidner. 1993. Sensible and latent heat flux estimates in Antarctica. Pages 109-138 in D. A. Bromwich and C. R. Stearns, eds. Antarctic Meteorology and Climatology: Studies on Automatic Weather Stations. American Geophysical Union, Washington, D.C.

Steig, E. J., D. P. Schneider, S. D. Rutherford, M. E. Mann, J. C. Comiso, and D. T. Shindell. 2009. Warming of the Antarctic ice-sheet surface since the 1957 International Geophysical Year. Nature 457: 459-462. 
Stroeve, J., J. E. Box, S. L. Gao, A. W. Nolin, and C. Schaaf. 2005. Accuracy assessment of the MODIS 16-day albedo product for snow: Comparisons with Greenland in situ measurements. Remote Sensing of the Environment 94: 46-60.

Takahashi, S., T. Endoh, N. Azuma, and S. Meshida. 1992. Bare ice fields developed in the inland part of Antarctica. Proceedings of the NIPR Symposium on Polar Meteorology and Glaciology 5: 128-139.

Taylor, G. 1916. With Scott: The silver lining. Smith, Elder, and Co., London.

Thompson, D. W., and S. Solomon. 2002. Interpretation of recent Southern Hemisphere climate change. Science 296: 895-899.

Unsworth, M. H., and J. L. Monteith. 1975. Long-wave radiation at the ground. Q. J. R. Meteorol. Soc. 101: 13-24.

van As, D., M. van den Broeke, and R. van de Wal. 2005. Daily cycle of the surface layer and energy balance on the high Antarctic Plateau. Antarctic Science 17: 121-133.

van den Broeke, M., and R. Bintanja. 1995. The interaction of katabatic winds and the formation of blue-ice areas in East Antarctica. Journal of Glaciology 41: 395-407.

van den Broeke, M., P. SMeets, J. Ettema, C. van der Veen, R. van de Wal, and J. Oerlemans. 2008. Partitioning of melt energy and meltwater fluxes in the ablation zone of the west Greenland ice sheet. The Cryosphere 2: 179-189.

van den Broeke, M., D. van As, C. Reijmer, and R. van de Wal. 2004. Assessing and improving the quality of unattended radiation observations in Antarctica. Journal of Atmospheric and Oceanic Technology 21: 1417-1431.

Wakahama, G., D. Kuroiwa, D. Kobayashi, K. Tanuma, Y. Endo, Y. Mizuno, and S. Kobayashi. 1973. Observations of permeating water through a glacier body. Low Temperature Science, Series A 31: 209-220.

Walcek, C. J. 1994. Cloud cover and its relationship to relative humidity during a spring midlatitude cyclone. Monthly Weather Review 122: 1021-1035.

Walsh, J. E. 2009. A comparison of Arctic and Antarctic climate change, present and future. Antarctic Science 21: 179-188.

Warren, S. G. 1982. Optical properties of snow. Reviews of Geophysics and Space Physics 20: 67-89.

Warren, S. G., R. E. Brandt, and P. O. Hinton. 1998. Effect of surface roughness on bidirectional reflectance of Antarctic snow. Journal of Geophysical ResearchPlanets 103: 25789-25807.

Wendler, G. 1986. The "Radiation Paradox" on the slopes of the Antarctic continent. Polarforschung 56: 33-41.

Wendler, G., and N. Ishikawa. 1973. Experimental study of the amount of ice melt using three different methods: A contribution to the International Hydrological Decade. Journal of Glaciology 12: 399-410.

Wendler, G., N. Ishikawa, and Y. Kodama. 1988. The Heat Balance of the Icy Slope of Adelie Land, Eastern Antarctica. Journal of Applied Meteorology 27: 52-65.

Wheler, B., and G. E. Flowers. 2011. Glacier subsurface heat-flux characterizations for energy-balance modelling in the Donjek Range, southwest Yukon, Canada. Journal of Glaciology 57: 121-133. 
Winther, J.-G., H. Elvehøy, C. Egede Bøggild, K. Sand, and G. Liston. 1996. Melting, runoff and the formation of frozen lakes in a mixed snow and blue-ice field in Dronning Maud Land, Antarctica. Journal of Glaciology 42: 271-278.

$\mathrm{Xu}, \mathrm{K}$., and D. A. Randall. 1996. A semiempirical cloudiness parameterization for use in climate models. Journal of the Atmospheric Sciences 53: 3084-3102. 


\section{Appendix A: LTER Meteorological Data Summary}

MEASUREMENT SUMMARY

This table is provided to show the general types of data collection and specific devices used at various meteorology stations over time.

\section{Valley Stations}

Measurement
Air temperature @3 m
Air temp. difference 1-3 m
Relative humidity @ $3 \mathrm{~m}$
Soil temperature @ $0 \mathrm{~cm}$
Soil temperature @ $5 \mathrm{~cm}$
Soil temperature@ $10 \mathrm{~cm}$
Wind speed
Wind direction
Solar Flux (incoming)
Solar Flux (outgoing)
Net radiation
UVA
UVB
PAR
Longwave radiation (incoming)
Longwave radiation (outgoing)
Precipitation
Surface Change (Snow Depth)

Valley Stations

Measurement
Air temperature @3 m
Air temp. difference 1-3 m
Relative humidity @3 m
Soil temperature@ $0 \mathrm{~cm}$
Soil temperature@ $5 \mathrm{~cm}$
Soil temperature @ $10 \mathrm{~cm}$
Lower Onyx River temperature
Wind speed
Wind direction
Solar Flux (incoming)
Solar Flux (outgoing)
PAR
Precipitation
Surface Change (Snow Depth)
Barometric pressure

Beacon Valley
$2000 / 01$
-
$2000 / 01$
$2000 / 01$
$2000 / 01$
$2000 / 01$
$2000 / 01$
$2000 / 01$
$2000 / 01$
$2000 / 01$
-
-
-
$2000 / 01$
-
-

$\begin{array}{cc}\text { Hoare }^{5} & \\ 1993 / 94 & \mathrm{a}, \mathrm{s} \\ 1995 / 96 & \mathrm{~b} \\ 1993 / 94 & \mathrm{a}, \mathrm{t} \\ 1993 / 94-1995 / 96 & 5, \mathrm{c} \\ 2002 / 03 & 5, \mathrm{c} \\ 1993 / 94-1995 / 96 & 5, \mathrm{c} \\ 2002 / 03 & 5, \mathrm{c} \\ 1993 / 94-1995 / 96 & 5, \mathrm{c} \\ 2002 / 03 & 5, \mathrm{c} \\ - & \\ 1993 / 94 & \mathrm{~d} \\ 1993 / 94 & \mathrm{~d} \\ 1993 / 94 & \mathrm{~g} / \mathrm{h} \\ 1993 / 94 & \mathrm{~g} / \mathrm{h} \\ 1993 / 94 & \mathrm{~m} \\ 1994 / 95-2001 / 02 & \mathrm{p} \\ 2001 / 02 & \mathrm{v} \\ - & \\ 1994 / 95 & \mathrm{q}\end{array}$

Bonney
$1993 / 94$
-
$1993 / 94$
$1994 / 95$
$1994 / 95$
$1994 / 95$
$1993 / 94$
$1993 / 94$
$1993 / 94$
$1994 / 95$
-
-
-
$1993 / 94$
$1997 / 98$
$1997 / 98$
$1994 / 95$
$2002 / 03$

$\begin{array}{cc} & \text { Brownworth } \\ \text { a, s } & 1994 / 95 \\ & - \\ \text { a,t } & 1994 / 95 \\ \text { c } & 1994 / 95 \\ \text { c } & 1994 / 95 \\ \text { c } & 1994 / 95 \\ \text { d } & 1994 / 95 \\ \text { d } & 1994 / 95 \\ \mathrm{~g} / \mathrm{h} & 1994 / 95 \\ \mathrm{~g} / \mathrm{h} & 1996 / 97 \\ & 1994 / 95-1996 / 97 \\ & 1994 / 95-1996 / 97 \\ & 1994 / 95-1996 / 97 \\ \mathrm{~m} & 1996 / 97 \\ \mathrm{n} & - \\ \mathrm{n} & - \\ \mathrm{p} & - \\ \mathrm{u} & 2003 / 04 \\ & \end{array}$

$\begin{array}{cc}\text { Vanda } & \\ 1994 / 95 & \mathrm{a}, \mathrm{s} \\ - & \\ 1994 / 95 & \mathrm{a}, \mathrm{t} \\ 1994 / 95 & \mathrm{c} \\ - & \\ 1994 / 95-1995 / 96 & \mathrm{c} \\ 2003 / 04 & \mathrm{c} \\ 1994 / 95 & \mathrm{c} \\ - & \\ 1995 / 96-2003 / 04 & \mathrm{c} \\ 1994 / 95 & \mathrm{~d} \\ 1994 / 95 & \mathrm{~d} \\ 1994 / 95 & \mathrm{~g} / \mathrm{h} \\ 1994 / 95 & \mathrm{~g} / \mathrm{h} \\ 1994 / 95 & \mathrm{~m} \\ - & \\ - & \\ 2003 / 04 & \mathrm{u} \\ - & \end{array}$

Vida
$1995 / 96$
-
$1995 / 96$
$1995 / 96$
-
$1995 / 96$
-
$1995 / 96$
-
-
$1995 / 96$
$1994 / 95$
$1995 / 96$
$1995 / 96$
$1995 / 96$
-
-
$2003 / 04$
-

\begin{tabular}{cc}
\multicolumn{2}{c}{ Explorer Cove } \\
$1997 / 98$ & a, s \\
$97 / 98$ to 02/03 b & \\
$1997 / 98$ & a, t \\
$1997 / 98$ & c \\
- & \\
$2002 / 03$ & c \\
- & \\
$2002 / 03$ & $\mathrm{c}$ \\
- & \\
- & \\
$1997 / 98$ & $\mathrm{~d}$ \\
$1997 / 98$ & $\mathrm{~d}$ \\
$1997 / 98$ & $\mathrm{~g} / \mathrm{h}$ \\
$1997 / 98$ & $\mathrm{~g} / \mathrm{h}$ \\
$1997 / 98$ & $\mathrm{~m}$ \\
$1995 / 96$ & $\mathrm{p}$ \\
- & \\
- & \\
- &
\end{tabular}




\section{Glacier Stations \\ Measurement}

Air temperature@3m

Air temperature@2m

Air temperature@1m

Relative humidity@3m

Relative humidity@2m

Relative humidity @ 1 m

Ice temperature@20 cm

Ice temperature@50 cm

Ice temperature@1 m

Wind speed

Wind direction

Solar Flux (incoming)

Solar Flux (outgoing)

Net radiation

Longwave radiation (incoming)

Longwave radiation (outgoing)

Ice surface thermal infrared

Ice Surface Changes

Barometric pressure

Eddy correlation

\begin{tabular}{|c|c|c|c|c|c|c|c|}
\hline Canada $^{2}$ & & \multicolumn{2}{|c|}{ Commonwealth } & \multicolumn{2}{|l|}{ Taylor } & \multicolumn{2}{|l|}{ Howard } \\
\hline- & & 1993/94 & $\mathrm{a}, \mathrm{s}$ & $1994 / 95$ & $\mathrm{a}, \mathrm{s}$ & $1993 / 94$ & $\mathrm{a}, \mathrm{s}$ \\
\hline $1994 / 95$ & $\mathrm{a}, \mathrm{s}$ & - & & - & & - & \\
\hline - & & - & & $1995 / 96$ & $\mathrm{a}, \mathrm{s}$ & $1995 / 96$ & $\mathrm{a}, \mathrm{s}$ \\
\hline - & & 1993/94 & $\mathrm{a}, \mathrm{t}$ & $1994 / 95$ & $\mathrm{a}, \mathrm{t}$ & $1993 / 94$ & $\mathrm{a}, \mathrm{t}$ \\
\hline $1994 / 95$ & $\mathrm{a}, \mathrm{t}$ & - & & - & & - & \\
\hline & & $1995 / 96$ & & $1995 / 96$ & $\mathrm{a}, \mathrm{t}$ & $1995 / 96$ & $\mathrm{a}, \mathrm{t}$ \\
\hline 1995/96 - 2002/03 & $\mathrm{c}$ & $1993 / 94-2002 / 03$ & $\mathrm{c}$ & $94 / 95$ to $02 / 03 \mathrm{c}$ & $\mathrm{c}$ & $1993 / 94-2002 / 03$ & $\mathrm{c}$ \\
\hline $2002 / 03$ & w & $2002 / 03$ & w & $02 / 03 \mathrm{w}$ & w & $2002 / 03$ & w \\
\hline $1995 / 96-2002 / 03$ & $\mathrm{c}$ & $1993 / 94-2002 / 03$ & $\mathrm{c}$ & $1994 / 95-2002 / 03$ & $\mathrm{c}$ & $1993 / 94-2002 / 03$ & $\mathrm{c}$ \\
\hline $2002 / 03$ & w & $2002 / 03$ & w & $2002 / 03$ & w & $2002 / 03$ & w \\
\hline $1995 / 96$ & d & 1993/94 & d & $1994 / 95$ & d & 1993/94 & d \\
\hline $1995 / 96$ & d & 1993/94 & d & $1994 / 95$ & d & $1993 / 94$ & d \\
\hline $1995 / 96$ & $\mathrm{~g} / \mathrm{h}$ & 1993/94 & $\mathrm{i}$ & $1994 / 95$ & 6 & $1993 / 94$ & $\mathrm{i}$ \\
\hline $1995 / 96$ & $\mathrm{~g} / \mathrm{h}$ & 1993/94 & $\mathrm{i}$ & $1994 / 95$ & 6 & $1993 / 94$ & $\mathrm{i}$ \\
\hline $1995 / 96-1999 / 00$ & $\mathrm{j}$ & - & & - & & - & \\
\hline- & & $1995 / 96$ & $\mathrm{n}$ & $95 / 96$ to $97 / 98 \mathrm{n}$ & $\mathrm{n}$ & $1993 / 94-1994 / 95$ & $\mathrm{n}$ \\
\hline - & & $1995 / 96$ & $\mathrm{n}$ & - & & - & \\
\hline $1995 / 96$ & $7, o$ & $1995 / 96$ & 7,0 & $1995 / 96$ & 7,0 & - & \\
\hline- & $\mathrm{y}$ & $2003 / 04$ & $\mathrm{y}$ & $2003 / 04-2007 / 08$ & $\mathrm{y}$ & - & \\
\hline - & & - & & $2007 / 08$ & $\mathrm{z}$ & - & \\
\hline & & $2002 / 03$ & u & $2002 / 03$ & $\mathrm{u}$ & $2003 / 04$ & $\mathrm{u}$ \\
\hline $1994 / 95-2002 / 03$ & $q$ & - & & - & & - & \\
\hline $1994 / 95-1995 / 96$ & $7, \mathrm{r}$ & - & & - & & - & \\
\hline
\end{tabular}

1 New Stations built to replace older ones at same site. The old Lake Fryxell station was not operating.

2 Summer only eddy correlation station built in 94/95. Permanent station to be built 95/96

3 LTER took over the operation of USGS metereological station at Explorer's Cove in 1997/98. Installed new sensors.

4 95/96 equipment not installed at time of publication.

5 Lake Hoare soil temperature at $5 \mathrm{~cm}$ depth discontinued in $94 / 95$ to make room for a pressure sensor and soil temperature at $0 \mathrm{~cm}$ and $10 \mathrm{~cm}$ depths discontinued in 95/96 to make room for thermocouple. Three (3) 107 temperature probes were installed in Dec 2002

6 LI-COR(h) used in 94/95. Eppley(i) to be installed 95/96.

7 Summer-only measurements and only for a limited period.

8 Mean vapor pressure measured at 2 and $1 \mathrm{~m}$ during 1995/96

a Campbell Scientific 207 temp/rh probe.

b Chromel-constantan thermocouple wire.

c Campbell Sdentific 107B temperature probe.

d R.M. Young model 05103 wind monitor.

e Vector Instruments model A 101M anemometer.

f Vector Instruments model W200P wind vane.

g LI-COR model LI200S silicon pyranometer.

h LI-COR model L1200X silicon pyranometer.

i Eppley precision spectral pyranometer

j REBS net radiometer.

k Macam SDl04A-Cos UV-A sensor.

1 Macam SD104B-Cos UV-B sensor.

m LI-COR model 190SB quantum sensor.

$\mathrm{n}$ Eppley precision infrared radiometer (pyrgeometer).

- Everest model $40004 \mathrm{GL}$ infared temperature transducer

p Belfort precipitation gage with BEI natural binary shaft encoder. Custom-made nipher shields provided by Canada's Atmospheric Environment Service.

q Vaisala model PTA427 Barometric pressure sensor.

r Campbell Scientific model CA27 sonic anemometer and model KH2O krypton hygrometer

s Campbell Scientific 107 temp probe installed to replace the 207 temp/rh probe during 1999/00 and 2000/01 season.

t Vaisala HMP45C RH probe installed to replace the $207 \mathrm{temp} / \mathrm{rh}$ probe during 1999/00 and 2000/01 season.

u Campbell Scientific Inc. SR50 Ultrasonic Distance Senso

v Campbell Scientific Inc. TE525MM Tipping Bucket Rain Gage

w Fenwall Thermisters (192-102DEW-A01) and Caddock Tetrinox $\mathbb{R}$ (TF050N) hi precision resistor (10Kohm) with \pm 5 ppm/celcius and $0.01 \%$ Resistor

y Everest Interscience MODEL 3600ZH Micro-Miniature Infrared Thermometer System

z Apogee Infrared Radiometer Precision Temperature Sensor (IRR-P) 


\section{Appendix B: Details of Effective Ice Grain Radius Calibration}

In Chapter 5, I used ice temperatures in the upper meter of the ice measured by thermistors to calibrate effective ice grain radius $\left(\mathrm{r}_{\mathrm{eff}}\right)$ within the model. I perform this calibration using constant values for the other two parameters within the model. Results indicate that optimal $r_{\text {eff }}$ is highly independent of surface roughness length. I used a value of $\mathrm{z}_{0}=0.05 \mathrm{~mm}$, and varying $\mathrm{z}_{0}$ over the range of values considered $(0.01$ to $5 \mathrm{~mm})$ has a negligible effect on the calibration of $r_{\text {eff. }}$. However, optimal $r_{\text {eff }}$ does increase slightly with the thickness of the surface layer for thicknesses greater than $0.5 \mathrm{~cm}$, particularly for thermistors at shallow depths. Increasing surface layer thickness increases the SRSF, which leaves less energy to be absorbed in the subsurface for a given grain radius. Larger $r_{\text {eff }}$ generate more scattering deeper within the ice, which compensates for increases in surface layer thickness. To standardize the calibration, the thickness of the surface layer was set to $0.5 \mathrm{~cm}$; surface layer thickness values smaller than this value yield the same optimal EIGR. Increasing surface layer thickness to $3 \mathrm{~cm}$ yields optimal EIGR about $30 \%$ larger, and increasing to $9 \mathrm{~cm}$ yields optimal EIGR about 2.5 times larger.

Because the thermistors gradually ablate out of the ice, I started by restricting my analysis to the initial season after thermistor installation when depth of the sensors is well-known. Changes in thermistor depth over time are estimated from stake measurements of ablation at the surface and are subject to increasing uncertainty with each subsequent season. This yielded a total of 39 comparisons between modeled and measured ice temperatures, with depth of comparison ranging from 10 to $106 \mathrm{~cm}$ and comparisons covering portions of six different summers (Figure 5.2). The time periods were categorized as early summer (November and December with ice temperatures less than $\sim-5^{\circ} \mathrm{C}$ at $20-50 \mathrm{~cm}$ depths), mid summer (December and January with ice temperatures greater than $\sim-5^{\circ} \mathrm{C}$ at $20-50 \mathrm{~cm}$ depths), or late summer (January and 
February with ice temperatures less than $\sim-5^{\circ} \mathrm{C}$ at $20-50 \mathrm{~cm}$ depths). For these time periods, the average optimal $\mathrm{r}_{\mathrm{eff}}$ is about $0.1 \mathrm{~mm}$, and the range is 0.01 to $0.2 \mathrm{~mm}$.

In Chapter 5 I note that comparisons made at different depths during the same time period indicate smaller effective grain radii tend to be optimal at shallower depths (Figure 5.2), but lack a definitive explanation of this pattern. My initial hypothesis was that partial melting within the subsurface reduces $r_{\text {eff }}$ through the creation of pockets of liquid water or air, should the melt drain. Air bubbles in lake and sea ice increase multiple scattering significantly, and brine pockets in sea ice scatter and absorb radiation (Grenfell 1983, Mullen and Warren 1988, Jin et al. 1994). Increased scattering of solar radiation has been observed in sea ice after the draining of brine leaves air pockets (Buckley and Trodahl 1987). I have measured reductions in ice density in the upper 20 $\mathrm{cm}$ over the course of summer (Figure 2.9), and we also see a marked increase in ice albedo during many summers at midseason (Figure 2.21). Since these effects are not considered explicitly in the model, they would result in smaller optimal $r_{\text {eff }}$ during mid or late summer at depths affected by this process. Because the model uses a constant $r_{\text {eff }}$ with depth, the optimal $r_{\text {eff }}$ at greater depths may actually represent an integration of varying $r_{\text {eff }}$ in the ice above.

However, in comparing optimal grain radii from early, mid, and late summer periods (black, colored, and white markers, respectively, in Figure 5.2), there is not a clear pattern of optimal grain radius evolution over summer. Furthermore, I do not see a constant optimal grain radius with depth in early summer prior to the onset of subsurface melt, which would be expected if the pattern with depth was related to changes in ice density related to subsurface melt and draining, because the layer of reduced density would be removed by sublimation each winter. I do see a low optimal $r_{\text {eff }}$ of $0.02 \mathrm{~mm}$ at CAA during midsummer 2004-2005, but in general time of summer seems to have an equivocal relationship to optimal $r_{\text {eff. }}$. Though I do not see clear evidence for changes in $r_{\text {eff }}$ over the summer, it does not exclude the possibility, because near optimal values of $\mathrm{r}_{\text {eff }}$ span $0.5-1$ orders of magnitude. Thus, I sought an alternate explanation of the pattern of increasing optimal grain radius with depth. 
Possible alternative explanations include deficiencies in calculation of the extinction coefficients or error in the estimation of the thermal conductivity used in the model, although in the latter case I would expect different patterns in early and late summer when deeper ice is colder and warmer, respectively, than shallower ice. Measurement bias in the form of greater radiative heating of thermistors at shallower depths (Brandt and Warren 1993) is not a potential explanation, as that would cause the model to favor larger $r_{\text {eff }}$ at shallower depths to provide the additional energy to match artificially higher temperatures recorded there. Errors in the solar radiative source term of the model is the only possible explanation that appears likely.

After analyzing the thermistor data for the initial season after installation (Figure 5.2), I extended the calibration of $r_{\text {eff }}$ to include thermistor data from subsequent years. This was done in part to add additional tests of the hypothesis for drainage of subsurface melt lowering the effective grain radius. I restricted data from those years to thermistors at depths of less than $50 \mathrm{~cm}$, the region where subsurface melt is predicted and that I therefore am most concerned with representing well. This provides eight summers at TAR and six summers at CAA with which to calibrate effective grain radius (Figures B.1 - B.2).

Including the additional summers, optimal $\mathrm{r}_{\text {eff }}$ values range from $10^{-2}$ to $10^{-1} \mathrm{~mm}$, but there is high variability between summers and between different periods of some summers (Figures B.1 - B.2). Optimal $\mathrm{r}_{\text {eff }}$ typically corresponds to mean absolute error in hourly ice temperatures of less than $0.5^{\circ} \mathrm{C}$. However, grain radii values that yield mean absolute error in hourly ice temperatures less than $1{ }^{\circ} \mathrm{C}$ typically span $0.5-1$ orders of magnitude, with a wider range at shallower depths, particularly so less than $30 \mathrm{~cm}$. Mid-summer periods often have a wider range of tolerable $r_{\text {eff }}$ values, presumably because once ice temperatures reach $0^{\circ} \mathrm{C}$, further heating of the ice does not change ice temperature but instead causes a phase change to water; the model may be reproducing the heating of the ice poorly but still accurately reproduce an ice temperature of $0^{\circ} \mathrm{C}$. Though there are some instances of late summer requiring a smaller grain radius than earlier in the season (e.g. 2003 at Taylor), I do not find strong support for the hypothesis 
that drainage of subsurface melt changes grain radius. The apparent temporal variability shown in Figures B.1-B.2 may instead be due to uncertainty, particularly since the depth to thermistors in many of the years shown is only known approximately. 

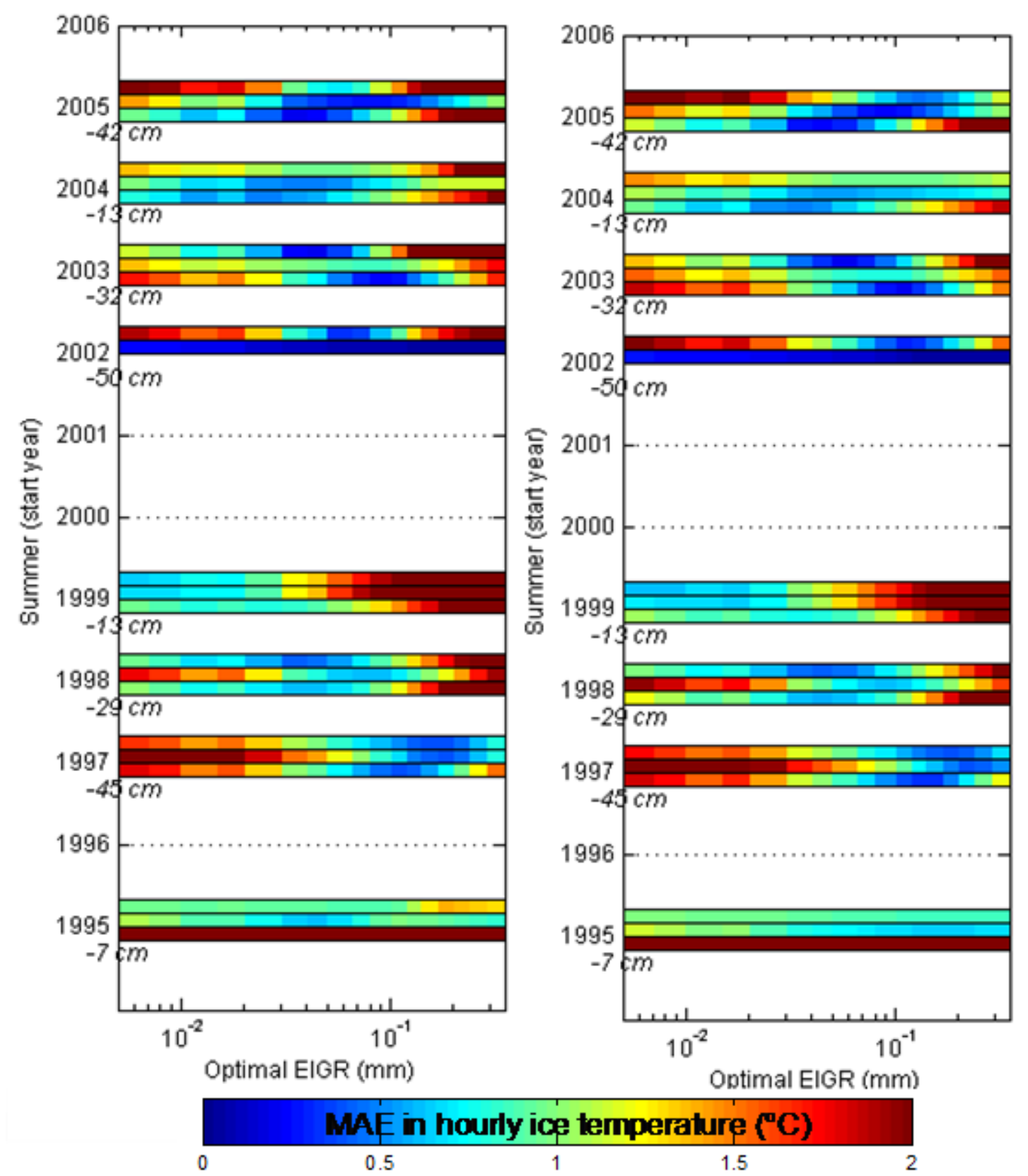

Figure B.1: Mean absolute error in hourly ice temperature at TAR using the Refreezing Model (right) and the Drainage Model (left). The three rows for each summer correspond to early (bottom), mid (middle), and late (top) summer periods as explained in text. Below the label for each year is a note of the average depth of thermistor for that season. Early summer 2002 is missing. 

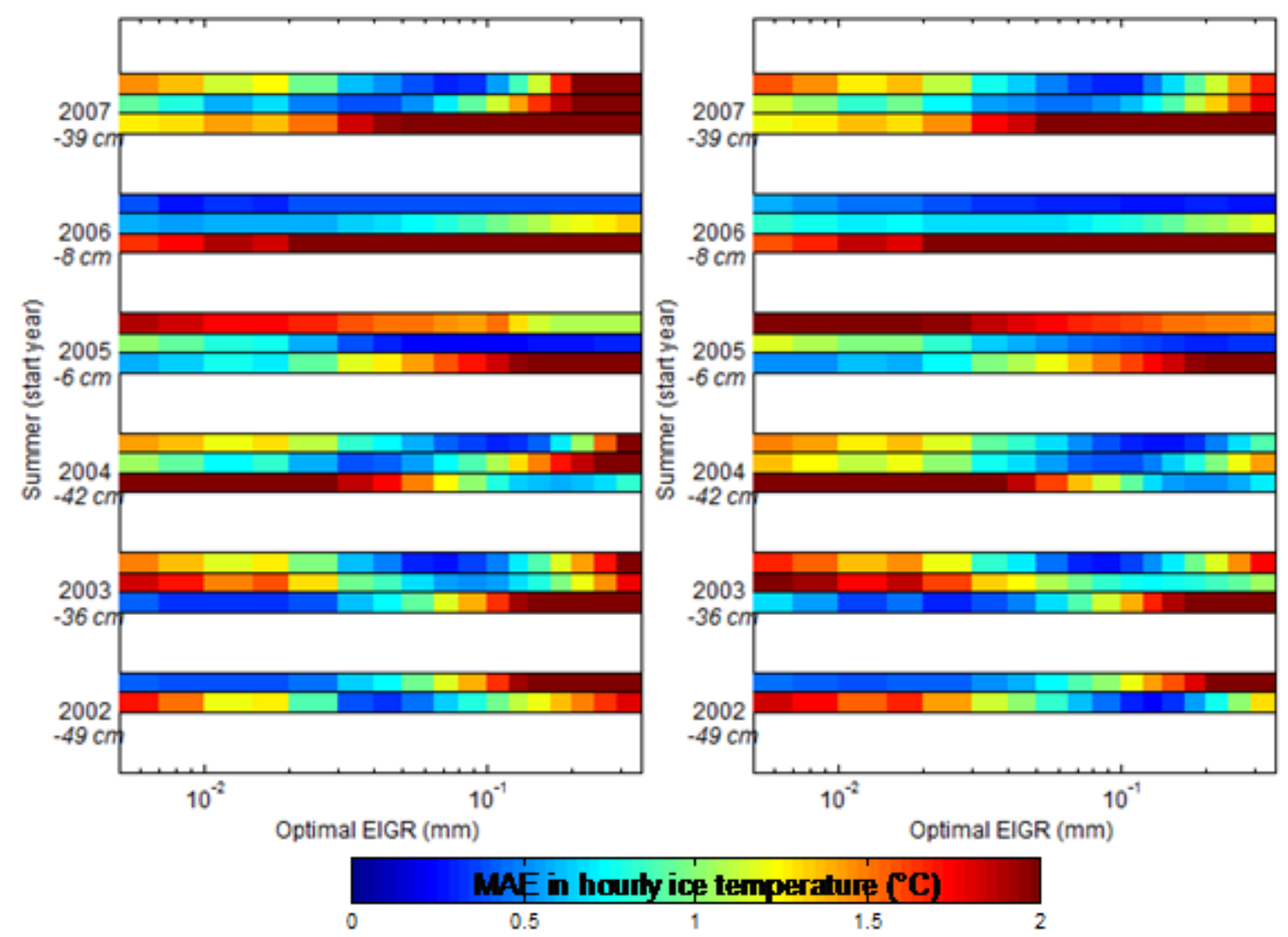

Figure B.2: Mean absolute error in hourly ice temperature at CAA using the Refreezing Model (right) and the Drainage Model (left). The three rows for each summer correspond to early (bottom), mid (middle), and late (top) summer periods as explained in text. Below the label for each year is a note of the average depth of thermistor for that season. Early summer 2002 is missing.

Examining the ice temperature time-series in detail in some summers revealed that the Refreezing Model gave unrealistic estimates of the timing of fall freezeup due to the modeling of a large latent heat reservoir (Figures 5.3 - 5.4). The difference between the Refreezing and Drainage models in late summer appears less prominently in 20042005 at TAR (Figure B.3) and CAA (Figure B.4). In many years subsurface melt is of such limited extent that there is little difference between the Refreezing and Drainage Models for the range of optimal grain radii. However, as indicated in Chapter 5, when subsurface melt is significant the Drainage model predicts more realistic ice temperatures. 

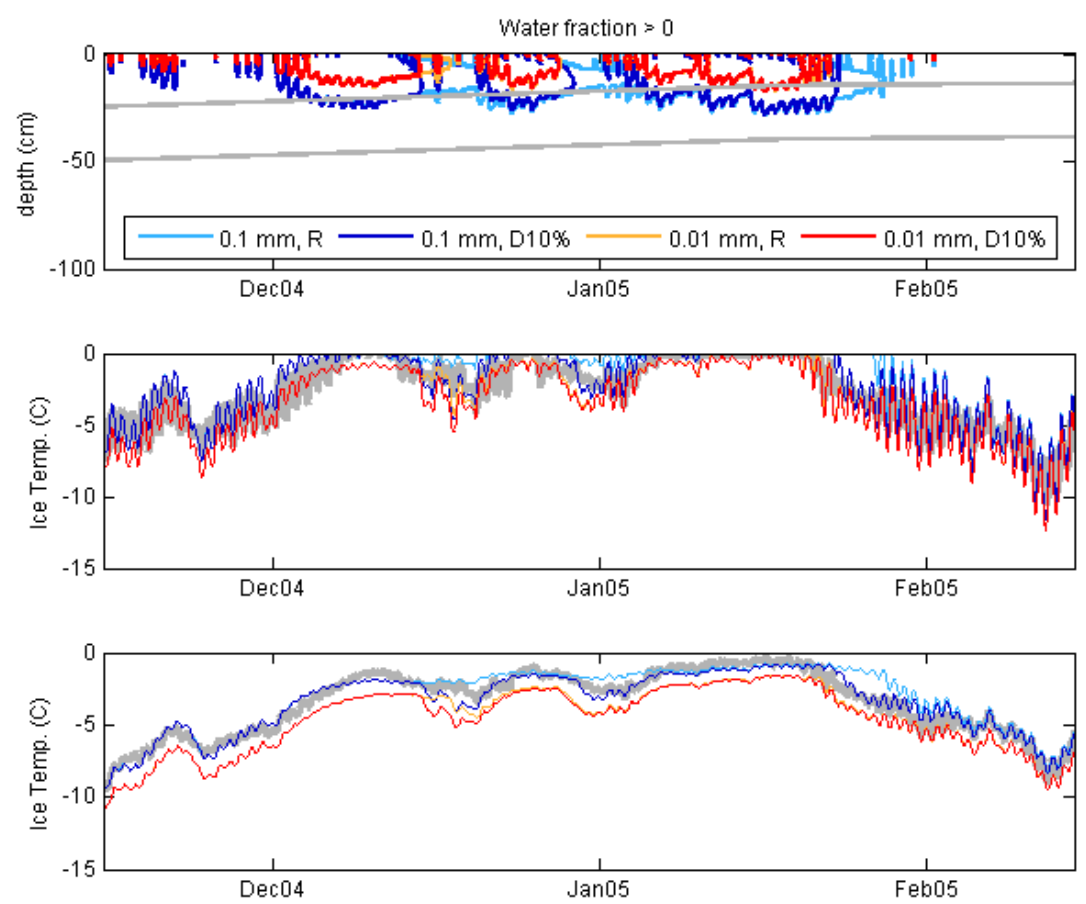

Figure B.3: Subsurface melt and ice temperatures at TAR in summer 2004-2005. Upper panel: Depth and duration of modeled subsurface melt. Model results using two different grain radii for both the Refreezing and Drainage Models are shown. The gray lines indicate the depths of the thermistors shown in the bottom two panels. Bottom two panels: Measured (gray) and modeled (colors) ice temperatures. The colors represent the same model versions as in the upper panel.
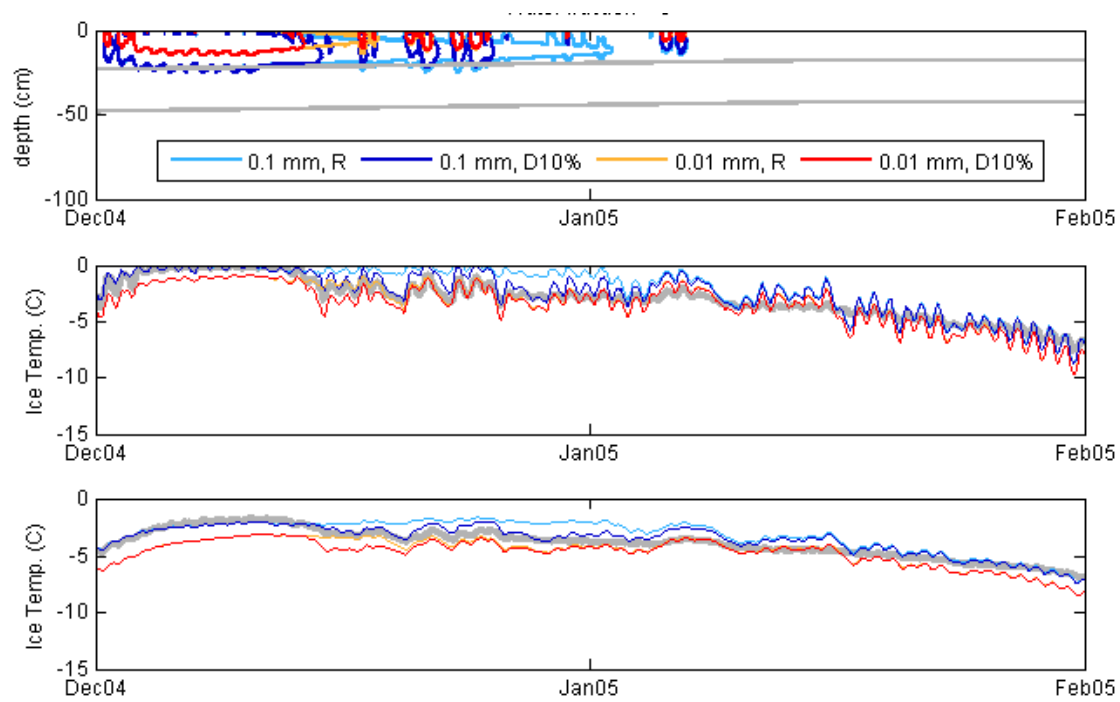

Figure B.4: Subsurface melt and ice temperatures at CAA in summer 2004-2005. Upper panel: Depth and duration of modeled subsurface melt. Model results using two different grain radii for both the Refreezing and Drainage Models are shown. The gray lines indicate the depths of the thermistors shown in the bottom two panels. Bottom two panels: Measured (gray) and modeled (colors) ice temperatures. The colors represent the same model versions as in the upper panel. 
The effective ice grain radius appears to control the modeled depth of subsurface melt, while the extent of drainage in the model appears to be an important control on the duration of subsurface melt. Thus, adjusted together these model parameters allow the modeling of subsurface melt to be tuned in two dimensions - depth and time. Summer 2005-2006 at CAA illustrates this, as one thermistor passes through the zone of subsurface melting while another exists below it (Figure B.5). For this season, the larger grain radius of $0.1 \mathrm{~mm}$ is necessary to reproduce the proper vertical profile of ice temperatures. Additionally, when using that grain radius, the Drainage Model must be employed to properly replicate that timing of freezeup, as can be seen for the deeper thermistor in late January.
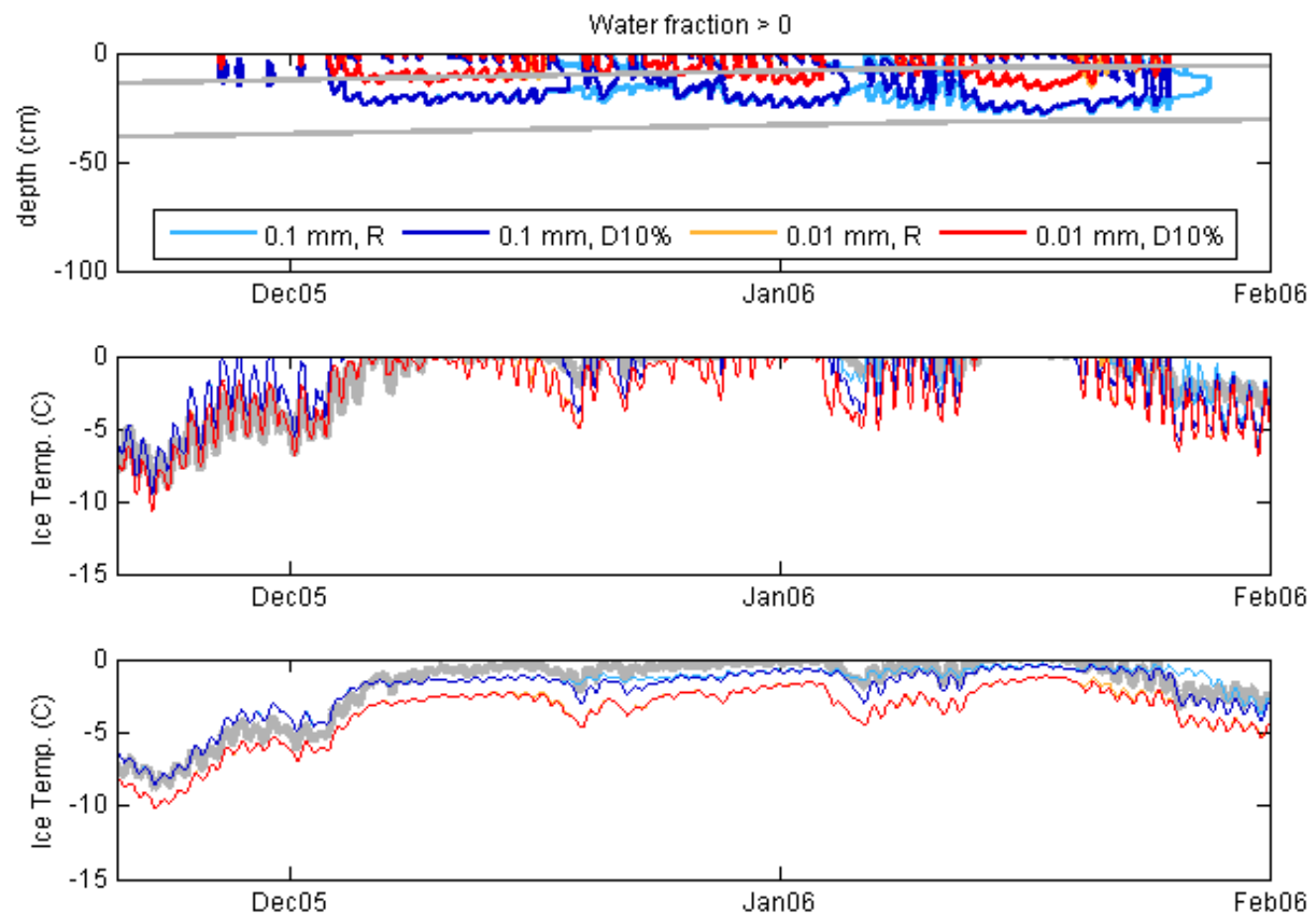

Figure B.5: Subsurface melt and ice temperatures at CAA in summer 2005-2006. Upper panel: Depth and duration of modeled subsurface melt. Model results using two different grain radii for both the Refreezing and Drainage Models are shown. The gray lines indicate the depths of the thermistors shown in the bottom two panels. Bottom two panels: Measured (gray) and modeled (colors) ice temperatures. The colors represent the same model versions as in the upper panel. 


\section{Appendix C: Remote Sensing of Snowcover on Dry Valley Glacier Ablation Zones}

I investigated the feasibility of using satellite imagery to map the extent of snowcover on the glacier ablation zones over time. Such a product may improve the skill of the spatial runoff model since it uses albedo measured at two locations (Canada and Taylor glacier meteorological stations) to be indicate the presence of absence of snow over all glacier ablation zones with Taylor Valley. I did not continue with this pilot study because 1) the substantial effort required; 2) I found that the melt model version that largely ignores snow works about as well as a version that considers snow in detail (Section 5.5.3); and 3) the spatial model that uses snow conditions at the two meteorological stations worked reasonably well (Section 6.5). Snowcover detection on the glacier ablation zones using satellite imagery is fundamentally an exercise in differentiating snow and ice. I did consider classifying snow or ice versus rock, because I know where the glaciers are, but if this pilot study were to be expanded it may be fruitful to extend the algorithm to map snow on the soils as well.

There are a number of schemes in existence for mapping snow using optical and near-infrared imagery (e.g. Normalized Difference Snow Index), but many are intended to identify the presence of snow in unglaciated landscapes and do not distinguish between snow and ice. However, a number of remote sensing studies of Antarctic blue ice have used band ratios to distinguish blue ice areas from snow, and these approaches are good candidates for application to the Dry Valleys. Boresjo-Bronge and Bronge (1999) use Landsat-5 Thematic Mapper (30 m spatial resolution) to classify an Antarctic blue-ice region into snow, blue ice, rock, and clouds. They investigate band ratios using all combinations of bands 3, 4, and 5. They find the Landsat 5 band ratio 3 / 4 (red / nearinfrared) discriminates well between snow and blue ice because they found separation between the ranges of the two:

Blue ice ratios are 2.0 to 2.3 
Snow ratios are 1.5 to 1.7

Similar studies have instead used band ratios of bands 2 (green) and 4 (nearinfrared) (Orheim and Lucchitta 1990, Reijmer et al. 2001), but I pursued the method of Boresjo-Bronge and Bronge (1999) because Landsat bands 3 and 4 cover very similar wavelengths as MODIS (Moderate Resolution Imaging Spectroradiometer) bands 1 and 2. MODIS bands 1 and 2 are the only MODIS bands with $250 \mathrm{~m}$ spatial resolution - all the others have 500 or $1000 \mathrm{~m}$, which is too coarse for the small glaciers and varied topography of Taylor Valley. MODIS is preferable to Landsat because MODIS passes Taylor Valley about 5 times per day, so it is possible to get daily coverage when cloud cover is not present. With so many passes, it is also possible to choose an image acquired close to solar noon ( 23:00 UTC) so that shadowing is at a minimum. Landsat on the other hand, would only allow repeat coverage every few weeks at best.

\section{Results using Landsat}

I browsed Landsat ETM imagery of Taylor Valley using the USGS GLOVIS tool until I found one that was cloud-free and had low snow cover. November 21, 2001 (day 325) was the first one I came across. I downloaded the Landsat imagery and converted the pixel values to radiance values using the metadata. The red band is shown in Figure C.1. It is fairly easy to manually discriminate lighter snow and darker ice using the LS red band alone. I also noted little shadowing, making this a good test image. 


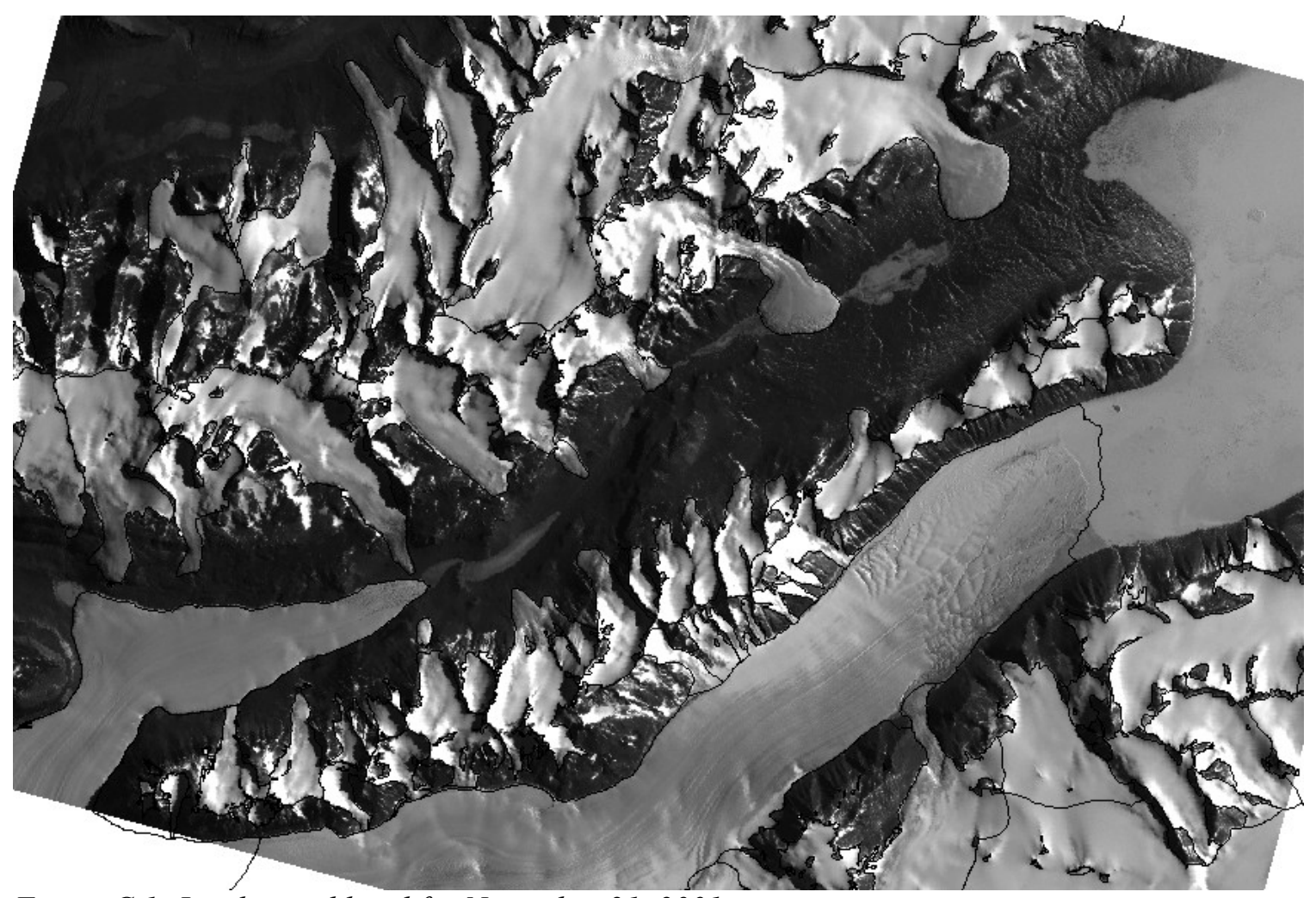

Figure C.1: Landsat red band for November 21, 2001

Following Boresjo-Bronge and Bronge (1999), I calcualted the ETM 3 / 4 ratio to detect snow (Figure C.2). (The wavelength ranges of the 3 and 4 bands are essentially the same on the Landsat 5 and Landsat ETM instruments.) Using a ratio should reduce issues related to shadowing and contrast. The ETM 3 / 4 ratio seems to highlight the difference between snow and ice (Figure C.2). Interestingly, snow has a similar value to soil/rock, making this a poor method for detecting snowfall on the valley floor.

However, that might be done easily without using a ratio. Areas that look like ice in Figure C.1 map to white to medium gray in Figure C.2 (the termini of the glaciers in the Kukri Hills make good examples). Anything darker than medium gray is snow or soil/rock. The lake moats and Taylor Glacier have much higher ratios (lighter color in Figure C.2) than the other glaciers. Commonwealth has slightly lower ratios (darker color) because there is a dusting of snow on parts of the glacier. I was impressed with how well this method worked for snow versus ice. 


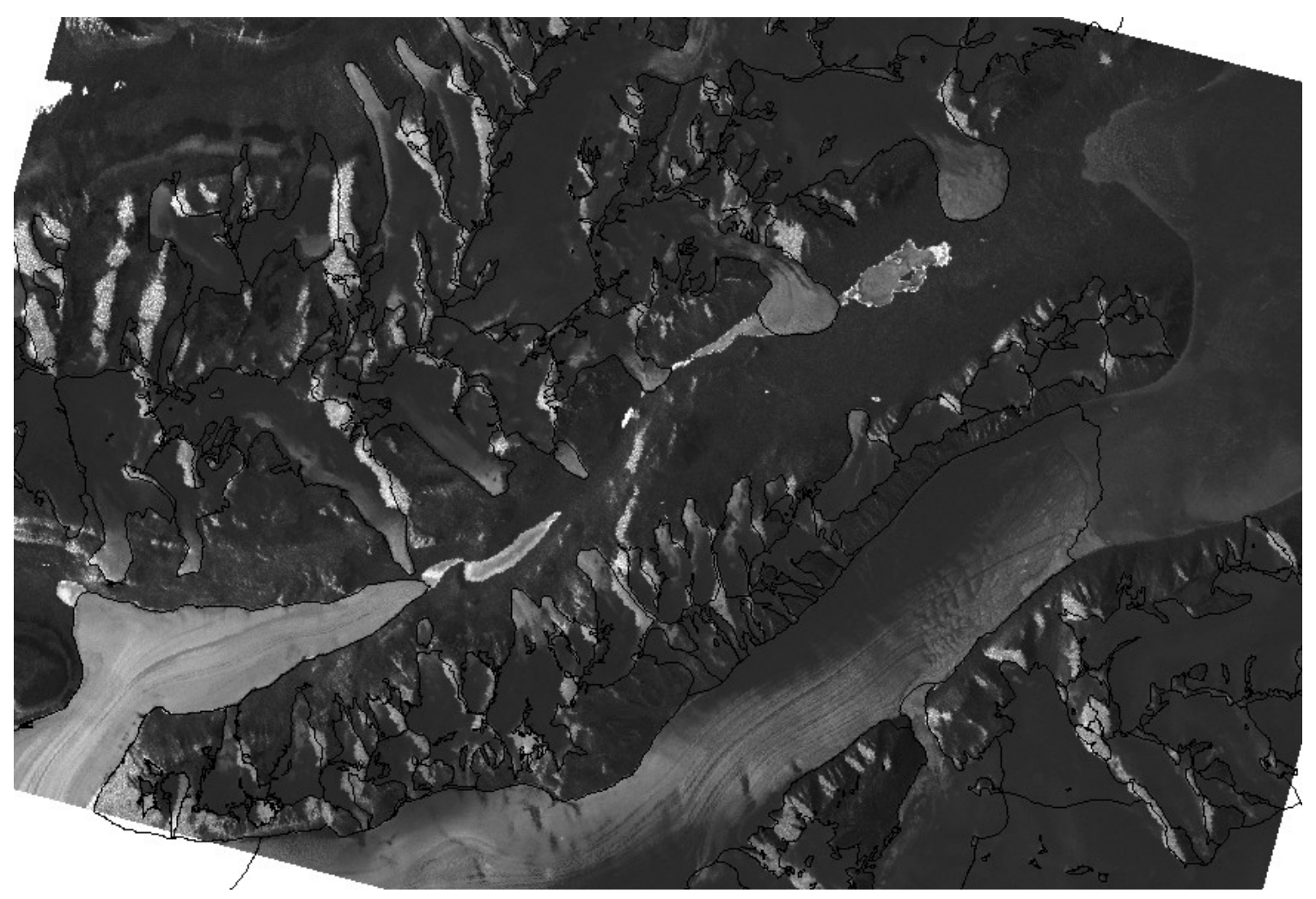

Figure C.2: Landsat ETM 3 / 4 band ratio used for differentiating snow and blue ice

To see how clean the classification is, I changed Figure C.2 to a classified symbology with the following scheme:

\begin{tabular}{lll}
\hline \hline ETM 3 / 4 ratio & my color & BB\&B (1999) class \\
\hline $0-1.5$ & white & (below snow) \\
$1.5-1.7$ & purple & snow \\
$1.7-2.0$ & green & between snow and ice \\
$2.0-2.3$ & yellow & blue ice \\
$>2.3$ & red & (above ice) \\
\hline
\end{tabular}

Boresjo-Bronge and Bronge (1999) had found that snow and blue ice mapped to mutually exclusive ranges of the TM 3 / 4 ratio. Applying their classes to Taylor Valley (Figure C.3), I find that most of the snow maps to the range between snow and ice, and much of the ice maps to values above the range for ice. One possibility is that Boresjo-Bronge and Bronge (1999) were using reflectance values, whereas I was using radiance values for simplicity. Nevertheless, the method seems to discriminate pretty well between snow 
and ice using a cutoff of 2.0 (i.e. yellow and red are ice, everything else is snow or soil/rock).

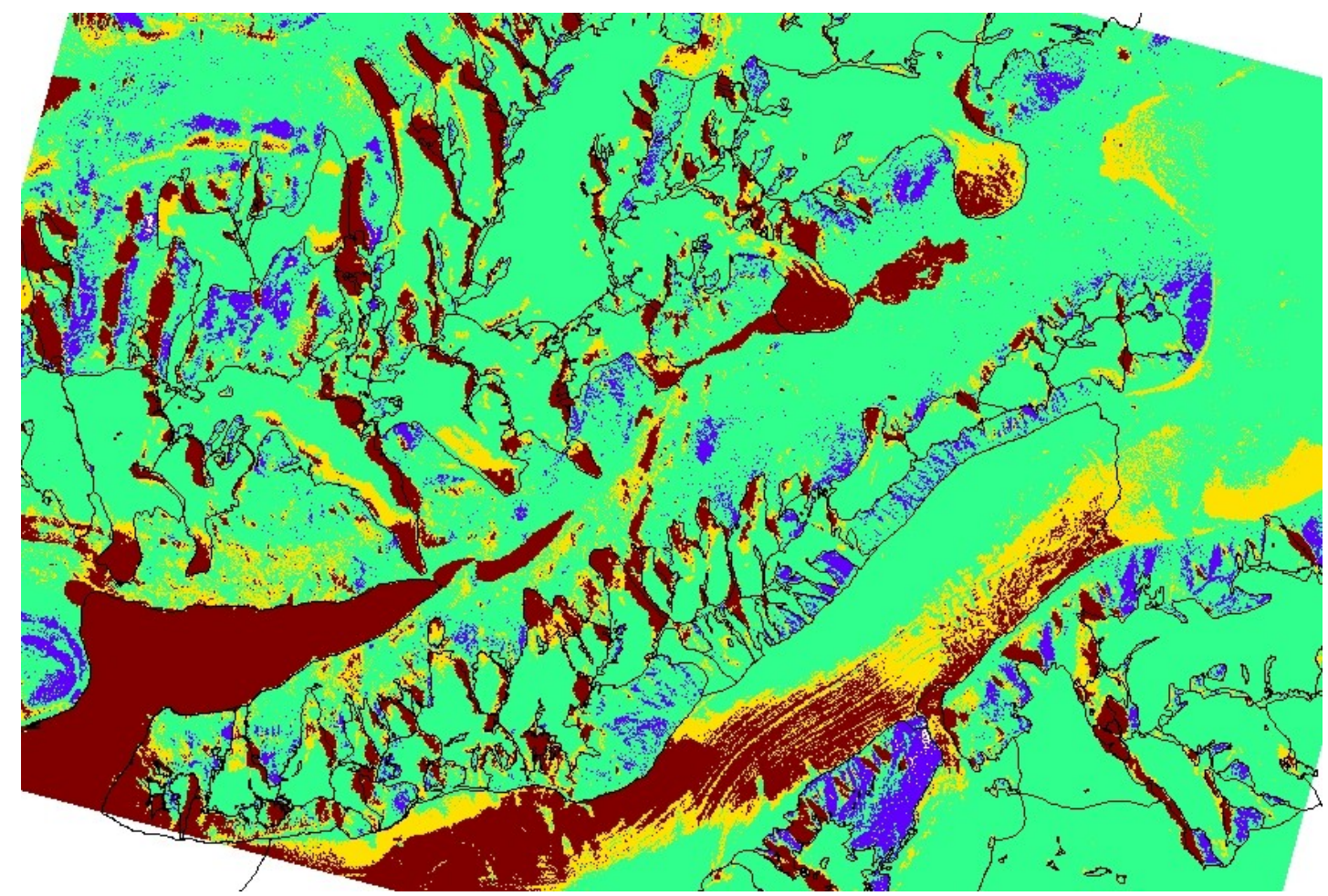

Figure C.3: ETM 3 / 4 band ratio used for differentiating snow and blue ice, classified using the BB\&B1999 scheme.

\section{Results using MODIS}

I downloaded the MODIS MOD02QKM product for the same day (November 21, 2001) from http://ladsweb.nascom.nasa.gov/data/search.html which is the only website that allows access to the level $1 \mathrm{~b}$ MODIS product (calibrated radiance). I had previously investigated the Level 2 MOD09 product (surface reflectance), but I have been unable to find any granules processed at the $250 \mathrm{~m}$ resolution even though the product specification exists. The MOD09 is processed with a radiative transfer model to reduce/eliminate atmospheric scattering effects which would be preferable to the unprocessed radiance values. However, in addition to not being able to find any data, the MOD09 product may not be favorable for this application because it is a daily gridded product that merges measurements taken from multiple passes of the satellite during each day. This means 
that the final values could include measurements taken at unfavorable solar geometry and shadowing could be corrupting the results in a high-relief area like Taylor Valley. Note the MODIS Rapid Response website provides composites of the level 1b radiance product, but $250 \mathrm{~m}$ data is only available starting 2007 . I have restricted my attention to the Terra satellite (MOD products), but additional images exist from Aqua (MYD products). Aqua has a broken band 6 which can be used for cloud detection. Terra provides favorable overpass time (near local noon). Aqua may as well, but I have not checked.

The MODIS band 1 (red) looks similar to the Landsat red band but with much coarser resolution (Figure C.4). At this coarse resolution, it is not very easy to manually differentiate snow and ice. Note that geolocation of the MODIS product is rougher than the Landsat product (i.e. glacier outlines do not always quite match up). There is a MOD03 product that might improve geolocation, but I have not used it in my analysis. The default geolocation might be adequate for this application because mixed soil/ice pixels along the edges of the glaciers will result in unreliable values anyway.

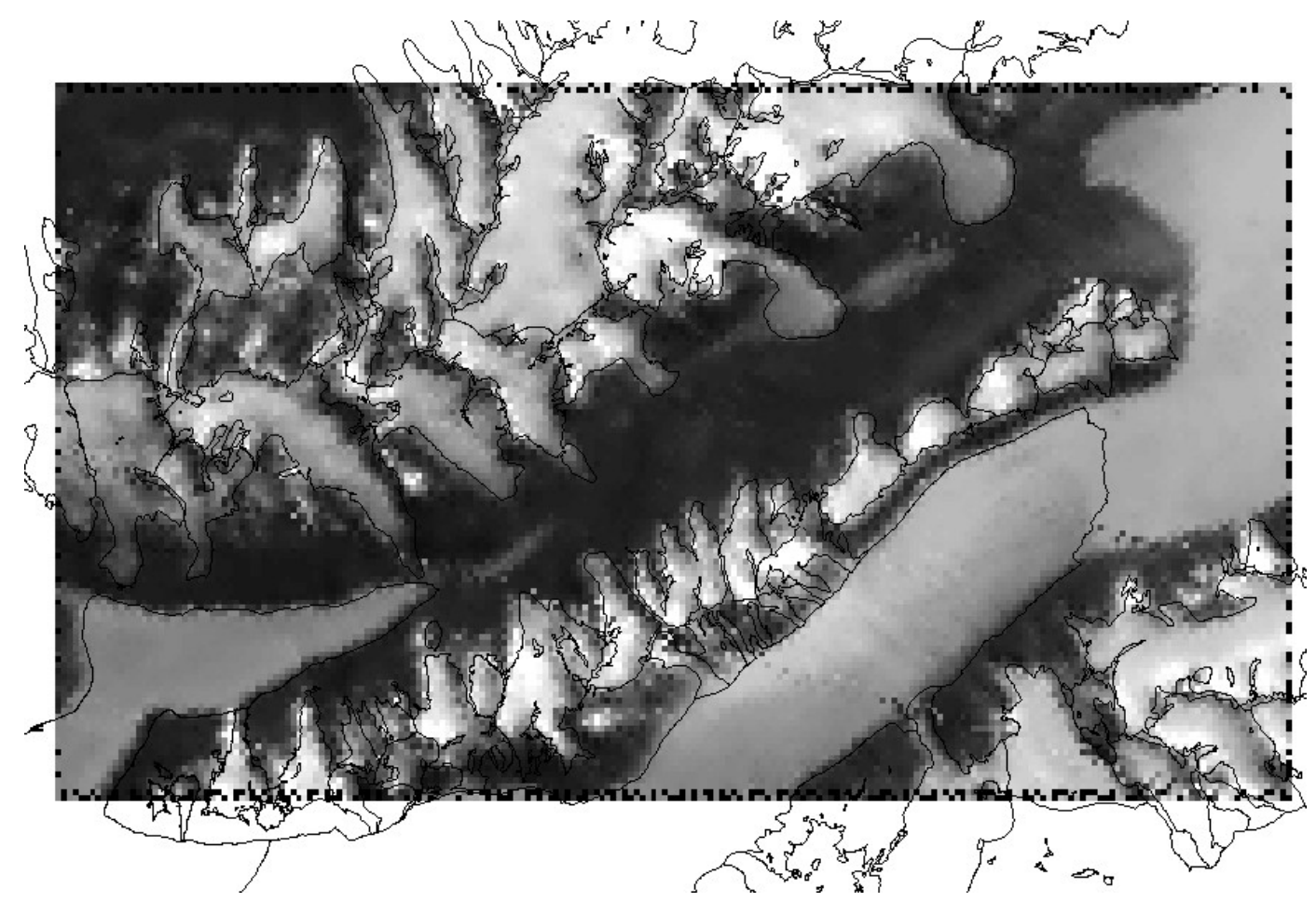

Figure C.4: MODIS red band for November 21, 2001 
Theoretically, taking the MODIS 1 / 2 ratio (Figure C.5) should yield similar results as the Landsat 3 / 4 ratio (Figure C.2). The results are somewhat different in that most of the snow and soil/rock areas fall into the snow class (purple) with MODIS, while they generally fell above snow ratios (green) using Landsat. As with Landsat, many of the ice areas have ratios above the ice class (red) using the MODIS imagery, but not to the same extent. The ice class (yellow) is not as extensive in the MODIS image, and most of the green areas (ratios between the snow and ice classes) would have to be included in the MODIS version to match the ice in the LandSat classification (grayed out areas in Figure C.5). Even though the MODIS and Landsat techniques yield different threshold values, they both seem generally capable of distinguishing snow and ice. The MODIS technique seems to be not quite as good. Using a threshold of 1.7 to classify ice (green, yellow, and red in Figure C.5), then MODIS does a pretty good job of matching the Landsat classification (grayed out areas). However, there are some problem areas where green appears in regions that are snow, for example Canada Glacier in the throat and the upper basin. Those areas are definitely snow, but there is extensive "green" mapped there, as well as some yellow and red. I assume this is due to problems with extensive shadowing, but there could be other reasons. Since I am only concerned with the ablation zones which have much less shadowing, this might not be a problem - the piedmont lobes seem to be classified properly. 


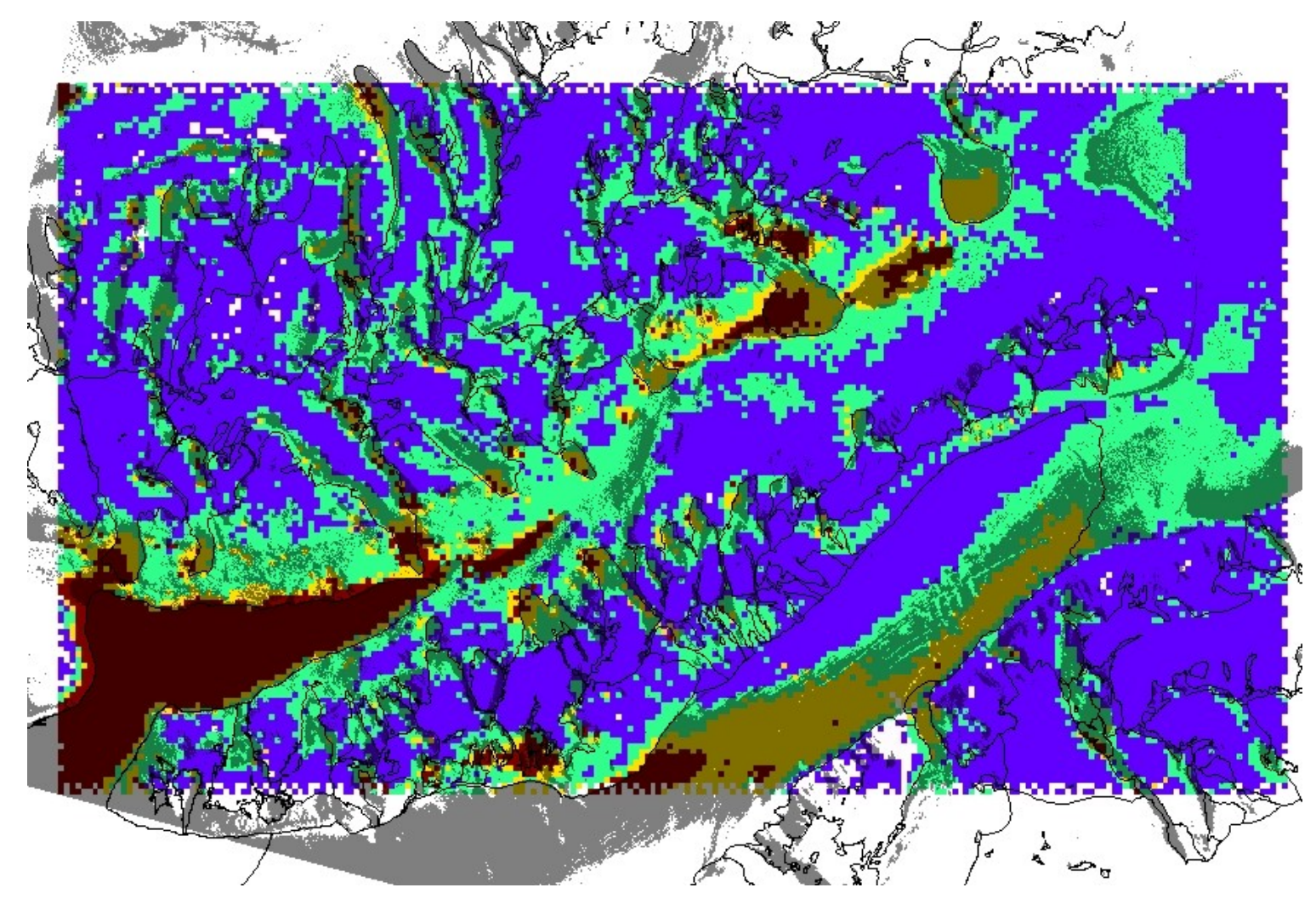

Figure C.5: MODIS 1 / 2 band ratio, classified using the Boresjo-Bronge and Bronge (1999) scheme. The dark tinted areas were classified as ice (TM $3 / 4>2.0)$ using the LandSat image.

\section{Conclusion}

I think the MODIS classification could work to distinguish snow from ice, but further testing is needed of the threshold between snow and ice. Between the geolocation and shadowing problems, it may be hard to get reliable data from the smaller glaciers. However, it may work fine for Commonwealth, Canada, and Taylor, at least in highlighting gross changes in snowcover. The MODIS method may not be sensitive enough to determine mixed snow/ice pixels or snow dustings, while the Landsat method might be capable of that level of detail.

Some additional work is needed to automate the process of developing time-series maps of snowcover. Each day will need to be screened for clouds, which could be done manually, or by using band 6. Clouds are not necessarily easy to pick out at $250 \mathrm{~m}$ resolution (they are pretty easy to manually identify on the higher resolution Landsat 
images). Each image also needs to be reprojected to a gridded projection because the native swatch format is difficult to work with, and each image should be subset to just the Taylor Valley area to speed up processing time substantially. Having an automated system setup would make it easy to extend this analysis to multiple seasons or to do additional calculations to look for snow on soil. 


\section{Appendix D: Cliff Model Applied to Taylor Glacier}

A second test of the cliff model predicted cliff ablation on the northside of Taylor Glacier. Two years of meteorological observations of air temperature, relative humidity, and wind speed (E. Pettit, pers. comm.) located about $10 \mathrm{~m}$ from the Taylor Glacier cliff face near the terminus of Rhone Glacier (Figure 2.2) were used to drive the model. These observations were combined with MicroMet estimates of incoming shortwave and longwave radiation on the cliff face. Modeled ablation for three seasons was compared to stake measurements of ablation from three vertical arrays of ten stakes drilled horizontally into the cliff from 3 to $24 \mathrm{~m}$ above the ground (Sniffen 2008). Because the cliffs on this part of Taylor Glacier have basal and englacial debris with low albedo exposed along the lower $10 \mathrm{~m}$ of the cliff face, I only consider the stakes higher on the cliff that are installed in clean ice. For each season I calculate average cliff ablation from 5-10 stakes.

To apply the model here I use the optimal parameters values found for the nearby TAR2 location (Chapter 5; $\mathrm{z}_{0}=1 \mathrm{~mm}, \mathrm{r}_{\mathrm{eff}}=0.03 \mathrm{~mm}, \mathrm{SRSF}=34 \%$ ). In contrast to the Canada Glacier cliffs (Section 6.4.2), the optimal parameter values for the nearby horizontal glacier surface severely underpredict ablation at the cliff for both summer and winter (Figure D.1a). Using a higher $\mathrm{z}_{0}$ value of $20 \mathrm{~mm}$ provides a better result for winter ablation, but only a slight improvement for summer ablation (Figure D.1c). Increasing SRSF from 34\% to $100 \%$ (which maximizes surface melt) results in a slight overestimate of summer ablation (Figure D.1b,d).

These experiments give results contrary to those from Canada Glacier and thus introduce significant uncertainty in the appropriate parameter values to use for the cliffs. It is unclear if the model has limitations for the high ablation rates present at this site or if the discrepancy is due to errors in the meteorological, albedo, or ablation observations. The meteorological station may be recording conditions that differ from those at the cliff face itself (particularly wind speed) since it is located $\sim 10 \mathrm{~m}$ from the cliff. It is unclear 
why ablation of $39 \mathrm{~cm}$ weq at the cliff site in winter 2005 is so much greater than the value of $15 \mathrm{~cm}$ weq at the nearby glacier surface TAR2 site. In contrast, winter ablation at the Canada Westside cliff is comparable to that at the CAA meteorological station.
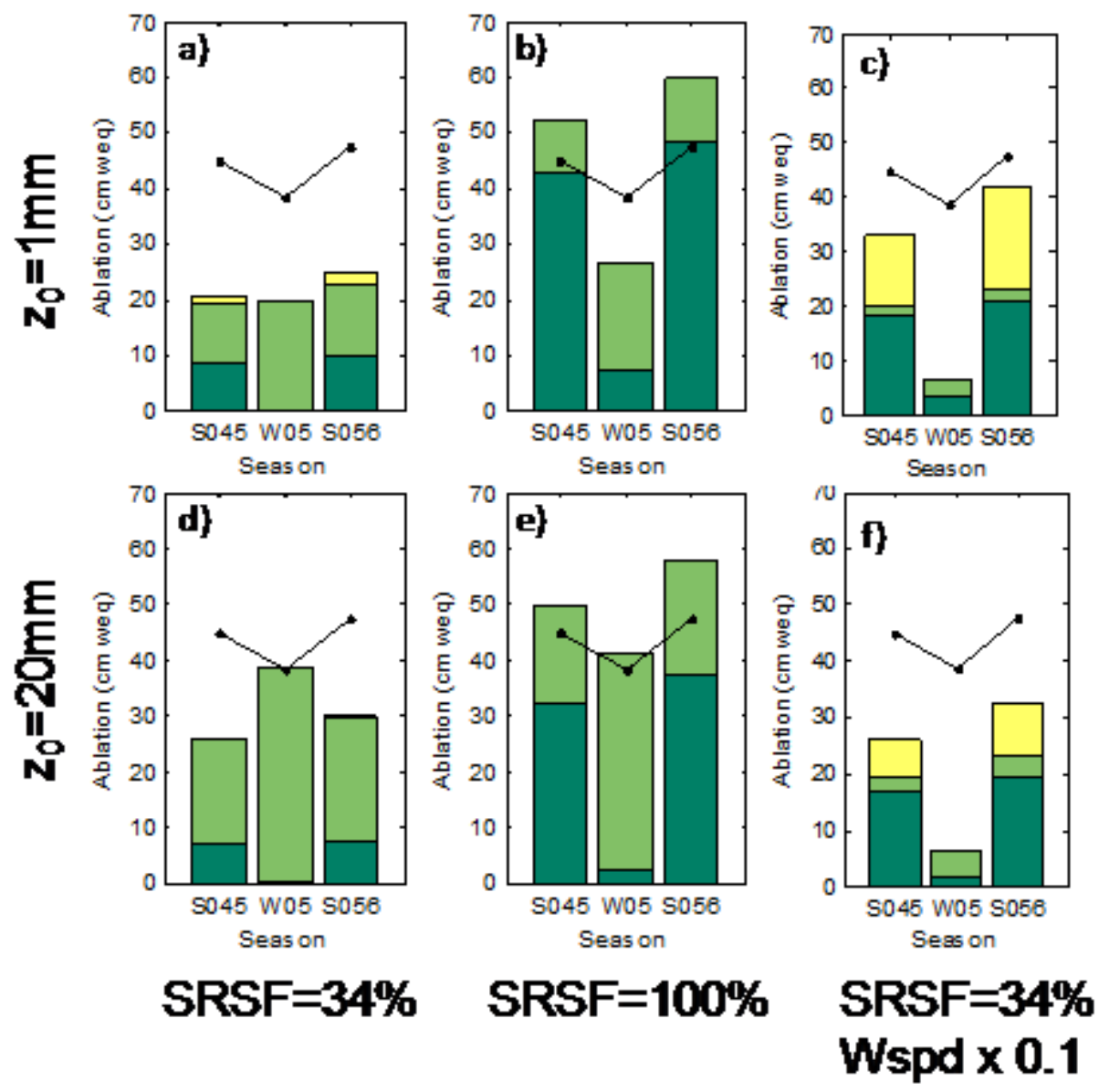

Figure D.1: Melt model results for three seasons (summer 2004-2005, winter 2005, and summer 2005-2006) along Taylor Glacier northside cliff. Black line is measured ablation averaged over 4-8 cliff stakes. Stacked bars show modeled ablation. Dark green is melt, light green is sublimation, and yellow is the component due to density reduction from drainage of subsurface melt. The upper row (a-c) show results for $z_{0}=1 \mathrm{~mm}$, and the bottom row (d-f) show results for $z_{0}=20 \mathrm{~mm}$. The left column ( $a$ and $d$ ) shows results for $S R S F=34 \%$, the center column ( $b$ and $e$ ) shows results for $S R S F=100 \%$, and the right column (c and f) shows results for $S R S F=34 \%$ with wind speed multiplied by a factor of 0.1. All runs use $r_{\text {eff }}=0.03 \mathrm{~mm}$. 